KAM YU KANG

ESTUDO DO COMPORTAMENTO DE PLATAFORMAS FPSO COM MOONPOOL E AVALIAÇÃO DOS PARÂMETROS BÁSICOS DE PROJETO

Versão Corrigida 
KAM YU KANG

\title{
ESTUDO DO COMPORTAMENTO DE PLATAFORMAS FPSO COM MOONPOOL E AVALIAÇÃO DOS PARÂMETROS BÁSICOS DE PROJETO
}

\author{
Versão Corrigida
}

\author{
Dissertação apresentada à Escola \\ Politécnica da Universidade de São \\ Paulo para obtenção do título de \\ Mestre em Ciências
}




\title{
ESTUDO DO COMPORTAMENTO DE PLATAFORMAS FPSO COM MOONPOOL E AVALIAÇÃO DOS PARÂMETROS BÁSICOS DE PROJETO
}

\author{
Versão Corrigida
}

\author{
Dissertação apresentada à Escola \\ Politécnica da Universidade de São Paulo \\ para obtenção do título de Mestre em \\ Ciências
}

Área de concentração: Departamento de engenharia naval e oceânica

Orientador: Prof. Dr. Kazuo Nishimoto 
Autorizo a reprodução e divulgação total ou parcial deste trabalho, por qualquer meio convencional ou eletrônico, para fins de estudo e pesquisa, desde que citada a fonte.

Este exemplar foi revisado e corrigido em relação à versão original, sob responsabilidade única do autor e com a anuência de seu orientador.

São Paulo, 12de fevereiro de 2021

Assinatura do autor: Kam Yu Kana

Assinatura do orientador:

Catalogação-na-publicação

Kam, Yu Kang

ESTUDO DO COMPORTAMENTO DE PLATAFORMAS FPSO COM MOONPOOL E AVALIAÇÃO DOS PARÂMETROS BÁSICOS DE PROJETO / Y. K. Kam -versão corr. -- São Paulo, 2021.

$164 \mathrm{p}$.

Dissertação (Mestrado) - Escola Politécnica da Universidade de São Paulo. Departamento de Engenharia Naval e Oceânica.

1.moonpool 2.FPSO I.Universidade de São Paulo. Escola Politécnica. Departamento de Engenharia Naval e Oceânica II.t. 


\section{AGRADECIMENTOS}

Em primeiro lugar desejo agradecer ao meu orientador Prof. Dr. Kazuo Nishimoto, pois sem ele, este trabalho nunca teria sido possível. Agradeço profundamente a sua compreensão, paciência, profissionalismo e dedicação me auxiliando no meu desenvolvimento, tanto pessoal quanto profissional.

Eu também sou igualmente agradecido ao Dr. Allan Carre de Oliveira pela instrução, inspiração e entusiasmo que me possibilitou completar esta etapa da minha carreira profissional.

Agradeço aos professores doutores Cláudio Mueller Sampaio e Cheng Liang Yee pelo auxílio e sugestões sempre pertinentes para a condução deste trabalho.

Estou eternamente em débito com a equipe do Tanque de Provas Numérico, especialmente aos doutores Pedro Cardozo de Mello, Edgard Borges Malta e Daniel Prata Vieira por todas as experiências profissionais compartilhadas durante este período de aprendizado.

Quero desejar um agradecimento especial aos meus amigos Bruno Mendes, Bruno Giordano, Cristiana Pirpiris, Fernanda Hille, Fernanda Laureti, Jordi Mas Soler, Lariuss Zago, Lucas Carmo, Oscar Lopera e Raíza Oliveira com quem tive o privilégio de dividir experiências profissionais e recreativas. Desejo que todos tenham sucesso em suas respectivas carreiras.

Por fim gostaria de agradecer toda a minha família pelo encorajamento e motivação em todas as etapas deste trabalho. Sempre estou pensando no bemestar de vocês, mesmo quando nas muitas vezes que não demonstrei meu afeto.

Do fundo do meu coração, obrigado a todos. 
"The barriers are not erected which can say to aspiring talents and industry, 'Thus far and no farther."' 


\section{RESUMO}

A seleção de unidade flutuante adequada para o desenvolvimento em águas profundas é uma tarefa difícil e é governada por diversos fatores como a profundidade da lâmina d'água, região do campo de extração de óleo, condições ambientais, requisitos de armazenamento e offloading. $\mathrm{Na}$ exploração offshore brasileira, este conjunto de fatores favorece a utilização de FPSO's (Floating Production Storage and Offloading) baseados na adaptação de navios existentes, devido ao seu menor prazo de construção e pela falta de infraestrutura de oleodutos para o escoamento da produção de óleo. $\mathrm{O}$ aumento da produção de petróleo e a presença de contaminantes e altas concentrações de gases nos reservatórios de petróleo são desafios tecnológicos que aumentam a complexidade do processamento de petróleo, aliado a regras ambientais mais rigorosas. $\mathrm{O}$ uso de risers de maior diâmetro para atender a maior produção também requer o uso de SCR's (Steel Catenary Risers), economicamente mais vantajoso em relação às linhas flexíveis nesse cenário. No entanto, o uso de risers rígidos requer uma Unidade de Produção Flutuante com baixo nível de movimento, o que implica em uma unidade flutuante com maior complexidade. A utilização de moonpools como um sistema auxiliar da plataforma é uma solução utilizada em navios de perfuração e permitiria, no caso de extração de petróleo, a instalação do balcão de risers pelo centro da plataforma para a redução de movimentos e acelerações impostas à aos risers. No caso das plataformas de perfuração, estas operações são possíveis apenas no caso da água interna ao moonpool continue calma. Ondas ou movimentos da embarcação podem induzir oscilações de líquido dentro do moonpool. Em condições de ressonância, a operação da plataforma torna-se impossível e os risers de perfuração são muitas vezes desconectados da plataforma. O presente estudo busca estudar novas geometrias e sistemas auxiliares para redução dos movimentos e acelerações do FPSO e apontar os parâmetros relevantes para melhorar o seu desempenho através de avaliações numéricas e comparações com ensaios experimentais que represente os efeitos hidrodinâmicos plataforma e seus sistemas auxiliares.

Palavras-chave: FPSO, Moonpool, Risers em Catenária de Aço. 


\begin{abstract}
The evaluation of a floating production unit suitable to the development of deepwater fields is a difficult task and is heavily influenced by factors such as water depth, oil extraction field region, environmental conditions, storage requirements and offloading requirements. For offshore exploration in Brazil, this set of factors favors the use of FPSO's (Floating Production Storage and Offloading) based on the conversion of existing ships, due to their shorter construction period and the lack of pipeline infrastructure for production flow. Increased oil production and the presence of contaminants and high concentrations of gases in oil reservoirs are technological challenges that increase the complexity of oil processing, coupled with stricter environmental regulations. The use of larger diameter risers to meet increased production also requires the use of Steel Catenary Risers (SCR's), which is economically more advantageous than the flexible lines in this scenario. However, the use of SCR's requires a Floating Production Unit with low level of movement, which implies a more complex unit. The use of moonpools as an auxiliary platform system is a solution frequently used in drilling ships and allows, in case of oil extraction, the installation of the riser counter in the center of the platform, which contributes to the reduction of movements and accelerations to the risers. These operations are possible just in case the internal water to the moonpool continues calm. However, waves or even vessel motions in calm waters can induce oscillations of liquid within the moonpool. Under resonance conditions, the operating condition of the platform becomes impossible and the piping is often disconnected from the platform. The present study aims to study new geometries and auxiliary systems to reduce the FPSO movements and accelerations and to point out the relevant parameters to improve its performance. Through numerical studies and comparisons with experimental trials that represent the hydrodynamic effects platform and its auxiliary systems.
\end{abstract}

Key-words: FPSO, Moonpool, Steel Catenary Risers. 


\section{LISTA DE FIGURAS}

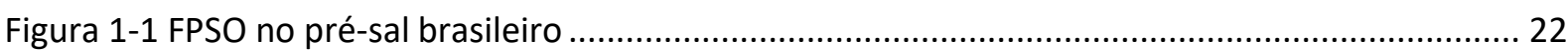

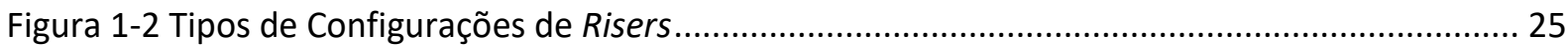

Figura 1-3 Representação de riser conectado à UF e ao fundo do oceano ......................................... 25

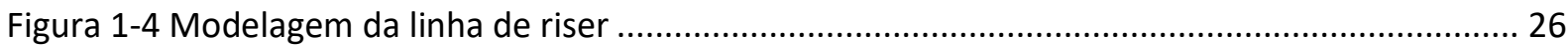

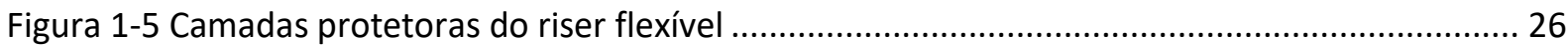

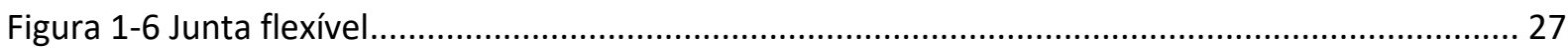

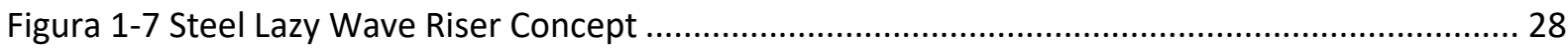

Figura 1-8 Esforços aplicados em uma tubulação para FPSO ........................................................... 30

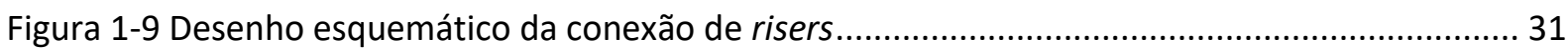

Figura 1-10 Organização do sistema de Amarração/Risers de um FPSO …........................................... 32

Figura 1-11 Seção transversal de um moonpool ............................................................................... 34

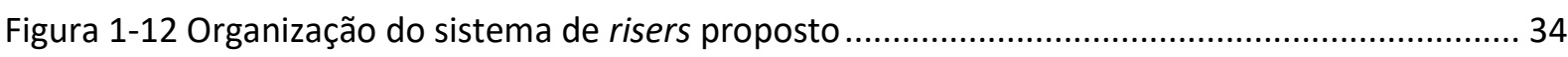

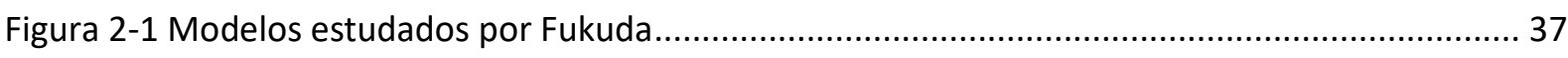

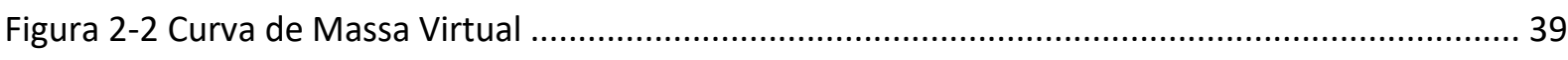

Figura 2-3 Comparação período natural do moonpool ..................................................................... 43

Figura 2-4 Vista superior da divisão de tanques internos do ULFPSO. Legenda: amarelo - óleo; azul -

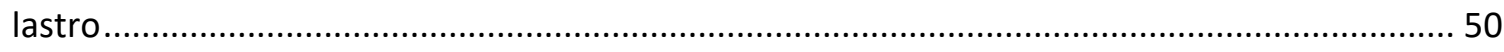

Figura 3-1 Fluxograma de Desenvolvimento do FPSO proposto ……................................................ 53

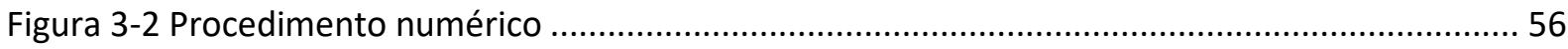

Figura 4-1 Geometria do Casco - Vista frontal e perspectiva............................................................ 57

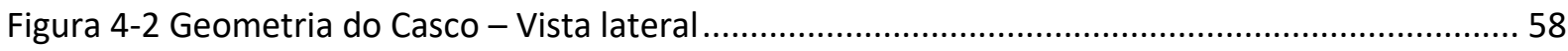

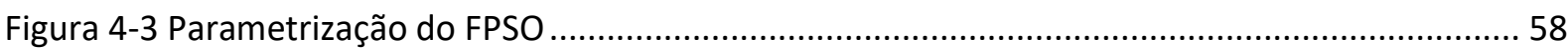

Figura 4-4 Deslocamento em massa pela capacidade de armazenamento de óleo para os modelos

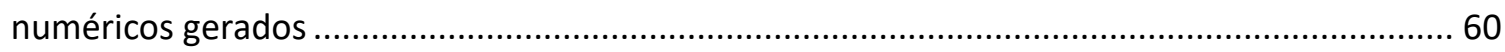

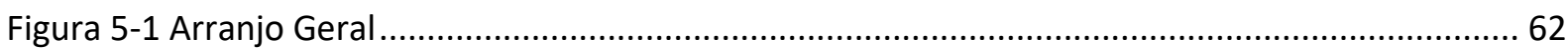

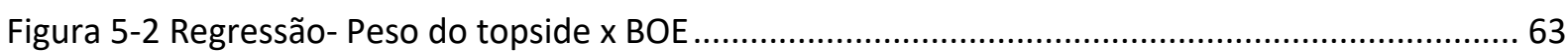

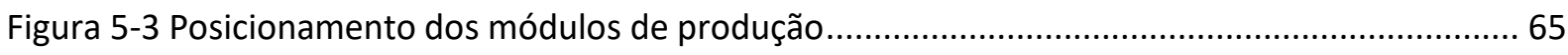

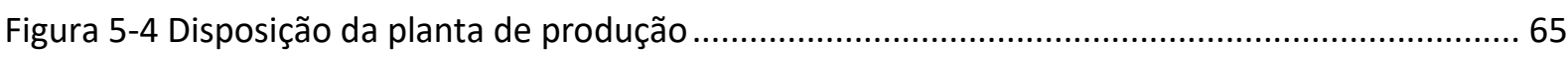

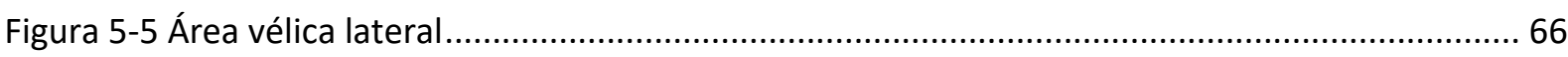

Figura 5-6 Posição da antepara longitudinal em relação ao centro do pontoon ................................... 68

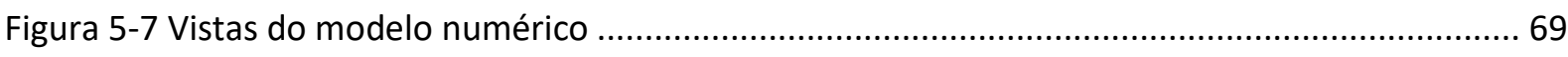

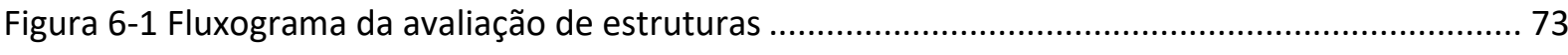

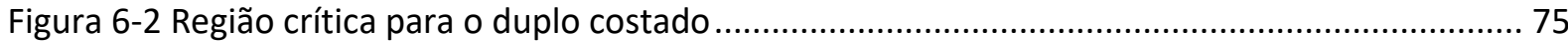


Figura 6-3 Exemplo de obteção de uma Seção Mestra (esq.) e de uma antepara (dir.) .....

Figura 6-4 Análise do carregamento da plataforma

Figura 7-1 Fluxograma do modelo de estabilidade.

Figura 7-2 Curva Momento Restaurador

Figura 7-3 Curva GZ do FPSO a) 50\% carregado; b) 100\% carregado. .................................................. 86

Figura 7-4 Estabilidade intacta do ULFPSO em condição 90\% carregado.............................................. 87

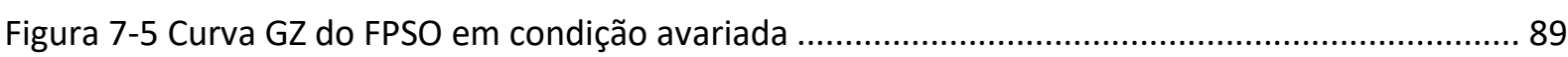

Figura 8-1 Seis graus de liberdade de um corpo flutuante ................................................................. 91

Figura 8-2 Comparação entre ressonância dos sistemas flutuantes e espectros de mar...................... 92

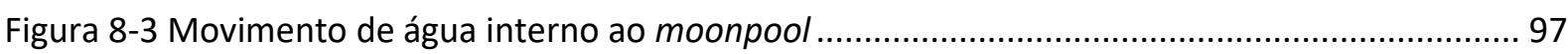

Figura 8-4 Modelagem da plataforma com lid (visão de topo) como um sistema massa-mola-

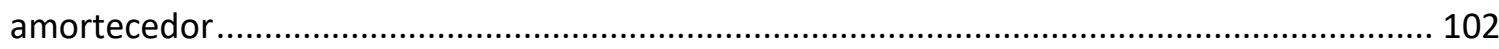

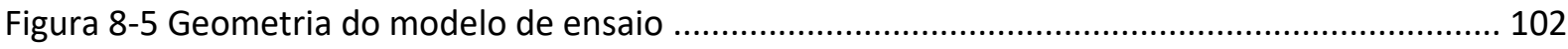

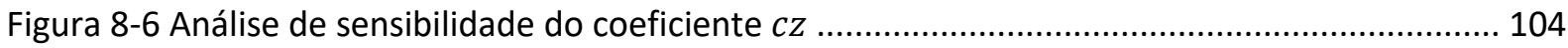

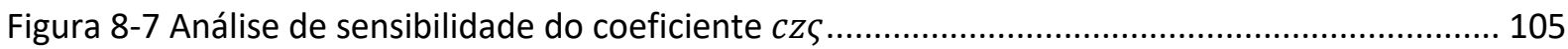

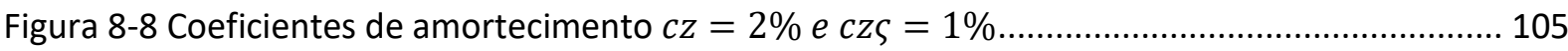

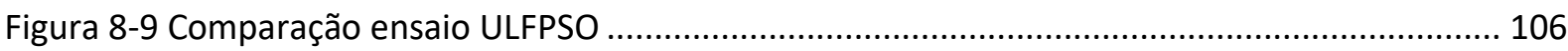

Figura 8-10 Aplicação de saia hidrodinâmicas em uma monocoluna ................................................. 107

Figura 8-11 Modelo de saia hidrodinâmicas em um pontoon do FPSO ........................................... 108

Figura 8-12 Comparação das dimensões de saia hidrodinâmicas ..................................................... 109

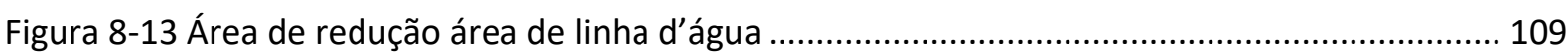

Figura 8-14 Comparação parâmetro $\beta-$ Heave …............................................................................... 110

Figura 8-15 Comparação parâmetro $\beta$-Heave ULFPSO .................................................................... 111

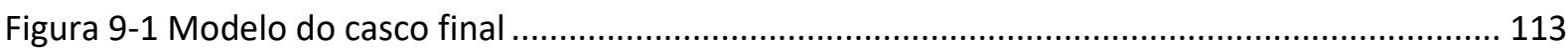

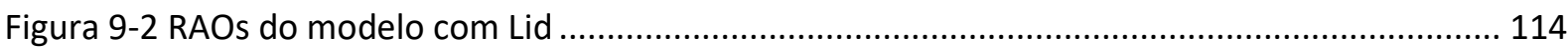

Figura 9-3 Geometria do casco submerso da plataforma P55 .................................................... 115

Figura 9-4 Vista superior da geometria do casco submerso da plataforma ULFPSO......................... 116

Figura 9-5 Comparação dos módulos de seção Z para cada configuração analisada. ......................... 117

Figura 9-6 Comparação entre os momentos de tosamento e alquebramento para as diversas

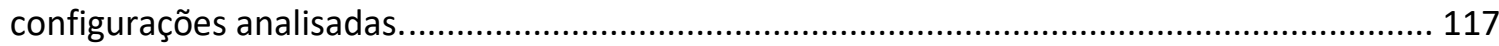

Figura 9-7 Comparação entre os valores de capacidade de armazenamento de óleo e de KG obtidos para cada configuração e para os dois carregamentos estudados: 50\% (esq.) e 100\% (dir.).... 118

Figura 9-8 Avaliação do parâmetro B e b para a curva GZ e movimento de roll .................................. 119

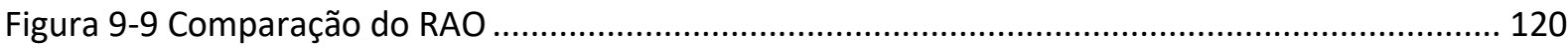

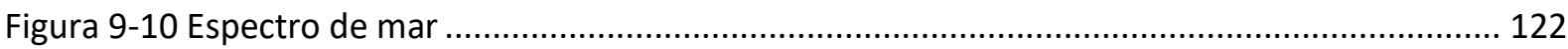




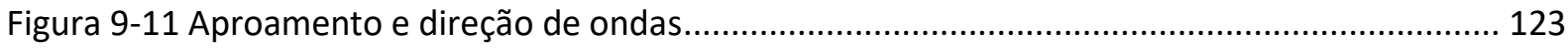

Figura 9-12 Série temporal de onda IRR, Tp=10s e elevação relativa da coluna d'água .................... 125

Figura 9-13 Vista superior da malha de pontos para o cálculo da elevação da superfície ................. 126

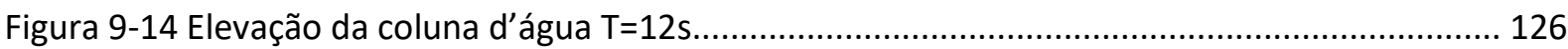

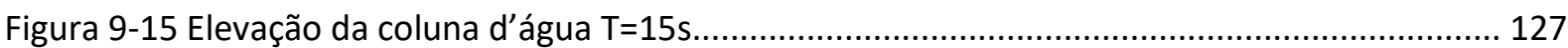

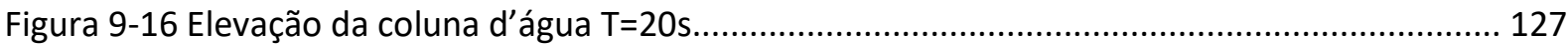

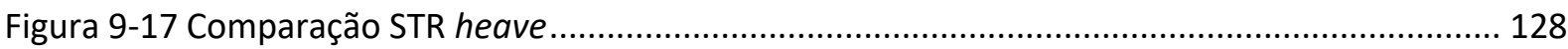

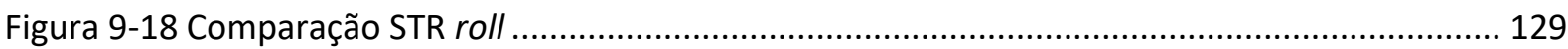

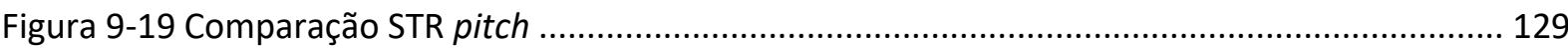

Figura 9-20 Posição dos pontos de medição - Vista de topo .......................................................... 130

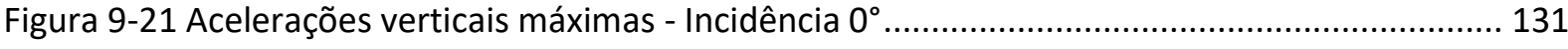

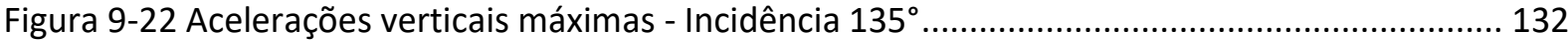

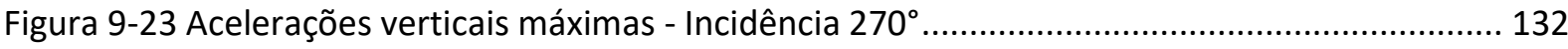

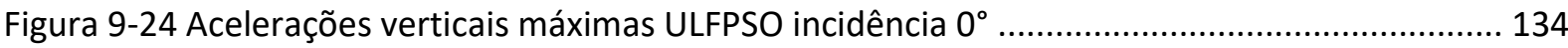

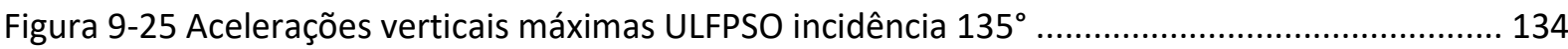

Figura 9-26 Acelerações verticais máximas ULFPSO incidência $270^{\circ}$............................................. 135

Figura 9-27 Acelerações verticais máximas P55 incidência $270^{\circ}$................................................... 135

Figura 11-1 Absorvedor Dinâmico de Vibração ............................................................................ 145

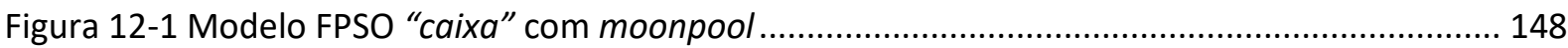

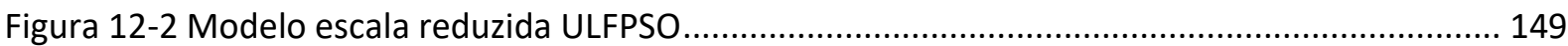

Figura 12-3 - Câmera com dispositivo infravermelho ........................................................................ 151

Figura 12-4 Wave probes para calibração da onda no tanque. ...................................................... 153

Figura 12-5 Comparação modelo "caixa" Sway - incidência 90 ................................................... 154

Figura 12-6 Comparação modelo "caixa" Heave - incidência 90 ..................................................... 155

Figura 12-7 Comparação modelo "caixa" Roll - incidência 90 …..................................................... 155

Figura 12-8 Comparação modelo ULFPSO Sway - incidência 90 ..................................................... 156

Figura 12-9 Comparação modelo ULFPSO Heave - incidência 90 ................................................. 156

Figura 12-10 Comparação modelo ULFPSO Pitch - incidência 90 ...................................................... 157

Figura 12-11 Série temporal onda, modelo "caixa" IRR1, Tp=10s ..................................................... 158

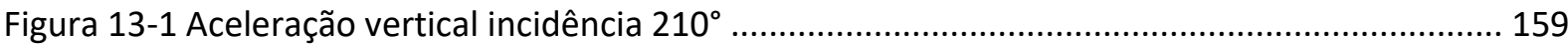

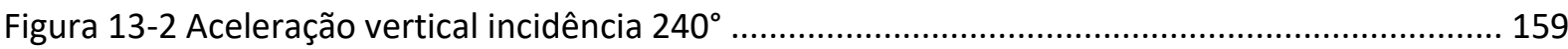

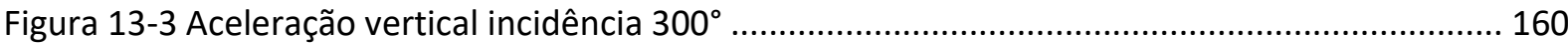

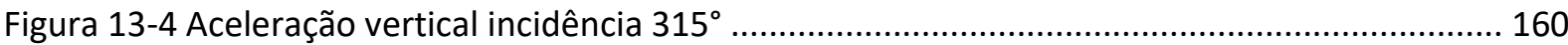

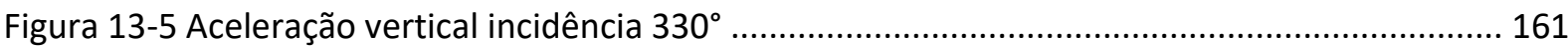




\section{LISTA DE TABELAS}

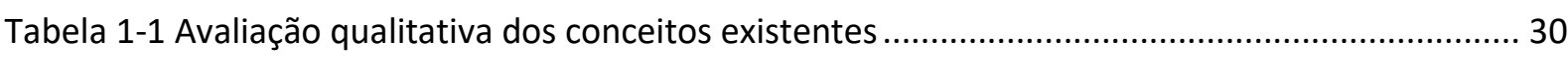

Tabela 2-1 Dimensões dos modelos de Fukuda, K (1977) ..................................................................... 38

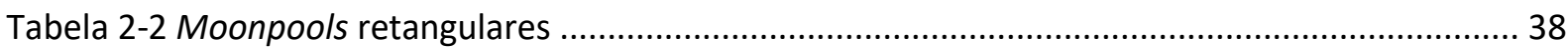

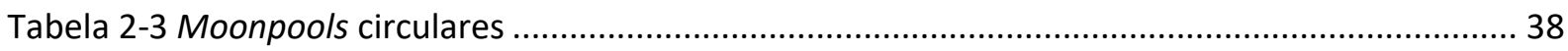

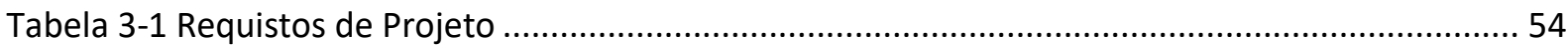

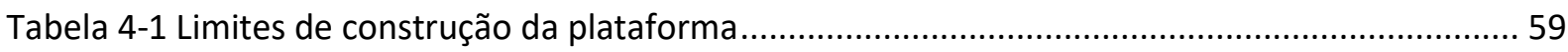

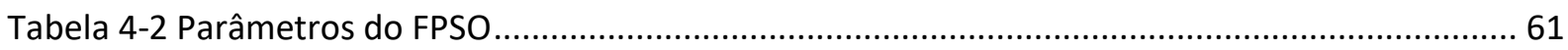

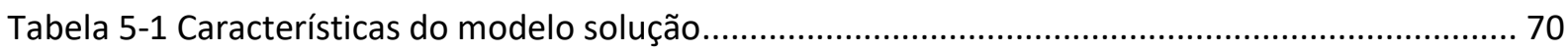

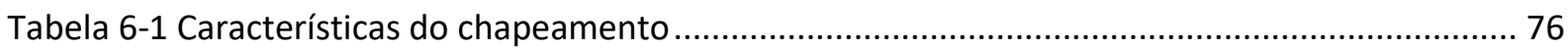

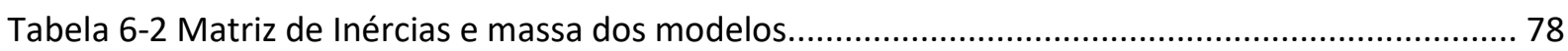

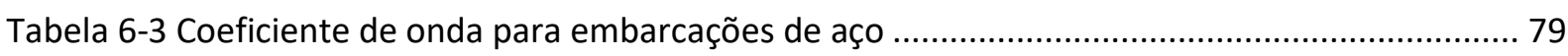

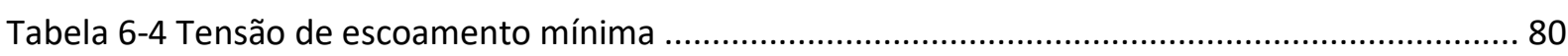

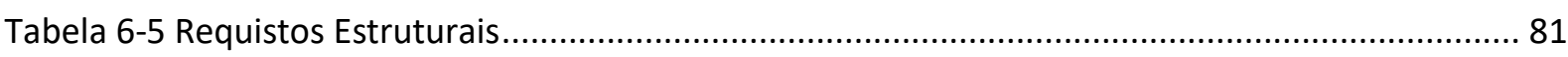

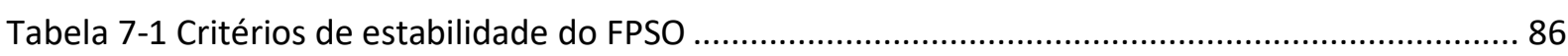

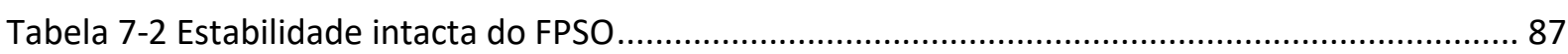

Tabela 7-3 Estabilidade intacta do ULFPSO em condição 100\% carregado ......................................... 88

Tabela 7-4 Critérios de estabilidade do ULFPSO em condição 100\% carregado ................................... 88

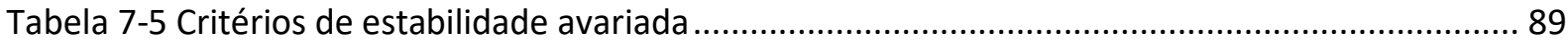

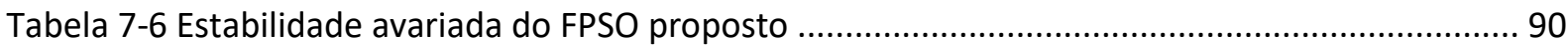

Tabela 7-7 Critérios de estabilidade do FPSO em condição avariado .................................................. 90

Tabela 8-1 Critérios do comportamento em ondas da plataforma ................................................... 95

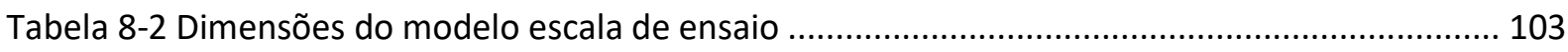

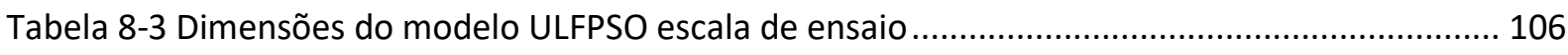

Tabela 8-4 Dimensionamento da saia hidrodinâmica..................................................................... 108

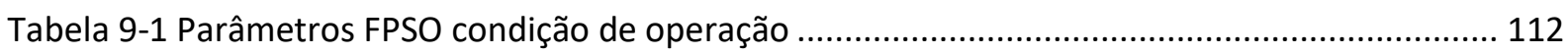

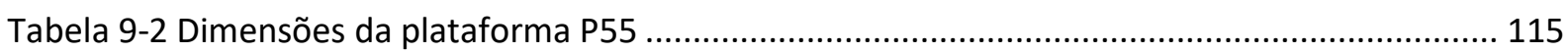

Tabela 9-3 Dimensões da plataforma ULFPSO e do modelo proposto ............................................. 116

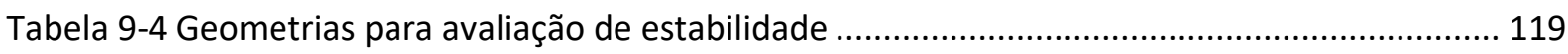

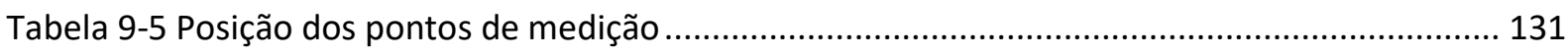

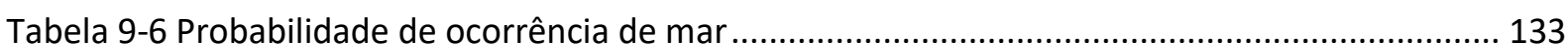

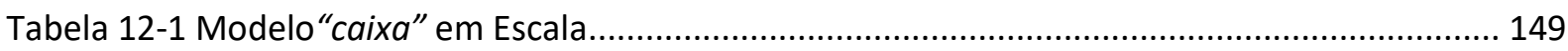

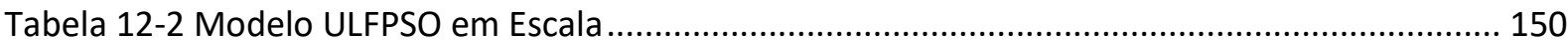

Tabela 12-3 - Principais características das câmeras de monitoração de movimentos..................... 151 


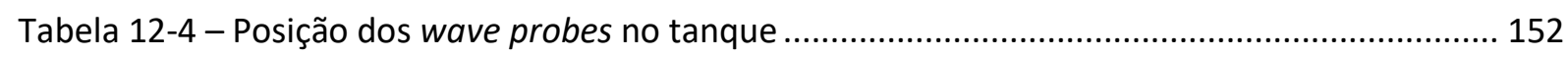

Tabela 12-5 Posição dos wave probes no modelo "caixa"................................................................... 154

Tabela 14-1Dimensões principais, inércia e capacidade de óleo...................................................... 162

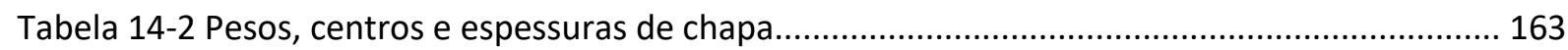

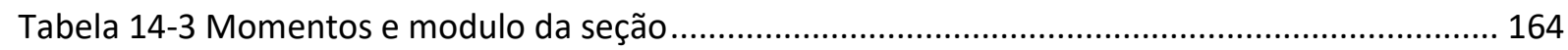




\section{LISTA DE ABREVIAÇÕES}

FPSO

Floating Production Storage and Offloading

SCR

Steel Catenary riser

VLCC

Very Large Crude Carrier

SOLAS

Safety of Life at Sea

MARPOL

Maritime Pollution

IMO

International Maritime Organization

DNV GL

Det Norske Veritas - Germanischer Lloyd

ABS

American Bureau of Shipping

SLWR

Steel Lazy Wave Riser

RAO

Response Amplitude Operatot

WAMIT

Wave Analisys MIT

WP

Wave Probe

TPN

Tanque de Provas Numérico 
LISTA DE SIMBOLOS

\begin{tabular}{|c|c|}
\hline Awl & Área de linha d'água \\
\hline LOA & Comprimento total da plataforma \\
\hline Lpp & Comprimento entre paralelas \\
\hline B & Boca da plataforma \\
\hline D & Pontal \\
\hline I & Comprimento do moonpool \\
\hline b & Boca do moonpool \\
\hline $\mathrm{l}_{\text {long }}$ & $\begin{array}{l}\text { Posição da antepara longitudinal (em } \\
\text { relação ao centro do pontoon) }\end{array}$ \\
\hline$V_{c p}$ & Volume corpo paralelo \\
\hline$V_{\text {proa/popa }}$ & Volume da proa/popa \\
\hline$V_{\text {total }}$ & Volume total \\
\hline$V_{\text {Ballast }}$ & Volume de lastro armazenado \\
\hline$V_{\text {oil }}$ & Volume de óleo armazenado \\
\hline$W_{l s}$ & Peso leve \\
\hline$\Delta_{\text {des }}$ & Deslocamento \\
\hline $\mathrm{F}_{\text {ext }}$ & Força externa aplicada ao corpo \\
\hline $\mathrm{F}_{\mathrm{i}}^{\mathrm{H}}$ & Componente da força hidrostática de um corpo \\
\hline $\mathrm{g}$ & Aceleração da gravidade $\mathrm{m} / \mathrm{s}^{2}$ \\
\hline$T$ & Calado da plataforma moonpool \\
\hline $\mathrm{h}$ & Altura da coluna d'água interior ao moonpool \\
\hline $\mathrm{hr}$ & Altura da saia hidrodinâmica (restrição) \\
\hline $\mathrm{T}_{\mathrm{S}}$ & Período natural do moonpool \\
\hline $\mathrm{v}$ & Velocidade genérica \\
\hline $\mathrm{V}$ & Volume genérico \\
\hline$z, \dot{z}, \ddot{z}$ & $\begin{array}{l}\text { Respectivamente: Amplitude, velocidade e } \\
\text { aceleração da plataforma na direção vertical }\end{array}$ \\
\hline $\mathrm{p}$ & Pressão genérica \\
\hline$a_{i j}$ & Massa adicional provinda da teoria potencial \\
\hline$b_{i j}$ & $\begin{array}{l}\text { Coeficiente de amortecimento potencial que } \\
\text { atuante no modo i e resultante de um } \\
\text { movimento j }\end{array}$ \\
\hline
\end{tabular}




\begin{tabular}{|c|c|}
\hline $\mathrm{c}_{\mathrm{ij}}$ & $\begin{array}{l}\text { Coeficiente de amortecimento representante } \\
\text { das forças viscosas linearizadas que atuam no } \\
\text { modo i e resultante de um movimento j }\end{array}$ \\
\hline$\alpha, \beta, \gamma$ & Ângulos em geral \\
\hline$\rho$ & Massa específica da água do mar \\
\hline$\phi$ & Potencial de velocidades \\
\hline$\omega_{n}$ & Frequência natural da plataforma \\
\hline$\omega_{\varsigma}$ & $\begin{array}{l}\text { Frequência natural da coluna d'água interna ao } \\
\qquad \text { moonpool }\end{array}$ \\
\hline$\varsigma, \dot{\varsigma}, \ddot{\varsigma}$ & $\begin{array}{l}\text { Respectivamente: Amplitude, velocidade e } \\
\text { aceleração da coluna d'água interna ao } \\
\text { moonpool na direção vertical }\end{array}$ \\
\hline$S_{r}, \dot{S}_{r}, \ddot{S}_{r}$ & $\begin{array}{l}\text { Respectivamente: Amplitude, velocidade e } \\
\text { aceleração da coluna d'água interna ao } \\
\text { moonpool para o movimento vertical relativo }\end{array}$ \\
\hline $\mathrm{D} / \mathrm{Dt}$ & Derivada material \\
\hline $\mathrm{d} / \mathrm{dt}$ & Derivada ordinária \\
\hline$\frac{\delta}{\delta t}$ & Derivada parcial \\
\hline dS & Elemento de área \\
\hline
\end{tabular}




\section{SUMÁRIO}

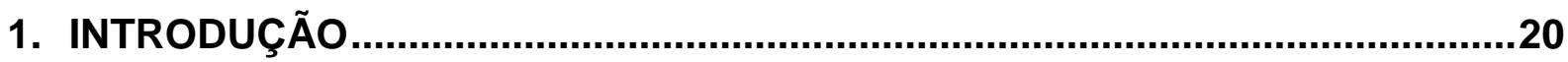

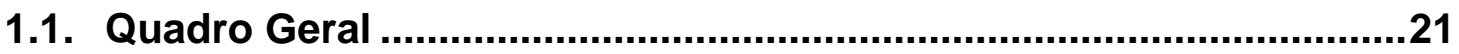

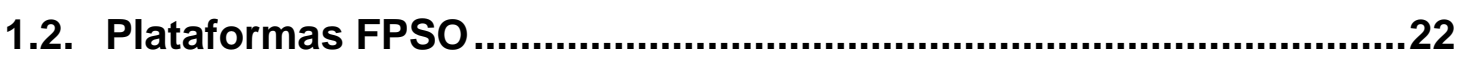

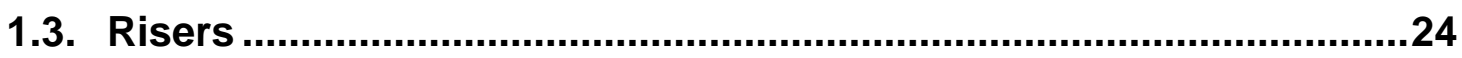

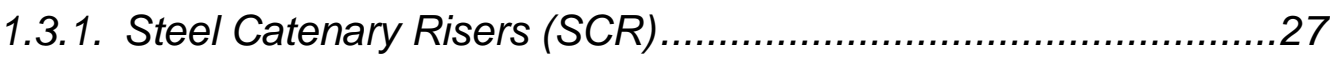

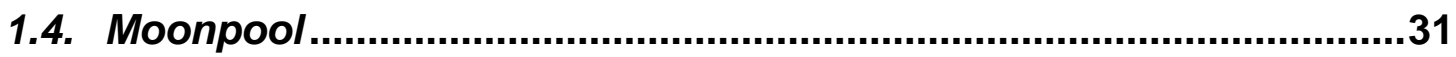

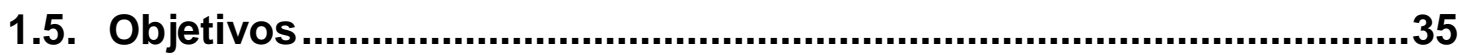

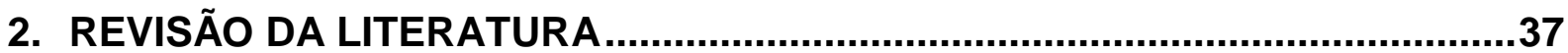

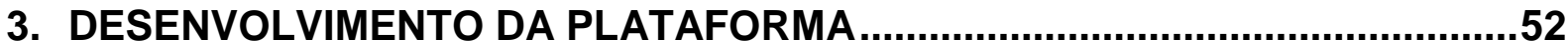

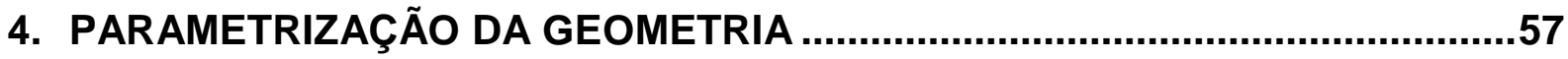

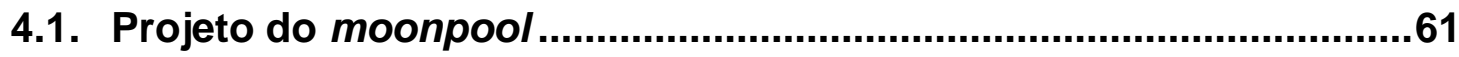

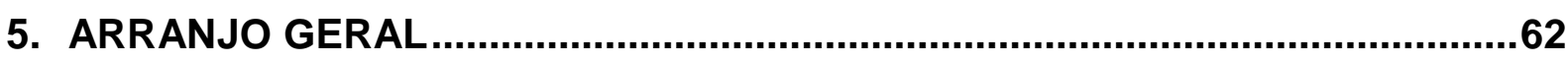

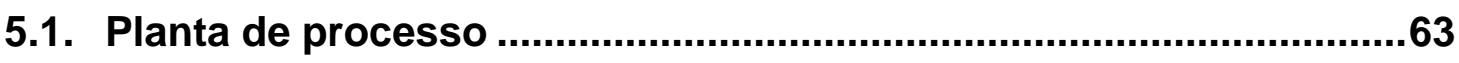

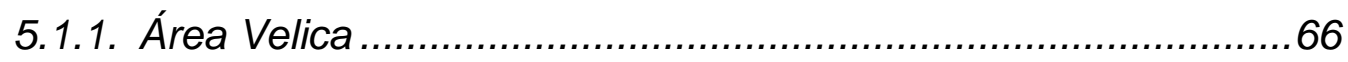

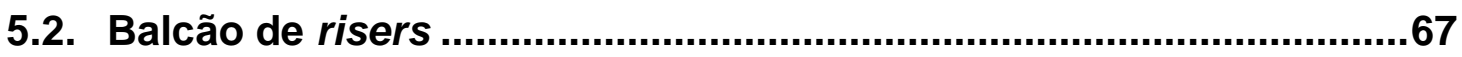

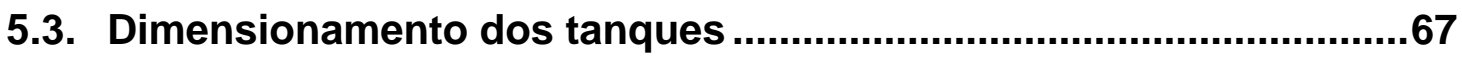

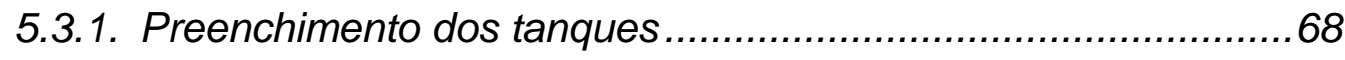

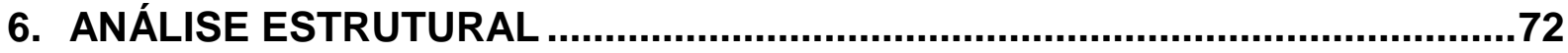

6.1. Modelo estrutural .................................................................................

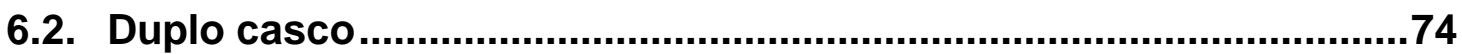

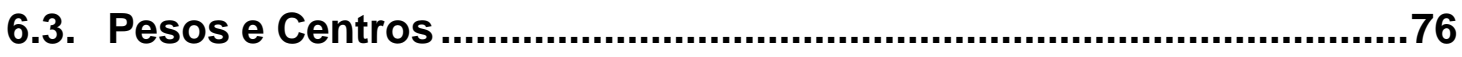

6.3.1. Cálculo do Momento de Inércia de Massa do Casco Leve.........77

6.3.2. Critérios Estruturais .............................................................. 79

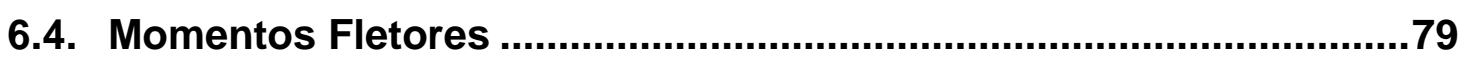

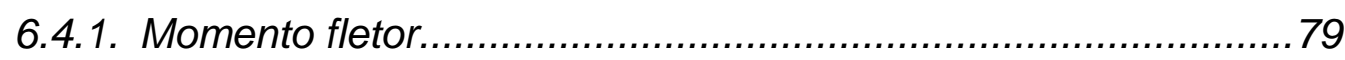

6.4.2. Análise preliminar das Vigas do casco .................................... 80 


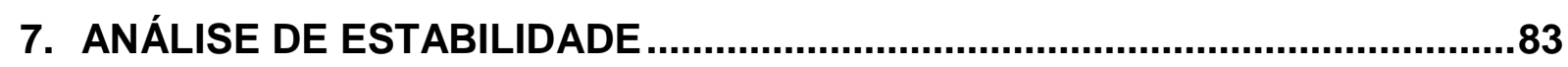

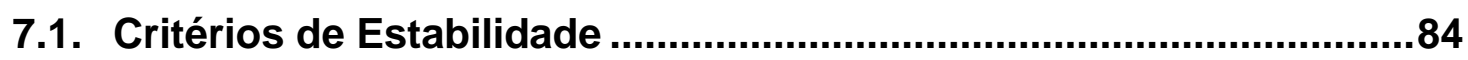

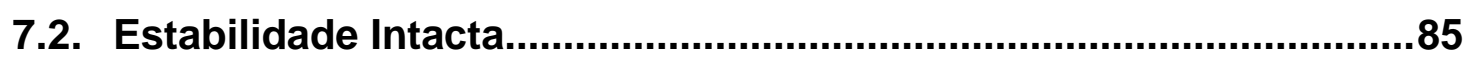

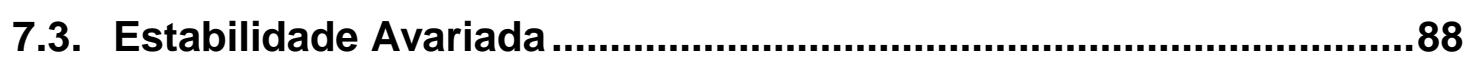

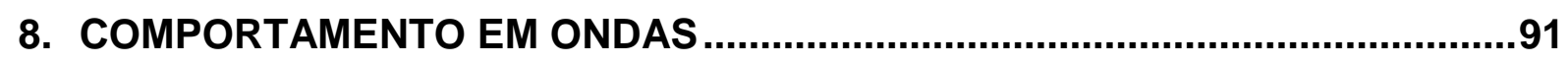

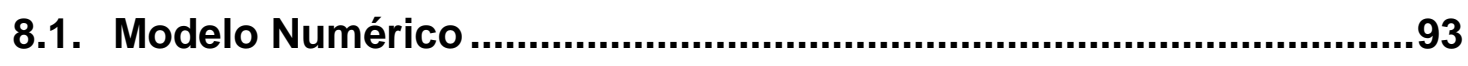

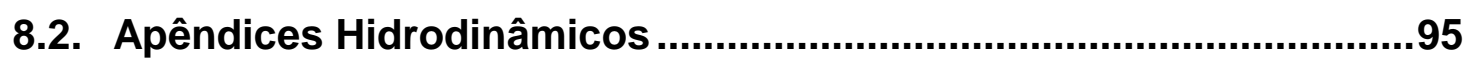

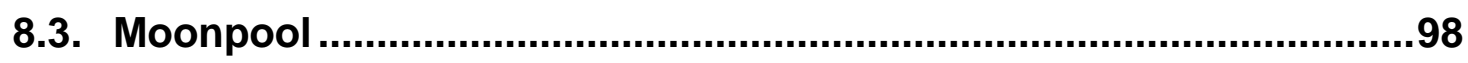

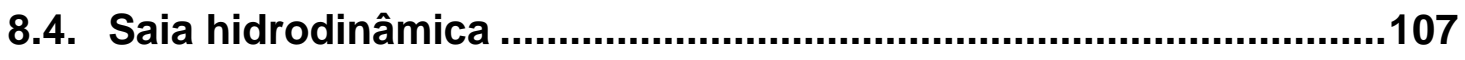

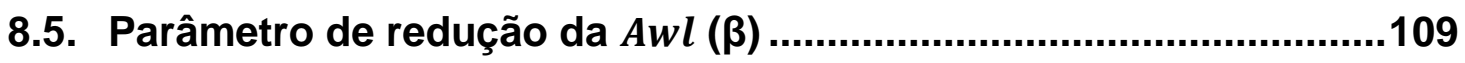

9. ANÁLISES DE RESULTADOS E COMPARAÇÕES .....................................112

9.1. Comparação de geometrias ............................................................114

9.2. Avaliação Estrutural......................................................................116

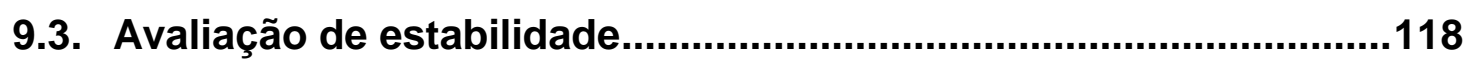

9.4. Avaliação comportamento em ondas..........................................120

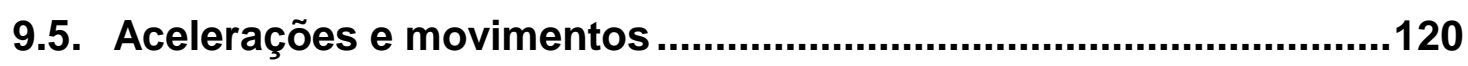

9.6. Movimento da coluna d'água .....................................................123

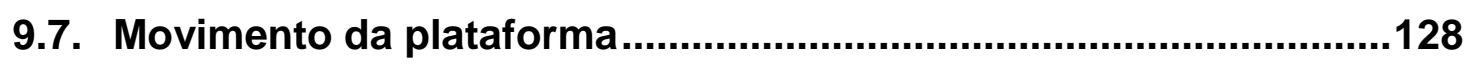

9.8. Avaliação da aceleração vertical e disponibilidade de operação..130

10.CONCLUSÕES E TRABALHOS FUTUROS..................................................137

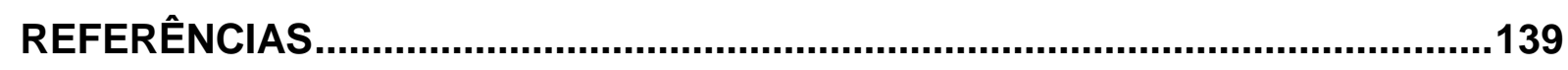

11. ANEXO A MODELAGEM DE SISTEMA MASSA-MOLA-AMORTECEDOR ....143

12. ANEXO B ENSAIO EM ESCALA REDUZIDA …..........................................148

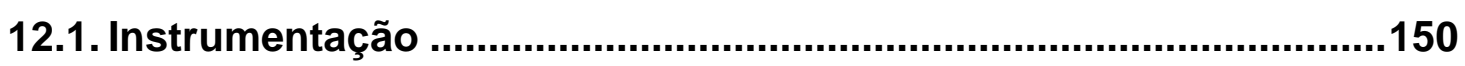

12.2. Monitoração dos movimentos da plataforma ................................150

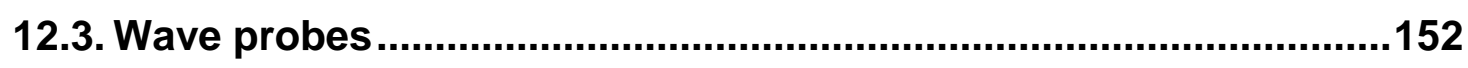

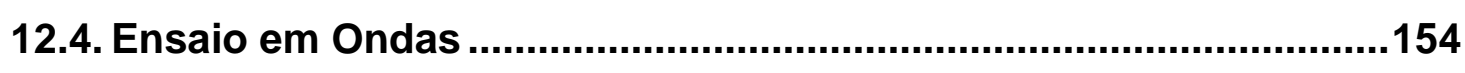


12.5. Avaliação do volume de água dentro do moonpool .......................157

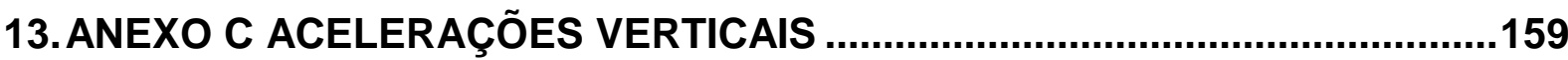

14. ANEXO D CARACTERÍSTICAS DOS CASOS ESTUDADOS..........................162 


\section{INTRODUÇÃO}

A exploração em águas profundas pela indústria offshore tem estado em uma expansão muito ativa na atualidade. No Brasil, há um grande potencial para exploração offshore de grandes reservas de petróleo e gás natural, o que tem gerado um grande volume de investimentos no setor offshore.

Desde a descoberta das reservas do "Pré-Sal", uma imensa quantidade de petróleo e gás natural pode ser extraída de águas ultraprofundas, com lâmina d’água superior a $2.000 \mathrm{~m}$, sua crescente demanda é encorajadora para o desenvolvimento de novos conceitos de unidades flutuantes, capazes de processar grandes quantidades de hidrocarbonetos. Entretanto, existem inúmeras adversidades e desafios tecnológicos para extrair petróleo e gás natural desta região, mas o sucesso desta operação é importante e de grande relevância econômica para o Brasil.

Para atender esta grande demanda, a exploração offshore no Brasil incentiva o uso de plataformas com especializadas em produção e transporte conhecidas como FPSO (Floating Production Storage and Offloading). Embora estas plataformas apresentem um comportamento em ondas especialmente sensíveis aos movimentos de roll e heave, a utilização deste tipo de plataforma é importante para exploração offshore do Brasil, onde é necessário realizar a exploração a grandes profundidades, em localizações remotas e com pouco acesso a infraestrutura, pois, não é economicamente interessante construir oleodutos submarinos para o transporte de óleo do local de produção até refinarias. Estes desafios para exploração de óleo em conjunto com a grande demanda nacional incentivam a pesquisa para refinar o projeto de plataformas e desenvolver novas geometrias.

Convencionalmente, plataformas FPSO utilizam risers do tipo flexível em suas operações diferentemente de outras opções de plataforma como a TLP (Tension Leg Platform), MonoBr e semissubmersível que utilizam risers rígidos. A opção por SCR (steel catenary risers) não é apenas uma opção economicamente atrativa, mas também permite o uso de linhas de produção de grande diâmetro, conforme dimensionadas para suportar a alta pressão hidrostática em profundidades maiores. Todavia, a utilização de SCR para profundidades superiores a $2000 \mathrm{~m}$ têm 
apresentado dificuldades devido aos maiores movimentos dinâmicos da plataforma (Shahab Shahriari et. al, 2015).

Desta forma, SCR's ainda não encontraram a sua aplicação nas plataformas FPSO (Floating Production Storage and Offloading) em águas profundas com condições ambientais moderadas (costa do Brasil) e ambientes severos (Golfo do México \& Mar do Norte). A razão para isso pode ser explicada devido à redução de desempenho do SCR, devido a extensos movimentos dinâmicos do FPSO que provocam grandes tensões no topo do riser, junto ao seu ponto de conexão com a plataforma, e grandes cargas de flexão e fadiga na região crítica conhecida por TDZ (touchdown zone) da linha e assim, resultando em danos a sua fadiga e vida reduzida. Este trabalho considera um estudo sobre soluções alternativas de geometria para plataformas FPSO para a viabilização do uso de risers rígidos em catenária e utilizando possivelmente saia hidrodinâmicas laterais para redução da influência das ondas sobre os risers. Para a realização deste estudo, serão definidos os parâmetros necessários para o desenvolvimento de um modelo numérico de acordo com as normas classificadoras e serão realizadas simulações numéricas através do software WAMIT® (WAMIT User Manual Version 7.3).

\subsection{Quadro Geral}

Desde a descoberta do pré-sal do campo de Lula, na Bacia de Santos, em 2006, e o primeiro óleo da camada pré-sal, no campo de Jubarte, na Bacia de Campos, em 2008, uma grande quantidade de reservas provadas de petróleo foram consecutivamente descobertos na camada pré-sal e entrou em desenvolvimentos de projetos. A formação do pré-sal contém cerca de 16,4 bilhões de barris de reservas de petróleo bruto na área de águas ultraprofundas no litoral brasileiro.

O desenvolvimento dos campos do pré-sal enfrenta como principais desafios, incluindo condições oceanográficas adversas nas bacias de Santos e Campos; um ambiente de águas ultraprofundas sem infraestrutura de produção pré-instalada, que fica a $300 \mathrm{~km}$ da costa com profundidade de água superior a $2 \mathrm{~km}$ e um reservatório de óleo posicionado a $5 \mathrm{~km}$ abaixo do leito do mar com uma camada de sal de $2 \mathrm{~km}$ de espessura; a necessidade de desenvolver novas tecnologias para suportar a alta pressão nos reservatórios e os contaminantes nos fluidos, juntamente com a produção. 
O principal objetivo do presente trabalho consiste na proposição de um projeto alternativo de FPSO que permita:

- Uso de risers rígidos;

- Redução dos efeitos devidos à ação de ondas: elevação dos períodos naturais de Heave e Roll;

- Atenda toda legislação pertinente em relação à sua operação

- Possua uma planta de processos e capacidade de armazenamento comparável ao de FPSO's disponíveis no mercado atual

\subsection{Plataformas FPSO}

Uma plataforma FPSO, sigla para Floating Production Storage and Offloading, é uma estrutura flutuante projetada para receber hidrocarbonetos produzidos por ela própria ou de plataformas próximas e, portanto, muito utilizada pela indústria para o processamento de hidrocarbonetos, armazenamento e descarregamento de óleo para navios tanque ou menos frequentemente através de dutos até a costa. Os FPSO's são preferidos nas regiões de fronteira marítima, pois são fáceis de instalar e não exigem uma infraestrutura de tubulação local devido a sua grande capacidade de armazenamento de óleo produzido em sua planta de processos. A Figura 1-1 ilustra uma plataforma FPSO sendo rebocado para a região de operação.

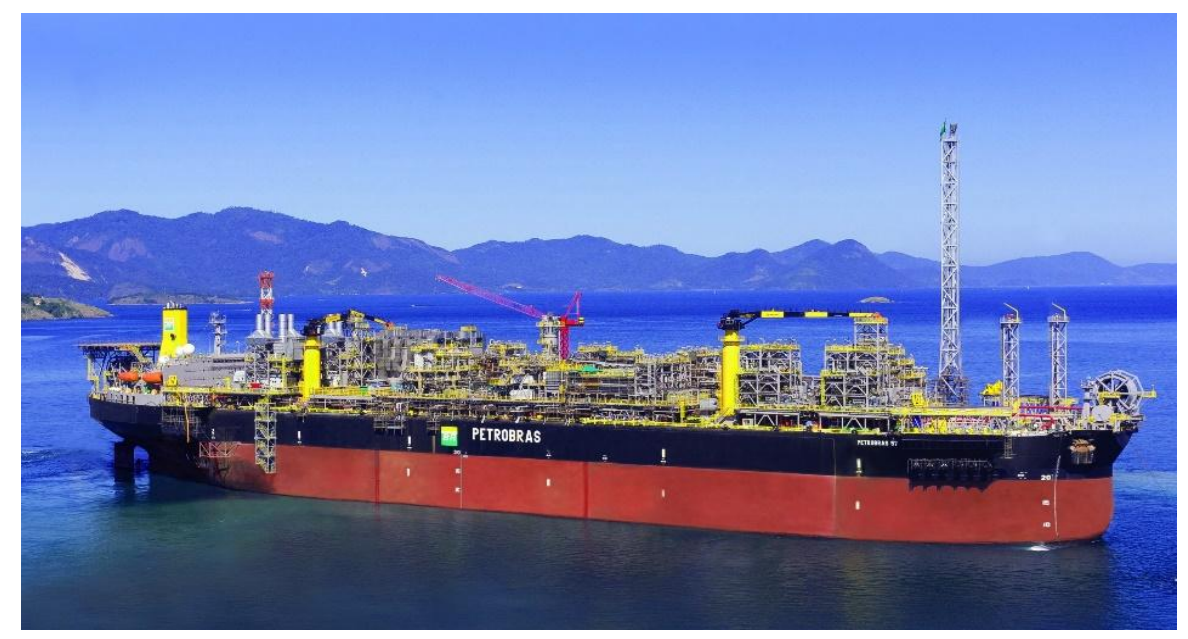

Figura 1-1 FPSO no pré-sal brasileiro

FONTE:Petrobrás

As características de operação do FPSO o fazem desejável para a região do Pré-Sal brasileiro devido à ausência de dutos para o transporte de óleo, grande 
capacidade de armazenamento, fácil instalação e exploração em grandes profundidades. Além disso, em uma situação com pequenos campos de petróleo, onde existe pouco petróleo a ser explorada, esta solução permite a instalação e desinstalação de um poço de petróleo para outro, reduzindo a necessidade do uso de oleodutos. Apesar desta plataforma não apresentar nenhuma característica que inviabilize o seu uso na costa brasileira, os seus movimentos e acelerações nos pontos de conexão de risers não são favoráveis para a utilização de risers rígidos, economicamente mais atraentes do que risers flexíveis, aumentando assim o custo da operação.

Historicamente, este tipo de estrutura começou a ser construída a partir de navios VLCC's convertidos, que após terem sido adaptados e reestruturados tornamse capazes de atuar satisfatoriamente nas condições acima descritas, entretanto, observa-se uma tendência da construção de FPSO com projetos inteiramente novos na atualidade em parte devido à diminuição de VLCC's (Very Large Crude Carriers) no mercado. Diferentemente de um VLCC convencional, um projeto dos novos FPSO's visa tanto minimizar seus movimentos no mar e custos de construção quanto maximizar a capacidade de armazenamento do casco. Nota-se também que uma plataforma dedica a maior parte de seu tempo em operação fixa. Por isso, sua forma tem grandes coeficientes de bloco e grande extensão do corpo paralelo, com popa e proa pouco curvos. Estes cascos têm maior resistência ao avanço, mas navegam (geralmente são rebocados) por pouco tempo durante sua vida útil, e por isso as perdas de tempo e combustível na navegação são compensadas pela melhor operacionalidade.

Do ponto de vista da engenharia naval, o design de FPSO deve considerar o regime regulatório da região de sua operação. Normas de sociedades classificadoras têm como objetivo principal garantir a segurança de toda operação de extração de óleo e gás para a tripulação. Entre as normas utilizadas estão:

- Det Norske Veritas (DNV-GL, Part 3, Chapter 3-6, Structural design principles, 2011)

- American Bureau of Shipping Rules for building and classing Steel vessels (Part 5C, Chapters 5-13,2012) 
Ainda existem diversas normas essenciais para garantir a segurança da plataforma como normas de amarração, comunicação, tubulações elétricas, posicionamento do helideck. Como este trabalho prioriza o desenvolvimento da geometria inicial da plataforma, 0 atendimento de normas referentes ao detalhamento do projeto FPSO serão avaliados em um trabalho futuro.

O uso de projetos inovadores vem se tornando cada vez mais importante ao redor do mundo para desenvolver cascos novos para FPSO's, com projetos específicos para cada condição de operação, que visam atender ao campo de exploração onde a plataforma irá operar como, por exemplo, o estudo do projeto ULFPSO feito por Oliveira, A.C. (2012).

Tradicionalmente, a teoria do projeto de plataformas lida com questões relacionadas a propriedades técnicas e econômicas de toda unidade flutuante, que são frequentemente determinados usando métodos de otimização de parâmetros que podem afetar substancialmente o custo de construção naval e afretamento de unidades flutuantes, além do custo de operação do FPSO. Trata-se de um processo extremamente complexo uma vez que a plataforma opera em um ambiente exposto à ação de muitos diferentes agentes externos e internos resultantes que variam de acordo com tipo de operação e condições ambientais.

\subsection{Risers}

A estrutura tubular responsável pelo transporte de óleo à superfície, injeção de água e $\mathrm{CO}_{2}$ nos poços é denominada riser. A tubulação apoiada na superfície do fundo do mar também auxilia no transporte do óleo entre os poços antes de levá-lo à superfície (Saeed Imani Bidgoli et al). A configuração estática do riser deve ser determinado através da teoria de catenária baseada no ângulo de hang-off, profundidade da lâmina d'água, uso de elementos de flutuação e o peso da unidade. Estas configurações são conforme se verifica na Figura 1-2: 


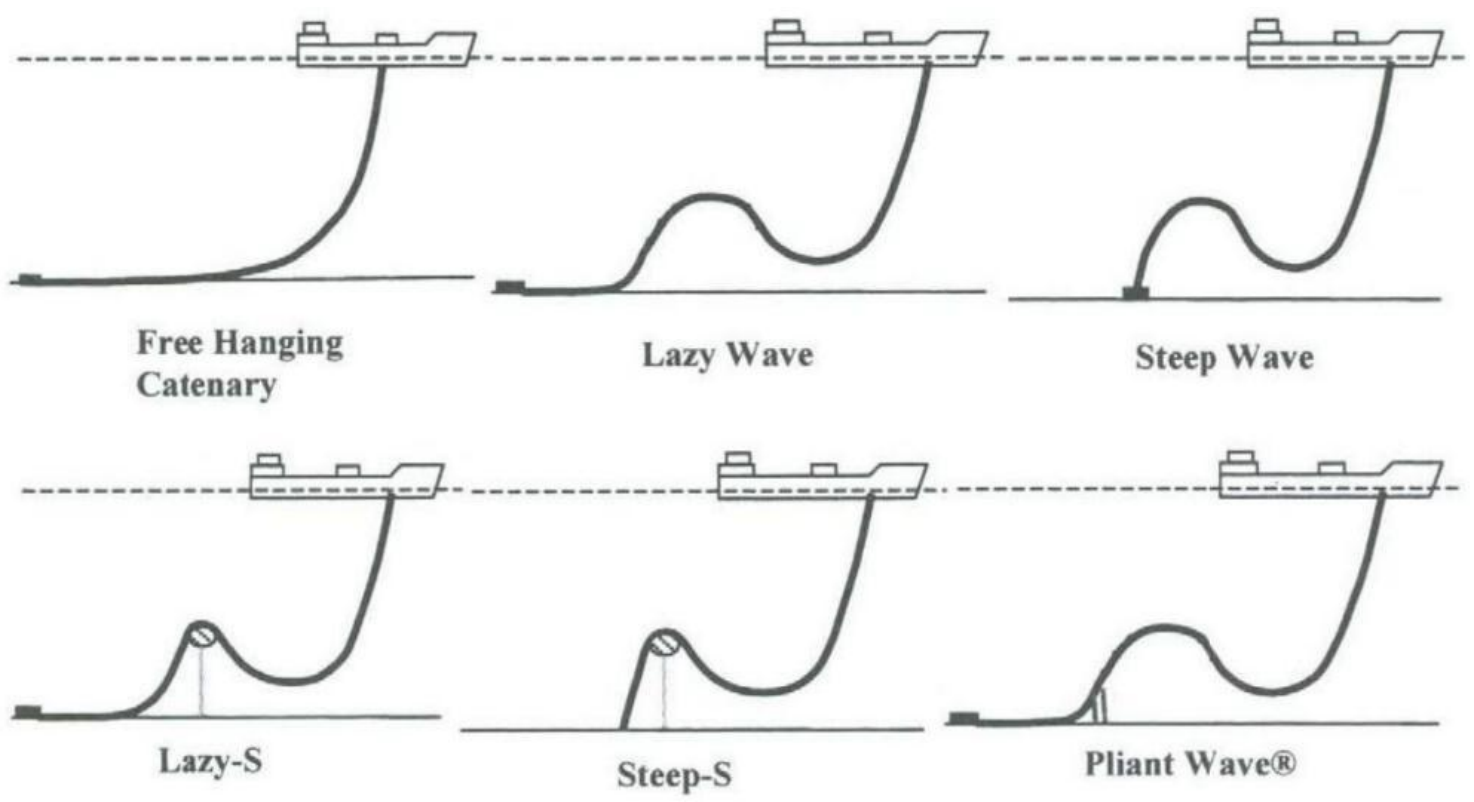

Figura 1-2 Tipos de Configurações de Risers

FONTE: Saeed Imani Bidgoli et al. / IJCOE 2017, No. 5; p.45-55

A Figura 1-3 a seguir mostra o desenho esquemático de uma linha de riser em configuração de catenária livre conectada entre a unidade flutuante (UF) a uma profundidade $\mathrm{D}$ do solo submarino em um ponto chamado de touchdown point (TDP) a uma distancia d da plataforma. Nestas condições, o carregamento y sob os risers estão relacionados diretamente ao efeito de ondas e efeito de correnteza, além de indiretamente pelo movimento da unidade flutuante. A modelagem do carregamento é apresentada na Figura 1-4.

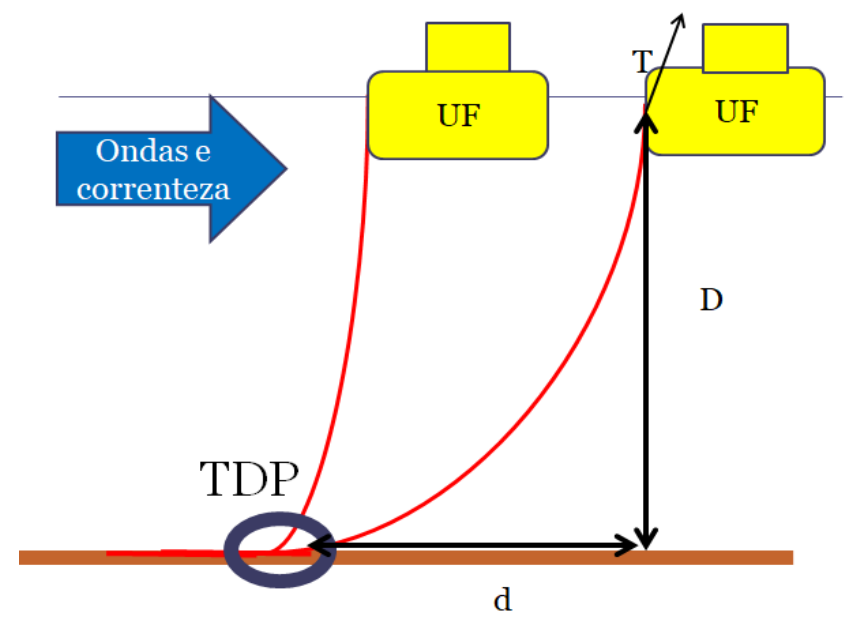

Figura 1-3 Representação de riser conectado à UF e ao fundo do oceano FONTE: Elaborada pelo autor 

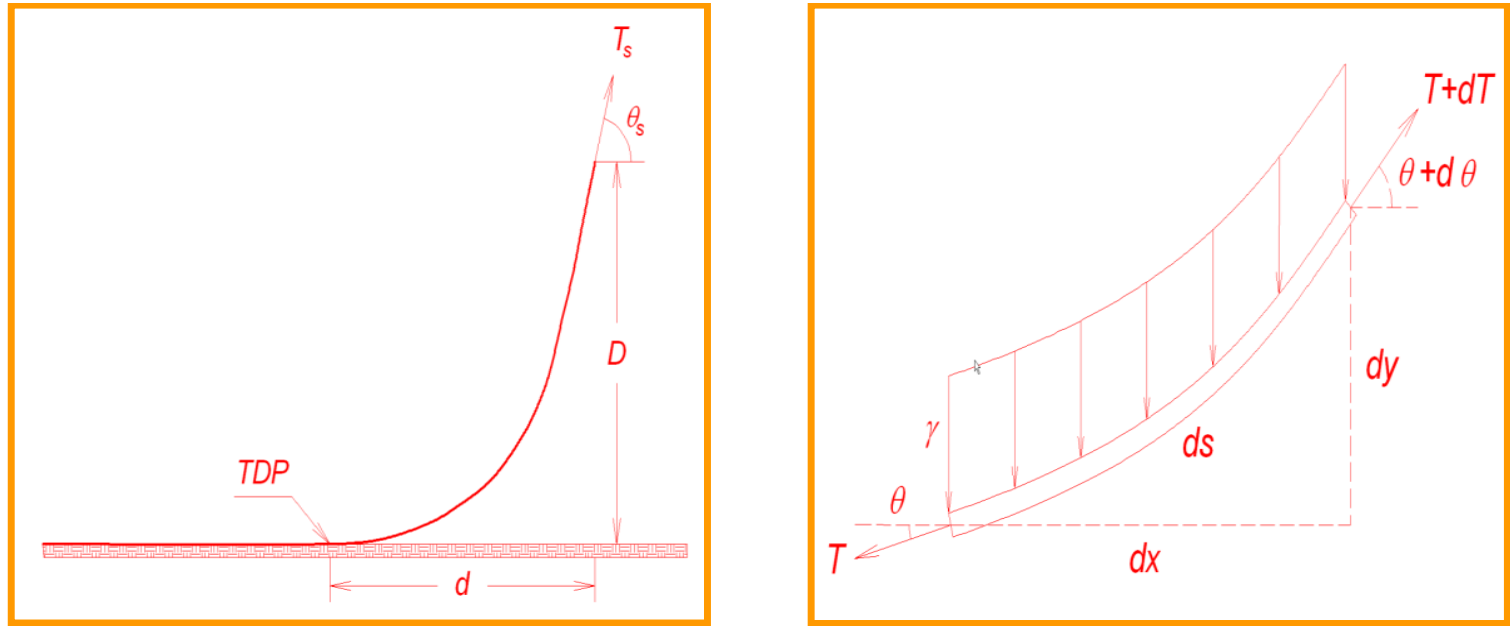

Figura 1-4 Modelagem da linha de riser

FONTE: Elaborada Pesce, C.P. e Martins, C.

Risers podem ser classificados em dois grupos principais: flexíveis e rígidos. Risers flexíveis são tubulações construídas por diversas camadas de materiais revestindo a tubulação metálica interna e capaz de compensar grandes deflexões. Cada camada tem a função de proteger a tubulação de efeitos como pressão, tração e garantir estanqueidade. A Figura 1-5 a seguir mostra as camadas de riser flexíveis.

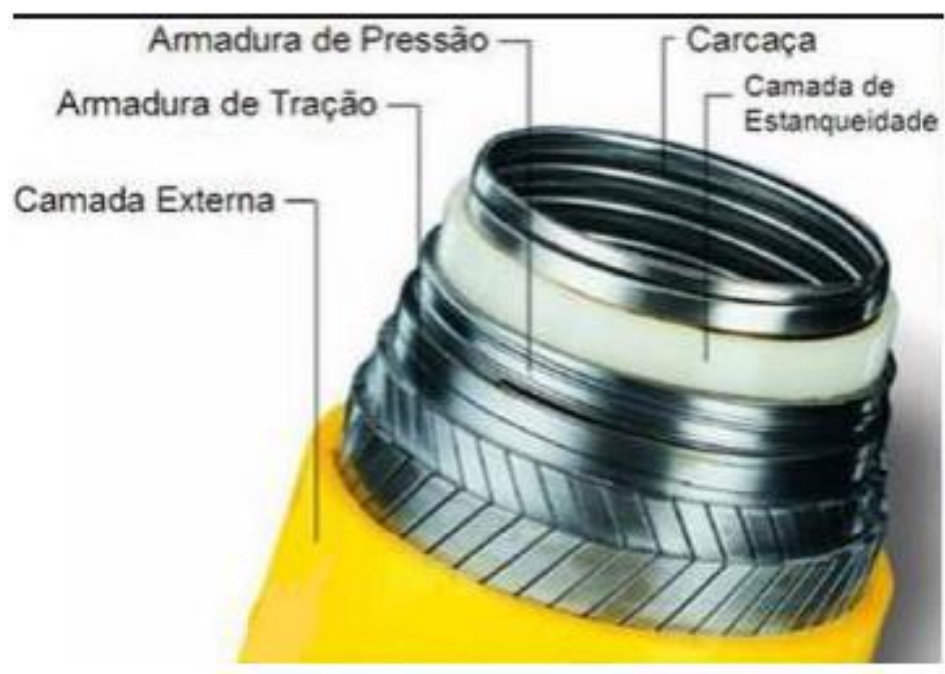

Figura 1-5 Camadas protetoras do riser flexível FONTE: Martins, C.O.D. ET AL 2011

Entretanto, as grandes profundidades e a presença de contaminantes ácidos como $\mathrm{CO} 2$ nos poços da região do Pré-sal brasileiro reduzem a eficiência deste tipo de riser e aumentam os custos de operação da produção de óleo. 
Risers rígidos metálicos são tubulações geralmente de aço que se estende do soo marítimo até a unidade flutuante em vários tipos de configurações. Estas estruturas são conectadas ao FPSO ou unidade flutuante por uma junta flexível que, segundo a DNV-OS-F201, é uma peça de metal laminado que possui uma abertura de dimensões iguais ou maiores do que o diâmetro do riser instalado. Desta forma, a junta flexível absorve parte do momento de flexão causado pelos movimentos da plataforma. A Figura 1-6 ilustra uma junta flexível.
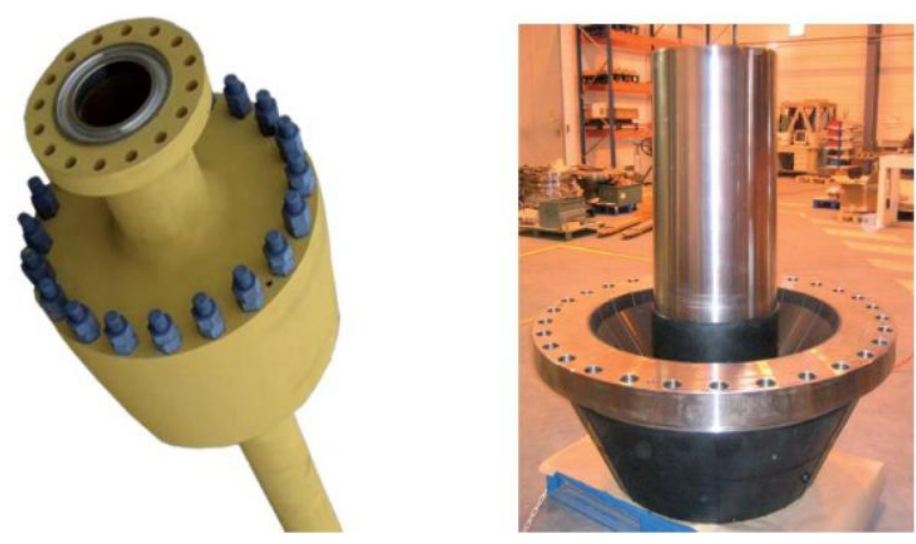

Figura 1-6 Junta flexível

FONTE: Hutchinson Catalogue, 2010

O uso de risers rígidos em configuração de catenária livre permite a tubulações com maiores diâmetros e resistentes a maiores pressões e corrosão. Desta forma, a viabilização desta estrutura é um ponto de interesse deste trabalho por possibilitar a exploração de petróleo em águas profundas com maior eficiência.

\subsubsection{Steel Catenary Risers (SCR)}

Segundo Bai et al., (2004), risers em catenária de aço são uma das soluções preferidas para águas profundas, incluindo produção de poços, injeção de água ou $\mathrm{CO}_{2} \mathrm{e}$ exportação de óleo e gás natural por meio de um duto em catenária.

No Brasil, o conceito de SCR's foi utilizado em uma plataforma semissubmersível (P-18) e recentemente em FPSO's com sistemas de risers desacoplados (FPSO cidade de São Paulo e FPSO cidade de Paraty). 
Internacionalmente, risers rígidos em catenária são geralmente utilizados em plataformas com movimentos verticais reduzidos. As plataformas FPSO, entretanto, possuem grandes movimentos verticais em comparação a este tipo de plataforma. Assim, os movimentos deste tipo de plataforma fazem o emprego de riser SCR em águas profundas uma tarefa desafiadora. Em grandes profundidades, um dos marcos histórico com o uso de risers rígidos foi à instalação de SLWR (Steel Lazy Wave Riser) na plataforma FPSO Espírito Santo a $1780 \mathrm{~m}$ de profundidade em águas brasileiras no Parque das Conchas (Hoffmann et al (2010)) como apresentado na Figura 1-7 a seguir.

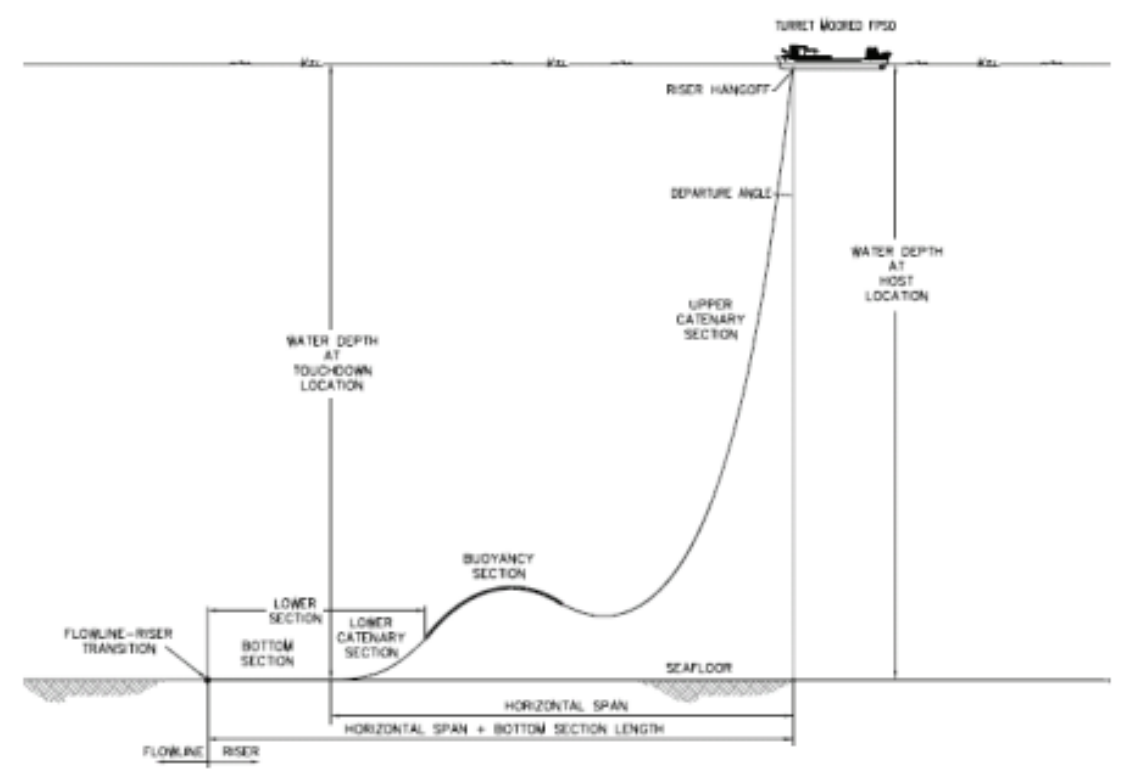

Figura 1-7 Steel Lazy Wave Riser Concept

FONTE: Hoffman ET AL (2010)

Segundo Keprate, D. (2004), as principais vantagens para a preferência de risers rígidos sobre risers flexíveis são:

- Redução de custos

- Resistência a Corrosão

- Maior resistência ao colapso

- Instalação simples

- Mercado não monopolizado 
Entretanto, deve-se tomar uma atenção especial no projeto às regiões ligadas diretamente ao FPSO através de juntas ou articulações flexíveis, assim como a touchdown zone com o propósito de reduzir danos causados pela concentração de esforços como ilustrado na Figura 1-8. Movimentos excessivos e acelerações são aspectos-chave na análise do emprego deste tipo de estrutura no FPSO, uma vez que eles estão diretamente ligados com o tempo de disponibilidade operação da plataforma. Dentre os principais aspectos, pode-se citar:

- Grandes movimentos da plataforma: Os FPSOs podem passar por grandes movimentos em condições ambientais severas. Para os risers acoplados, isto pode ser problemático, pois a ação de tração e/ou compressão excessiva em casos extremos pode causar que o riser falhe. No caso de arranjos SCR, uma resposta extrema poderia causar compressão do riser na TDZ ou choque entre risers adjacentes.

- Grandes carregamentos da plataforma: Em ambientes severos, além dos efeitos de onda e correnteza, risers recebem cargas mais elevadas pela plataforma conectada.

- Perda de calor: Devido ao aumento da profundidade da água, o comprimento do riser também aumenta, o que significa que a área de superfície da perda de calor aumenta, causando mais perdas térmicas.

- Fadiga crítica: Quando sujeitos a ambientes severos e grandes movimentos, risers tem a sua vida útil reduzida e são sujeitos a fadiga. 


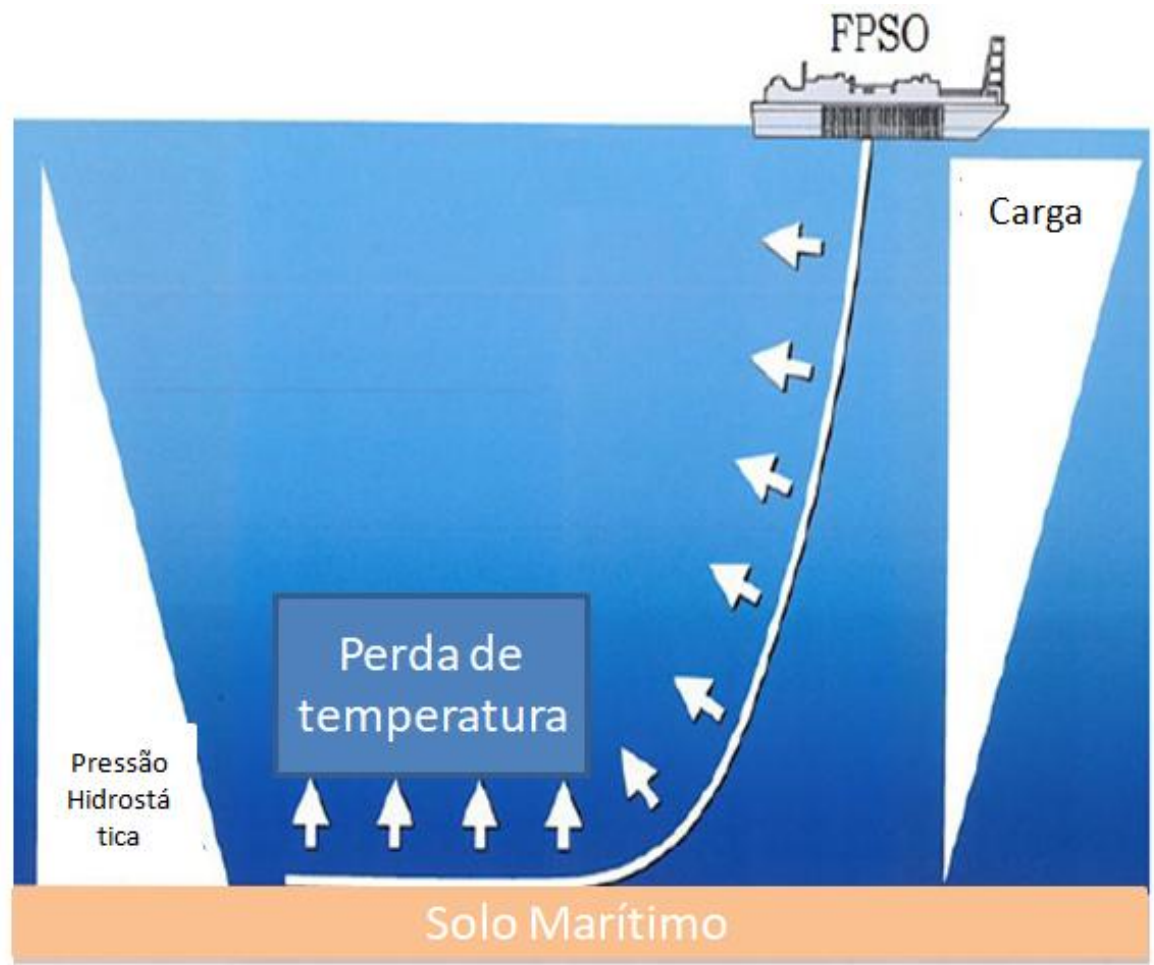

Figura 1-8 Esforços aplicados em uma tubulação para FPSO

FONTE: Keprate, D. (2004), alterado pelo autor

Observa-se um dilema ao considerar as condições de operação do Pré-sal, a necessidade de plataformas capazes de produzir e armazenar óleo por grandes intervalos de tempo e os requisitos para o uso de risers rígidos, pois a maioria das unidades flutuantes em operação consegue atender integralmente os requisitos de operação exigidos pelos risers e como apresentado na Tabela 1-1 apresentada no estudo de Vilameá, E. M., (2017).

\begin{tabular}{|l|c|c|c|c|}
\hline \multicolumn{1}{|c|}{ Critérios } & Semi-submersível & $\begin{array}{c}\text { Monocoluna sem } \\
\text { moonpool }\end{array}$ & $\begin{array}{c}\text { Monocoluna com } \\
\text { moonpool }\end{array}$ & FPSO \\
\hline Uso de SCR & Viável & $\begin{array}{c}\text { Apenas SCR em } \\
\text { configurações } \\
\text { complexas }\end{array}$ & Viável & $\begin{array}{c}\text { Apenas SCR em } \\
\text { configurações } \\
\text { complexas }\end{array}$ \\
\hline Armazenamento & Depende de FSO & Viável & Viável & Viável \\
\hline Arranjo e Topside & $\begin{array}{c}\text { Estudos de } \\
\text { segurança são } \\
\text { necessários }\end{array}$ & $\begin{array}{c}\text { Estudos de } \\
\text { segurançá são } \\
\text { necessários }\end{array}$ & $\begin{array}{c}\text { Estudos de } \\
\text { segurançá são } \\
\text { necessários }\end{array}$ & Viável \\
\hline
\end{tabular}

Tabela 1-1 Avaliação qualitativa dos conceitos existentes FONTE: Vilameá, E. M. (2017) 
Este estudo sugere que o desenvolvimento de uma plataforma com grande capacidade de armazenamento e área de convés similar ao FPSO e com movimentos verticais reduzidos para garantir a disponibilidade de risers rígidos.

Uma possível solução é para a redução dos efeitos causados pelo movimento vertical da plataforma é instalar o balcão de risers no centro desta através de um moonpool. Além de transferir os pontos de conexão de riser ao eixo de rotação solidário a plataforma, espera-se reduzir os movimentos verticais da plataforma utilizando a coluna d'água interna do moonpool como um amortecedor passivo como apresentado nos estudos de Torres, F. (2007). A Figura 1-9 mostra um possível arranjo de risers através de uma plataforma FPSO com moonpool:

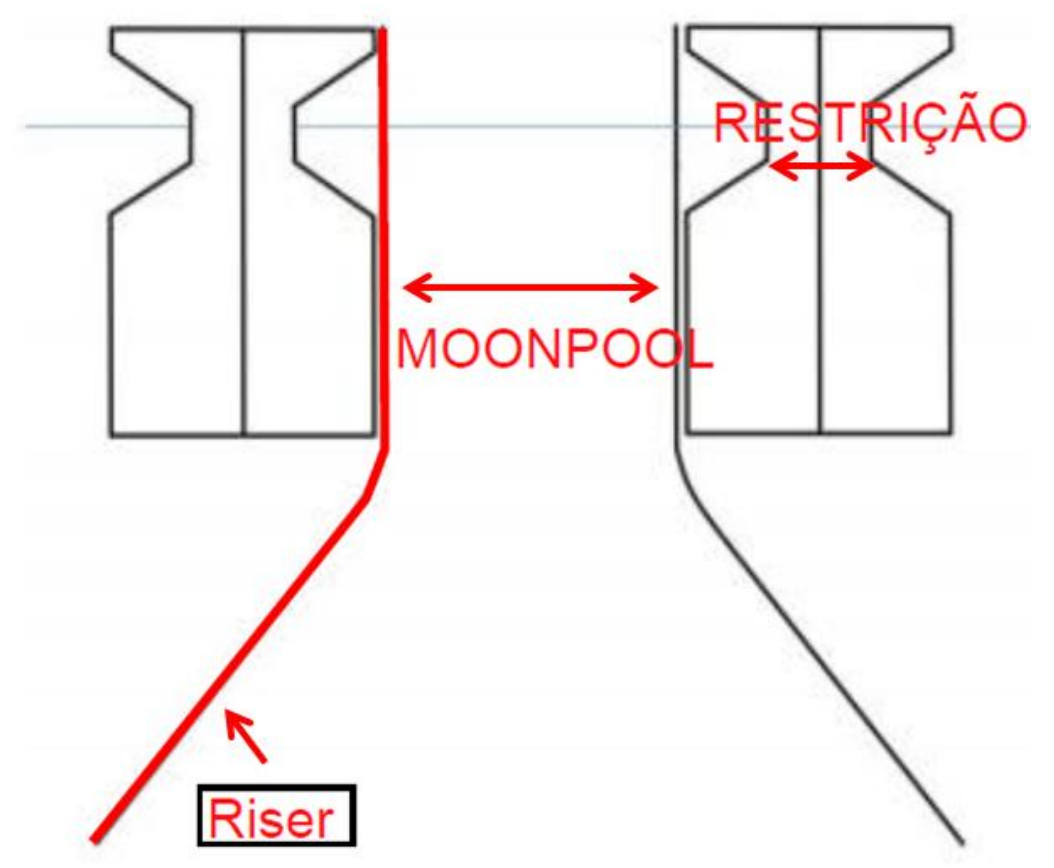

Figura 1-9 Desenho esquemático da conexão de risers FONTE: Vilamea, E. M. (2017)), alterado pelo autor

\subsection{Moonpool}

O termo moonpool refere-se ao apêndice utilizado em plataformas petrolíferas, navios de perfuração, navios de apoio ao mergulho, com o propósito principal de exploração subaquática. Por meio de uma abertura no fundo ou na base do casco que tem acesso à água abaixo, permitindo a introdução de instrumentação e equipamento da embarcação a regiões submersas. Além disso, fornece abrigo e 
proteção, de modo que, mesmo que, no caso de um navio em alto-mar ou cercado por gelo, a tripulação possa trabalhar confortavelmente e não num convés exposto às intempéries.

Usualmente, um navio FPSO utilizado em exploração possui o sistema de risers na lateral da plataforma, próxima ao costado como apresentado na Figura 1-10 para um FPSO utilizando spread mooring.

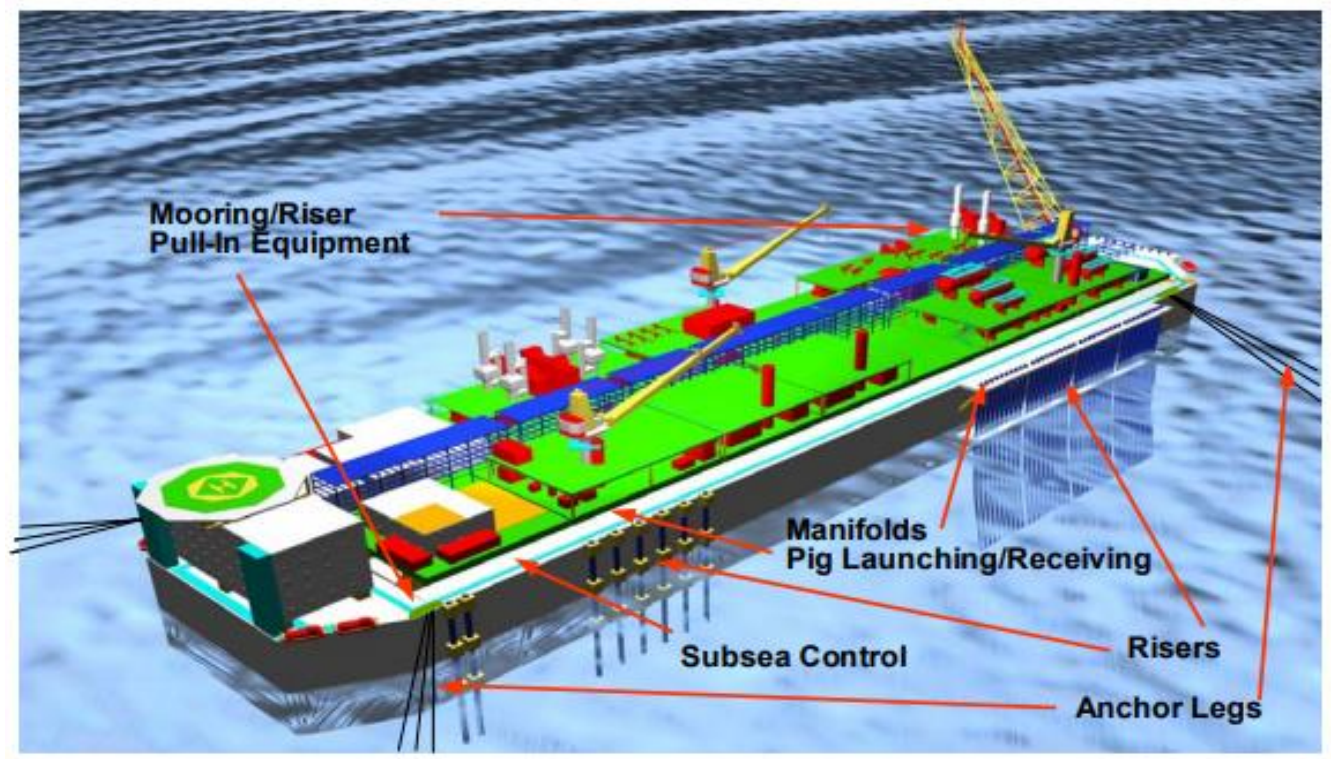

Figura 1-10 Organização do sistema de Amarração/Risers de um FPSO

FONTE: Howell, G. Boyd et al (2006)

Aplicando este design para uma plataforma FPSO, a solução mais simples seria transferir o balcão de risers para dentro da embarcação através de um moonpool. O moonpool adotado seria inevitavelmente maior do que aquelas usadas para os navios de perfuração, de lançamentos e recuperação de equipamentos submarinos, devido ao tamanho das embarcações envolvidas. Uma vantagem adicional do uso do moonpool é reduzir os efeitos dos movimentos angulares do FPSO aos equipamentos durante a operação.

Estas operações só são possíveis caso a água dentro do moonpool permaneça calma o que evidencia um problema significativo associado ao conceito do moonpool. As ondas e os movimentos correspondentes do corpo flutuante podem induzir oscilações no interior do moonpool. 
Em condição de ressonância, as oscilações internas podem ser amplificadas e atingir grandes alturas da onda, inviabilizando as operações da plataforma e podendo danificar equipamentos. Estes movimentos relativos entre a plataforma e a coluna d'água interna ao moonpool podem causar acidentes durante a operação da plataforma como, por exemplo, na área do convés acima ao moonpool, utilizado para manuseio do sistema submersível no caso de uma embarcação de apoio de mergulho ou manuseio de risers no caso de uma plataforma de produção flutuante, pode ser inundada. Isso é indesejável para a segurança daqueles que trabalham no manuseio de equipamentos e, em termos gerais, para a segurança da embarcação como um todo. Estas grandes oscilações também aumentam o risco de uma falha do equipamento instalado devido acelerações verticais no qual ele estará sujeito.

Estes efeitos amplificação são característicos da coluna d'água interior ao moonpool ou da região de vãos ou gaps entre plataformas durante operações de offloading com inúmeros estudos publicados sobre o assunto. Para este trabalho, interessa-se por estudos em que os movimentos dinâmicos da plataforma são influenciados pelo moonpool como apresentado em Sphaier et al (2007) para o design de uma plataforma do tipo monocoluna. Apesar do uso de uma plataforma diferente, os resultados obtidos são interessantes para a modelagem matemática do moonpool neste trabalho principalmente sobre a avaliação do coeficiente de amortecimento viscoso que não é considerado na maioria dos softwares numéricos disponíveis no mercado.

Estes problemas relacionados ao moonpool podem ser evitados na fase de projeto da embarcação com uma avaliação crítica da geometria, acelerações verticais, espaço utilizado da plataforma e picos de ressonância do moonpool além das análises tradicionais para investigar o comportamento da plataforma. Desta forma, o entendimento do funcionamento do moonpool e a sua influência no comportamento da plataforma pode auxiliar na melhoria do seu desempenho.

A intenção deste trabalho é desenvolver uma nova geometria ao incluir um moonpool como um tanque passivo na plataforma ao fazer com que a coluna d'água interna ao moonpool interaja com o movimento do navio de maneira semelhante a plataformas monocolunas como descrito na Figura 1-11. 
Além de avaliar o uso de moonpools na plataforma, será estudado o uso uma redução no corpo paralelo do FPSO na altura da linha d'água e o uso da saia hidrodinâmica na altura da quilha da plataforma.

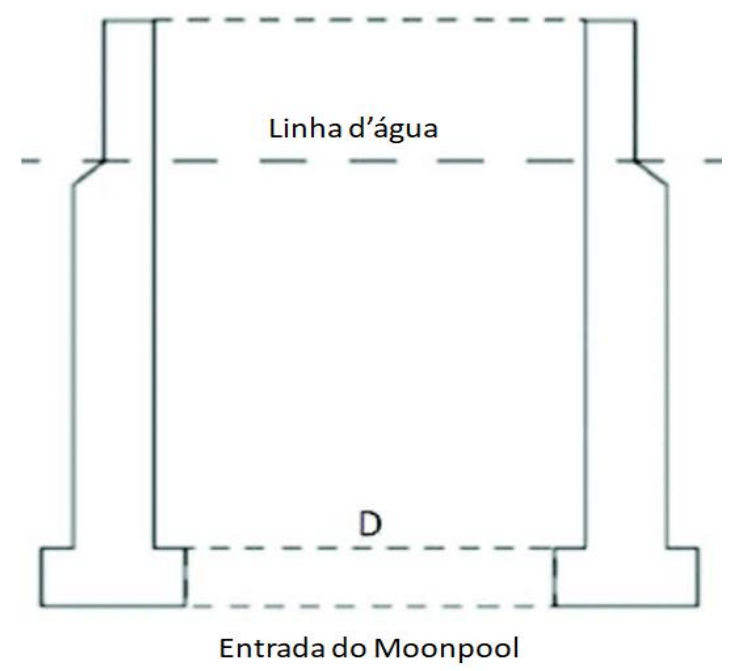

Figura 1-11 Seção transversal de um moonpool

FONTE: Sphaier et al. (2007), alterado pelo autor

A introdução do moonpool na plataforma exige mudanças na organização dos módulos da planta de operação, tanques de armazenamento e na disposição do balcão de risers para o centro da plataforma como apresentado na Figura 1-12.

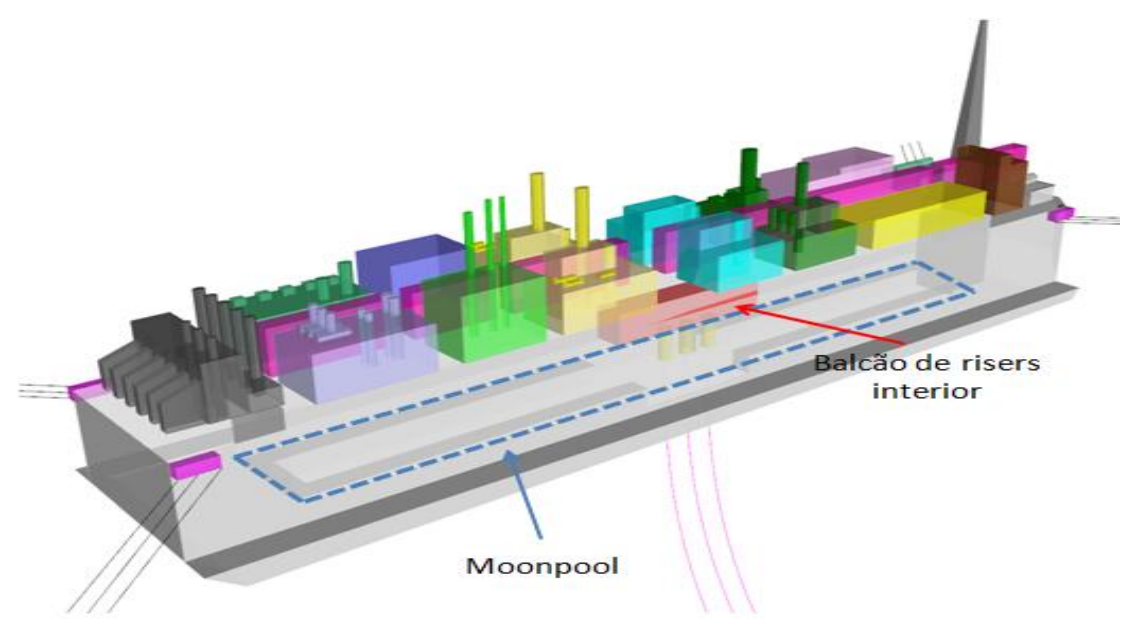

Figura 1-12 Organização do sistema de risers proposto

FONTE: Elaborada pelo autor 
Estas alterações na geometria da plataforma são absolutamente importantes para minimizar os movimentos e acelerações da unidade, que é outro requisito a ser levado em consideração durante as fases preliminares de projeto. A avaliação de dimensões da saia hidrodinâmica e reduções da área de linha d'água também se tornam importantes para o comportamento em ondas final da plataforma.

Este conceito de plataforma é conhecido como ULFPSO (Ultra-Large Floating Production Storage and Offloading) foi desenvolvido para atingir nível de movimentos tão baixos que permitam conexão de risers de grande diâmetro e, também, aproamentos diferentes dos utilizados em FPSO's, possibilitando arranjos submarinos mais baratos convencionais como apresentado em Oliveira, A.C., (2012). A redução do nível de movimentos verticais da unidade é principalmente obtida por meio do aumento do período natural do movimento de heave, que é obtido pela área de linha d'água reduzida em relação ao volume submerso restante do casco.

Desta forma, através da parametrização das dimensões da plataforma FPSO e do moonpool, pretende-se propor uma solução com movimentos e acelerações viáveis para o uso de SCR's.

\subsection{Objetivos}

O principal objetivo deste trabalho é utilizar o moonpool como um instrumento hidrodinâmico auxiliar vantajoso durante a operação da plataforma e que não seja apenas uma abertura inconveniente no seu casco. Desta forma, seria possível obter uma plataforma cuja resposta tenha menores amplitudes de movimentos e com um comportamento dinâmico de menores movimentos e acelerações para uma determinada condição de mar.

Do ponto de vista operacional, a utilização do moonpool possibilita o posicionamento do balcão de risers no centro da plataforma, o que torna a utilização de risers rígidos uma opção viável para a extração de petróleo em águas ultraprofundas com plataformas FPSO devido a uma redução significativa de movimentos e acelerações no ponto de conexão de risers. 
Este trabalho propõe-se a estudar e avaliar as seguintes questões:

- Desenvolver uma plataforma FPSO com moonpool com o balcão de risers posicionado próximo ao centro solidário da plataforma

- Avaliar o uso de outros sistemas auxiliares (apêndices hidrodinâmicos) como saia hidrodinâmicas e redução da área de linha d'água na altura do calado operacional da plataforma

- Avaliar o desempenho dinâmico desta plataforma, reduzindo os movimentos verticais desta a fim de viabilizar o uso de SCR's para suas operações.

Além disso, o trabalho proposto visa apresentar uma solução viável do ponto de vista construtivo e operacional. Portanto este estudo deve utilizar como hipótese as normas e os critérios das sociedades classificadoras. Avaliações de critérios estruturais e de estabilidade foram feitas em concordância com as normas vigentes.

A solução proposta também deve atender requisitos mínimos de armazenamento, com autonomia de operação semelhante ao de projetos de plataformas FPSO's convencionais em operação na atualidade.

Por fim, a plataforma desenvolvida também deve atender os critérios de acelerações e movimentos nos pontos de conexão da plataforma com os risers em catenária (SCR).

Por fim, foi utilizada uma abordagem no domínio da frequência com uma simplificação do modelo "caixa", a fim de facilitar o estudo dos parâmetros de projeto e reduzir processos computacionais. 


\section{REVISÃO DA LITERATURA}

Este capítulo apresentará as principais referências ao estudo de moonpools como um dispositivo de amortecimento e sobre o desenvolvimento de unidades flutuantes utilizando esta estrutura.

Como brevemente discutido no Capítulo 1, o termo moonpool refere-se à cavidade no casco de sistemas offshore encontrada principalmente em embarcações de mergulho e plataformas de perfuração com o propósito de permitir a passagem de pessoal e equipamentos da unidade flutuante ao mar. Esta abertura ainda permite que a equipe de operação e equipamentos trabalhe de forma menos exposta às condições ambientais.

Um dos primeiros estudos sobre a influência de moonpools na hidrodinâmica das embarcações é o trabalho de Fukuda, K (1977). Em seus experimentos, Fukuda concentrou-se em avaliar o comportamento da água interior ao moonpool quando existe um fluxo externo e em estudar a influência nos movimentos da embarcação devido à formação acoplada entre o casco e o fluido interior ao moonpool. Os modelos utilizados no experimento são apresentados a seguir:

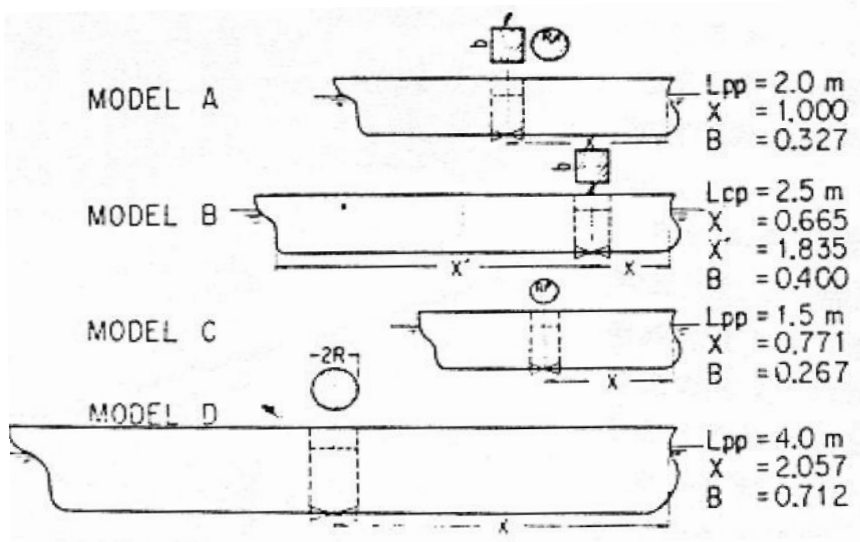

Figura 2-1 Modelos estudados por Fukuda

FONTE: Fukuda, K (1977)

Cada medição foi feita variando a forma do moonpool (retangular ou circular) e as dimensões da embarcação e do moonpool como descrito nas tabelas a seguir: 


\begin{tabular}{|c|c|c|c|c|c|}
\hline Model & Lpp $(m)$ & $X(m)$ & $B(m)$ & Lpp/X & Lpp/B \\
\hline A & 2.00 & 1 & 0.327 & 2.00 & 6.12 \\
\hline B & 2.50 & 0.665 & 0.400 & 3.76 & 6.25 \\
\hline C & 1.50 & 0.771 & 0.267 & 1.95 & 5.62 \\
\hline D & 4.00 & 2.057 & 0.712 & 1.94 & 5.62 \\
\hline
\end{tabular}

Tabela 2-1 Dimensões dos modelos de Fukuda, K (1977)

FONTE: Fukuda, K (1977)

\begin{tabular}{|c|c|c|c|c|}
\hline $\mathrm{d}$ & $\mathrm{l} / \mathrm{d}$ & $\mathrm{b} / \mathrm{d}$ & $\mathrm{l}$ & $\mathrm{b}$ \\
\hline \multirow{3}{*}{0.10} & 0.6 & 2.4 & 0.06 & 0.24 \\
\cline { 2 - 5 } & 1.2 & 2.4 & 0.12 & 0.24 \\
\cline { 2 - 5 } & 1.8 & 2.4 & 0.18 & 0.24 \\
\hline \multirow{4}{*}{0.12} & 1 & 2.00 & 0.12 & 0.24 \\
\cline { 2 - 5 } & 1 & 1.33 & 0.12 & 0.16 \\
\cline { 2 - 5 } & 1 & 1.00 & 0.12 & 0.12 \\
\cline { 2 - 5 } & 1 & 0.50 & 0.12 & 0.06 \\
\hline \multirow{3}{*}{0.15} & 1 & 2.00 & 0.08 & 0.24 \\
\cline { 2 - 5 } & 0.4 & 1.6 & 0.06 & 0.24 \\
\cline { 2 - 5 } & 0.8 & 1.6 & 0.12 & 0.24 \\
\hline
\end{tabular}

Tabela 2-2 Moonpools retangulares

FONTE: Fukuda, K (1977)

\begin{tabular}{|c|c|c|}
\hline$D(m)$ & $2 R(m)$ & $R / d$ \\
\hline 0.0650 & 0.093 & 0.715 \\
\hline 0.0930 & 0.093 & 0.500 \\
\hline 0.1200 & 0.113 & 0.471 \\
\hline
\end{tabular}

Tabela 2-3 Moonpools circulares

FONTE: Fukuda, K (1977)

Em seus experimentos, cada modelo é deslocado com diferentes velocidades em um tanque de arrasto e a elevação da coluna d'água é verificada. Foi observado que a superfície livre do moonpool desloca-se regularmente quando o modelo está fixado com ondas incidindo sobre ele. 
O principal resultado do trabalho de Fukuda para esta dissertação é a curva de massa virtual relacionada ao movimento de sloshing contido no moonpool obtida através de ensaios de decaimento da água interna do moonpool. A seguir é apresentada a curva de massa virtual onde $S$ é a área de linha d'água interna ao moonpool e $\mathrm{d}$ corresponde à massa virtual indicada pela fórmula seguir:

$$
d^{\prime}=\frac{m^{\prime}}{\rho . S}=\frac{g}{\omega^{2}{ }_{n}}
$$

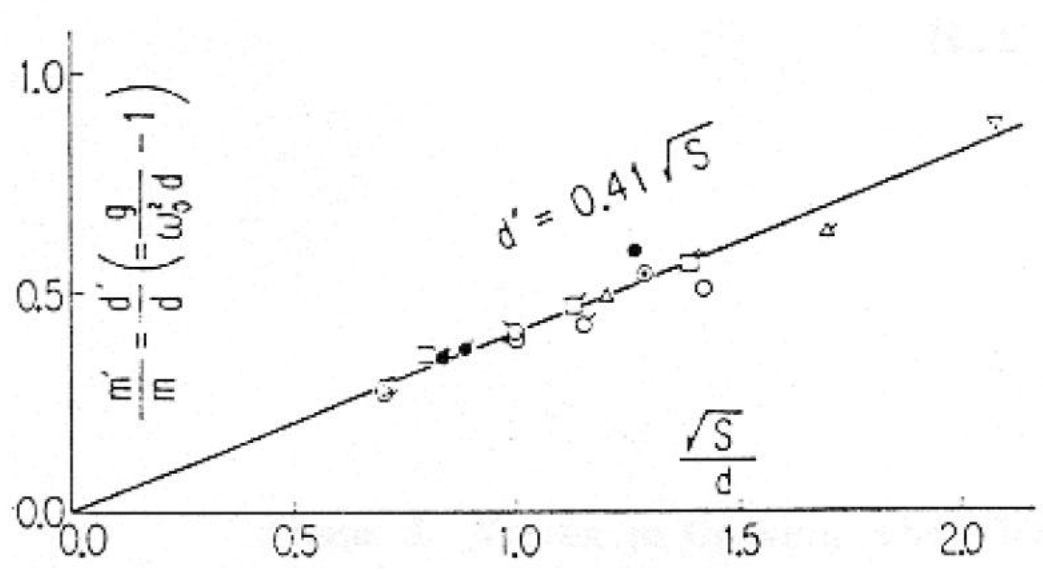

Figura 2-2 Curva de Massa Virtual

FONTE: Fukuda, K (1977)

Portanto, o movimento de água interna ao moonpool depende da velocidade de fluxo da água externa ao moonpool e do formato da sua abertura. Por fim, ele propõe o uso de placas fixas à parede vertical do moonpool e abaixo da superfície d'água como método de reduzir a amplitude de movimento da água interna ao moonpool.

O comportamento de água interna aos tanques verticais em navios também foi estudado por Aalbers, A. B. (1984) com o objetivo de desenvolver métodos para a redução dos movimentos de oscilação de água e apontar semelhanças entre o movimento de água interna ao moonpool acoplado ao movimento de um navio e um sistema massa-mola. Desta maneira os experimentos de Aalbers tinham como objetivo gerar grandes amplificações no movimento da água no moonpool para determinadas frequências. Estas grandes amplificações existem devido à falta de amortecimento atuante no fluxo de água, pois as paredes do moonpool são lisas em 
geral. Estas amplificações estão entre as causas dos problemas existentes durante as operações executadas nestas aberturas como, por exemplo, ocorrência de slamming em câmaras de mergulho.

Um modelo matemático foi desenvolvido para obtenção da equação do movimento relativo da água interna ao moonpool, utilizando a teoria do potencial de ondas e a segunda Lei de Newton, com efeitos não lineares inicialmente sendo desconsiderados. Para que seu modelo seja coerente com o fenômeno, foi incorporada uma parcela de amortecimento não linear, e uma componente de massa variável que depende da posição do nível da superfície livre da água interna do tanque. Considera-se que o centro de coordenadas do sistema e o centro de gravidade do sistema são coincidentes. Posicionando assim o eixo de simetria do corpo e o termo de acoplamento de pitch e roll nos movimentos verticais.

A lei de conservação do momento linear médio de um sistema também é empregada neste trabalho. Assim, a taxa de variação da quantidade de movimento média de um sistema em um volume de controle deve ser igual à resultante de forças externas atuantes no sistema. Para o caso do moonpool fixo, aplicando o teorema de Gauss, foi obtida a seguinte equação:

$$
\frac{\partial}{\partial t} \iiint_{\Omega} \rho v_{i} \cdot d V+\iint_{d \Omega} \rho v_{i} \cdot \bar{v} \cdot \bar{n} . d S=\iiint_{d \Omega} \rho f_{i} \cdot d V+\iint_{d \Omega} \tau_{i j} n_{j} \cdot d S
$$

Onde:

$\bar{v} \bullet \bar{n}$ é o produto escalar entre o vetor velocidade $\bar{v}$ e o vetor normal à superfície $\bar{n}$

$\tau_{i j}$ é o tensor de tensões proposto por Newman, J. N. (1977)

$f_{i}$ é força gravitacional que atua em cada elemento de volume i 
Aplicando a força gravitacional em função do elemento de volume i na equação 2-3 obtém-se:

$$
\frac{\partial}{\partial t}\left[\rho A_{m} \cdot(h+\varsigma) \frac{d \varsigma}{d t}\right]+\rho A_{m}\left(\frac{d \varsigma}{d t}\right)^{2}=-\rho A_{m} \cdot g(h+\varsigma) \iint_{d \Omega} \tau_{i j} n_{j} \cdot d S
$$

Nas paredes paralelas do moonpool, a resultante de força é zero. $\mathrm{Na}$ superfície superior, obtém-se:

$$
\iint_{S \text { sup }} \tau_{i j} n_{j} \cdot d S=A_{m} p_{a t m}
$$

Para a superfície inferior do tanque (moonpool) aplica-se a lei de Bernoulli:

$$
\begin{gathered}
p+\frac{1}{2} \rho \cdot(\nabla \phi)^{2}+\rho \cdot g \cdot z_{3}+\rho \frac{\partial \phi}{\partial t}+p_{a t m}=0 \\
\iint_{\text {S sup }} p_{i j} \cdot n_{j} \cdot d S=-\frac{1}{2} \rho A_{m}\left(\frac{d \zeta}{d t}\right)^{2}+\rho A_{m} g h-p_{a t m} A_{m}-\rho \iint_{\text {Sinf }} \frac{\partial \phi}{\partial t} n d S
\end{gathered}
$$

Substituindo na equação anterior obtém-se:

$$
\rho A_{m} \cdot(h+\zeta) \cdot d \frac{d^{2} \zeta}{d t^{2}}+\frac{1}{2} \rho \cdot A_{m}\left(\frac{d \zeta}{d t}\right)^{2}+\rho A_{m} g \cdot \varsigma=-\rho \iint_{S \text { inf }} \frac{\partial \phi}{\partial t} n d S
$$

Utilizando-se da teoria linear potencial, o termo do lado direito da equação 2-8 pode ser reescrito como:

$$
-\rho \iint_{\text {Sinf }} \frac{\partial \phi}{\partial t} n d S=-a_{\varsigma} \frac{d^{2} \varsigma}{d t^{2}}-b_{\varsigma} \frac{d \varsigma}{d t}
$$

E representa o resultado das forças hidrodinâmicas atuantes.

Para a consideração o efeito de viscosidade, foi introduzido um termo não linear na equação devido ao amortecimento originado pelo atrito entre as paredes do corpo e o fluido, e principalmente pelos vórtices gerados na entrada e saída do fluido na região inferior do moonpool. Este termo é representado por $b_{2 \varsigma} \dot{\zeta}_{r}\left|\dot{\zeta}_{r}\right|$. Aalbers 
empregou o modelo matemático de Van Oortmersen (1979) que descreve um acoplamento de dois corpos flutuantes em ondas e obtém o conjunto de equações finais que representam o acoplamento de movimento entre moonpool e plataforma.

$$
\begin{gathered}
\left\{\rho A_{m}(h+\varsigma)+a_{\zeta}\right\} \ddot{\zeta}_{r}+b_{\zeta} \cdot \dot{\zeta_{r}}+b_{2 \varsigma} \dot{\zeta_{r}}\left|\dot{\zeta}_{r}\right|+\rho \cdot g \cdot A_{m} \cdot \dot{\zeta_{r}}+ \\
+\left\{a_{\zeta z}+\rho \cdot A_{m} \cdot\left(h+\zeta_{r}\right)+a_{\zeta}\right\} \ddot{z}+\left(b_{\zeta z}+b_{\zeta}\right) \cdot \dot{z}+\rho A_{m} g z=F_{w \varsigma}
\end{gathered}
$$

A primeira linha da equação descreve os aspectos hidrodinâmicos do moonpool em função do movimento relativo. A segunda linha descreve a interação do movimento de água interna ao moonpool e o movimento do FPSO.

A influência da forma do moonpool também foi estudada por Day A.H. (1990) onde se verificou dois resultados para minimizar a amplitude de água interna do moonpool: A redução das oscilações da água interna ao moonpool por meio do aumento de amortecimento e o movimento do período de ressonância do movimento vertical da água interna pra regiões de frequências fora da predominância de existência de ondas.

Foram propostos três tipos de alteração da geometria para serem estudados:

1. Introdução de uma placa fina a uma altura $h$ em relação à quilha

2. Introdução de uma expansão diâmetro do moonpool a uma altura h de sua abertura inferior

3. Introdução na abertura inferior do moonpool de uma restrição com espessura h

Day, A. H. (1990) mediu a eficiência dos dispositivos através do parâmetro PRWN shift (Peak Response Wave Number Shift), que mostra o quanto o período natural do moonpool se deslocou em relação ao caso sem nenhum apêndice. 


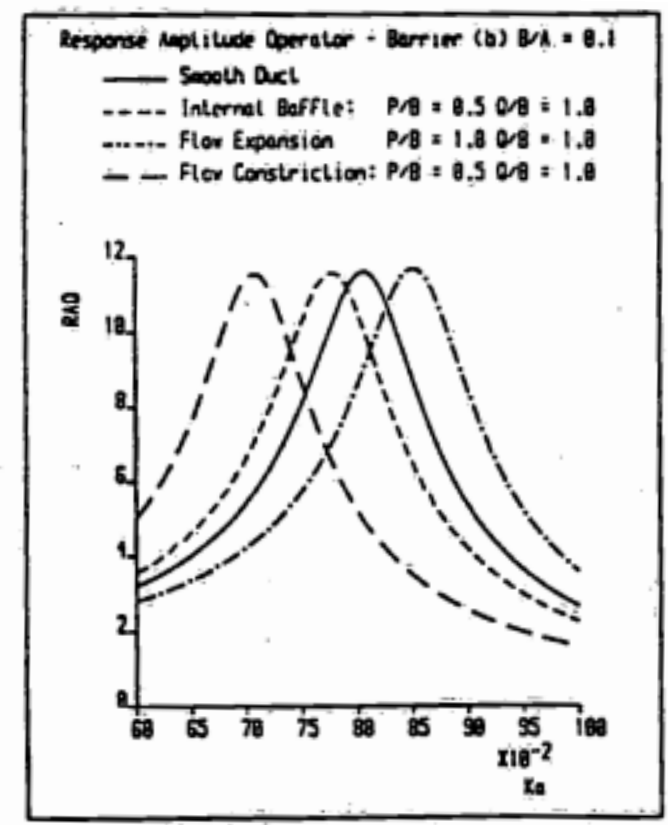

Figura 2-3 Comparação período natural do moonpool

FONTE: Day, A.H (1987). An Integrated approach to the design of moonpools for subsea operations

A análise do moonpool com placa mostra que o aumento da distância até a quilha provoca uma ligeira queda de sua eficiência, reduzindo o movimento do período natural do moonpool. Já a redução do diâmetro interno da placa acarreta um acréscimo significativo de eficiência, obtendo-se um aumento do período natural.

A expansão do diâmetro em sua abertura inferior mostra que o aumento de $h$ (altura da expansão) acarreta na redução do período do moonpool. O aumento do diâmetro da expansão produz o mesmo efeito, isto é, tem como consequência uma redução linear do período natural do moonpool.

O uso de uma restrição com espessura demonstra que o aumento de h (altura da restrição) acarreta o crescimento de sua eficiência, aumentando significativamente o movimento do período natural do moonpool (Matsuura, M. et al (1995)). A redução do diâmetro interno da restrição apresenta o mesmo comportamento, só que linear, mas sendo muito significativo.

Também seguindo a linha parametrização da plataforma com moonpool, Matsuura, 1995 apresenta o estudo de um casco monocoluna com o objetivo de 
melhorar os parâmetros geométricos, todavia. Dentre os dispositivos adotados, ele também estuda o moonpool como um sistema de geração de amortecimento.

Um moonpool central para funcionar como gerador de amortecimento para o movimento de heave, moonpools externos para geração de amortecimento para o movimento de pitch.

Para o moonpool central, ele estuda a utilização de uma restrição com duto. Matsuura conclui que quanto menor for o diâmetro interno desta restrição, maior será o amortecimento em heave para uma região mais abrangente de frequência de ondas.

Com a análise dos moonpools laterais, Matsuura obtém uma formulação para o período natural de oscilação vertical da água interna ao tanque com restrições com comprimento da saia (a mesma apresentada por Tasaka et al 1965) dada por:

$$
\begin{gathered}
T_{\zeta}=2 \pi \sqrt{\frac{h_{o}}{g}} \\
h_{o}=\int_{0}^{L} \frac{A_{m}}{A_{L}} d l
\end{gathered}
$$

Apesar de o objeto de estudo ser uma monocoluna, a relação entre as dimensões da restrição e o período de ressonância do moonpool pode ser observada na plataforma proposta.

Posteriormente, Fung (1996) desenvolveu seus experimentos sugerindo dois métodos para reduzir os movimentos da água interna do moonpool: instalação de dispositivos para aumento do amortecimento; configuração apropriada destes dispositivos para remover o período natural da água interna ao moonpool fora da região de alta energia de ondas.

Fung realizou uma série de testes de oscilação forçada da água interna a um moonpool circular com paredes lisas, e com uma placa fina de furo central presa em sua parede. Três condições de ensaio foram realizadas: moonpool sem restrições; moonpool com placa presa na metade do calado; moonpool com placa presa à altura da quilha. Com os ensaios, foram obtidos os valores de massa adicional, 
coeficiente de amortecimento potencial e de amortecimento quadrático para uma grande faixa de frequências apenas ao período natural de oscilação. Os valores foram obtidos separadamente para diferentes períodos de movimento de água, ou seja, saída e entrada de água interna ao moonpool. Ao final de seus experimentos, Fung concluiu que:

- O moonpool com placa plana sempre apresenta períodos maiores

- O caso com placa plana na região da quilha é o que apresenta maior período natural;

- A placa plana apresenta maior formação de massa adicional tanto no movimento de entrada de água como no de saída de água em comparação ao moonpool sem restrições.

- O moonpool com placa apresenta maior amortecimento do que o moonpool liso.

- Durante o movimento de entrada de água ocorre a formação de turbilhões.

Posteriormente, Molin (2001) propôs um referencial teórico para derivar as frequências ressonantes para moonpools retangulares com paredes verticais. Seu trabalho foi baseado em algumas suposições simplificadoras: o suporte flutuante é imóvel, a profundidade da água é infinita, o comprimento e a largura do suporte são infinitos.

O domínio fluido é então decomposto em duas partes: o moonpool e um domínio fluido semi-infinito abaixo do nível da quilha. A teoria do potencial de fluxo linearizado é usada, o potencial de velocidade sendo escrito como uma expansão de autofunção no moonpool. A condição de correspondência com o domínio de fluido inferior é escrita como uma equação integral relacionando o potencial e sua derivada vertical. A teoria descrita é apresentada com maior rigor no anexo.

A seguir são apresentadas as equações do efeito de cancelamento vertical da coluna d'água interior ao moonpool (também conhecido como modo pistão) e de sloshing para um moonpool retangular e com paredes verticais: 
Hipóteses:

- Não há efeitos de superfície livre externa (comprimento e boca são infinitos)

- Profundidade infinita

- Teoria potencial linear

A velocidade potencial no domínio superior do moonpool é dada por:

$$
\Phi^{\sup }(x, y, z, t)=\varphi(x, y, z) \cos (\omega t+\theta)
$$

A expressão geral para a velocidade potencial dentro do moonpool:

$$
\varphi(x, y, z)=\sum_{n=0}^{N} \sum_{q=0}^{Q} \cos \lambda_{n} x \cos \mu_{q} y\left(A_{n q} \cosh v_{n q} z+B_{n q} \sinh v_{n q} z\right.
$$

Onde:

$$
\lambda_{n}=\frac{n \pi}{l}, \mu_{q}=\frac{q \pi}{b}, v_{n q}^{2}=\lambda_{n}^{2}+\mu_{q}^{2}
$$

Para $n=q=0$, as funções hiperbólicas são substituídas por:

$$
\varphi(x, y, z)=\sum_{n=0}^{N} \sum_{q=0}^{Q} \cos \lambda_{n} x \cos \mu_{q} y\left(A_{00}+B_{00} z / h\right.
$$

Condição de superfície livre:

$$
g \varphi_{z}-\omega^{2} \varphi=0
$$

Aplicando esta condição para o escoamento do domínio inferior: 


$$
\varphi(x, y, 0, t)=\frac{1}{2 \pi} \int_{0}^{l} d x^{\prime} \int_{0}^{b} d y^{\prime} \frac{\varphi_{z}\left(x^{\prime}, y^{\prime}, 0, t\right)}{\sqrt{(x-x)^{2}+\left(y-y^{\prime}\right)^{2}}}
$$

Aplicando o procedimento de Galerkin, obtêm-se aproximações para modo único:

Efeito Pistão:

$$
\omega_{o o}=\sqrt{\frac{g}{h+b f_{3}(b / l)}}
$$

Onde:

$$
f_{3}=\frac{1}{\pi}\left(\sinh ^{-1}\left(\frac{l}{b}\right)+\frac{l}{b} \sinh ^{-1}\left(\frac{b}{l}\right)\right)+\frac{1}{3}\left(\frac{b}{l}+\frac{l^{2}}{b^{2}}\right)-\frac{1}{3}\left(1+\frac{l^{2}}{b^{2}}\right) \sqrt{\frac{b^{2}}{l^{2}}+1}
$$

Modo de Sloshing Longitudinal

$$
\omega_{n o}^{2} \cong g \lambda_{n} \frac{1+J_{n 0} \tanh \lambda_{n} h}{J_{n 0}+\tanh \lambda_{n} h}
$$

Onde:

$$
J_{n 0}=\frac{2}{n \pi^{2} r}\left\{\int_{0}^{1} \frac{r^{2}}{u^{2} \sqrt{u^{2}+r^{2}}}\left[1+(u-1) \cos (n \pi u)-\frac{\sin (n \pi u)}{n \pi}\right] d u\right\}
$$

Equação de Dispersão:

$$
\omega_{n o} \cong g \lambda_{n} \operatorname{coth}\left[\lambda_{n} h+\beta_{n 0}\left(\lambda_{n} b\right)\right]
$$

Com

$$
J_{n 0}=\tanh \beta_{n 0}
$$

Desta forma, plataformas com moonpool são sujeitas a problemas de ressonância e é, portanto, desejável prever a suas frequências de ressonância ainda no estágio de projeto. Segundo Molin et al. (Molin, 2001; Molin et al., 2002), os modos naturais do moonpool consistem no efeito pistão resultante do movimento vertical da água aprisionada dentro do moonpool e dos modos de sloshing que são similares ao comportamento de um tanque. 
Moreu (2015) realizou um trabalho sobre o sistema risers em águas ultraprofundas brasileiras. Neste estudo, Moreu preocupou-se principalmente com a redução da fadiga em risers em catenária na chamada touchdown zone (TDZ). Propondo uma mudança da posição do banco de risers, localizados normalmente em um deck lateral, para a linha central da plataforma e a meia nau. Desta forma, o banco de risers encontra-se dentro de um moonpool o que reduz a fadiga causada pelos movimentos induzidos pela plataforma.

O caso estudado por Moreu consistia dos seguintes passos:

- Dimensionamento do FPSO e seleção da característica de carregamento

- Descrição do sistema de amarração e do sistema de risers e do cálculo da matriz de restauração do sistema

- Cálculo dos movimentos induzidos por ondas utilizando métodos de painéis de primeira ordem

- Seleção dos estados de mar considerados desfavoráveis "a priori" em relação à vida útil do sistema de risers (assumindo que a distribuição de tensões na TDZ está diretamente relacionada aos movimentos verticais dos risers nos pontos de conexão com a plataforma)

- Geração da série temporal dos movimentos verticais, horizontais e angulares dos pontos de conexão dos risers que são utilizados como condição de contorno em uma análise de método dos elementos finitos.

- Estimação da vida de fadiga analisando os resultados de saída do método de elementos finitos no domínio do tempo considerando a hipótese que o processo de tensões é uma banda estreita e gaussiana

Desta forma, almejando estudar principalmente os danos causados por fadiga induzida por ondas (especialmente na TDZ), movimentos dos pontos de conexão da bancada de risers e as diferenças consequentes da mudança da banca de risers da lateral da plataforma para o eixo central, Moreu optou por uma análise de movimentos do corpo flutuante desacoplado, considerando apenas o carregamento induzido por ondas.

Além disso, em águas ultra profundas, a TDZ tem a sua extensão por várias centenas de metros de tubulações, pois a unidade é sujeita ao vento, corrente e forças de deriva, causando assim uma mudança constante da sua posição e 
distribuindo os danos por fadiga de forma que a SCR pode ser uma solução possível mesmo em FPSO's em condições adversas.

Por fim, apesar da ênfase da análise nos danos de fadiga causados pela indução movimentos na bancada de riser pela estrutura flutuante, Moreu concluiu que existe uma redução dos danos de fadiga significativa ao mover a bancada de risers para o eixo da plataforma.

Assim, um investimento inicial maior em uma unidade flutuante inovadora pode ser positivo para redução de gastos com manutenção do sistema submarino ao longo da vida útil do sistema. Além disso, as altas produções por poços encontrados nos campos do pré-sal brasileiro permitem também um incremento da produção com o mesmo número de risers, o que requer uma maior capacidade produtiva da planta. Em outras palavras, significa que seria possível obter economias de escala aumentando a capacidade da planta de processo da plataforma e as dimensões do navio.

Oliveira e Vilamea (2015) realizaram um trabalho sobre uma forma das plataformas FPSO operarem com risers SCR em água ultra profundas. Como mencionado anteriormente, os SCR's economizam custos em sistemas submarinos, mas aumentam os custos da plataforma flutuante. Em geral, para águas profundas e ultraprofundas, os custos com sistemas submarinos são maiores que os da UEP (unidade estacionária de produção) convencional, portanto, o investimento na unidade flutuante pode ser positivo para economia no sistema submarino.

Esta solução é o chamado conceito ULFPSO que foi projetado para ter um moonpool de grande porte, sendo longo o suficiente para conectar os SCR's pelo lado interno da plataforma além de permitir uma grande área para a planta de processo colocada em um deck contínuo acima do convés do navio. A geometria do casco é mostrada na Figura 2-4. 


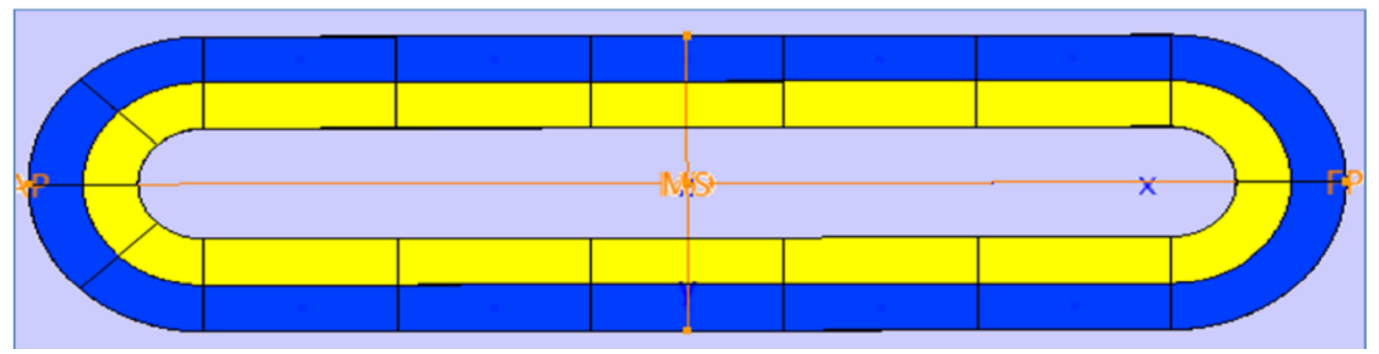

Figura 2-4 Vista superior da divisão de tanques internos do ULFPSO. Legenda: amarelo - óleo; azul lastro

Fonte: Oliveira, A.C. \& Vilameá, Eduardo. (2015)

Em relação ao comportamento hidrodinâmico, este conceito tem como grande diferencial os movimentos verticais reduzidos e as baixas acelerações verticais no interior do moonpool. Portanto, sugere-se instalar as conexões de risers rígidos nesta região para redução do movimento no topo equipamento. Uma questão importante a ser considerada é o comportamento da superfície livre nesta região e o estabelecimento de critérios de avaliação que serão apresentados neste trabalho.

O método numérico utilizado para avaliar o comportamento em ondas e da superfície livre do moonpool é feito por meio do software WAMIT (WAMIT User Manual, 2016) embasado na Teoria Linear Potencial de Ondas (NEWMAN,1977) para avaliar a pressão hidrodinâmica, cargas e movimentos do corpo, bem como a pressão e velocidade no domínio do fluido. Presume-se que o escoamento seja potencial e as condições de superfície livre e de contorno do corpo são linearizadas.

Considerações dos movimentos da coluna d'água interior ao moonpool foram representadas através do amortecimento de superfícies externas ao corpo equivalente ao FPSO. As superfícies amortecidas de fluidos devem ser definidas por painéis, além daquelas necessárias para definir a superfície do corpo em adição à matriz amortecimento externo como descrito em WAMIT User Manual, 2016. Por fim, o método avalia a solução completa correspondente ao corpo (plataforma FPSO) e a superfície amortecida (coluna d'água interna) resolvendo o problema de radiação e difração de ondas incidentes e são encontradas frequências ressonantes que maximizam a elevação da superfície livre.

Desta maneira, neste trabalho procura-se utilizar do conceito ULFPSO, no entanto com geometrias mais simplificadas, semelhantes aos modelos "caixa". A ideia é determinar uma metodologia para se avaliar a influência de outros apêndices 
hidrodinâmicos conhecidos pela indústria atribuindo parâmetros para as dimensões de cada componente da plataforma FPSO. 


\section{DESENVOLVIMENTO DA PLATAFORMA}

O dimensionamento da plataforma flutuante será feito em função das características de produção das Bacias do Pré-sal brasileiro, onde as plantas de processos devem ser projetadas para a remoção de elevados níveis de contaminantes e um futuro tratamento ou exportação de gás, o que demanda equipamentos maiores e mais pesados que permitam este tratamento adicional. Por consequência, o casco da plataforma FPSO necessita ser maior do que o de um VLCC (Very Large Crude Carriers) padrão para atender a maior demanda da planta de processo. Desta forma, devem-se estipular alguns requisitos para o desenvolvimento do modelo paramétrico. Considerando o objetivo de viabilizar a utilização de SCR's em FPSO's, propõem-se os seguintes requisitos de projeto:

- Capacidade de armazenamento mínima para uma planta de 300.000 barris de produção diária; com capacidade de operação de 6 dias

- Margens do offloading (quantidade mínima de óleo nos tanques);

- Dimensões, dados de massa e inércias da planta de processo;

- Limite de movimentos do SCR, quantidade de risers, propriedades dos risers; restrições de movimento vertical, angulares etc.

- Limites operacionais da planta;

- Dimensões balcão de risers e eventuais limites de carga/estruturais com relação a impacto d'água;

- Limites internos do moonpool

- Requisitos posição das acomodações

- Limites construtivos dos estaleiros considerados;

- Metocean atualizado do local de instalação;

- Critério de avaria e compartimentagem

- Problemas de instalação e operação 
Para cumprir estes requisitos, é apresentada a seguir uma metodologia para parametrização do comprimento total $L$ e largura (boca) $B$ da plataforma, do comprimento da proa/popa I e da largura $b$ dos pontoons que compõem o corpo paralelo do FPSO e definem as dimensões das paredes do moonpool. Foram definidos parâmetros $\alpha$ e $\beta$ para as dimensões das restrições na entrada do moonpool e para as dimensões do recesso na altura da linha d'água.

Desta forma, partindo de uma premissa de projeto definida, foi avaliado o arranjo geral de cada geometria, critérios estruturais e de estabilidade de acordo com as normas das sociedades classificadoras. Por fim, é feita uma avaliação do comportamento em ondas da plataforma como apresentado no fluxograma a seguir:

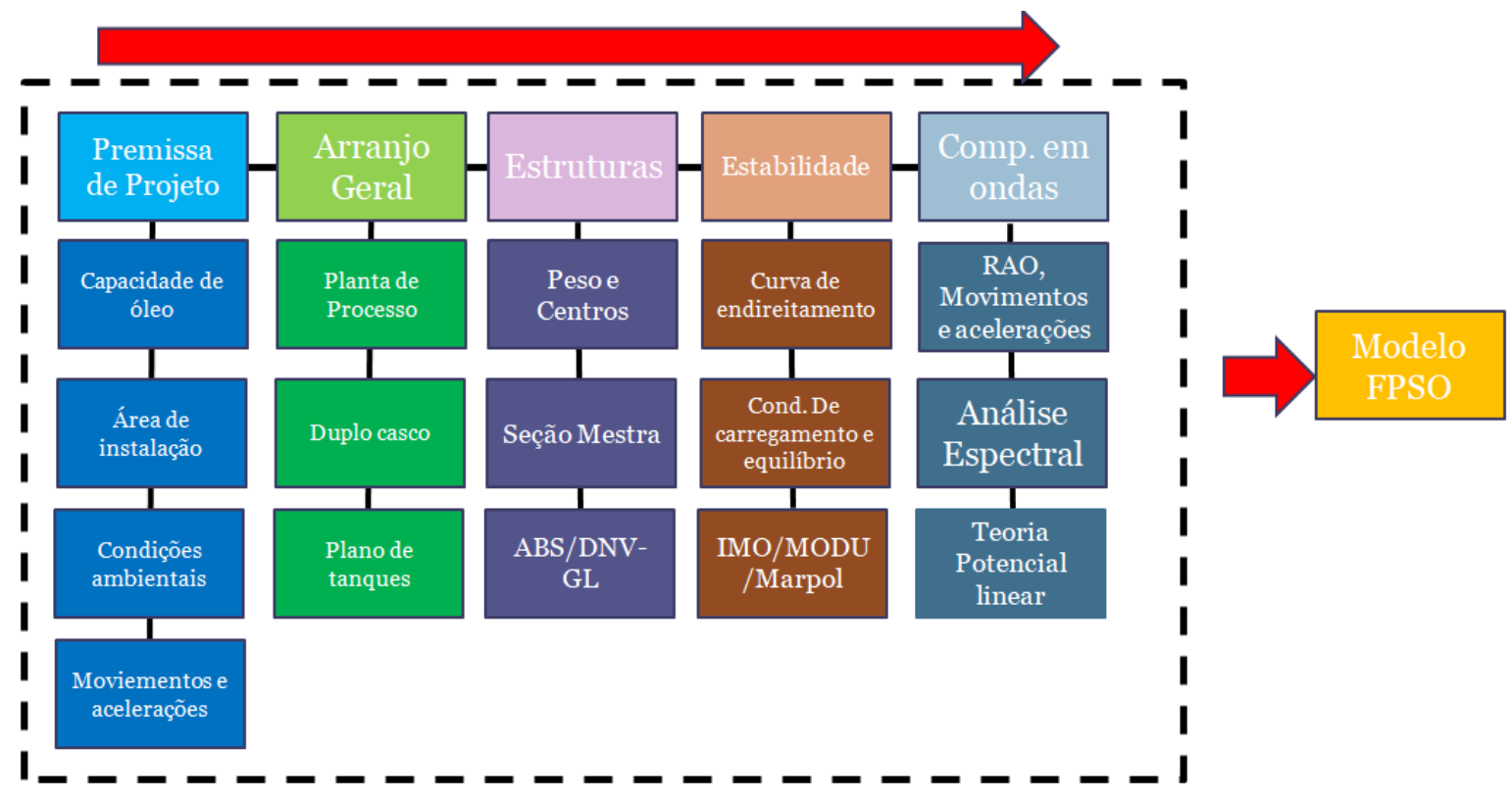

Figura 3-1 Fluxograma de Desenvolvimento do FPSO proposto

FONTE: Elaborada pelo autor

A premissa de projeto é definida a partir dos requisitos propostos pelo armador, e assim será definida a partir de formulações matemáticas a capacidade de volume dos tanques de carga, a área necessária para instalação de equipamentos, a faixa de períodos e altura significativa de ondas esperadas no ambiente de instalação e os carregamentos e acelerações da plataforma. Os requisitos a serem atendidos na premissa de projeto são apresentados a seguir: 


\begin{tabular}{|c|c|c|}
\hline Processo & Premissas & Valor \\
\hline Dimensões Principais & $\begin{array}{l}\text { Restrição das dimensões } \\
\text { principais em diques de } \\
\text { construção }\end{array}$ & $\begin{array}{c}\text { LOA<340m } \\
B<110 m \\
D<40 m\end{array}$ \\
\hline $\begin{array}{c}\text { Arranjo Geral e } \\
\text { compartimentagem }\end{array}$ & $\begin{array}{c}\text { Atender às normas de } \\
\text { segurança da tripulação } \\
\text { Atender a manutenção do } \\
\text { calado operacional } \\
\text { Garantir volume óleo } \\
\text { mínimo }\end{array}$ & $\begin{array}{c}V_{\text {ballast }}>250.000 \text { ton } \\
V_{\text {oil }}>1.800 .000 \mathrm{bbl}\end{array}$ \\
\hline Estabilidade & $\begin{array}{c}\text { Atender os requisitos } \\
\text { estatuários }\end{array}$ & -- \\
\hline Estruturas & $\begin{array}{c}\text { Atender os requisitos } \\
\text { estatuários }\end{array}$ & -- \\
\hline Comportamento em ondas & $\begin{array}{l}\text { Aceleração Máxima no } \\
\text { ponto de conexão dos } \\
\text { SCR's }\end{array}$ & $\begin{array}{c}T_{\text {heave }}>20 \mathrm{~s} \\
a_{z}<0.8 \mathrm{~m} / \mathrm{s}^{2}\end{array}$ \\
\hline
\end{tabular}

Tabela 3-1 Requistos de Projeto

FONTE: Elaborada pelo autor

Em seguida serão definidas as características de três sistemas: Planta de processo, balcão de risers e o arranjo de tanques. Todos os cálculos devem considerar o posicionamento dos diversos módulos que estão à cima do deck assim como definir o seu centro de gravidade e área de operação.

A região do balcão de risers deve ser posicionada de modo a reduzir as acelerações nos pontos de conexão levando-se em conta as dimensões do moonpool. Usualmente posicionado na lateral de FPSO's convencionais, o balcão de riser foi posicionado interior ao moonpool, ao centro da plataforma, com o objetivo de reduzir as acelerações verticais nos riser principalmente ocasionadas pelos movimentos de roll.

Os principais requisitos de normas DNV-GL (Det Norske Veritas. 2011) são calculados inicialmente, independentemente da inércia fornecida pela adição da estrutura do tanque. Assim, usando tanto as principais dimensões L, B e D como parâmetros da geometria do casco são determinadas a seção estrutural da meia nau 
e os elementos estruturais do casco. Por fim, será feita uma análise de esforços da plataforma completamente carregada incluindo a estrutura dos tanques.

Para o novo casco parametrizado, um modelo de estabilidade é calculado para avaliar as suas características particulares. Da mesma forma que os navios de aço e FPSO convencionais, o foco principal do projeto do casco é a superfície molhada e os efeitos da superfície livre dos tanques (FSE). Com a definição das principais dimensões, configuração do navio e carregamento de carga como parâmetros de entrada; o modelo de estabilidade avalia a curva do braço de endireitamento (GZ) do casco parametrizado, conforme os efeitos da superfície livre dos tanques de lastro e carga e outras propriedades hidrostáticas do FLNG são calculados de acordo com os critérios da IMO (Organização Marítima Internacional).

Um modelo numérico no domínio da frequência, realizado pelo software WAMIT para análise de ondas com base na teoria linear potencial (Newman, 1977), foi utilizado para o estudo do sistema oceânico. As principais propriedades avaliadas são forças de onda, coeficientes hidrodinâmicos (massa adicionada, potencial de amortecimento e restauração hidrostática), bem como o operador de amplitude de resposta (RAO).

Para avaliar as forças de primeira ordem, foi utilizado o método padrão de código, conforme apresentado em Newman \& Sclavounos (1988). Primeiro, a superfície molhada de cada navio foi projetada em um ambiente de rotina computacional que criou um arquivo de dados geométricos (GDF) para a condição de carregamento. Cada condição de carregamento foi modelada de usas maneiras: Primeiramente foi criado um arquivo GDF contendo apenas a plataforma e foram avaliados os seis graus de liberdade da plataforma. Após a avaliação do comportamento da plataforma, é incluída a influência da coluna d'água interna do moonpool. Por meio de um artifício numérico para solucionar o problema de difração e radiação do escoamento potencial, onde os modos do moonpool são considerados como modos generalizados adicionais, apresentado por Newman, J. N., (2004), o amortecimento da superfície livre da coluna d’água é incluído por meio de uma placa fina posicionado na superfície livre do moonpool (tampa ou lid). Desta forma, é avaliado um modelo com dois corpos e 12 graus de liberdade. Testes experimentais em escala reduzida são feitos para confrontar os resultados numéricos. 
Por fim, é feito um cruzamento espectral com o espectro de Jonswap para o cálculo e avaliação dos movimentos e acelerações da plataforma.

A Figura 3-2 seguir sintetiza o procedimento computacional feito neste trabalho

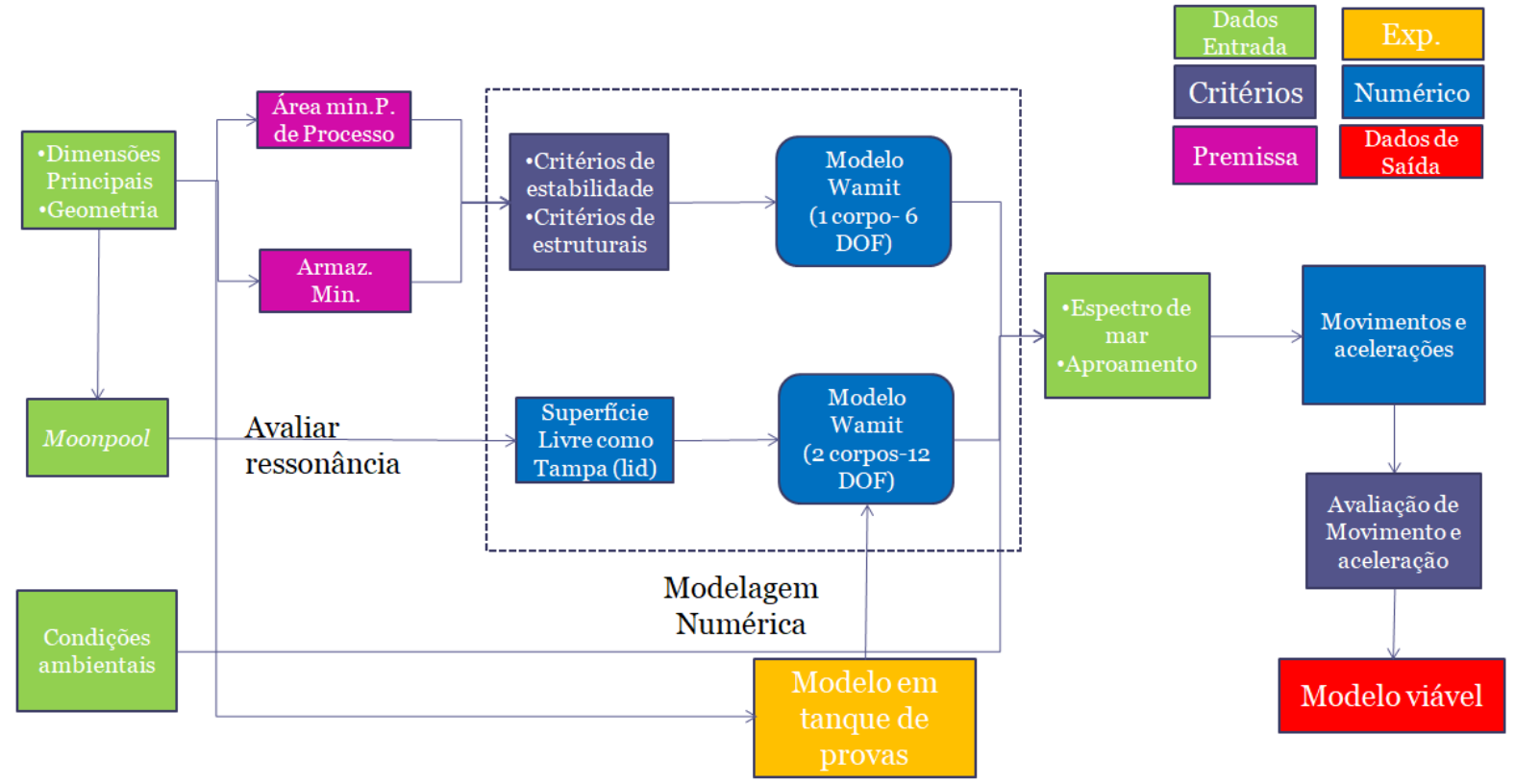

Figura 3-2 Procedimento numérico

FONTE: Elaborada pelo autor

A aplicação de dois métodos para avaliar o comportamento hidrodinâmico na modelagem numérica tem o propósito de tornar o processamento computacional mais rápido. O processamento computacional do modelo WAMIT com 1 corpo tem como objetivo o descarte de geometrias inadequadas. Assim, tempo de processamento é economizado para o método WAMIT com 2 corpos que demanda maior processamento computacional. Apenas a geometria ULFPSO e do moonpool com paredes lisas tiveram comparações com ensaios em tanque de provas com o objetivo de validação de resultados. 


\section{PARAMETRIZAÇÃO DA GEOMETRIA}

A geometria do casco foi dividida em três partes principais, como apresentado na Figura 4-1. A parte submersa rosa contém os tanques de carga e a maior parte do lastro, a região azul foi projetada com o propósito de reduzir a área de linha d'água e, portanto, reduzir a restauração hidrostática, a parte superior em verde providencia uma maior área de convés, permitindo a instalação de uma planta de produção maior do que a de FPSO's convencionais, convertidos de VLCC's por exemplo.

Foram considerados parâmetros principais de projeto o comprimento total LOA, o comprimento I da proa e popa, a boca B, a largura do pontoon b. No fundo do casco há uma placa de restrição do moonpool, definida como uma porcentagem a da área total da superfície de água interior ao moonpool de modo que um valor zero representa um moonpool aberto e um valor um representa um moonpool completamente coberto de acordo com a Figura 4-2.
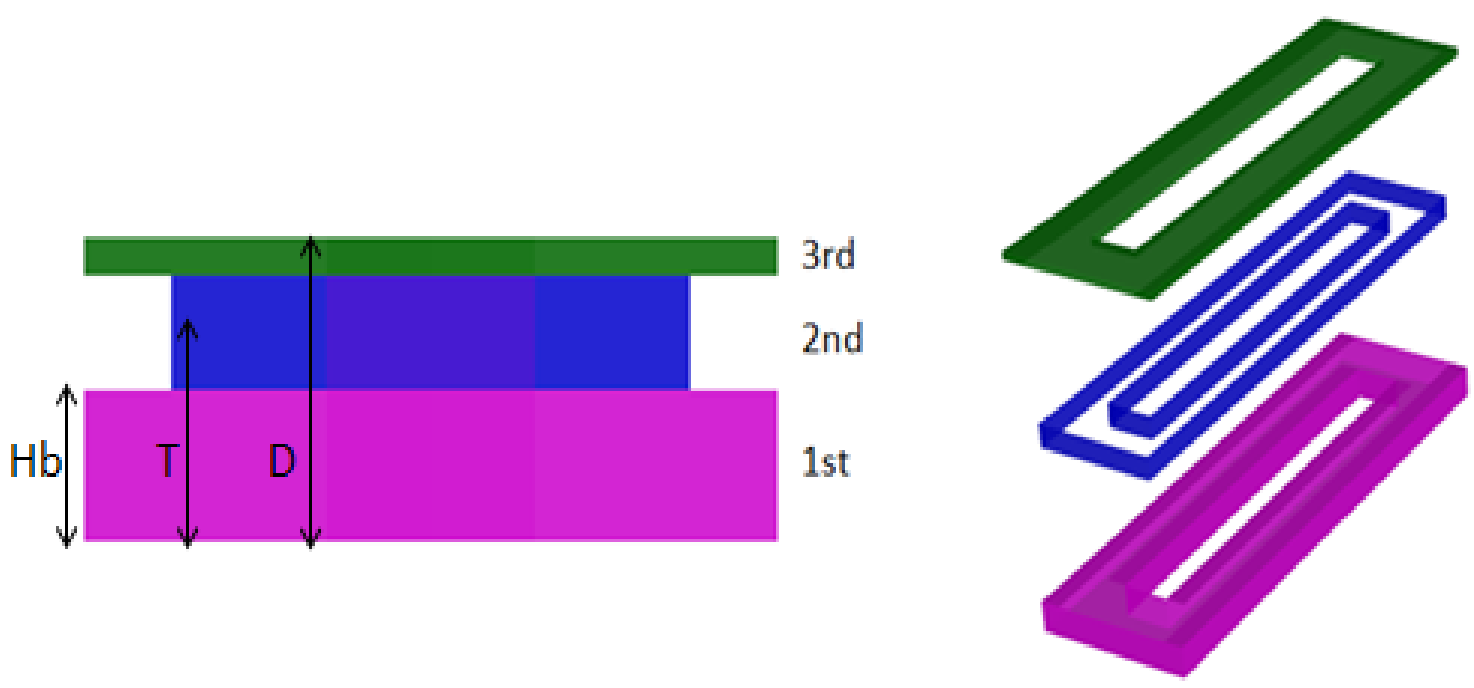

Figura 4-1 Geometria do Casco - Vista frontal e perspectiva

FONTE: Elaborada pelo autor 
LOA

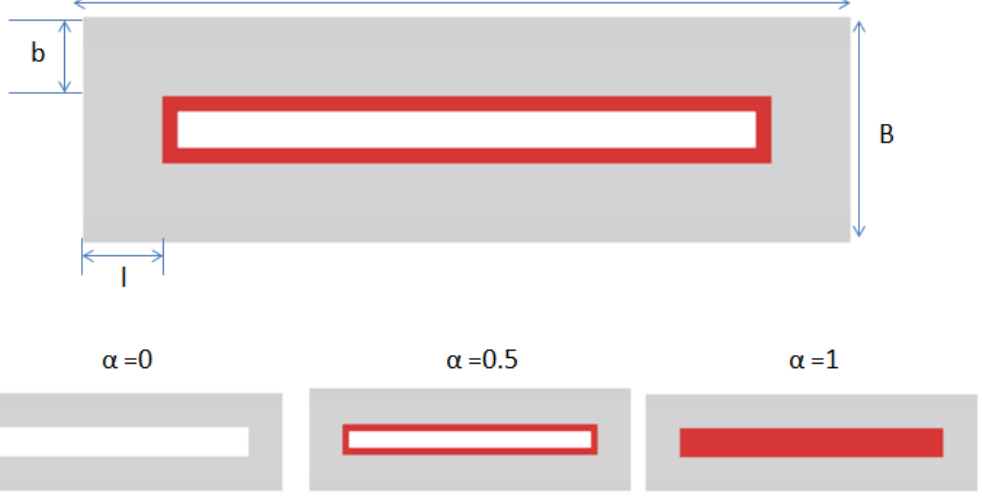

Figura 4-2 Geometria do Casco - Vista lateral

FONTE: Elaborada pelo autor

A seção transversal do casco, cuja geometria apresentada na Figura 4-3 é constante ao longo de toda sua extensão. As variáveis de projeto são a altura do pontoon $\mathrm{Hb}$, o calado $\mathrm{T}$ e o fator de redução da boca na linha d'água $\beta$, que multiplica a largura do pontoon para definir a boca na região de linha d’água.

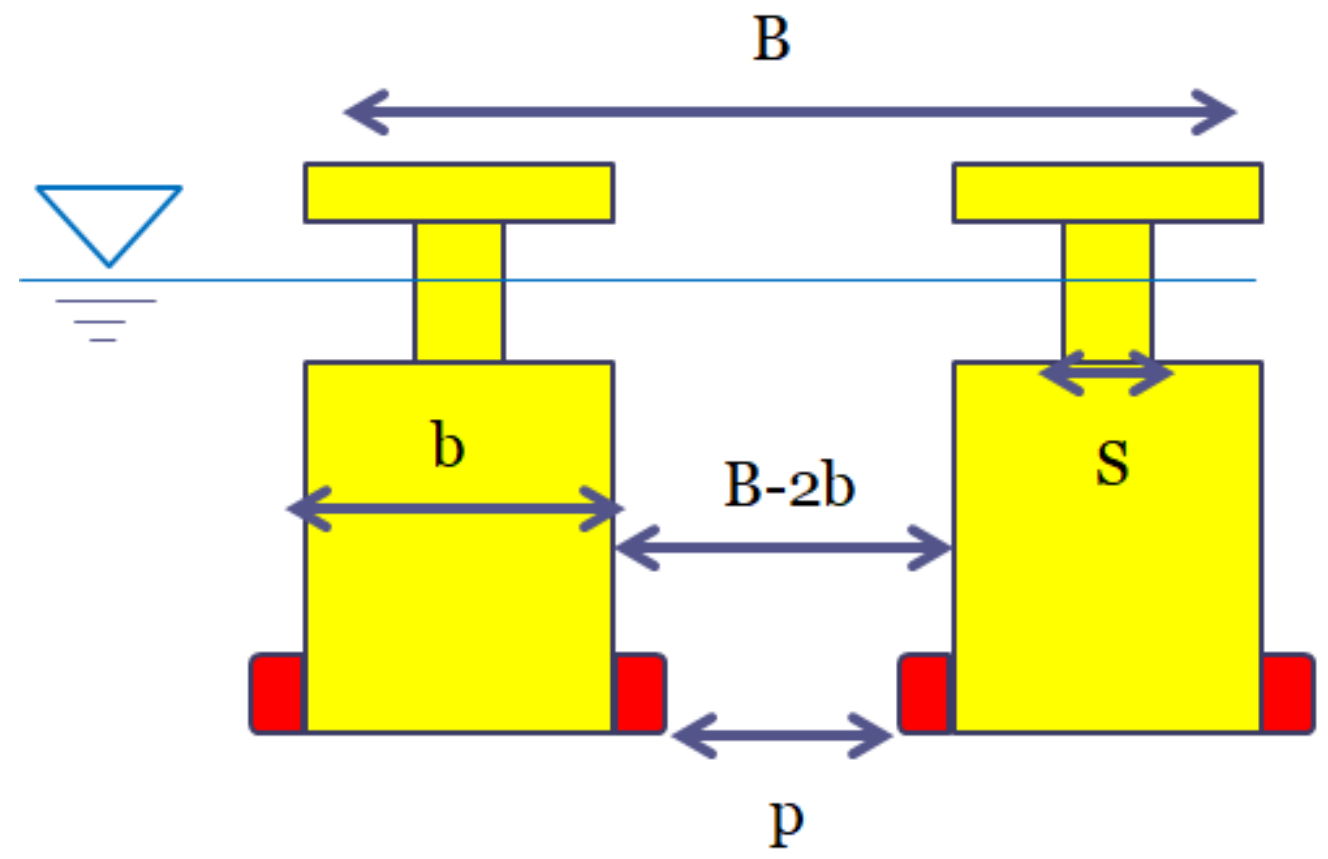

Figura 4-3 Parametrização do FPSO

FONTE: Elaborada pelo autor 
A Tabela 4-1 mostra os limites adotados para o desenvolvimento do projeto de acordo com as restrições descritas anteriormente. Foram considerados os seguintes critérios para a definição destes limites:

- Limites construtivos de estaleiros no Brasil

- Capacidade de armazenamento para uma planta de 300.000 barris de produção diária

- Margens do offloading (quantidade mínima de óleo nos tanques)

- Dimensões, dados de massa e inércias da planta de processo

- Limites internos de moonpool

- Requisitos posição das acomodações

- Aspectos de segurança e posicionamento de módulos;

\begin{tabular}{|c|c|c|c|}
\hline Variável & Descrição & Limite Inferior & Limite Superior \\
\hline $\operatorname{LOA}(\mathrm{m})$ & Comprimento total & 300 & 340 \\
\hline $\mathrm{B}(\mathrm{m})$ & Boca total & 90 & 110 \\
\hline $\mathrm{Hb}(\mathrm{m})$ & $\begin{array}{c}\text { Altura do casco até } \\
\text { o início da praia }\end{array}$ & 20 & 30 \\
\hline $\mathrm{I}(\mathrm{m})$ & $\begin{array}{c}\text { Comprimento da } \\
\text { unidade, descontado } \\
\text { o moonpool }\end{array}$ & 35 & 45 \\
\hline$b(m)$ & $\begin{array}{c}\text { Meia boca da } \\
\text { unidade, descontado } \\
\text { o moonpool }\end{array}$ & 30 & 40 \\
\hline$\beta=S / b$ & $\begin{array}{c}\text { Relação de } \\
\text { estreitamento do } \\
\text { casco na altura da } \\
\text { linha d'água }\end{array}$ & 0.3 & 1.0 \\
\hline$\alpha=p /(B-2 b)$ & $\begin{array}{c}\text { Relação de área da } \\
\text { saia hidrodinâmica } \\
\text { (saia hidrodinâmica) } \\
\text { pela área do } \\
\text { moonpool }\end{array}$ & 0 & 1 \\
\hline
\end{tabular}

Tabela 4-1 Limites de construção da plataforma

FONTE: Elaborada pelo autor 
Utilizando o programa de CAD Rhinoceros, foram desenvolvidos modelos numéricos variando-se cada parâmetro dentro dos limites estabelecidos e aplicando os requisitos de projeto descritos na tabela Tabela 3-1. A Figura 4-4 mostra um gráfico com todos os casos avaliados em relação a sua capacidade de armazenamento e o deslocamento da plataforma.

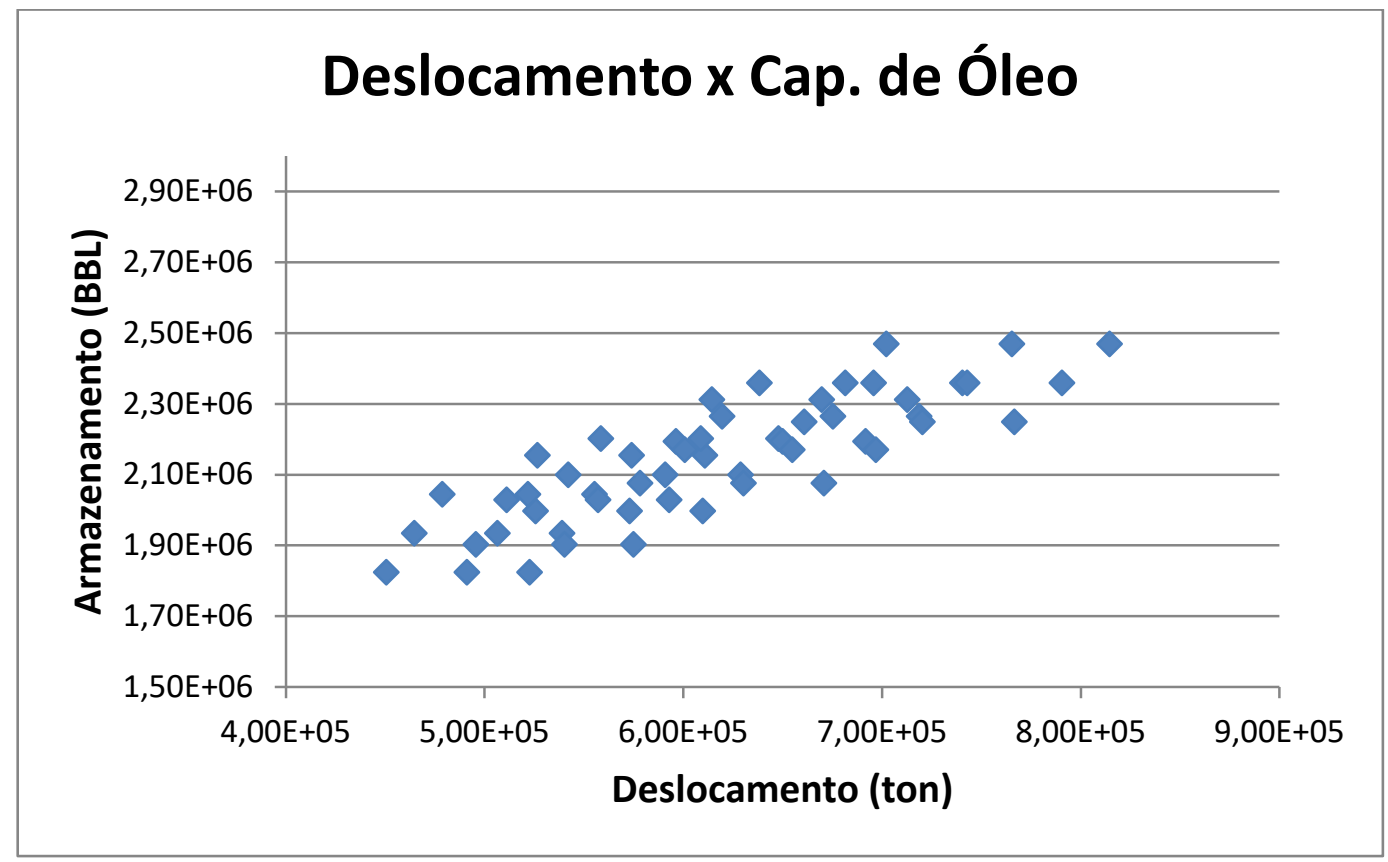

Figura 4-4 Deslocamento em massa pela capacidade de armazenamento de óleo para os modelos numéricos gerados

FONTE: Elaborada pelo autor

O modelo apresentado neste trabalho foi selecionado priorizando o desempenho hidrodinâmico enquanto atendendo os critérios estabelecidos de armazenamento mínimo e normas de construção. Em um estudo de otimização de parâmetros como apresentado em Vilamea, E. M. (2017), possivelmente outro modelo seria selecionado. A Tabela 4-2 a seguir mostra os parâmetros da geometria escolhida para este trabalho. As geometrias dos demais modelos gerados são apresentadas no Anexo D. 


\begin{tabular}{|c|c|c|}
\hline Dimensão & valor & unid \\
\hline $\mathrm{L}$ & 340 & $\mathrm{~m}$ \\
\hline $\mathrm{B}$ & 100 & $\mathrm{~m}$ \\
\hline $\mathrm{D}$ & 40 & $\mathrm{~m}$ \\
\hline Imoonpool & 270 & $\mathrm{~m}$ \\
\hline bmoonpool & 30 & $\mathrm{~m}$ \\
\hline deslocamento & 586000 & ton \\
\hline
\end{tabular}

Tabela 4-2 Parâmetros do FPSO

FONTE: Elaborada pelo autor

O modelo paramétrico apresentado será então estudado em termos do arranjo geral, estrutura, estabilidade e comportamento em ondas.

\subsection{Projeto do moonpool}

O emprego do moonpool tem como objetivo alterar o comportamento da plataforma de forma que as acelerações obtidas permitam o uso de risers rígidos além de permitir a passagem deste equipamento pela região central da plataforma. Como explicado anteriormente, o projetista deve dimensionar o moonpool de modo que a oscilação da coluna d'água aprisionada ao sistema não danifique os equipamentos de operação da plataforma. Portanto, a frequência de oscilação da plataforma e da coluna d'água interior ao moonpool devem ser distantes das frequências predominantes das ondas no local de instalação da unidade.

Em termos de analogia com um oscilador mecânico "massa-molaamortecedor", deseja-se que o amortecimento do sistema seja aumentado, enquanto a massa adicionada imposta pela coluna d'água ao sistema seja considerada. Para finalidades práticas de projeto, uma alteração na geometria da moonpool irá provocar uma alteração na massa adicionada e também afetará o amortecimento do sistema.

A utilização de restrições no moonpool (saia hidrodinâmicas) foi adotada na meia altura do pontoon $\mathrm{Hb} / 2$. Estas variáveis iniciais são adotadas no modelo 
paramétrico em conjunto às considerações sobre o arranjo geral e adequação as recomendações e regras de sociedades classificadoras.

\section{ARRANJO GERAL}

O posicionamento e o arranjo geral dos módulos em uma planta de processos de uma plataforma dependem do objetivo e da função que a plataforma a ser projetada desempenhará. Assim, optou-se por desenvolver um arranjo geral prezando a segurança da operação uma vez que este trabalho aborda uma geometria inovadora.

Os tanques de carga e lastro são alocados abaixo do convés exposto, separados por uma simples antepara longitudinal. O óleo é alocado nos tanques da região interna, isto é, nos tanques entre a antepara e o moonpool, enquanto o lastro é alocado nos tanques da região externa, isto é, nos tanques entre a antepara e o costado, como mostra a Figura 5-1.

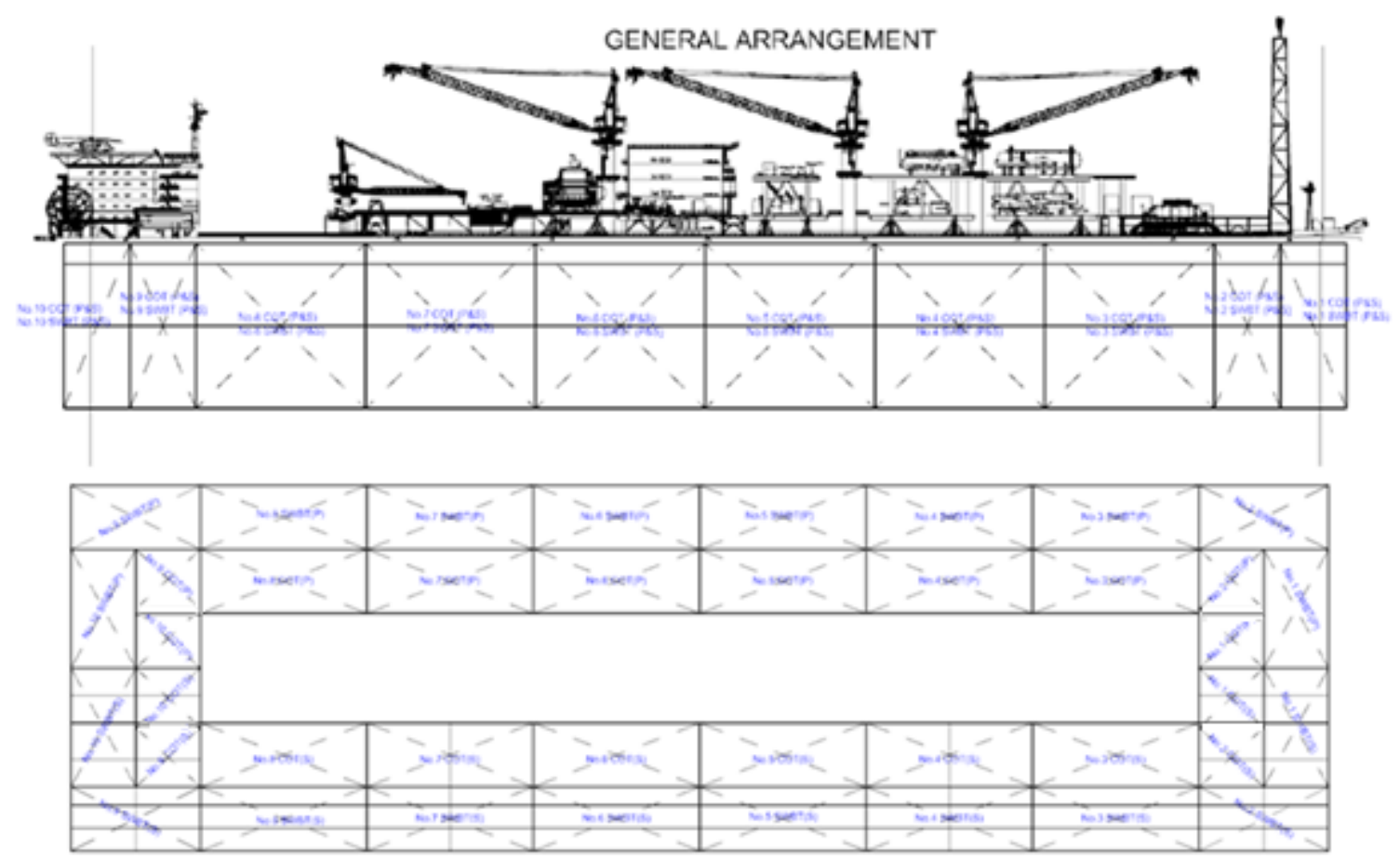

Figura 5-1 Arranjo Geral

FONTE: Elaborada pelo autor 
Calcula-se o volume disponível abaixo do convés exposto, para armazenamento de óleo e água de lastro, a partir da integral considerando as regiões do corpo paralelo médio, proa e popa. O volume disponível no corpo paralelo médio é dado pela equação (5-1), enquanto o das regiões de proa e popa é definido com base na equação (5-2), de modo que o volume total é dado pela equação (5-3).

$$
\begin{gathered}
V_{c p}=2(L O A-2 l) \cdot\left(H_{b} b+3 h \beta b\right) \\
V_{\text {proa } / \text { popa }}=2\left(H_{b} B l+3 h(B-b(1-\beta)\right. \\
V_{\text {total }}=V_{c p}+V_{\text {proa } / \text { popa }}
\end{gathered}
$$

\subsection{Planta de processo}

A planta de processo de uma plataforma FPSO tem como função a separação do óleo, da água e do gás natural provindos dos poços submersos. Desta forma, ela deve reunir todo o aparato necessário para a execução da operação como, módulos, tubulações, bombas, válvulas, separadores e turbinas. Utilizou-se como primeira referência a regressão de peso de topsides para novos FPSO's (DRL Engineering Capabilities Offshore), apresentado na Figura 5-2 para estimar o peso da planta de produção assumindo uma produção diária superior a 300,000 BOE.

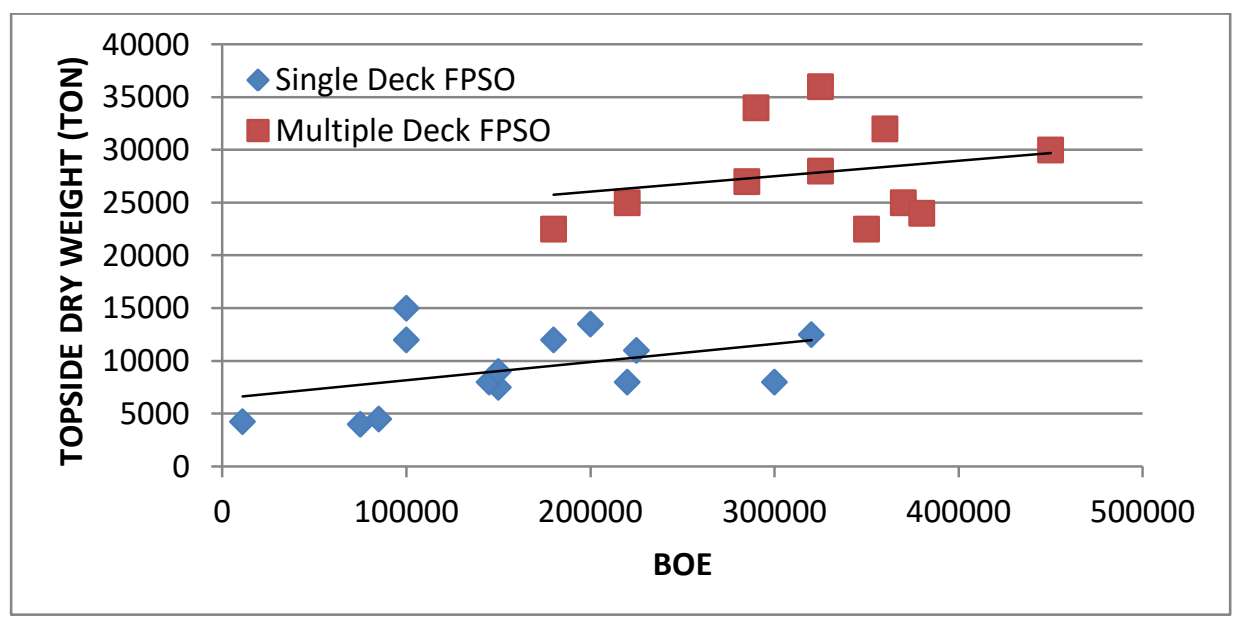

Figura 5-2 Regressão- Peso do topside x BOE

FONTE: DRL Capabilities Offshore Rev N6 Feb 2017 (alterada pelo autor) 
Uma segunda referência para a estimativa do peso do topside é o estudo apresentado em Vilamea, E. M.(2017) para o ULFPSO. No trabalho referido, o peso do topside foi estimado como equivalente a 60.000 toneladas.

A planta de processos foi considerada como uma estrutura integrada dos módulos requeridos para o processamento de óleo e gás. Em geral, os módulos do sistema dedicados para o processo são parte do topside da plataforma acima do deck. Dentre os principais sistemas incluem-se:

- Sistema de gás combustível

- Sistema de aquecimento

- Sistema de resfriamento

- Sistema de turbinas a gás

- Sistema de injeção e tratamento de água do mar

- Sistema de flare (queima de gases)

A primeira avaliação a ser feita no dimensionamento da planta de processos é o posicionamento de cada módulo e equipamento. É imediato notar que, com a mudança do balcão de riser para o centro da plataforma, módulos que tradicionalmente são posicionados no centro da plataforma devem ser reavaliados em questão de segurança. Desta forma, optou-se por posicionar cada módulo pelo risco de perigo de operação com o objetivo de orientar a especificação de equipamentos elétricos e evitar as fontes de ignição em áreas com probabilidade de ocorrência de mistura inflamável ou explosiva, classificando estas áreas em zonas como descrito a seguir: 


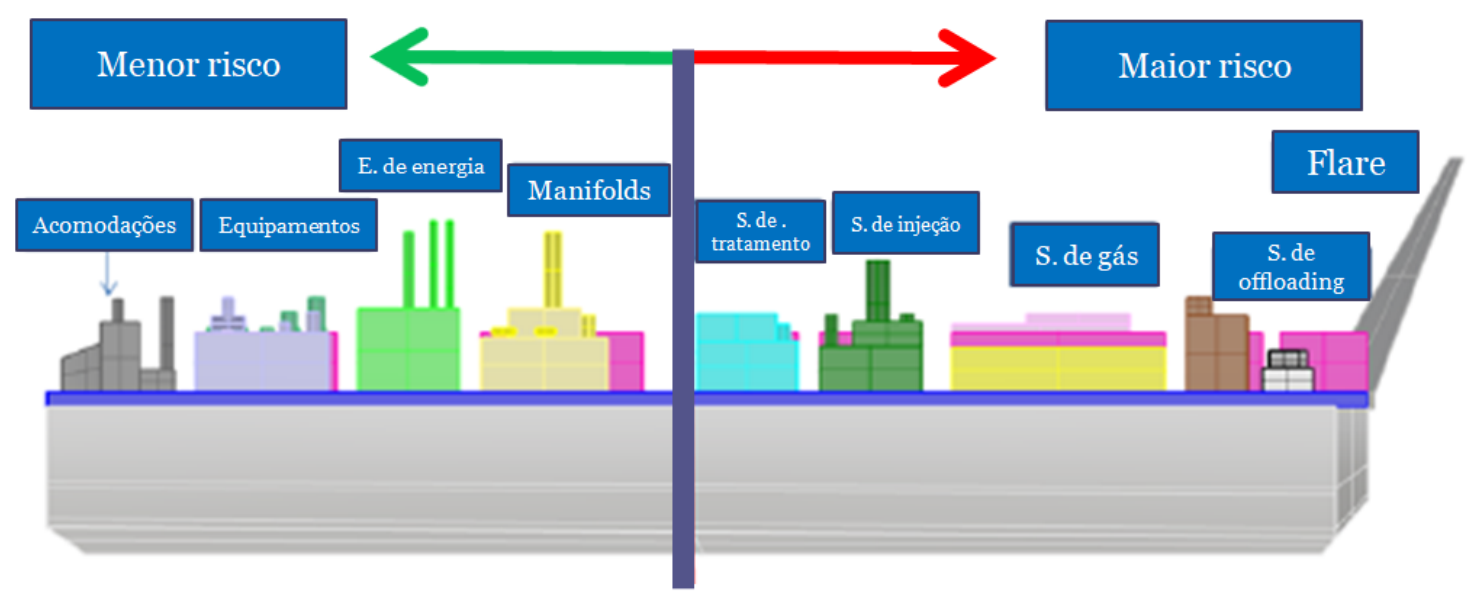

Figura 5-3 Posicionamento dos módulos de produção

FONTE: Elaborada pelo autor

Foi adotada a divisão da área da tripulação e equipamentos do restante da planta de processo, começando 50 metros a partir da popa até a proa, como dado pela equação.

$$
A_{p p}=(L O A-50) B
$$

O arranjo do convés é mostrado na Figura 5-4, na qual a área vermelha representa a área disponível para a planta de produção a cima do deck.

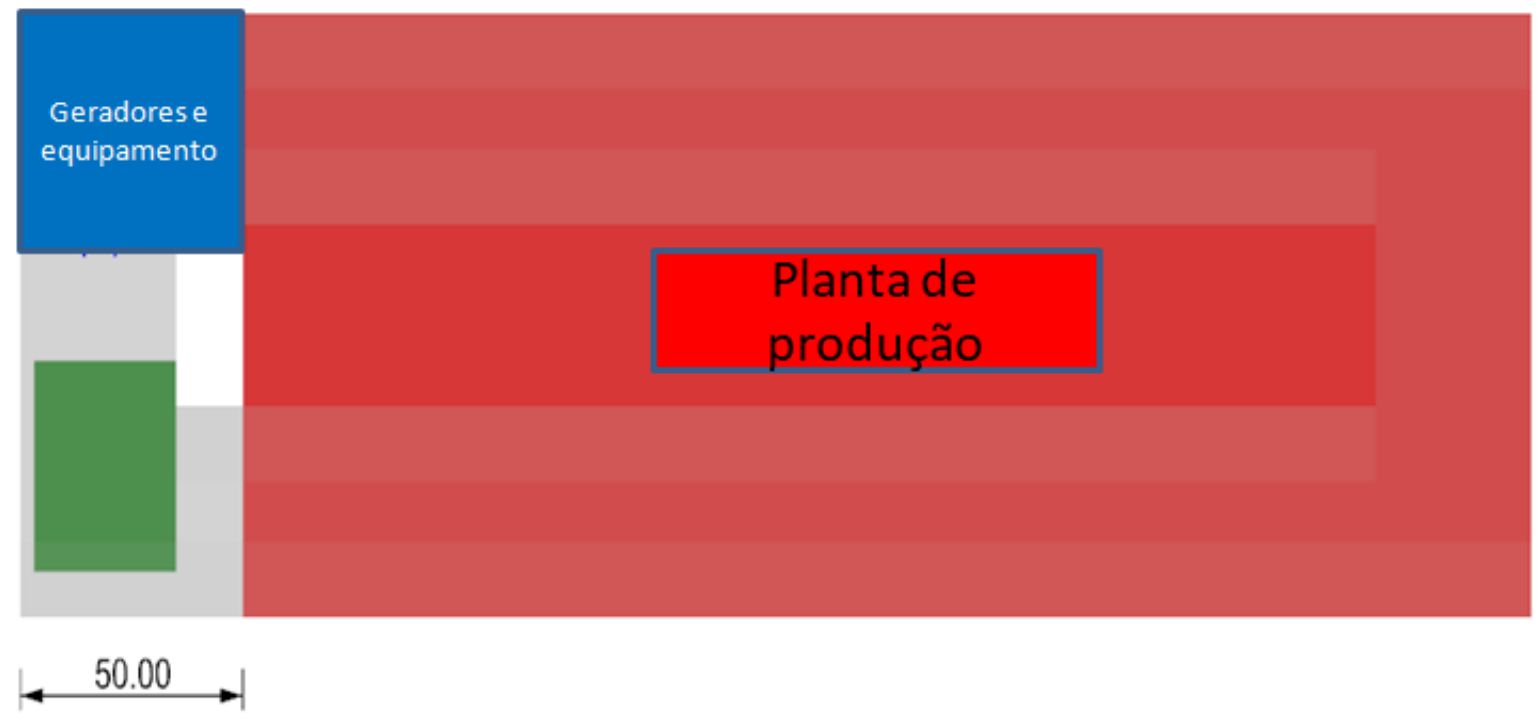

Figura 5-4 Disposição da planta de produção

FONTE: Elaborada pelo autor

Neste conceito de planta de processos, foi proposto um piso acima do deck ao longo de toda a área de topsides, inclusive na região do moonpool. Os módulos e equipamentos são instalados sobre esse piso neste caso. 


\subsection{1. Área Velica}

A área velica é importante para avaliar efeitos da resistência ao ar e ao vento enquanto as plataformas estão em operação no mar. A resistência do vento é proporcional à velocidade relativa do vento ao quadrado, à direção do vento e à área projetada do navio.

A área velica lateral será definida como a área da planta de produção (App) combinada com o valor de borda livre conforme a equação:

$$
A=A_{\text {pp }, \text { lateral }}+3 h L O A
$$

A altura do centro de área velica requerida pela DNV-GL (2011) é dada pela equação:

$$
l_{w}=2.5 h+0.5 h_{p p}+\frac{H_{b}+1.5 h}{2}
$$

A figura a seguir representa a aproximação proposta:

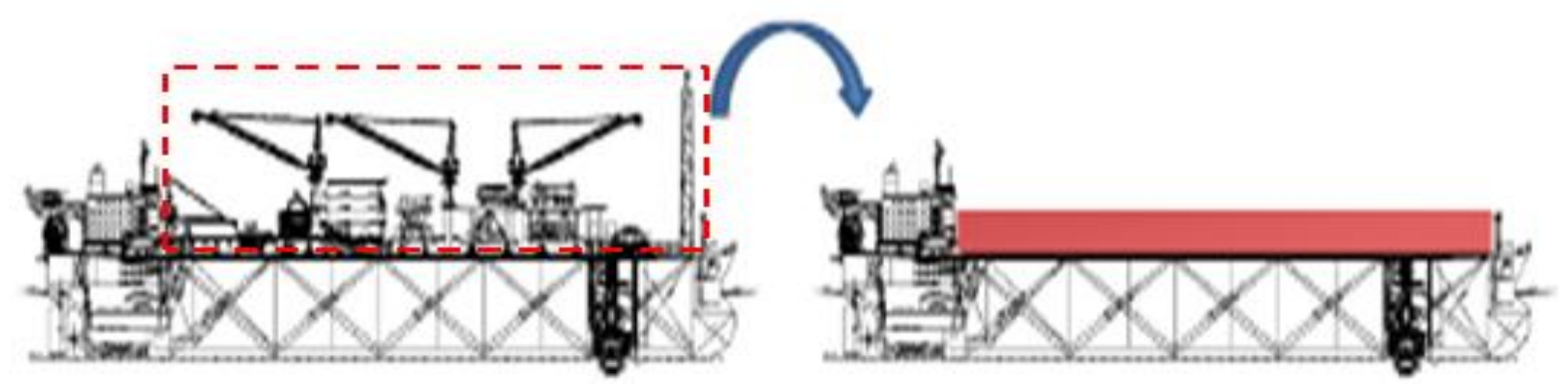

Figura 5-5 Área vélica lateral

FONTE: Elaborada pelo autor

O momento de emborcamento devido ao vento é então calculado pela equação onde $\theta$ é o ângulo de emborcamento:

$$
M_{w}(\theta)=F_{w} l_{w} \cos ^{2}(\theta)
$$


A influência da força do vento será considerada para o cálculo da estabilidade inicial apresentado no Capítulo 7.

\subsection{Balcão de risers}

Usualmente, o balcão de risers é posicionado na lateral da plataforma FPSO convencional. Nesta configuração, o balcão de risers apresenta grandes movimentos verticais devido aos movimentos de roll da plataforma, o que inviabiliza o uso de risers rígidos em catenária no caso do FPSO convencional.

Ao posicionar o balcão de risers próximo das paredes internas do moonpool, ou seja, mais próximo ao centro de rotação da plataforma, obtêm-se movimentos verticais reduzidos nos pontos de conexão de risers. Entretanto, esta alteração requer uma redistribuição de todo o arranjo da plataforma devido à inclusão do moonpool para a passagem da tubulação.

Foi decidido para uma estimativa inicial que o moonpool da plataforma seja no mínimo 50\% maior do que a estrutura de risers. Desta forma, a relação das dimensões do balcão de risers e os parâmetros da plataforma são dados por:

$$
\begin{aligned}
& L_{\text {riser,max }}<\left(\frac{L O A-2 l}{2}\right) \\
& B_{\text {riser,max }}<\left(\frac{B-2 b}{2}\right)
\end{aligned}
$$

Estas dimensões foram utilizadas para definir os pontos de medição da elevação da coluna d'água no ensaio experimental.

\subsection{Dimensionamento dos tanques}

Primeiramente é necessário estabelecer limites para a quantidade e as dimensões dos tanques para o modelo. Utilizando como padrão as normas vigentes da MARPOL 73/78 (Anexo 1 Regras para prevenção da poluição por óleo) para tanques de um VLCC de dimensões semelhantes, a quantidade máxima de tanques permitida é definida pela seguinte fórmula: 


$$
N_{\text {tanks }}=\left[\frac{2(B+(L O A-B))}{50}\right]
$$

Analogamente, o comprimento máximo de cada tanque é dado pela seguinte formulação:

$$
L_{\text {tanks }}=\left[\frac{2(B+(L O A-l))}{N_{\text {tanks }}}\right]
$$

A geometria dos tanques de carga e lastro do corpo paralelo é parametrizada em função das características principais do casco descritas na Tabela 4-1 e em função da antepara longitudinal $l_{\text {long }}$ que separa a compartimentagem destinada ao lastramento da compartimentagem destinada à armazenagem de óleo como mostra Figura 5-6. A distância entre esta antepara e o moonpool foi definida no modelo paramétrico como meio pontoon para garantir que a plataforma seja capaz de armazenar a quantidade adequada de lastro para assegurar o calado de operação constante.

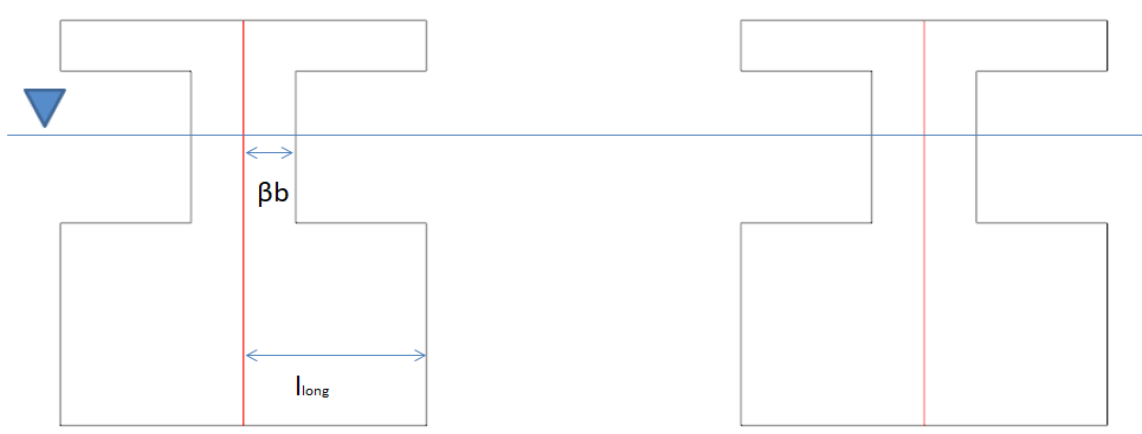

Figura 5-6 Posição da antepara longitudinal em relação ao centro do pontoon

FONTE: Elaborada pelo autor

\subsubsection{Preenchimento dos tanques}

O dimensionamento inicial dos tanques de carga e lastro considerou que o líquido esteja homogeneamente distribuído nos tanques. O calado de operação deve ser constante, independente da condição de carregamento descrita na equação 5-12:

$$
\Delta_{\text {des }}=W_{l s}+\rho_{w} V_{\text {Ballast }}+\rho_{\text {oil }} V_{\text {oil }}
$$


O volume do lastro e do óleo $\mathrm{V}$ nos respectivos tanques é calculado usando uma integração numérica dependendo do nível de enchimento $z$, dada pela equação 5-13:

$$
V(x)=\int_{0}^{x}\left(2(L O A-l) \frac{b}{2} H_{b}+\beta b\left(h(z)-H_{b}\right)+\frac{\left(B-\frac{b}{2}\right)}{2} h(z)\right) d x
$$

Por fim, o modelo numérico é então gerado a partir da definição dos parâmetros descritos anteriormente. Os módulos da planta de produção são representados como blocos com dimensões equivalentes para simplificação conforme apresentado na Figura 5-7 e as principais características da planta de processos e dimensões dos tanques de lastro e tanques de óleo são apresentadas na tabela a seguir considerando a capacidade de estocagem mínima de 1.800.00 barris como requisito de projeto.

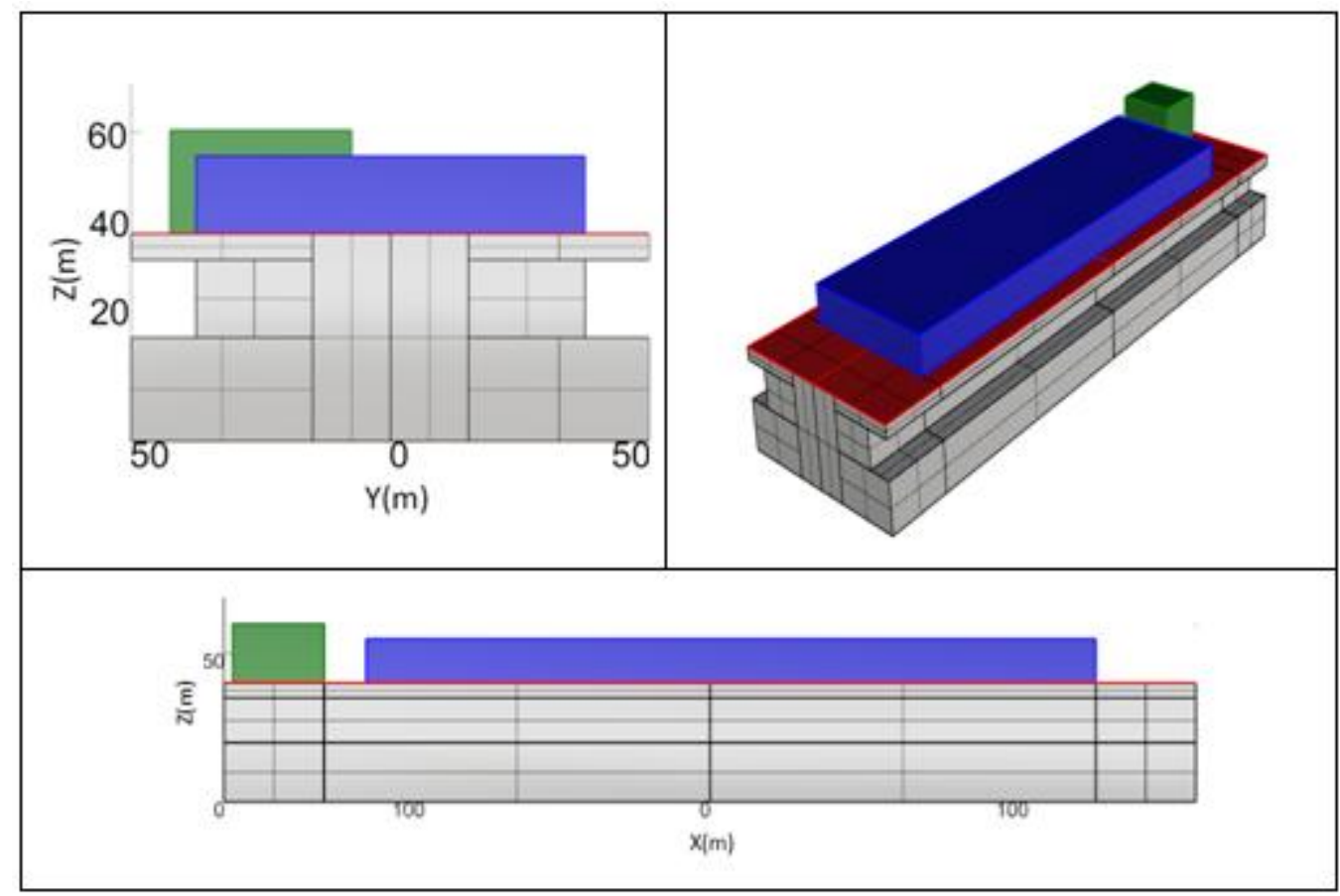

Figura 5-7 Vistas do modelo numérico FONTE: Elaborada pelo autor

A Tabela 5-1 descreve as características do modelo suposto utilizando a parametrização descrita neste capítulo. 


\begin{tabular}{|c|c|c|}
\hline \multicolumn{2}{|c|}{ Características da Planta de Processos } & Unidade \\
\hline Área velica lateral & 7839 & $\mathrm{~m}^{2}$ \\
\hline Área total do deck & 34.000 & $\mathrm{~m}^{2}$ \\
\hline $\begin{array}{c}\text { Área disponível da planta de } \\
\text { processos }\end{array}$ & 29.000 & $\mathrm{~m}^{2}$ \\
\hline $\begin{array}{c}\text { Peso da planta de processos } \\
\text { Peso leve }\end{array}$ & 60.000 & ton \\
\hline $\begin{array}{c}\text { Posição da antepara } \\
\text { longitudinal (em relação ao } \\
\text { centro do pontoon) }\end{array}$ & 90.000 & $\mathrm{~m}$ \\
\hline $\begin{array}{c}\text { Volume total dos tanques de } \\
\text { lastro }\end{array}$ & 17.5 & $\mathrm{~m}$ \\
\hline $\begin{array}{c}\text { Volume total dos tanques de } \\
\text { óleo }\end{array}$ & 340.672 & $\mathrm{bbl}$ \\
\hline Balcão de risers & $120 \times 8$ & $\mathrm{~m}$ \\
\hline
\end{tabular}

Tabela 5-1 Características do modelo solução

FONTE: Elaborada pelo autor

É importante ressaltar que o arranjo apresentado é uma solução baseada nas informações preliminares disponíveis, sendo assim outras soluções também são possíveis. Além disso, a disposição e dimensão dos módulos propostos podem ser alteradas em uma futura etapa de detalhamento das tubulações, módulos, tanques e apêndices hidrodinâmicos.

A restrição mais importante para esta parametrização foi o critério de armazenamento mínimo para reduzir o risco de parada de operação. Assim, adotaram-se a uma capacidade mínima de 1.800 .000 barris de óleo com um intervalo de carregamento dos tanques de sete dias no pico de produção de óleo.

Os demais parâmetros foram avaliados de forma a reduzir o peso em aço da plataforma, isto é, reduzir os custos de construção e gerar a planta de processos com a maior capacidade possível garantindo as restrições construtivas estabelecidas na Tabela 4-1.

Utilizando como referência a frota de FPSO's apresentado em MOREU (2015), a solução proposta apresenta dimensões e planta de processo superior às plataformas utilizadas atualmente. Conforme descrito em VILAMEA (2017), estas características são adequadas à produção no campo estudado, devido à remoção de elevados 
níveis de contaminante e posterior tratamento. Consequentemente, as plataformas projetadas para operação nesta região demandam cascos maiores do que um VLCC padrão ou uma redução da capacidade de operação. 


\section{ANÁLISE ESTRUTURAL}

Neste capítulo, serão avaliados os pesos e centros, os esforços cortantes e os momentos fletores do FPSO detalhado no capítulo anterior. Utilizou-se a hipótese de que a plataforma é projetada para permanecer o máximo de tempo possível em calado operacional e deslocamento constante e, portanto, não se espera uma alteração brusca no comportamento de esforços atuantes no casco. É importante notar que este estudo considerou o comportamento de uma unidade "box shaped" por motivos de simplificação do problema. Assim, em relação à suas dimensões principais, podem aparecer componentes de torção típicos de uma plataforma semissubmersível para uma menor relação L/B que deverá ser avaliada em uma etapa posterior de refinamento do projeto.

O modelo estrutural sugerido permite estimar para diferentes características dimensionais, geométricas e de capacidade da plataforma:

1. A espessura mínima requerida para cada elemento solicitado pela norma;

2. A espessura mínima requerida para as chapas e o módulo mínimo requerido por cada um dos reforçadores leves e pesados das anteparas.

3. Cálculo de pesos e centros

4. O módulo de seção mínimo requerido por cada um dos reforçadores longitudinais;

5. O módulo de seção mínimo requerido para a seção mestra como um todo;

O centro de gravidade, as características de massa e de inércia da plataforma foram avaliadas considerando as dimensões principais do FPSO e do moonpool propostos.

\subsection{Modelo estrutural}

Como explicado anteriormente, este trabalho tem como objetivo propor o uso viável de SCR's em um FPSO do ponto de vista do comportamento hidrodinâmico. Desta forma, a maior preocupação do modelo estrutural inicial é que a plataforma proposta atenda de maneira satisfatória as normas classificadoras. 
Um arranjo típico da estrutura do casco é avaliado sem considerar as anteparas longitudinais que serão fornecidas pelo tanque. Assim, um arranjo típico da estrutura do casco é compor por elementos básicos:

- Costado;

- Duplo costado;

- Elementos secundários:

- Reforçadores pesados;

- Reforçadores leves

De modo semelhante ao projeto ULFPSO, a plataforma proposta possui um calado elevado e, portanto, não é esperado acidentes no chapeamento do fundo, de modo que o duplo fundo não é necessário e por isso não será considerado, evitando assim diversas complicações do ponto de vista operacional, em termos de inspeção e ventilação.

Para gerar o modelo de seção mestra, deve-se definir a distância entre os reforçadores longitudinais e transversais, depois os elementos estruturais são dimensionados de acordo com os requisitos locais da norma e, por fim, é calculada a área, o módulo e a inércia da seção projetada a fim de assegurar que o modelo atenda aos critérios mínimos globais de viga navio. Com isso, define-se o arranjo da seção mestra do corpo paralelo médio.

O fluxograma de rotina é apresentado na Figura 6-1 consiste basicamente em avaliar o arranjo de seção central, o arranjo de estrutura transversal, o peso em aço do casco e centro de gravidade.

\section{ENTRADA}

•Dimensões

Principais

-Geometria do

casco

- Características

do convés
Saída

•Cálculo dos

elementos

estruturais

•Pesose

Centros

-Inércias

Figura 6-1 Fluxograma da avaliação de estruturas

FONTE: Elaborada pelo autor 


\subsection{Duplo casco}

Segundo Terpstra, T. (2001), os FPSO's novos são fornecidos com um único fundo se não forem autopropelidos. O duplo costado é normalmente ajustado para fornecer proteção contra colisão.

Utilizando como referência a norma da DNV-GL (2011) item D102, define-se a equação para o cálculo do duplo casco, que não deve ser inferior a $760 \mathrm{~mm}$ e tampouco precisa ser superior a 2000 mm, sendo B é a boca da embarcação.

Também é recomendado o atendimento da convenção da MARPOL 73/78 (Anexo 1 Regras para prevenção da poluição por óleo) que também exige valores acima de $2000 \mathrm{~mm}$. Os critérios da MARPOL também estabelece que tanques de carga em contato com água devem ter um casco duplo (fundo/costado) para prevenir o derramamento de óleo em caso de acidentes.

É importante ressaltar que o duplo costado é adotado apenas na região entre a antepara longitudinal e o costado externo, dado que a probabilidade de ocorrer uma colisão da região do moonpool é bastante remota. Além disso, qualquer vazamento nesta região ficaria confinado à própria região do moonpool, uma vez que a densidade do óleo é inferior à da água.

O duplo costado terá uma largura consideravelmente superior à requerida pela DNV-GL (2011), pois a plataforma necessita uma quantidade bastante elevada de lastro para ser capaz de manter o calado de operação sempre fixo.

O caso crítico de colisão seria a seção reduzida, na linha d'água. No entanto, espera-se um duplo costado de pelo menos $5 \mathrm{~m}$ nesta região, de modo que nenhum vazamento é esperado no caso da colisão de embarcações pequenas. Na situação de colisão de um navio maior (e.g. Aliviador Suezmax), o navio colidiria na região da praia abaixo da linha d'água, de forma que o casco estaria tão vulnerável quanto uma FPSO convencional, ver o exemplo da Figura 6-2. 


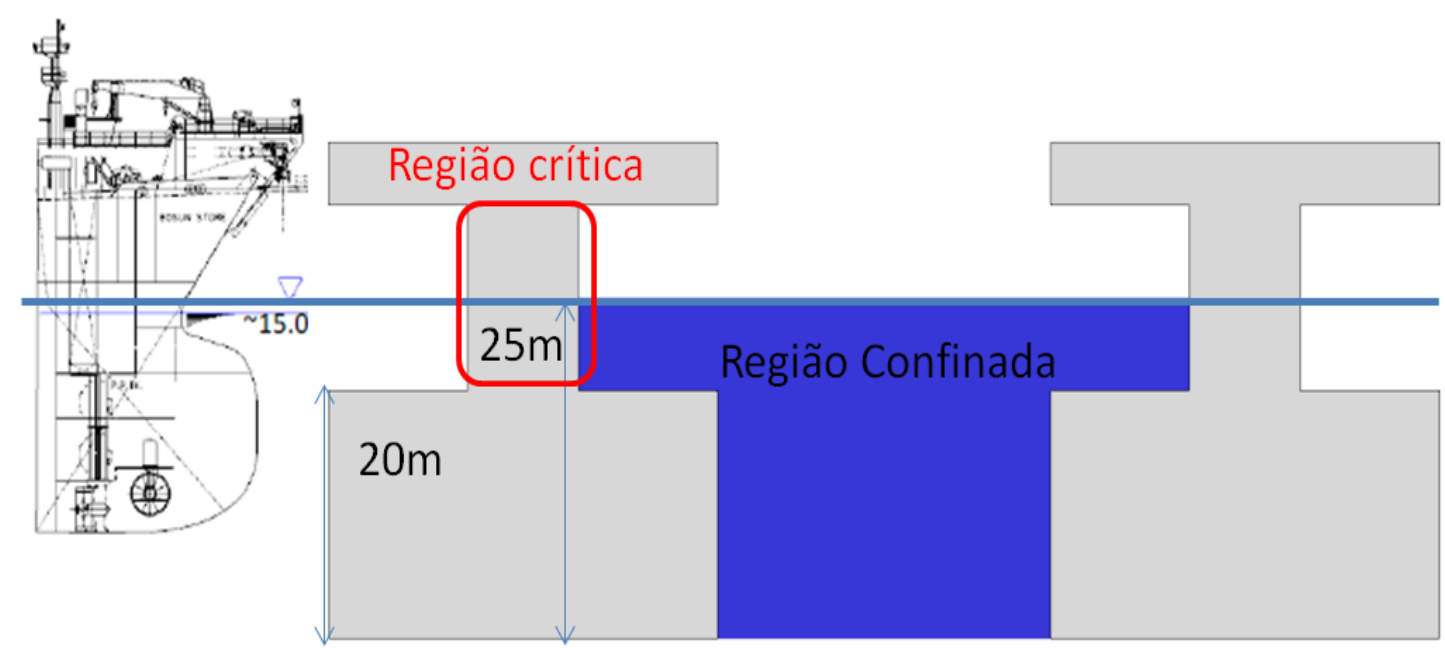

Figura 6-2 Região crítica para o duplo costado

FONTE: Elaborada pelo autor

Segundo as normas da ABS (American Bureau Shipping), 2012 - Parte 3 seção 2 - regra 3.13 para embarcações de aço com comprimento entre perpendiculares superior a 305 metros, a espessura mínima das chapas do fundo, do costado e do convés são calculadas segundo as equações a seguir: Os resultados dos demais casos são apresentados no Anexo D.

$$
\begin{gathered}
t_{\text {fundo }}=\left(\frac{s}{671}\right) \sqrt{L-105\left(\frac{d}{D s}\right)}+2.5[\mathrm{~mm}] \\
t_{\text {costado }}=\left(\frac{s}{671}\right) \sqrt{L-175\left(\frac{d}{D s}\right)}+2.5[\mathrm{~mm}] \\
t_{\text {convés }}=\frac{24.38 \mathrm{~s}}{1615.4-1.1 \mathrm{~L}}[\mathrm{~mm}]
\end{gathered}
$$

Onde d é calado, Ds é o pontal e s é o espaçamento entre longitudinais. A Tabela 6-1 a seguir apresenta os resultados obtidos: 


\begin{tabular}{|c|c|c|}
\hline Característica & Valor & Unidade \\
\hline $\begin{array}{c}\text { Espaçamento entre } \\
\text { reforçadores (S) }\end{array}$ & 6000 & $\mathrm{~mm}$ \\
\hline $\begin{array}{c}\text { Espaçamento entre } \\
\text { longitudinais (s) }\end{array}$ & 800 & $\mathrm{~mm}$ \\
\hline $\begin{array}{c}\text { Espaçamento entre } \\
\text { cavernas (I) }\end{array}$ & 2000 & $\mathrm{~mm}$ \\
\hline$t_{\text {fundo }}$ & 22.7 & $\mathrm{~mm}$ \\
\hline$t_{\text {costado }}$ & 19.8 & $\mathrm{~mm}$ \\
\hline$t_{\text {convés }}$ & 15.7 & $\mathrm{~m}$ \\
\hline
\end{tabular}

Tabela 6-1 Características do chapeamento

FONTE: Elaborada pelo autor

\subsection{Pesos e Centros}

O modelo de pesos e centros calcula a posição do centro de gravidade e os momentos de inércia para três condições de carregamento, que são necessários no modelo de comportamento em ondas para obtenção dos operadores de amplitude de resposta (RAO). A posição do centro de gravidade é também necessária para a análise de estabilidade. $O$ modelo de pesos e centros recebe 0 arranjo geral, a geometria do casco, tanques e dados da planta de produção como entrada, e fornece a distribuição dos pesos e as inércias como saídas.

Devido à simetria transversal e longitudinal do modelo, a estimativa do centro de gravidade foi calculada apenas na posição vertical. O VCG da plataforma (KG) foi calculado a partir da média ponderada pelos pesos dos respectivos VCGs do casco nu e dos tanques de lastros e de combustível como descrito na equação:

$$
C G_{i}=\frac{m_{l w} V C G_{l w}+\sum_{i=1}^{20} m_{B_{i}} V C G_{B_{i}}+\sum_{j=1}^{20} m_{F_{i}} V C G_{F_{i}}}{\Delta_{\text {total }}}
$$




\subsubsection{Cálculo do Momento de Inércia de Massa do Casco Leve}

A primeira definição que tem que estar clara para a estimativa dos momentos de inércias do casco é o método de abordagem dos elementos estruturais calculados no modelo. Nesta seção, os elementos foram separados em elementos da seção mestra, cavernas e anteparas transversais.

Em relação aos elementos da seção mestra, foi considerado o arranjo da seção com uma espessura de $0.1 \mathrm{~m}$, tornando-a uma fatia com seção transversal igual ao seu arranjo. Depois, a seção foi dividida em elementos retangulares para facilitar o cálculo dos momentos de inércia de massa desta fatia.

O passo seguinte foi calcular os momentos de inércias próprios de cada elemento de acordo com as equações

$$
\begin{aligned}
& \operatorname{Ixx}_{\text {próprio }}(i)=\iiint\left(y^{2}+z^{2}\right) r_{a \zeta ̧ o} d v(i) \\
& I y y_{\text {próprio }}(i)=\iiint\left(x^{2}+z^{2}\right) r_{a \zeta ̧ o} d v(i) \\
& \operatorname{Izz}_{\text {próprio }}(i)=\iiint\left(x^{2}+y^{2}\right) r_{a \varrho ̧ o} d v(i)
\end{aligned}
$$

Em que $i$ representa o elemento retangular analisado e $r_{a c ̧ o ~}$ é a densidade do aço. A seguir é apresentada a tabela das inércias iniciais de cada modelo para um calado de 25 metros:

Depois de calculada a inércia própria de cada elemento, foi utilizado o teorema dos eixos paralelos para determinar os momentos de inércias com 0 referencial no $\mathrm{CG}_{\text {casco }}$, de acordo com as equações 6-8, 6-9 e 6-10:

$$
I x x_{\text {seção }}=\sum_{i=1}^{n}\left(I x x_{\text {próprio }}(i)+m_{e q}(i)\left(d y^{2}+d z^{2}\right)\right)
$$




$$
\begin{aligned}
& I y y_{\text {seção }}=\sum_{i=1}^{n}\left(\operatorname{Iy} y_{\text {próprio }}(i)+m_{e q}(i)\left(d x^{2}+d z^{2}\right)\right) \\
& I z z_{\text {seção }}=\sum_{i=1}^{n}\left(\operatorname{Izz}_{\text {próprio }}(i)+m_{e q}(i)\left(d x^{2}+d y^{2}\right)\right)
\end{aligned}
$$

Em que $n$ é o número de elementos da seção mestra, $m_{e q}(i)$ a massa equivalente do elemento $i, d x=L C G_{\text {casco }}-x(i), d y=y(i)$ e $d z=V C G_{\text {casco }}-z(i)$.

Já para os elementos transversais, foram consideradas simplificações no arranjo do modelo da caverna e da antepara transversal para facilitar a metodologia de cálculo dos momentos de inércia. O modelo da caverna foi aproximado por um arranjo de chapas retangulares com espessura equivalente, mantendo o volume de material do arranjo projetado pelo modelo de síntese. Já a antepara foi aproximada por uma chapa retangular, sem reforçadores e, também, com uma espessura equivalente que mantém o volume de material do modelo original. Definido o método de abordagem dos elementos transversais, os momentos de inércia de massa são calculados de forma análoga aos da seção mestra já apresentados.

A Tabela 6-2 apresenta os valores do peso leve da estrutura, do KG (considerando o casco nu e/ou considerando o carregamento dos tanques), da inércia e do deslocamento para um calado de $25 \mathrm{~m}$ considerando o FPSO com as dimensões apresentadas na Tabela 4-2. Os resultados dos demais casos são apresentados no Anexo D.

\begin{tabular}{|c|c|}
\hline Modelo FPSO moonpool & Valor \\
\hline desloc. (ton) & $5,59 \mathrm{E}+05$ \\
\hline peso leve (ton) & $1,37 \mathrm{E}+05$ \\
\hline Ixx (ton. ( $^{2}$ ) & $5,83 \mathrm{E}+08$ \\
\hline Iyy (ton.m ${ }^{2}$ ) & $5,66 \mathrm{E}+09$ \\
\hline Izz (ton.m ${ }^{2}$ ) & $5,93 \mathrm{E}+09$ \\
\hline KG casco nu (m) & 34,0 \\
\hline KG 30\% (m) & 17,4 \\
\hline KG $50 \%(m)$ & 15,15 \\
\hline KG $100 \%(m)$ & 19,62 \\
\hline
\end{tabular}

Tabela 6-2 Matriz de Inércias e massa dos modelos

FONTE: Elaborada pelo autor 


\subsubsection{Critérios Estruturais}

O dimensionamento dos elementos estruturais foi baseado nos critérios apresentados pela norma. Os efeitos considerados são as principais grandezas físicas que, junto com o arranjo estrutural, determinam o peso em aço do casco nu. A corrosão também é um fenômeno físico que interfere no peso estrutural, porém, em menor grau, e seus efeitos serão estudados em uma próxima etapa que foge o escopo do presente trabalho.

\subsection{Momentos Fletores}

Neste item, será feito um cálculo preliminar dos momentos fletores utilizando os critérios da ABS (American Bureau Shipping), 2012 - capítulo 8.

A partir da tabela 8.1.2 ABS para embarcações de aço, o coeficiente de onda $C_{w v}$ é definido como:

\begin{tabular}{|c|c|}
\hline \multicolumn{2}{|c|}{ Coeficiente de onda $C_{w v}$} \\
\hline $\mathrm{L}$ & $10.75-\left[\frac{300-L}{100}\right]^{3 / 2}$ \\
\hline $150 \leq L \leq 300$ & 10.75 \\
\hline $300 \leq L \leq 350$ & $10.75-\left[\frac{L-350}{150}\right]^{3 / 2}$ \\
\hline $350 \leq L \leq 500$ & \\
\hline
\end{tabular}

Tabela 6-3 Coeficiente de onda para embarcações de aço

FONTE: Tabela 8.1.2; ABS,2012

\subsubsection{Momento fletor}

Para águas calmas o carregamento estático para alquebramento e tosamento é dado por:

$$
\begin{gathered}
M s w_{a l q}=0.01 * C_{w v} * L^{2} * B *(11.92-1.9 C b) \\
M s w_{t o s}=-0.0515185 * C_{w v} * L^{2} * B *(C b+0.7)
\end{gathered}
$$

Da mesma forma, o carregamento longitudinal para ondas verticais é dado por: 


$$
\begin{gathered}
M v w_{a l q}=0.19 * C_{w v} * L^{2} * B * C b \\
M v w_{t o s}=-0.11 * C_{w v} * L^{2} * B *(C b+0.7)
\end{gathered}
$$

O momento fletor máximo para cada condição é dado por:

$$
\begin{aligned}
& M_{a l q}=M s w_{a l q}+M v w_{a l q} \\
& M_{t o s}=M s w_{t o s}+M v w_{t o s}
\end{aligned}
$$

$\mathrm{Na}$ seção transversal a meia nau o momento de inércia mínimo $I_{\min }$ abaixo da linha neutra deve ser dado por:

$$
I_{\min }=2.7 * C_{w v} * L^{3} * B *(C b+0.7) * 10^{-8}
$$

\subsubsection{Análise preliminar das Vigas do casco}

A tensão de escoamento mínima especificada para o cálculo do módulo da seção de viga do casco é estimada pela interpolação da tabela 6.1.1 da ABS 2012:

\begin{tabular}{|c|c|}
\hline$\sigma_{e s c}\left(\mathrm{~N} / \mathrm{mm}^{2}\right)$ & $\mathrm{k}$ \\
\hline 235 & 1 \\
\hline 265 & 0.93 \\
\hline 315 & 0.78 \\
\hline 340 & 0.74 \\
\hline 355 & 0.72 \\
\hline 390 & 0.68 \\
\hline \multicolumn{2}{|c|}{ obs: valores intermediários calculados por interpolação linear } \\
\hline
\end{tabular}

Tabela 6-4 Tensão de escoamento mínima

FONTE: Tabela 6.1.1; ABS, 2012

O módulo da seção de viga do casco Z no convés e na quilha não deve ser menor do que:

$$
Z_{\text {min }}=0.9 * K_{e s c} * C_{w v} * L^{2} * B *(C b+0,7) * 10^{-6}
$$




$$
\sigma_{\text {meia nau }}=190 / K
$$

Por fim é apresentado o módulo requerido para o momento fletor total das vigas:

$$
\begin{gathered}
Z_{\text {alq }}=\frac{M_{\text {alq }}}{\sigma_{\text {meia nau }}} \\
Z_{\text {tos }}=\frac{M_{\text {tos }}}{\sigma_{\text {meia nau }}}
\end{gathered}
$$

A tabela a seguir apresenta os requisitos estruturais para o modelo numérico considerando a capacidade de armazenamento descrita no capítulo anterior:

\begin{tabular}{|c|c|c|}
\hline $\mathrm{L}$ & 340 & $\mathrm{~m}$ \\
\hline $\mathrm{B}$ & 100 & $\mathrm{~m}$ \\
\hline $\mathrm{D}$ & 40 & $\mathrm{~m}$ \\
\hline $\mathrm{KG}$ & 22 & $\mathrm{~N} \cdot \mathrm{m}$ \\
\hline$M s w_{\text {alq }}$ & $13.25 \mathrm{e}+06$ & $\mathrm{~N} \cdot \mathrm{m}$ \\
\hline$M s w_{\text {tos }}$ & $-8.7 \mathrm{e}+06$ & $\mathrm{~N} \cdot \mathrm{m}$ \\
\hline$M v w_{\text {alq }}$ & $15.6+\mathrm{e} 06$ & $\mathrm{~N} \cdot \mathrm{m}$ \\
\hline$M v w_{\text {tos }}$ & $-18.6+\mathrm{e} 06$ & $\mathrm{~N} \cdot \mathrm{m}$ \\
\hline$M_{\text {alq }}$ & $28.85+\mathrm{e} 06$ & $\mathrm{~N} \cdot \mathrm{m}$ \\
\hline$M_{\text {tos }}$ & $-27.3+\mathrm{e} 06$ & $\mathrm{~m}^{4}$ \\
\hline$I_{\text {min }}$ & 1551.5 & $\mathrm{~m}^{3}$ \\
\hline$Z_{\text {min }}$ & 194.5 & $\mathrm{~m}^{3}$ \\
\hline$Z_{\text {alq }}$ & 327.2 & $\mathrm{~m}^{3}$ \\
\hline$Z_{\text {tos }}$ & -526.59 & $\mathrm{~m}$ \\
\hline
\end{tabular}

Tabela 6-5 Requistos Estruturais

FONTE: Elaborada pelo autor

No projeto estrutural foi considerado um modelo simples de arranjo do reforçador, anteparas reforçadas e um número reduzido de variáveis estruturais. A Figura 6-3 mostra um exemplo do modelo do arranjo da seção mestra para geometria definida. 
A metodologia escolhida para definir a combinação de variáveis estruturais que resulta em um arranjo viável com o cálculo do peso leve.

O modelo numérico avalia os elementos estruturais longitudinais e transversais do FPSO para cada combinação de variáveis estruturais para garantir a adequação com a norma estabelecida.
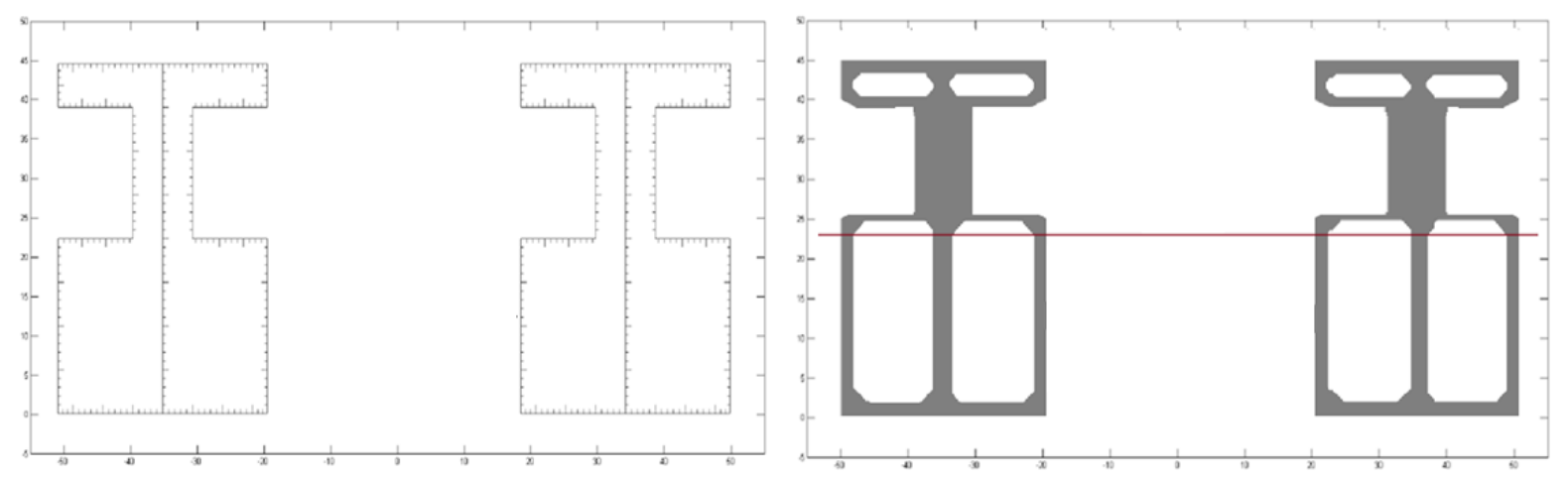

Figura 6-3 Exemplo de obteção de uma Seção Mestra (esq.) e de uma antepara (dir.)

FONTE: Elaborada pelo autor

Os esforços e momentos fletores foram calculados em relação ao arranjo inicial considerando a hipotese inicial de calado constante para todas as condições de carregamento da plataforma. Para realizar esta avaliação foi utilizado o programa SSTAB Coelho, L.C.G. \& Nascimento, A. A. (2003) de forma conjunta com o modelo de estabilidade apresentado no capítulo a seguir. A Figura 6-4 seguir foi feita para a plataforma em condição 100\% carregada de óleo. Devido às grandes dimensões do moonpool e a sua posição na plataforma, podem existir esforços de torção típicos de plataformas semissubmersíveis que devem ser estudados em um trabalho futuro.

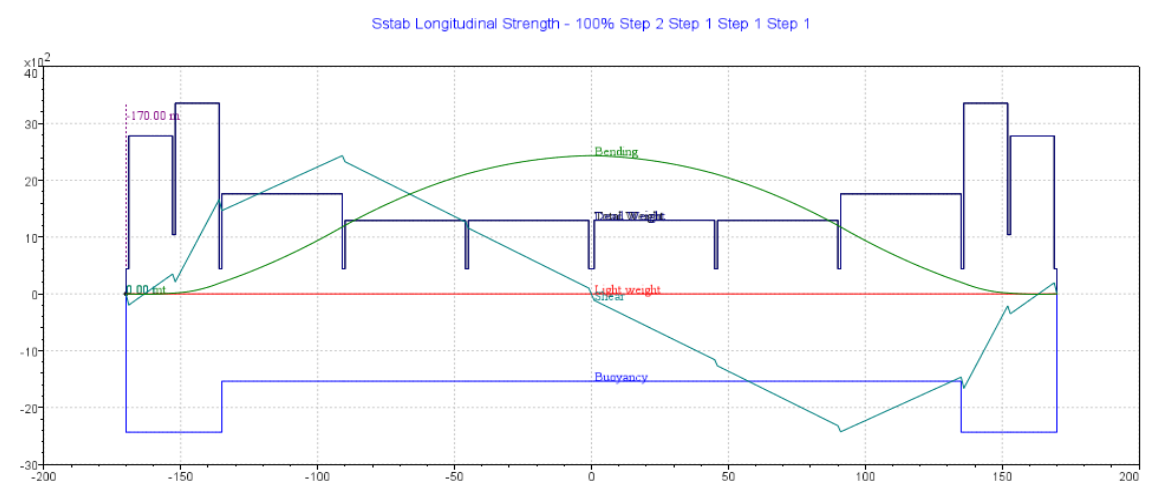

Figura 6-4 Análise do carregamento da plataforma

FONTE: Elaborada pelo autor 


\section{ANÁLISE DE ESTABILIDADE}

A avaliação de estabilidade intacta e avariada do casco do presente FPSO foi realizada com o programa SSTAB Coelho, L.C.G. \& Nascimento, A. A. (2003) amplamente utilizado na indústria nacional. Através desta ferramenta numérica, foram determinadas as propriedades hidrostáticas do casco, centros de gravidade da embarcação e dos tanques; área de linha d'água, características dos tanques de lastro, deslocamento total e calado de operação. Os cálculos levaram em consideração as normas e padrões da DNV-GL (2011) e IMO (2008). O fluxograma de estabilidade, descrito na Figura 7-1, ilustra a definição da curva GZ do FPSO e verificação das normas vigentes a partir da determinação dos seguintes fatores:

- Geometria da plataforma determinada a partir dos parâmetros da plataforma

- Posição do centro de gravidade definido pela distribuição de lastro e óleo nos tanques, peso da planta de processo e casco da plataforma.

- Área Velica definida pelas dimensões principais da plataforma e da planta de processo

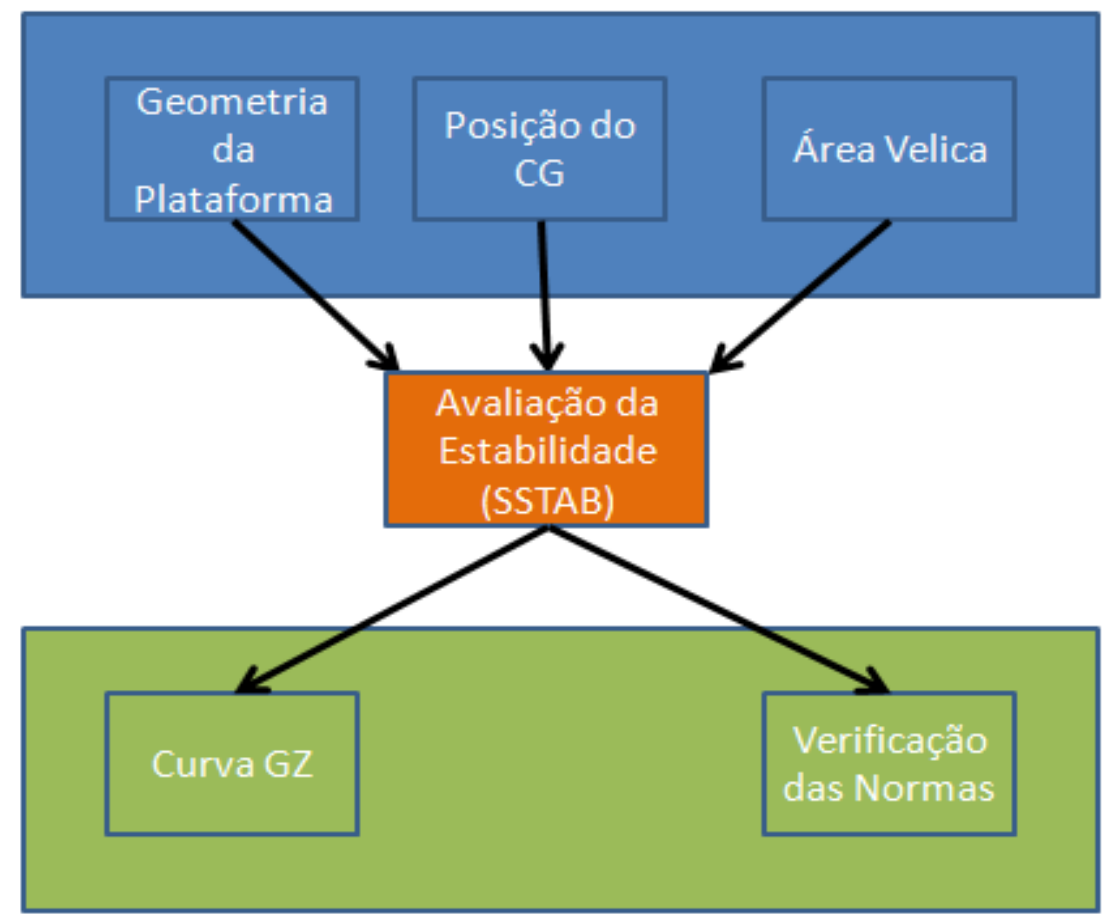

Figura 7-1 Fluxograma do modelo de estabilidade FONTE: Elaborada pelo autor 
A geometria da plataforma é descrita pelo formato de uma malha exportada pelo programa MG (Mesh Generator) para o programa SSTAB. Posições do CG e área velica são calculados pelo próprio SSTAB.

A estabilidade intacta (transversal e longitudinal) da plataforma é estimada, determinando o deslocamento em volume da embarcação e o seu centro de flutuação. Ainda nesta etapa, avaliam-se as condições iniciais de banda e trim, utilizando como referência as regras da DNV-GL (Part 6, Chapter 9, A304.5). Da mesma maneira, a estabilidade avariada da plataforma e a área alagada são definidas de acordo com os critérios descritos a seguir.

Por fim, A curva do braço de endireitamento é computada para grandes ângulos de banda para a aplicação do critério da DNV-GL (2011).

\subsection{Critérios de Estabilidade}

Como mencionado anteriormente, o modelo paramétrico deve atender critérios determinados pela norma das Classificadoras. Assim, optou-se por avaliar o modelo por meio de dois critérios: DNV-GL (2011).

Os seguintes critérios requeridos pela DNV-GL (Part 3, Chapter 3, Section 9, RL 101) são aplicados ao modelo paramétrico:

- A altura metacêntrica inicial $\mathrm{GM}_{0, \mathrm{t}}$ não deve ser menor que $0.15 \mathrm{~m}$.

- O braço de endireitamento (GZ) deve ser de pelo menos $0.20 \mathrm{~m}$ com um ângulo de inclinação igual ou superior a $30^{\circ}$.

- O braço de endireitamento máximo deve ocorrer a um ângulo de inclinação preferivelmente superior a $30^{\circ}$, mas não menor que $25^{\circ}$.

- A área sob a curva do braço de endireitamento (curva GZ) não deve ser menor que 0.055 rad.m até $30^{\circ}$ de ângulo de banda e não menor que 0.09 rad.m até $40^{\circ}$ ou ângulo de alagamento, se esse ângulo for menor que 40․

- Adicionalmente, a área abaixo da curva do braço de endireitamento entre os ângulos de $30^{\circ}$ e $40^{\circ}$ ou entre $30^{\circ}$ e o ângulo de alagamento, se este ângulo for menor do que $40^{\circ}$ não deve ser inferior a 0,03 rad.m.

- A área abaixo da curva do momento de endireitamento na segunda intersecção ou no ângulo de alagamento, o que for menor, não deve ser 
menor que $40 \%$ em excesso de área abaixo da curva do momento de emborcamento pelo vento para o mesmo ângulo limite, como mostrado na Figura 7-2.

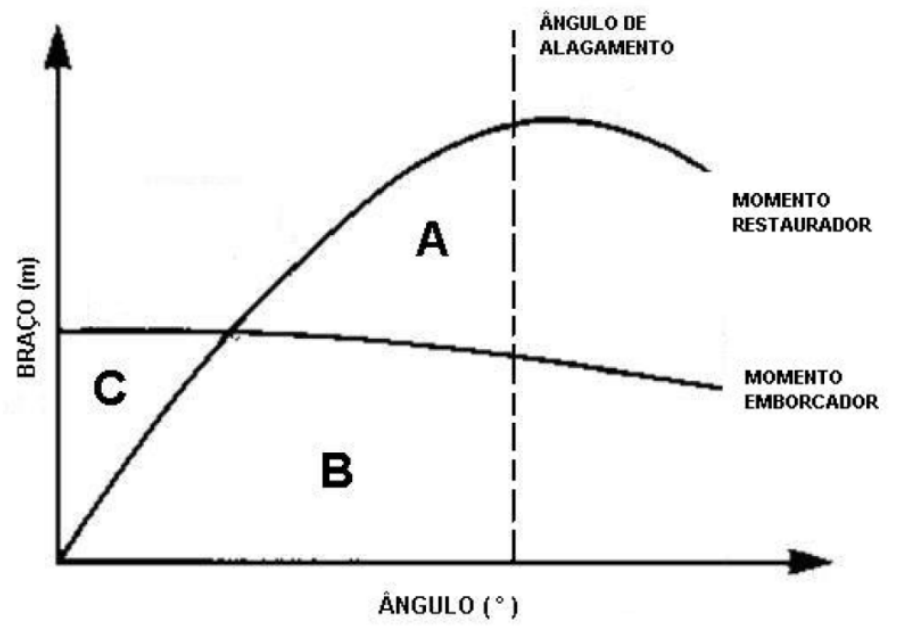

Figura 7-2 Curva Momento Restaurador

FONTE: DNV-GL (2011)

Uma vez que o modelo numérico é gerado, analisa-se a estabilidade da plataforma a partir da CEE (Curva de Estabilidade Estática) como descrito no item 7.1. A figura a seguir mostra o comportamento esperado da plataforma de acordo com a variação do ângulo de emborcamento $\theta$ :

\subsection{Estabilidade Intacta}

A operação da plataforma será feita sob a condição de calado constante. Desta forma, haverá uma constante alteração de carga e descarga dos tanques de lastro para a manutenção do calado plataforma durante a suas operações. Neste trabalho, o calado de operação foi estipulado em 25 metros.

Em relação ao volume de óleo, foi adotado que os tanques de óleo estarão com o nível de $50 \%$ de sua capacidade total. Os efeitos de superfície livre foram considerados no cálculo da altura metacêntrica (GM) e centro de gravidade (KG).

A mesma avaliação de estabilidade foi feita para a condição da plataforma com $100 \%$ do volume de óleo carregada. Nesta condição, o volume dos tanques de lastro é reduzido para compensar o aumento do volume de óleo, mantendo assim o 
deslocamento constante. As curvas de estabilidade e a verificação da norma são apresentadas a seguir para cada condição. A Figura 7-3 a seguir apresenta a curva GZ para o FPSO com 50\% carregado e 100\% carregado.

a)

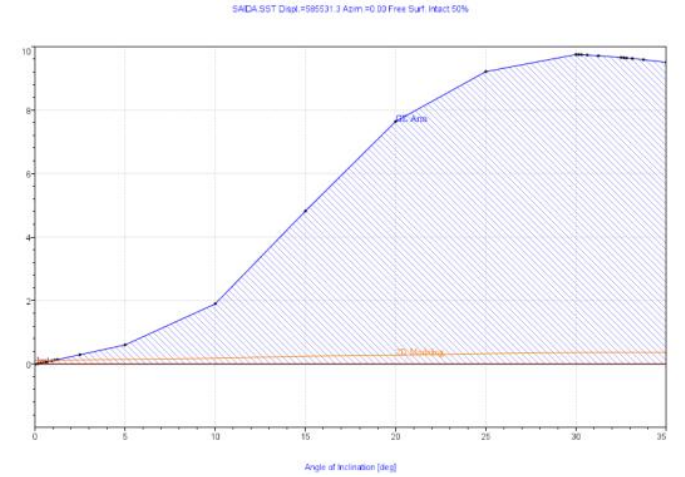

b)

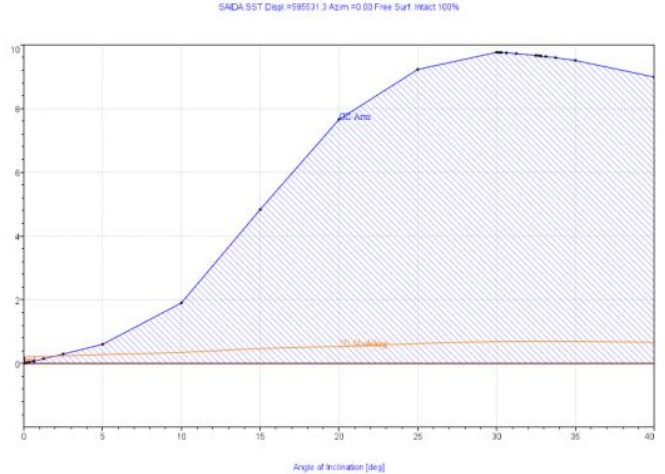

Figura $7-3$ Curva GZ do FPSO a) $50 \%$ carregado; b) $100 \%$ carregado.

FONTE: Elaborada pelo autor

\begin{tabular}{|c|c|c|}
\hline Critérios & Carr. 50\% & Carr. 100\% \\
\hline Área GZ até 30 $>0.055$ m.rad & 2.533 & 2.539 \\
\hline Área GZ até 40 $>0.09$ m.rad & 3.375 & 4.188 \\
\hline Área GZ de 30 até 40 $>0.03$ m.rad & 0.842 & 1.650 \\
\hline Braço GZ em 30 > 0.20 m & 9.750 & 9.763 \\
\hline GZ max (ㅇ) & 9.750 & 9.763 \\
\hline GZ max deve ocorrer em ângulo > 30 (25ㅇ) & 30.000 & 30.000 \\
\hline GM transversal em 0ㅇ 0.15 m & 6.999 & 7.109 \\
\hline
\end{tabular}

Tabela 7-1 Critérios de estabilidade do FPSO

FONTE: Elaborada pelo autor

As características da plataforma são apresentadas a seguir: 


\begin{tabular}{|c|c|c|c|}
\hline Descrição & Carr. 50\% & Carr. 100\% & Unidade \\
\hline Banda & 0 & 0 & $\circ$ \\
\hline Trim & 0 & 0 & $\circ$ \\
\hline Calado & 25 & 25 & $\mathrm{~m}$ \\
\hline KB & 11.2 & 11.2 & $\mathrm{~m}$ \\
\hline BM & 14.3 & 14.3 & $\mathrm{~m}$ \\
\hline KG & 18.2 & 18.4 & $\mathrm{~m}$ \\
\hline Efeito de superfície livre & 0.4 & 0.7 & $\mathrm{~m}$ \\
\hline GM & 7.3 & 7.1 & $\mathrm{~m}$ \\
\hline GM (c/Superfície livre) & 6.9 & 6.4 & $\mathrm{~m}$ \\
\hline Deslocamento & 585531 & 585531 & ton \\
\hline
\end{tabular}

Tabela 7-2 Estabilidade intacta do FPSO

FONTE: Elaborada pelo autor

Verificou-se que o momento causado pela força do vento é pequeno em comparação a grande restauração hidrostática da plataforma. Esta característica é semelhante a obtida para a plataforma ULFPSO (Oliveira, A. C., 2015) como visto na Figura 7-4:

CASCO9FULL1.SST Displ.=569700.7 Azim $=0.00$ Free Surf. Intact Condition_ 1

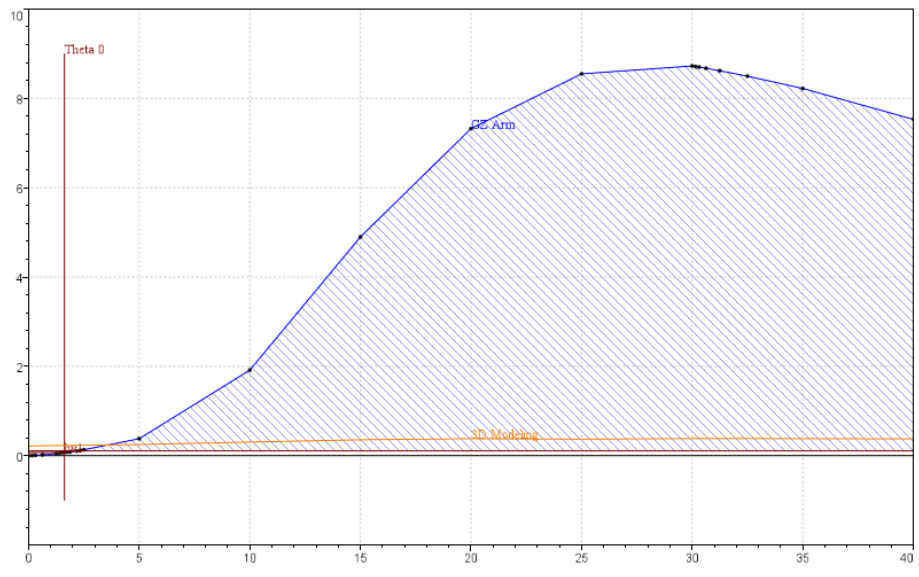

Figura 7-4 Estabilidade intacta do ULFPSO em condição 90\% carregado FONTE: Elaborada pelo autor 
A Tabela 7-3 ilustra as características do ULFPSO e a Tabela 7-4 ilustra verificação da norma para o ULFPSO, respectivamente.

\begin{tabular}{|c|c|c|}
\hline Descrição & Valor & Unidade \\
\hline Banda & 0 & $\circ$ \\
\hline Trim & 0 & $\mathrm{~m}$ \\
\hline Calado & 25 & $\mathrm{~m}$ \\
\hline KB & 11.7 & $\mathrm{~m}$ \\
\hline BM & 13.3 & $\mathrm{~m}$ \\
\hline KG & 20.9 & $\mathrm{~m}$ \\
\hline Efeito de Superfície livre & 1 & $\mathrm{~m}$ \\
\hline GM & 4.1 & $\mathrm{~m}$ \\
\hline GM (c/Superfície livre) & 5.1 & ton \\
\hline Deslocamento & 569700 & $\mathrm{c}$ \\
\hline
\end{tabular}

Tabela 7-3 Estabilidade intacta do ULFPSO em condição 100\% carregado

FONTE: Elaborada pelo autor

\begin{tabular}{|c|c|}
\hline Critérios & Resultado \\
\hline Área GZ até $30 \circ>0.055 \mathrm{~m} . \mathrm{rad}$ & 2.390 \\
\hline Área GZ até $40 \circ>0.09 \mathrm{~m} . \mathrm{rad}$ & 3.818 \\
\hline Área $\mathrm{GZ}$ de $30^{\circ}$ até $40^{\circ}>0.03 \mathrm{~m} . \mathrm{rad}$ & 1.428 \\
\hline Braço GZ em $30 \circ>0.20 \mathrm{~m}$ & 8.724 \\
\hline $\mathrm{GZ} \max (\stackrel{\circ}{)})$ & 8.724 \\
\hline GZ max deve ocorrer em ângulo > 30ㅇ (25) & 30.000 \\
\hline GM transversal em $0 \cong 00.15 \mathrm{~m}$ & 1.993 \\
\hline
\end{tabular}

Tabela 7-4 Critérios de estabilidade do ULFPSO em condição 100\% carregado

FONTE: Elaborada pelo autor

\subsection{Estabilidade Avariada}

Para a avaliação de estabilidade avariada foi utilizada como referência as normas da MARPOL 73/78 (Anexo 1 Regras para prevenção da poluição por óleo) para petroleiros com comprimento superior a $225 \mathrm{~m}$. Os critérios utilizados são descritos na Tabela 7-5 a seguir: 


\begin{tabular}{|c|c|c|}
\hline \multirow{3}{*}{ Avaria Lateral } & Extensão longitudinal & $\begin{array}{c}1 / 3\left(L^{2 / 3}\right) \text { ou } 14.5 \mathrm{~m} \text {, o que for } \\
\text { menor }\end{array}$ \\
\hline & Extensão transversal & $\mathrm{B} / 5$ ou $11.5 \mathrm{~m}$, o que for menor. \\
\hline & Extensão vertical & $\begin{array}{l}\text { Da linha do revestimento do } \\
\text { fundo na baliza central, para cima } \\
\text { sem limite. }\end{array}$ \\
\hline \multirow[b]{3}{*}{ Avaria no fundo } & Extensão longitudinal & $1 / 3\left(L^{2 / 3}\right)$ ou $5 \mathrm{~m}$, o que for menor \\
\hline & Extensão transversal & $\mathrm{B} / 6$ ou $11.5 \mathrm{~m}$, o que for menor. \\
\hline & Extensão vertical & $\begin{array}{l}\mathrm{B} / 15 \text { ou } 6 \mathrm{~m} \text {, o que for menor, } \\
\text { medido na linha do revestimento } \\
\text { no fundo na baliza central, para } \\
\text { cima sem limite. }\end{array}$ \\
\hline
\end{tabular}

Tabela 7-5 Critérios de estabilidade avariada

Fonte: MARPOL 78

Utilizando estes critérios de estabilidade avariada como referência, foi verificado que a plataforma proposta consegue manter o calado de operação e atender os critérios de estabilidade com uma avaria 10 tanques contínuos no mesmo bordo.

SADA.SST Disol =456357 D Azim $=0$ 00 Free Surt, Damage 100\% Step 2 Step 1 Step 1 Step 1

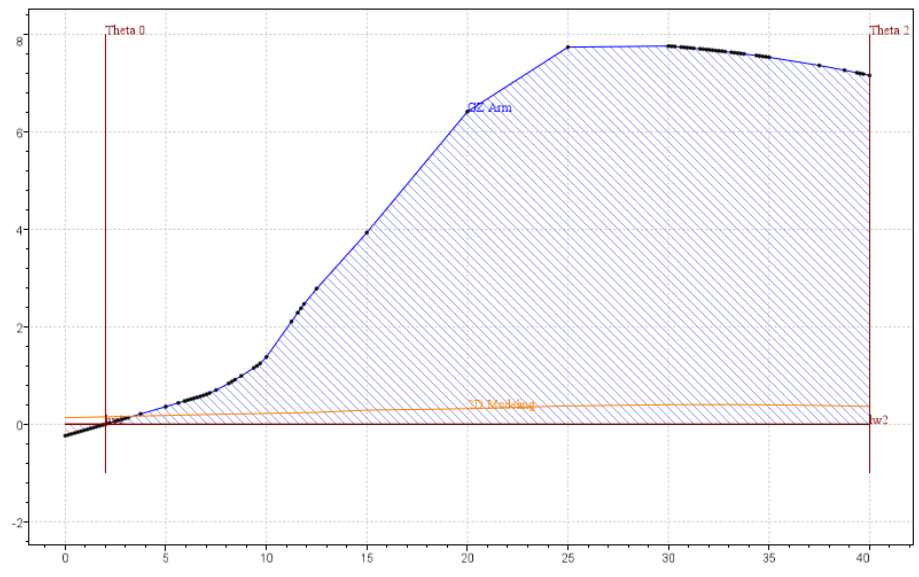

Figura 7-5 Curva GZ do FPSO em condição avariada

FONTE: Elaborada pelo autor 
A Tabela 7-6 ilustra as características da plataforma e a Tabela 7-7 ilustra a verificação de atendimento à norma, respectivamente.

\begin{tabular}{|c|c|c|}
\hline Descrição & Valor & Unidade \\
\hline Banda & -1.99 & $\circ$ \\
\hline Trim & 0.00 & $\mathrm{~m}$ \\
\hline Calado & 25 & $\mathrm{~m}$ \\
\hline KB & 11.15 & $\mathrm{~m}$ \\
\hline BM & 19.54 & $\mathrm{~m}$ \\
\hline KG & 16.79 & $\mathrm{~m}$ \\
\hline Efeito de Superfície Livre & 0.69 & $\mathrm{~m}$ \\
\hline GM & 13.90 & $\mathrm{~m}$ \\
\hline GM (c/ Superfície livre) & 13.21 & ton \\
\hline Deslocamento & 456356.96 & \\
\hline
\end{tabular}

Tabela 7-6 Estabilidade avariada do FPSO proposto

FONTE: Elaborada pelo autor

\begin{tabular}{|c|c|}
\hline Critérios & Resultado \\
\hline Área GZ até $30^{\circ}>0.055 \mathrm{~m} . \mathrm{rad}$ & 2.059 \\
\hline Área GZ até $400>0.09 \mathrm{~m} . \mathrm{rad}$ & 3.369 \\
\hline Área $\mathrm{GZ}$ de $30^{\circ}$ até $40 \circ>0.03 \mathrm{~m} . \mathrm{rad}$ & 1.310 \\
\hline Braço GZ em 30 >0.20 m & 7.761 \\
\hline $\mathrm{GZ} \max (\stackrel{\circ}{)})$ & 7.761 \\
\hline GZ max deve ocorrer em ângulo > 30ㅇ (25은 & 30.000 \\
\hline GM transversal em $0 \cong>0.15 \mathrm{~m}$ & 13.403 \\
\hline
\end{tabular}

Tabela 7-7 Critérios de estabilidade do FPSO em condição avariado

FONTE: Elaborada pelo autor 


\section{COMPORTAMENTO EM ONDAS}

A avaliação do comportamento em ondas tem como objetivo medir os movimentos dinâmicos da plataforma, em especial os movimentos de heave, roll e pitch, importantes para avaliar a aceleração vertical nos pontos de conexão do balcão de risers que é uma das premissas de projeto.

Os movimentos de corpo rígido de uma unidade flutuante, como é o caso do FPSO aqui estudado, são tradicionalmente descritos em termos de seis graus de liberdade: surge, sway e heave, pitch, roll e yaw. Sendo os três primeiros movimentos de translação e os três últimos movimentos de rotação conforme ilustrado na Figura 8-1.

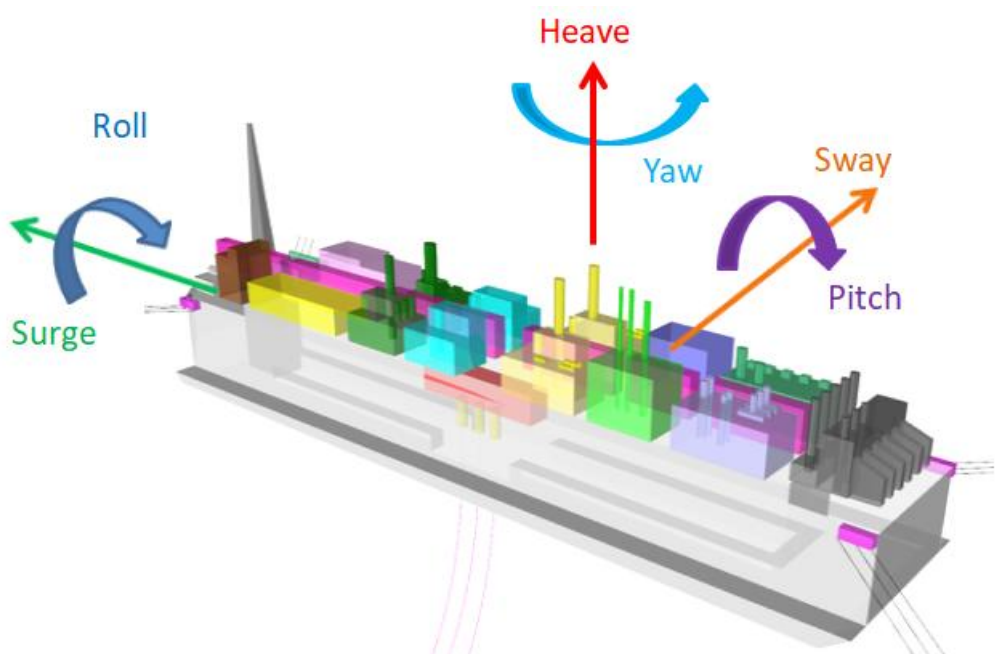

Figura 8-1 Seis graus de liberdade de um corpo flutuante

FONTE: Elaborado pelo autor

Os modos verticais dos movimentos da unidade flutuante (heave, roll e pitch) apresentam restauração hidrostática e consequentemente, possuem períodos naturais que podem ser excitados pela energia presente em ondas, entrando em ressonância.

O intuito desta análise é obter um sistema flutuante com períodos naturais o mais longe possível do pico de energia das ondas no ambiente em que a plataforma está instalada, a fim de evitar altos níveis de movimento, obtendo assim uma maior vida útil para os equipamentos, entre eles os risers. 
Conforme apresentado na Figura 8-2, o período ressonante de uma embarcação FPSO convencional está próximo da região de energia das ondas na faixa de $12 \mathrm{~s}$ a 16s, o que significa que esse tipo de FPSO apresenta grandes movimentos verticais que inviabiliza a utilização de risers SCR.

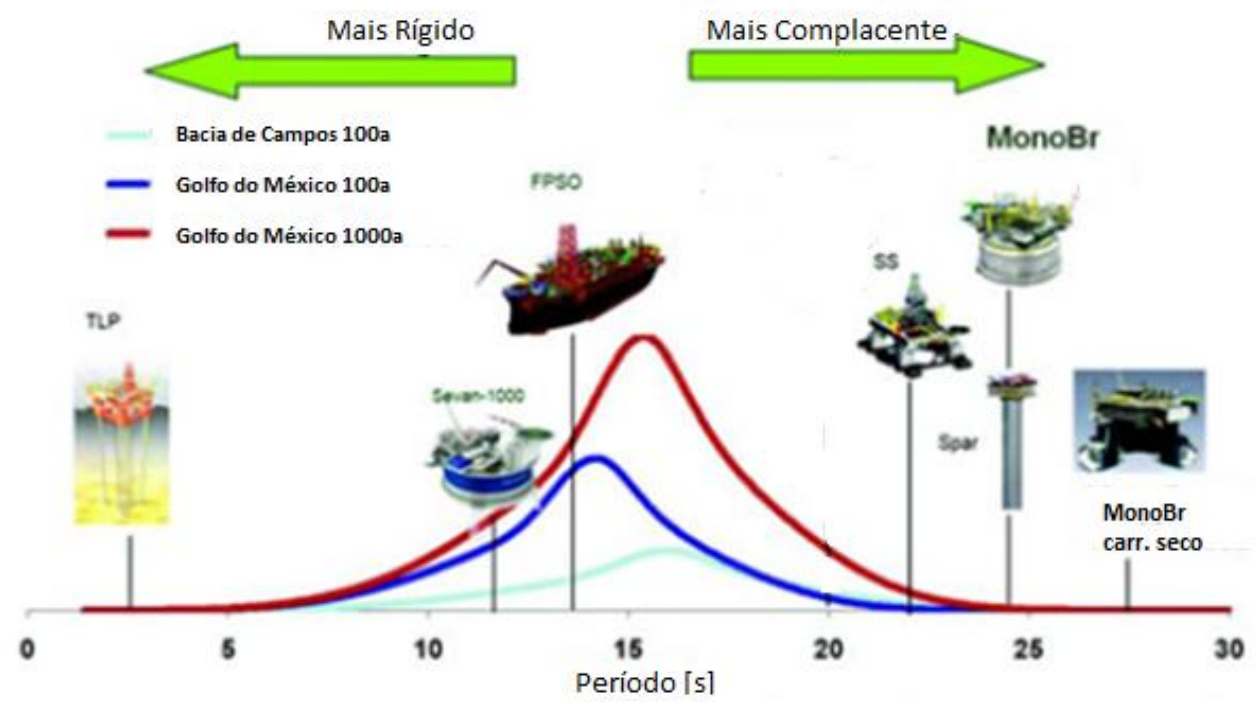

Figura 8-2 Comparação entre ressonância dos sistemas flutuantes e espectros de mar FONTE: Gonçalves et al. (2010) alterado pelo autor.

Uma possível alternativa ao problema em questão é utilizar apêndices hidrodinâmicos de forma alterar os períodos naturais da embarcação. Nesta fase serão estudados os efeitos dinâmicos da inclusão três tipos apêndices: a redução da área de linha d'água, saia hidrodinâmica e o moonpool.

A redução de área da linha d'água em plataformas tem o intuito de reduzir os movimentos da plataforma sem ser necessário aumentar o seu deslocamento. A modificação dessa característica foi estudada originalmente para a utilização em projetos de plataformas monocolunas como a apresentada em Gonçalves et al, 2010. Apesar da diferença de plataformas, os resultados destes estudos podem ser aproveitados neste trabalho dada à similaridade de estudo. A ideia principal é alterar o termo de restauração hidrostática, uma vez que o período natural de heave é inversamente proporcional à área de linha d'água.

A utilização de saias hidrodinâmicas em sistemas oceânicos também resulta em alteração do comportamento em ondas da plataforma, proporcional ao aumento de suas dimensões, o que significa o aumento de massa adicional e do 
amortecimento. Em navios, normalmente existe uma limitação da dimensão da saia hidrodinâmica devido à resistência ao avanço e ao peso estrutural do próprio apêndice. Entretanto, no caso de plataformas FPSO tal limitação não se aplica. Entretanto, se a saia hidrodinâmica for instalada no moonpool por todo corpo paralelo da plataforma, ela pode influenciar no espaço necessário para instalação de risers.

\subsection{Modelo Numérico}

As principais propriedades do modelo numérico avaliadas pelo WAMIT são as forças de onda e os coeficientes hidrodinâmicos (massa adicional, potencial de amortecimento e restauração hidrostática), necessários para solução da equação do movimento Eq. 8-1 e, desse modo, obter-se o RAO (Response Amplitude Operator), funções de transferência entre o movimento do corpo e onda, conforme a Eq. 8-4. É possível avaliar essas propriedades para um sistema de corpos flutuantes, considerando o acoplamento entre eles. Neste caso foi considerado que a coluna d'água interna é um segundo corpo com movimento acoplado ao FPSO.

$$
(M+A) \ddot{x}+\left(B_{\text {pot }}+B_{\text {visc }}\right) \dot{x}+C x=F_{\text {onda }}
$$

Onde:

$$
x=\left[\begin{array}{c}
X \\
Y \\
Z \\
\theta \\
\phi \\
\Psi
\end{array}\right]
$$

Com X, Y e Z sendo os movimentos de surge, sway e heave, respectivamente, $\theta$ e, $\Phi$ e $\psi$ correspondem aos movimentos de roll, pitch e yaw, respectivamente.

$\mathrm{E}$

$$
F_{\text {onda }}=\left[\begin{array}{c}
F_{X} \\
F_{Y} \\
F_{Z} \\
M_{X X} \\
M_{Y Y} \\
M_{Z Z}
\end{array}\right]
$$




$$
R A O=\frac{F_{\text {onda }}}{-\omega^{2}(M+A)+i \omega\left(B_{\text {pot }}+B_{\text {visc }}\right)+C}
$$

A entrada para o modelo numérico é basicamente:

- Malha da superfície molhada do navio

- Informações sobre massa e inércia

- Vetor de períodos (ou frequências) das ondas

- Vetor de incidências de onda

Como detalhado nos capítulos anteriores, o modelo passou por diversas iterações partindo de uma geometria simples de um navio caixa passando a incluir uma o moonpool,a saia hidrodinâmica e redução na linha d'água. Detalhes gerais sobre os apêndices escolhidos são apresentados no item 8.2 e uma avaliação específica de cada apêndice será apresentada nos itens 8.3, 8.4 e 8.5

A redução da área de linha d'água tem o objetivo principal de modificar o período natural dos movimentos de heave, roll e pitch. Embora estudos numéricos do uso da redução da área de linha d'água, representada pelo parâmetro $\beta$ neste trabalho, sejam comuns em monocolunas, as conclusões e resultados sobre a influência deste parâmetro no comportamento das plataformas obtidas nestes estudos podem ser aplicados no projeto proposto.

O uso de saia hidrodinâmicas na altura da quilha tem o objetivo de aumentar a massa adicional da plataforma e, desta maneira, aumentar os períodos de ressonância da plataforma.

A inclusão do moonpool causa uma mudança do comportamento da plataforma que pode ser percebida principalmente no movimento de heave da plataforma pelo efeito pistão descrito por Molin (2001).

Os critérios de projeto estabelecidos levaram em consideração a aceleração máxima nos pontos de conexão de risers e períodos naturais da plataforma $A$ descrição destes critérios é apresentada na Tabela 8-1 a seguir: 


\begin{tabular}{|c|c|c|}
\hline Critério & Descrição & Valor \\
\hline Aceleração no riser & $\begin{array}{c}\text { Max. Aceleração permitida } \\
\text { em risers rígidos SCR sem } \\
\text { risco de danos }\end{array}$ & $\mathrm{a}<0.8 \mathrm{~m} / \mathrm{s}^{2}$ \\
\hline Períodos naturais & $\begin{array}{c}\text { O período de ressonância } \\
\text { da plataforma da } \\
\text { plataforma deve estar o } \\
\text { mais distante possível do } \\
\text { espectro de energia do } \\
\text { ambiente. }\end{array}$ & $T_{\text {heave }}>20 \mathrm{~s}$ \\
\hline $\begin{array}{c}\text { Movimentos e acelerações } \\
\text { (roll) }\end{array}$ & $\begin{array}{c}\text { A plataforma deve garantir } \\
\text { movimentos pequenos } \\
\text { para operação }\end{array}$ & $d_{\text {roll }}<3^{\circ}$ \\
\hline $\begin{array}{c}\text { Movimentos e acelerações } \\
\text { (heave) }\end{array}$ & $\begin{array}{c}\text { A plataforma deve } \\
\text { pequenos para operação }\end{array}$ & $a_{\text {heave }}<0.8 \mathrm{~m} / \mathrm{s}^{2}$ \\
\hline heave & $<5 \mathrm{~m}$ \\
\hline
\end{tabular}

Tabela 8-1 Critérios do comportamento em ondas da plataforma

FONTE: Elaborada pelo autor

\subsection{Apêndices Hidrodinâmicos}

No caso de corpos oscilantes, a frequência natural de um sistema em uma única coordenada pode ser descrita em função de duas propriedades básicas: massa $(m)$ e a rigidez $(k)$. A frequência natural em radianos é dada por:

$$
\omega_{n}^{2}=k / m
$$

E, portanto, o período natural para um movimento de translação vertical é dado por:

$$
T_{\text {nheave }}=2 \pi \sqrt{m / k}=2 \pi \frac{\sqrt{(m+m a)}}{(\rho * A w l * g)}
$$


Os períodos naturais referentes aos movimentos de rotação (roll, pitch) são dados por:

$$
\begin{gathered}
T_{\text {nroll }}=2 \pi \sqrt{\frac{(I+I a d)}{\left(G M_{\text {transversal }} * \Delta * g\right)}} \\
T_{\text {npitch }}=2 \pi \sqrt{\frac{(I+I a d)}{\left(G M_{\text {longitudinal }} * \Delta * g\right)}}
\end{gathered}
$$

Onde:

- $\quad \rho$ é a massa específica da água

- $A_{w l}$ é a área de linha d'água

- g é a aceleração da gravidade

- M é a massa do sistema

- $M_{a d}$ é a massa adicional hidrodinâmica

- I é a inércia de massa do sistema

- $I_{a d}$ é a inércia de massa adicional hidrodinâmica

É imediato perceber que a redução da área de linha d'água aumenta o período de heave da plataforma. Desta forma, os parâmetros b e $\beta$ que definem a dimensão transversal do moonpool e a redução de área na altura de linha d'água respectivamente desempenham esta função de modificar o período de heave. Como discutido na avaliação do duplo casco no Capítulo 7, esta redução pode gerar uma região crítica em casos de acidentes durante uma operação de offloading, portanto, optou-se por um valor mínimo de 0.3 para o valor de $\beta$. Esta alteração dos períodos de heave deve-se redução da área de linha d'água pelo parâmetro $\beta$ que forma uma acaba aprisionando a água interna ao moonpool. Estudos numéricos para determinar as características da praia, como seu ângulo e posição em relação à linha d'água, são apresentados em Torres et al. (2004).

Também é possível alterar os períodos naturais da plataforma ao aumentar a massa adicional desta por meios de saias hidrodinâmicas representados pelo parâmetro $\alpha$. Este parâmetro está relacionado com a restrição de entrada de água no moonpool. 
Em geral, as saias hidrodinâmicas são utilizadas com o objetivo de adicionar amortecimento viscoso para uma embarcação com a sua eficiência sendo um compromisso entre a diminuição da amplitude do movimento de roll e o aumento da resistência introduzida pela superfície molhada adicional. No caso de uma plataforma estacionária, os efeitos de resistência ao avanço não são geralmente uma preocupação.

Matsumoto et al (2008) estudou o uso de saia hidrodinâmicas em sistemas oceânicos formando uma "saia" como observado na Figura 8-3 de forma que parte da água pode ficar confinada dentro do moonpool e gerando dois efeitos hidrodinâmicos: massa adicional e amortecimento viscoso. Os principais resultados obtidos por Matsumoto et al. (2008) mostram que este tipo de apêndice hidrodinâmico pode modificar significativamente os movimentos verticais de heave $e$ pitch devido ao aumento de massa adicional.

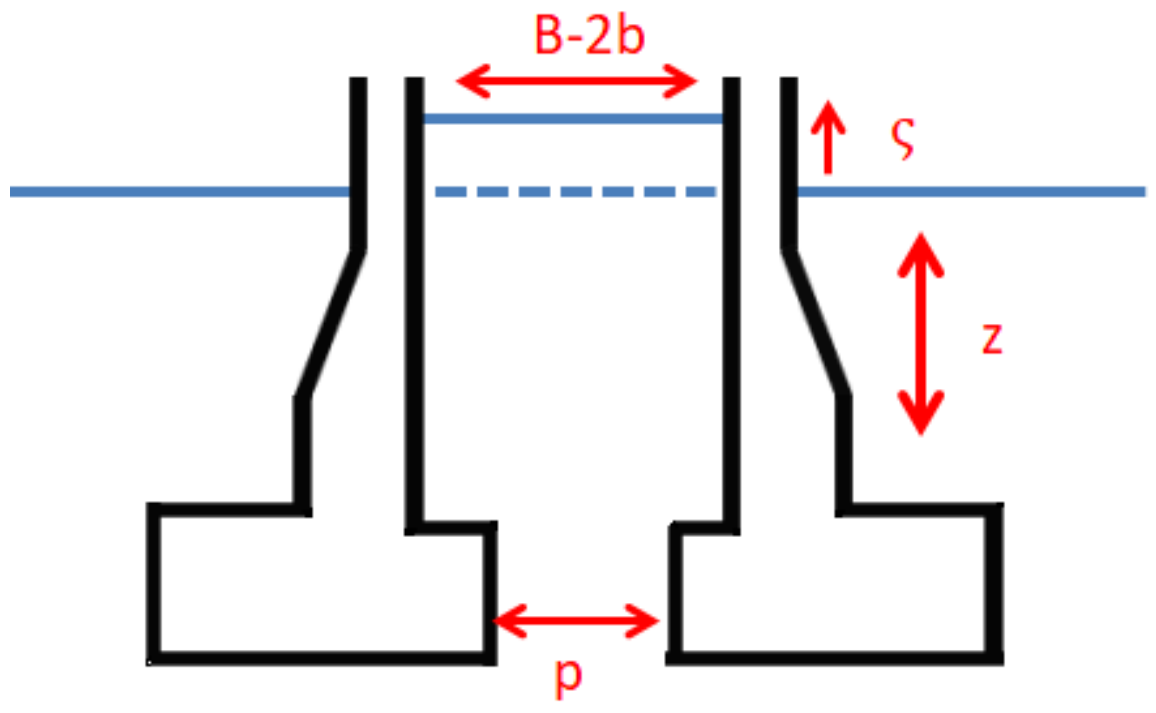

Figura 8-3 Movimento de água interno ao moonpool

FONTE: Matsumoto et al (2008) alterado pelo autor

Desta forma, para alterar o período natural de modo a viabilizar o nível de movimento necessário para a utilização de SCR's, é imprescindível trabalhar a relação entre estes parâmetros, sempre atendendo as normas estabelecidas pelas autoridades pertinentes. 


\subsection{Moonpool}

Como explicado na descrição do arranjo geral da plataforma, a inclusão do moonpool permite a alocação do balcão de risers da lateral da plataforma para o centro da plataforma. Deste fato, decorre a necessidade do desenvolvimento de um novo arranjo geral para o FPSO, com reposicionamento de tanques lastro e óleo ao longo da plataforma. Outro ponto importante a ser estudado é o comportamento em ondas da plataforma decorrente da inclusão deste apêndice hidrodinâmico.

Mecanicamente, o uso do moonpool em um navio se comporta de forma análoga a um sistema de massa-mola-amortecedor. A frequência natural do sistema passa a depender da dinâmica da coluna d'água dentro do moonpool, sendo esperado que essa frequência fique acima da faixa de frequência de energia das ondas do mar.

Durante movimento em ondas, observa-se um caráter oscilatório nas variações do nível da coluna água. Estas variações do nível da água, indicadas como os movimentos relativos da água no moonpool são conhecidas como efeitos de sloshing.

O problema de sloshing é altamente não linear e está relacionado a efeitos viscosos presentes na dinâmica do moonpool, fato este que aumenta a dificuldade de gerar um modelo numérico razoável. No entanto, é possível utilizar resultados obtidos por meio de ensaios experimentais em escala reduzida para obtenção e calibração destes efeitos através de ua simplificação por meio de coeficientes linearizados.

Verificou-se que a excitação em frequências sub-harmônicas da frequência natural também é possível nos ensaios em escala reduzida. Este fenômeno leva a um comportamento semelhante a batimentos, ressonância dos movimentos relativos a uma frequência que difere da frequência das ondas.

É necessário então entender o mecanismo de excitação da coluna de água no moonpool e as várias maneiras pelas quais o amortecimento efetivo pode ser obtido para avaliar o projeto do moonpool e dos demais apêndices hidrodinâmicos. 
Para o amortecimento do movimento relativo entre a coluna d'água e a plataforma, três mecanismos podem ser considerados: amortecimento potencial, atrito e amortecimento de pressão viscosa.

Fisicamente, o amortecimento potencial pode estar relacionado a ondas de saída geradas pelo movimento de um corpo em movimento. No sentido de teoria potencial, é o componente da fase de quadratura da força de reação hidrodinâmica a tal movimento.

A avaliação do amortecimento viscoso em plataformas não é considerada na teoria potencial. Isto ocorre, pois, todos os códigos numéricos empregados atualmente são baseados na teoria potencial de ondas que não resolve a equação completa de Navier-Stokes. Uma possível solução numérica seria o emprego de códigos CFDs (Computacional Fluid Dynamics), mas estes métodos usualmente exigem grande consumo computacional. Desta forma, outra solução é o uso de modelos em escala reduzida com um experimento de oscilação livre com o sinal analisado para a obtenção dos coeficientes de amortecimento (Malta, E. B. et al, (2010)).

Devido ao atrito entre o fluido e a parede interna do moonpool, um amortecimento adicional é criado. Em muitos casos a magnitude do amortecimento por atrito é muito pequena pode ser negligenciada em comparação com o potencial de amortecimento e perda de energia devido a vórtices.

A maior parte do amortecimento experimentado pela coluna oscilante de água do moonpool pode estar relacionada à geração de vórtices durante a entrada e a saída de água. Knott e Flower (1980) mostraram que a existência desses turbilhões depende do arredondamento da borda. No caso do moonpool de uma plataforma, pode-se supor que os vórtices e a energia dissipada neles criam um amortecimento quadrático que foi introduzido empiricamente no modelo matemático.

Um modelo matemático para um sistema massa-mola-amortecedor apresentado por Torres, F., (2007), descreve o movimento da plataforma relativo ao movimento vertical da água interna ao moonpool pela seguinte equação na forma matricial: 


$$
\left[\begin{array}{cc}
m_{z} & 0 \\
m_{\zeta} & m_{\zeta}
\end{array}\right] \cdot\left[\begin{array}{c}
\ddot{Z} \\
\ddot{\zeta_{r}}
\end{array}\right]+\left[\begin{array}{cc}
c_{z} & -c_{z \zeta} \\
0 & c_{z \zeta}
\end{array}\right] \cdot\left[\begin{array}{c}
\dot{Z} \\
\dot{\zeta_{r}}
\end{array}\right]+\left[\begin{array}{cc}
k_{z} & 0 \\
k_{\zeta} & k_{\zeta}
\end{array}\right] \cdot\left[\begin{array}{c}
Z \\
\zeta_{r}
\end{array}\right]=0
$$

Um ponto importante a ser notado neste sistema de equações é a assimetria das matrizes de massa e rigidez quando escritas em termos de movimento, velocidade e aceleração relativa do moonpool.

Baseando-se no estudo apresentado por Torres, F. (2015) e na verificação de que o sistema $\mathrm{FPSO} /$ moonpool funciona como um sistema dinâmico de dois corpos, uma nova abordagem foi escolhida para o estudo dos coeficientes de amortecimento utilizando o software WAMIT. Nesta abordagem considera os modos da superfície livre do moonpool como modos adicionais aos modos da própria plataforma, de maneira similar a um sistema com dois corpos conectados.

Como explicado anteriormente, a superfície livre é então modelada como uma tampa chamada neste trabalho de "lid" (WAMIT® Manual, version 7.2) possuindo seis graus de liberdade independentes da plataforma.

Para esta análise utilizou-se o método High Order descrito pelo em que a superfície molhada do casco (obras vivas) é representada por painéis e aproximadas por um conjunto de $B$-splines, com a curvatura do casco representada de maneira contínua.

O sistema a ser considerado possui seis graus de liberdade pertencentes à plataforma FPSO e seis graus de liberdade provindos da coluna d'água como um segundo corpo, totalizando um sistema com 12 DOF. Uma análise mais robusta deste método foi apresentada por Malta, E. B. (2006) para um modelo de monocoluna.

O software numérico descreve o movimento de heave de acordo com o sistema de equações apresentado a seguir.

$$
\begin{aligned}
& \left(m_{33}+a_{33}\right) \cdot \ddot{x_{3}}+\left(b_{33}+c_{33}\right) \cdot \dot{x_{3}}+k_{33} \cdot x_{3}+a_{39} \cdot \ddot{x_{9}}+\left(b_{39}+c_{39}\right) \cdot \dot{x}_{9}=F_{3} \\
& a_{93} \cdot \ddot{x_{3}}+\left(b_{93}+c_{93}\right) \cdot \dot{x_{3}}+\left(m_{99}+a_{99}\right) \cdot \ddot{x_{9}}+\left(b_{99}+c_{99}\right) \cdot \dot{x_{3}}+k_{99} x_{9}=F_{9}
\end{aligned}
$$


Onde:

$a_{i j}$ é a massa adicional no modo i a um movimento no modo j

$b_{i j}$ é o coeficiente de amortecimento potencial no modo i devido a um movimento no modo $\mathrm{j}$

$c_{i j}$ é o coeficiente de amortecimento viscoso linearizado no modo i devido a um movimento no modo $\mathrm{j}$

$k_{i j}$ é o coeficiente de restauração no modo i devido a um movimento no modo j

Para análise, os coeficientes de restauração em heave $k_{33}$ e $k_{99}$ são calculados como:

$$
k_{i j}=\rho \cdot g \cdot A_{w l}
$$

Onde:

$A_{w l}$ é a área de linha d'água da plataforma.

Desta forma, de acordo com a modelagem do movimento vertical da água interna ao moonpool feita por Torres, F. (2007) é descrita no Apêndice A. Conclui-se que, para se utilizar a matriz de amortecimento externo do WAMIT para análise com dois corpos, os coeficientes de amortecimento devem obedecer às relações:

$$
\begin{gathered}
c_{33}=c_{z}+c_{z \zeta} \\
c_{39}=c_{93}=c_{z \varsigma}=-c_{\zeta z} \\
c_{99}=c_{z \varsigma}
\end{gathered}
$$

Esta modelagem descreve a iteração do movimento da plataforma com a coluna d'água, que foi descrita por Torres (2007) como um sistema acoplado massamola-amortecedor com dois corpos. Neste caso, a coluna d'água interior ao 
moonpool pode ser considerada como um segundo corpo com ressonância própria e acoplada à plataforma FPSO. A figura a seguir apresenta a modelagem proposta, onde a plataforma (corpo 1) e o lid representando a coluna d'água (corpo 2) realizam um movimento acoplado.
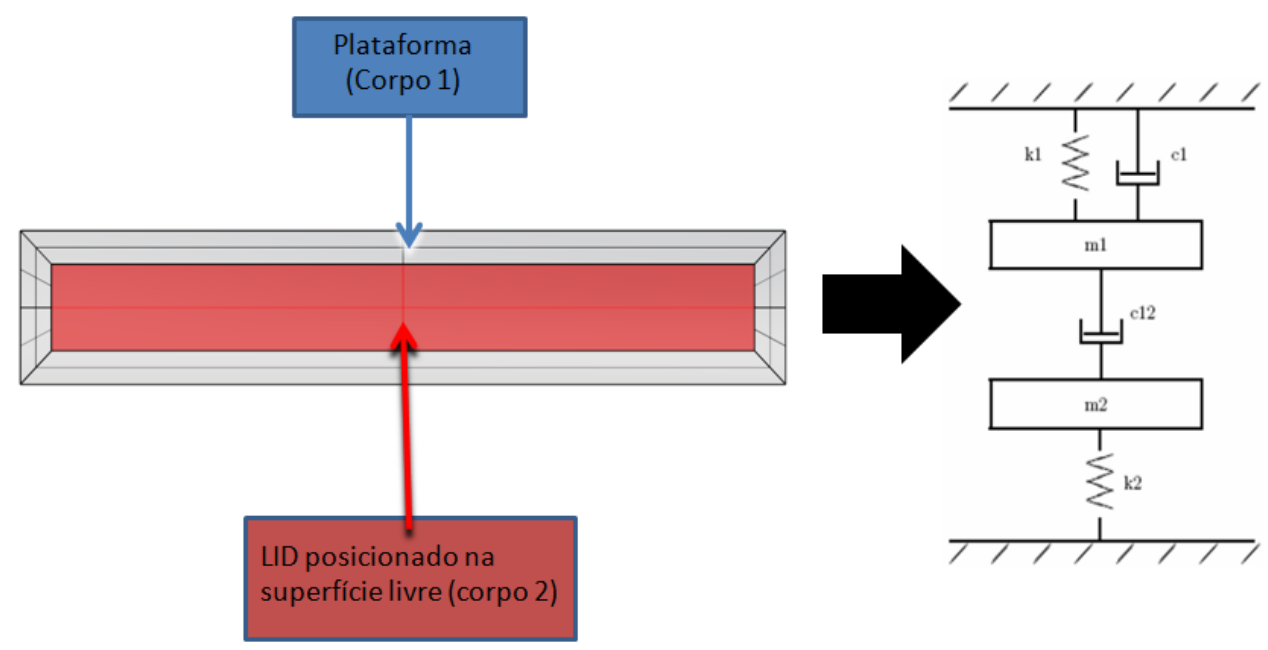

Figura 8-4 Modelagem da plataforma com lid (visão de topo) como um sistema massa-molaamortecedor

FONTE: Elaborada pelo autor

A validação deste método numérico foi feita utilizando um modelo com dimensões simplificadas como descrito na tabela a seguir:

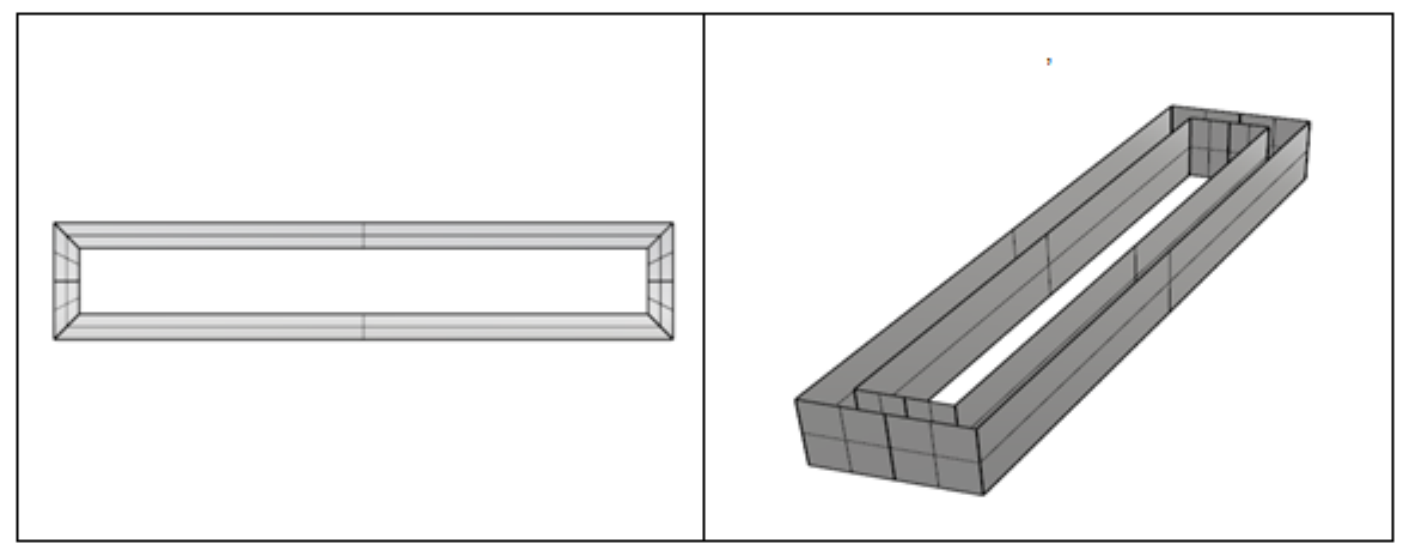

Figura 8-5 Geometria do modelo de ensaio

FONTE: Elaborada pelo autor 


\begin{tabular}{|c|c|c|}
\hline Dimensão & Valor & Unidade \\
\hline L & 2955 & $\mathrm{~mm}$ \\
\hline B & 555 & $\mathrm{~mm}$ \\
\hline D & 415 & $\mathrm{~mm}$ \\
\hline Calado & 210 & $\mathrm{~mm}$ \\
\hline$l_{\text {moonpool }}$ & 2685 & $\mathrm{~mm}$ \\
\hline$b_{\text {moonpool }}$ & 275 & $\mathrm{~mm}$ \\
\hline KG & 235 & $\mathrm{~mm}$ \\
\hline Deslocamento & 189.5 & $\mathrm{~kg}$ \\
\hline Escala & $1: 100$ & \\
\hline
\end{tabular}

Tabela 8-2 Dimensões do modelo escala de ensaio

FONTE: Elaborada pelo autor

O modelo numérico é então comparado com um modelo experimental estudado em escala reduzida feito no laboratório $\mathrm{CH}$-TPN. A descrição completa da matriz de ensaio do modelo construído é apresentada no Anexo B.

Os coeficientes de amortecimento do modelo numérico foram obtidos utilizando os resultados do ensaio como referência. Uma análise de sensibilidade foi realizada para calibrar os coeficientes de amortecimentos da plataforma $c_{z}$ e o coeficiente de amortecimento da coluna d'água interior ao moonpool $c_{z \zeta}$. Primeiramente, foram feitos estudos variando exclusivamente cada um dos coeficientes e mantendo o coeficiente restante igual a zero. Em seguida, foi feita uma análise utilizando ambos os coeficientes para recuperar os dados do ensaio. A Figura 8-6 apresenta a análise de sensibilidade para o coeficiente $c_{z}$. 


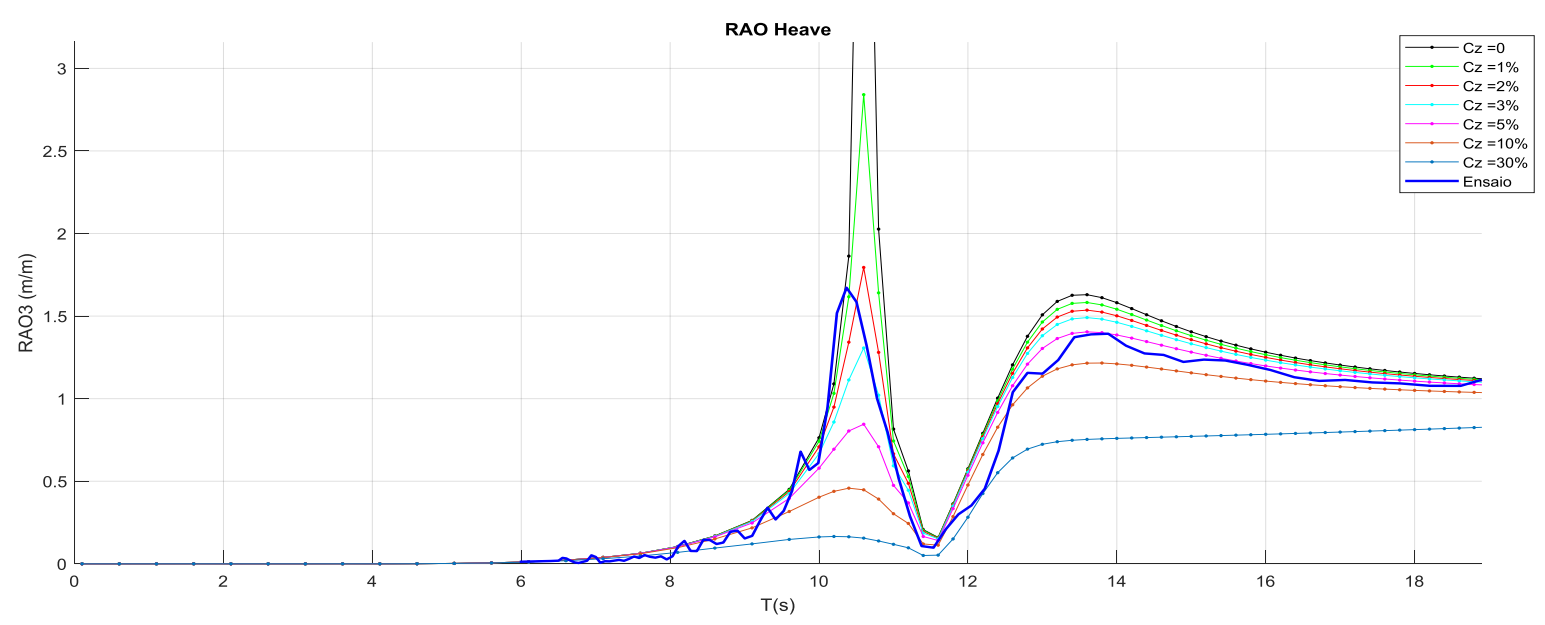

Figura 8-6 Análise de sensibilidade do coeficiente $c_{z}$

FONTE: Elaborada pelo autor

Como explicado anteriormente, o modo pistão do movimento de heave da plataforma ocorre em $\mathrm{T}=11.5 \mathrm{~s}$. Os resultados numéricos sem amortecimento apresentam grandes amplitudes de heave e forças de excitação. Os dois períodos adjacentes de ressonância em $T=11 \mathrm{~s}$ e $T=13.5 \mathrm{~s}$ referem-se à ressonância do moonpool e da plataforma respectivamente. Estas respostas com grandes amplitudes não são coerentes e a sua existência é atribuída à negligência ao amortecimento viscoso durante o cálculo computacional. No método utilizado para amortecer os movimentos de heave separadamente, o 'lid' é posicionado na superfície livre do moonpool e pode ser considerado como uma extensão da superfície do corpo e, portanto, representado como um painel adicional e com o seu próprio coeficiente de amortecimento.

A análise de sensibilidade também mostra que quando o coeficiente de amortecimento responsável por representar a plataforma e a água externa ao seu redor $c_{z}=c_{33}$ tende ao infinito, o sistema começa a se comportar como apenas um corpo, apresentando apenas uma frequência de ressonância e alterando sensivelmente a região do segundo período de ressonância.

Em seguida, o mesmo procedimento foi realizado para o coeficiente de amortecimento $c_{z \zeta}$ que é responsável pelo acoplamento dinâmico entre o FPSO e a água interna ao moonpool como apresentado na Figura 8-7. Verifica-se que a variação deste coeficiente é responsável pela variação da dinâmica do sistema, ou 
seja, este coeficiente altera o comportamento do moonpool e o movimento acoplado imposto por este à plataforma. Desta maneira observa-se que quando $c_{z \varsigma}=30 \%$ ou para grandes valores de amortecimento, o sistema passa a se comportar como um sistema dinâmico de apenas um corpo e apenas um período de ressonância.

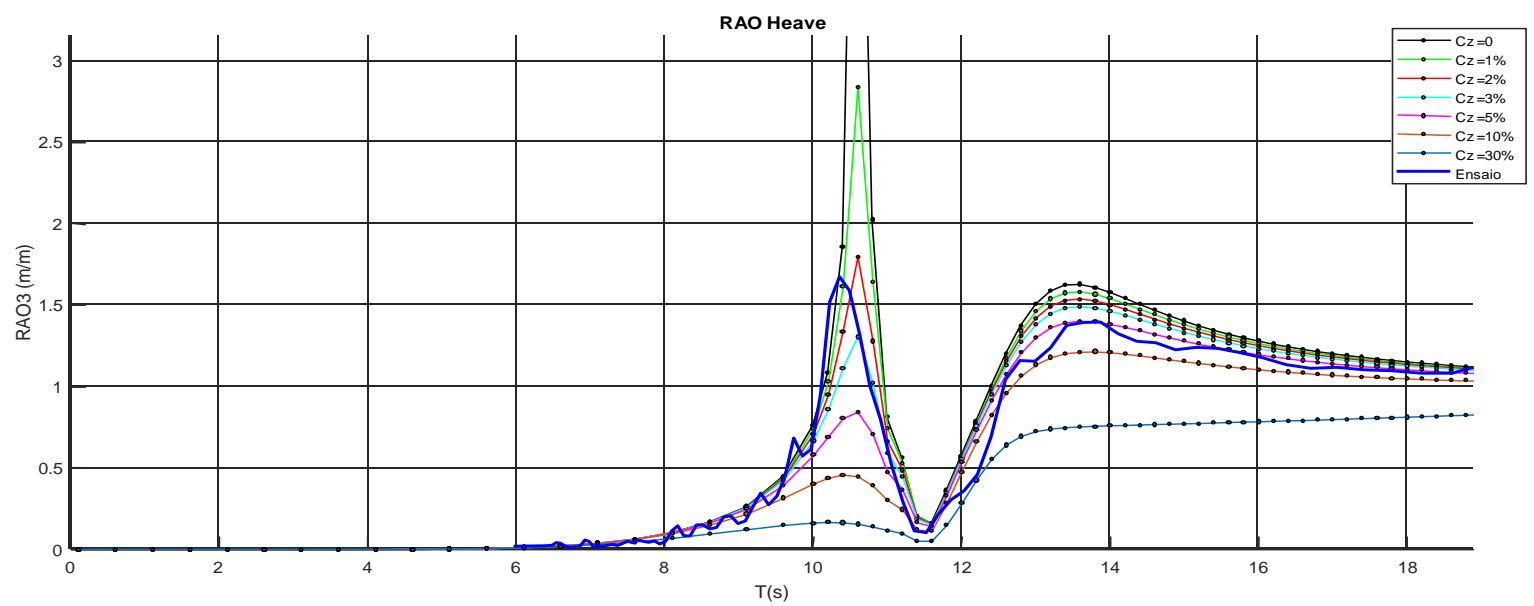

Figura 8-7 Análise de sensibilidade do coeficiente $c_{z \varsigma}$

FONTE: Elaborada pelo autor

Aplicou-se um processo empírico iterativo obtendo os coeficientes de amortecimento $c_{z}=2 \%$ e $c_{z \zeta}=1 \%$, a Figura 8-8 ilustra a comparação entre os dois métodos.

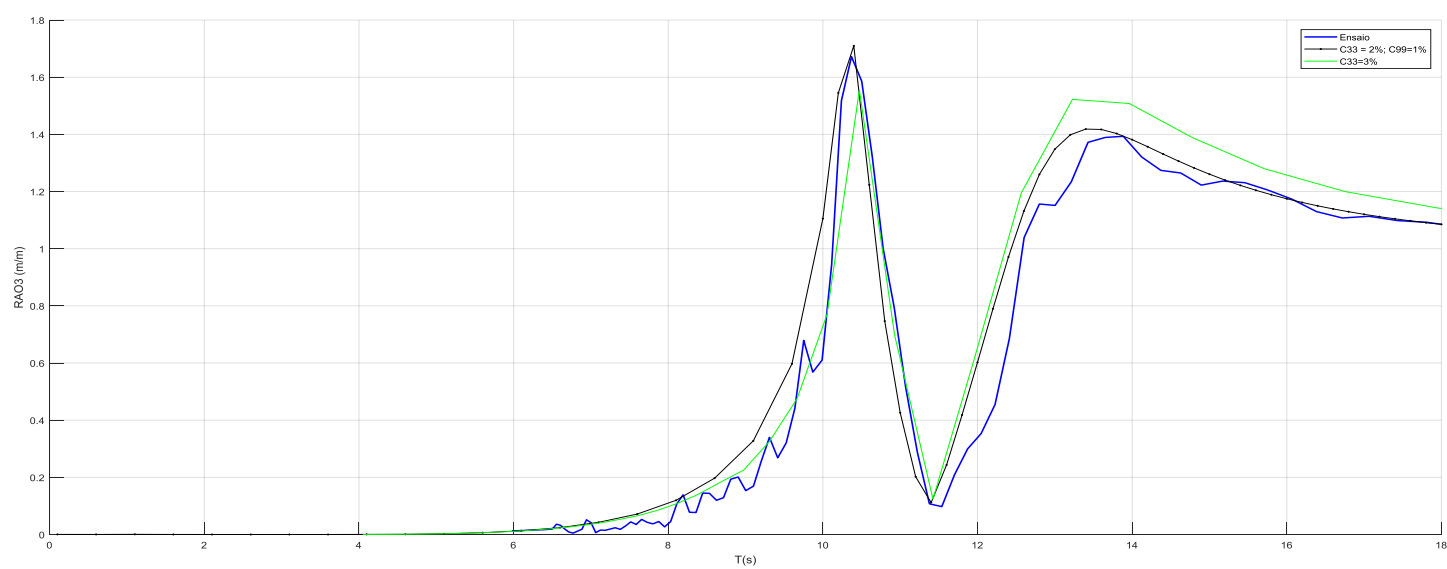

Figura 8-8 Coeficientes de amortecimento $c_{z}=2 \%$ e $c_{z \varsigma}=1 \%$

FONTE: Elaborada pelo autor 
Além de o modelo matemático apresentado mostrar boa coerência como os resultados do experimento como apresentado no trabalho de Torres F. (2007), o resultado mostrou boa coerência com o ensaio descrito no Anexo B.

O mesmo estudo é utilizado para a geometria ULFPSO com as características e condições apresentadas a seguir:

\begin{tabular}{|c|c|c|}
\hline Dimensão & Valor & Unidade \\
\hline L & 3400 & $\mathrm{~mm}$ \\
\hline B & 1000 & $\mathrm{~mm}$ \\
\hline D & 400 & $\mathrm{~mm}$ \\
\hline Calado & 250 & $\mathrm{~mm}$ \\
\hline$l_{\text {moonpool }}$ & 2950 & $\mathrm{~mm}$ \\
\hline$b_{\text {moonpool }}$ & 550 & $\mathrm{~mm}$ \\
\hline KG & 163,05 & $\mathrm{~kg}$ \\
\hline Deslocamento & 555,26 & \\
\hline Escala & $1: 100$ & \\
\hline
\end{tabular}

Tabela 8-3 Dimensões do modelo ULFPSO escala de ensaio

FONTE: Elaborada pelo autor

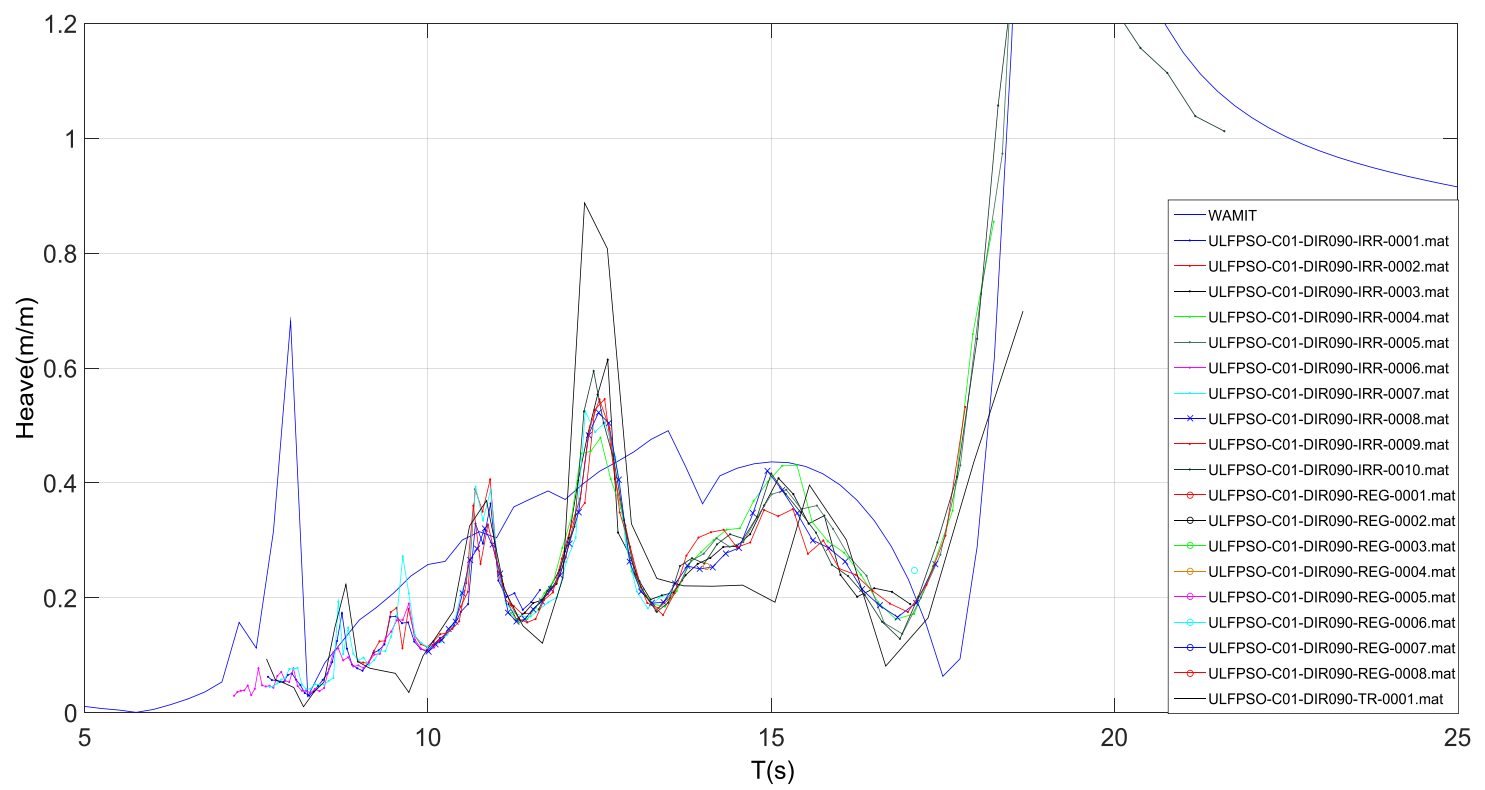

Figura 8-9 Comparação ensaio ULFPSO

FONTE: Relatório Ensaio ULFPSO: Ensaio em ondas de modelo em escala reduzida 
Foi percebido que o modelo "Box shaped" com paredes lisas apresentou maior coerência entre os resultados numéricos e experimentais principalmente em relação ao período do modo pistão.

Foram verificadas pequenas diferenças no modo pistão do modelo teórico e do ensaio, essas diferenças podem ser atribuídas a efeitos na praia do moonpool que emerge sobre a superfície d'água durante os movimentos verticais do FPSO e, assim, formando efeitos não lineares principalmente na região de redução de linha d'água. Apesar disto, as diferenças do período de cancelamento são pequenas e os valores obtidos são suficientes para o propósito deste trabalho e, portanto, uma análise mais detalhada sobre a ressonância do moonpool e sobre vorticidades na região da praia neste conceito pode ser interessante em trabalhos futuros. Como a geometria do modelo proposto apresenta grande semelhança ao modelo ULFPSO, utilizou-se os mesmos coeficientes de amortecimento para a análise.

\subsection{Saia hidrodinâmica}

A inclusão de saia hidrodinâmicas na plataforma contribui para o aumento dos períodos naturais de heave e pitch por meio de aumento de massa adicional além de amortecer o movimento de roll da plataforma. No caso de Monocoluna, Matsumoto et al (2008) incluiu uma saia hidrodinâmica interna e externa da plataforma formando uma "saia" hidrodinâmica conforme apresentado pela Figura 8-10.

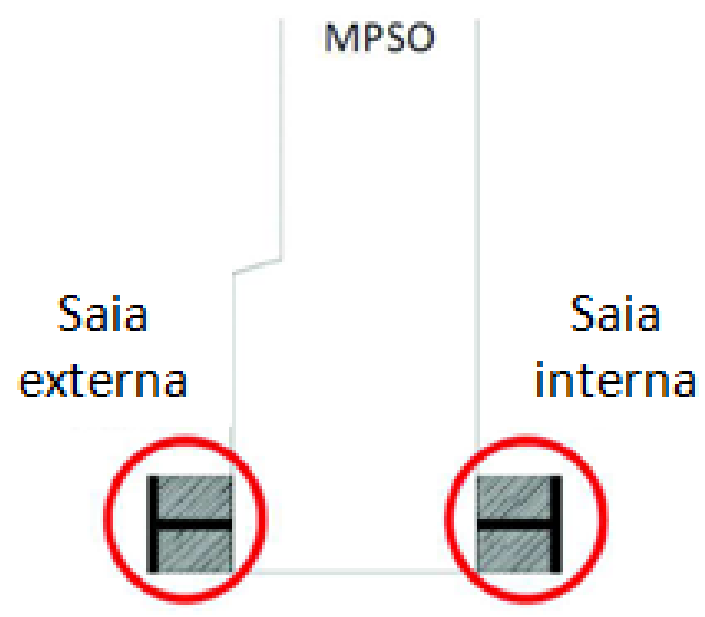

Figura 8-10 Aplicação de saia hidrodinâmicas em uma monocoluna Fonte: Matsumoto et al., (2008) 
No caso de uma plataforma FPSO, foram inclusas ambas as saias hidrodinâmicas internas e externas paralelamente ao longo do seu comprimento longitudinal conforme a Figura 8-11:

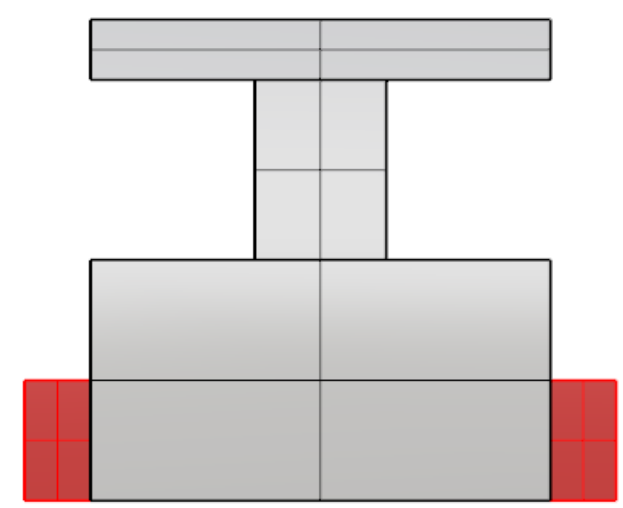

Figura 8-11 Modelo de saia hidrodinâmicas em um pontoon do FPSO

FONTE: Elaborada pelo autor

A Tabela 8-4 apresenta as características adotadas do parâmetro alfa e as dimensões da saia hidrodinâmica para a análise de sensibilidade:

\begin{tabular}{|c|c|c|}
\hline $\begin{array}{c}\text { Seção transversal } \\
\text { da saia } \\
\text { hidrodinâmica }(\mathrm{m})\end{array}$ & Alfa & $\begin{array}{c}\text { Deslocamento Total da } \\
\text { plataforma (ton) }\end{array}$ \\
\hline $\begin{array}{c}\text { s/saia } \\
\text { hidrodinâmica }\end{array}$ & 0 & 558625 \\
\hline $1 \mathrm{~m} \times 5 \mathrm{~m}$ & 0.06 & 564025 \\
\hline $2 \mathrm{~m} \times 5 \mathrm{~m}$ & 0.13 & 569425 \\
\hline $3 \mathrm{~m} \times 5 \mathrm{~m}$ & 0.2 & 574825 \\
\hline $4 \mathrm{~m} \times 5 \mathrm{~m}$ & 0.27 & 580225 \\
\hline $5 \mathrm{~m} \times 5 \mathrm{~m}$ & 0.33 & 585625 \\
\hline
\end{tabular}

Tabela 8-4 Dimensionamento da saia hidrodinâmica

FONTE: Elaborada pelo autor 

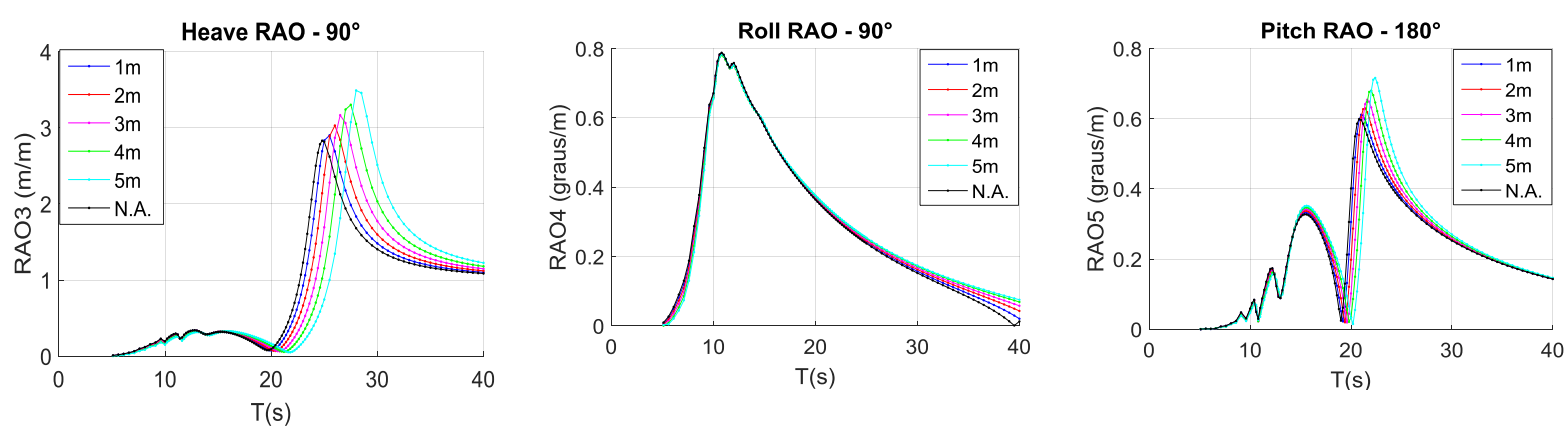

Figura 8-12 Comparação das dimensões de saia hidrodinâmicas

Analisando a Figura 8-12, observa-se que a geometria a com maior dimensão de saia hidrodinâmicas apresenta períodos de oscilação de heave e pitch maiores.

Desta forma, conclui-se que a saia hidrodinâmica aumenta a massa adicional da plataforma e pode ser utilizada para aumentar os períodos oscilatórios do FPSO.

Uma questão importante a ser analisada futuramente é o amortecimento não linear devido ao desprendimento de vórtices na saia hidrodinâmica e a sua interação com o casco.

\subsection{Parâmetro de redução da $A_{w l}(\beta)$}

O parâmetro $\beta$ representa a alteração na geometria do casco na altura de linha d'água e tem objetivo similar à saia hidrodinâmica: alterar o comportamento da plataforma por meio de uma redução da área de linha d'água. Quando excitada, esta região gera ondas dissipando energia como uma "praia" e aumentando o amortecimento e a massa adicionada do sistema. Isto permite a mudança de períodos naturais do sistema para longe da faixa de energia do mar. A Figura 8-13 mostra em destaque a região definida para esta modificação geométrica.
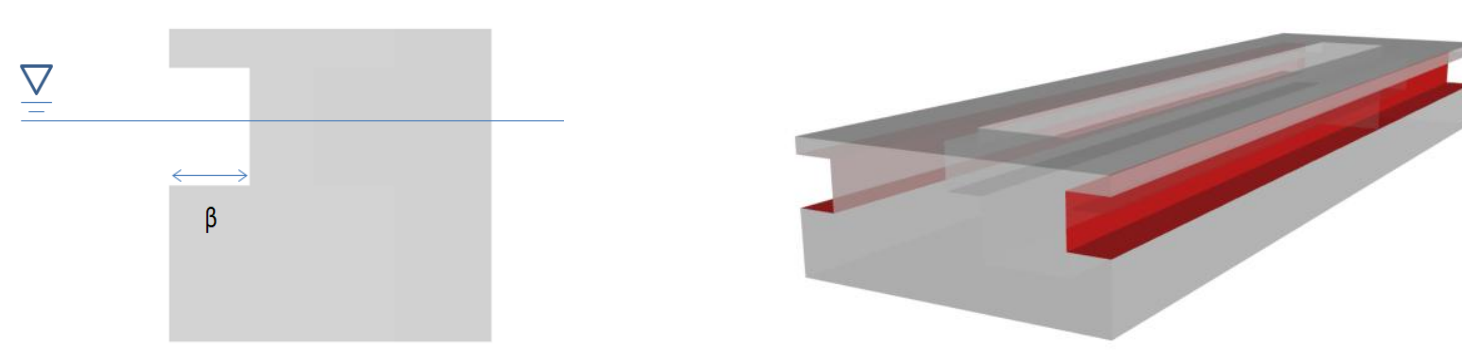

Figura 8-13 Área de redução área de linha d'água

FONTE: Elaborada pelo autor 
Uma limitação importante para a parametrização da plataforma é que, ao reduzir a área de linha d'água utilizando o parâmetro $\beta$, há uma redução da capacidade de armazenamento de óleo e lastro total da plataforma que implicaria em uma alteração das dimensões principais L, B e D da plataforma para atender o critério de armazenamento mínimo. Consequentemente, também existe uma limitação estrutural em relação a este parâmetro.

Os resultados são apresentados a seguir:

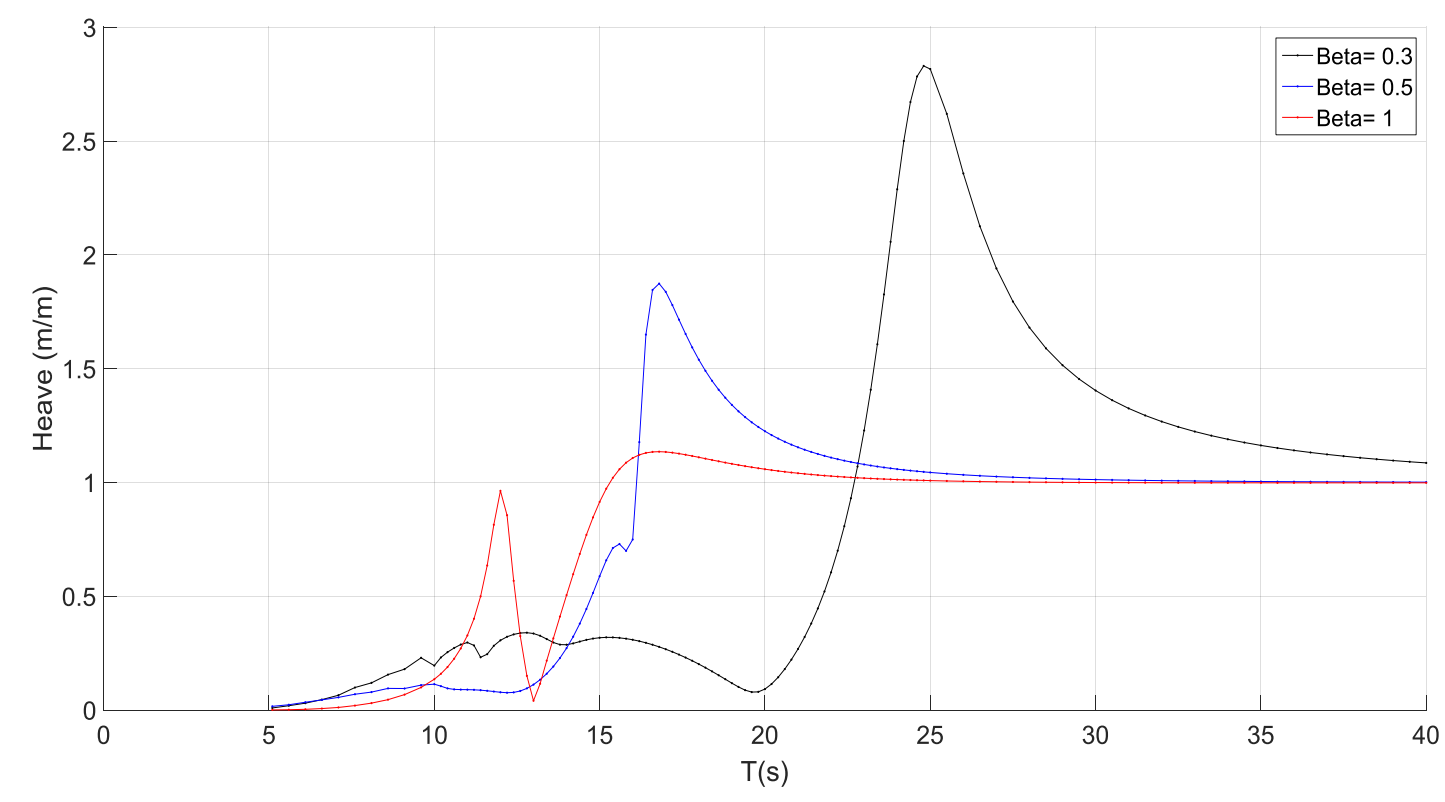

Figura 8-14 Comparação parâmetro $\beta$ - Heave

FONTE: Elaborada pelo autor

A redução da área de linha d'água aumenta do período natural de heave da plataforma. Nota-se também uma diferença nas amplificações na coluna d'água interna ao moonpool devido ao aprisionamento da coluna d'água como descrito em Matsumoto et al (2008).

Estes resultados são similares com os resultados da geometria ULFPSO para diferentes reduções de linha d'água como apresentado na Figura 8-15 a seguir: 


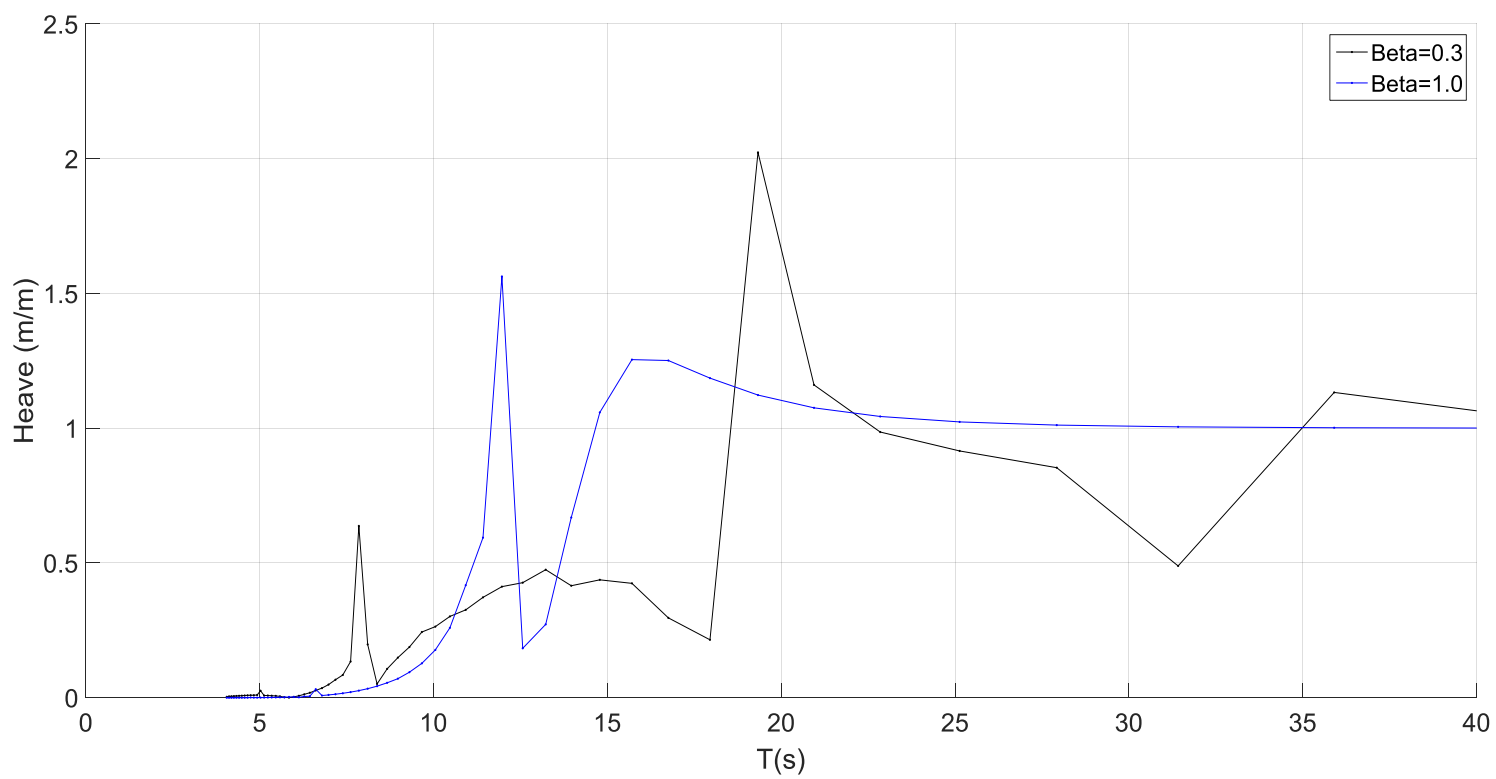

Figura 8-15 Comparação parâmetro $\beta$-Heave ULFPSO

FONTE: Elaborada pelo autor

Entretanto, do ponto de vista de construção de plataformas, como a utilização da redução de área de linha d'água é tipicamente utilizado em plataformas do tipo monocolunas como a MonoBr e, portanto, o uso de uma geometria inovadora pode exigir uma avaliação mais refinada do que a exigida pela legislação descrita no Capítulo 7. Desta forma, apesar dos resultados apresentados neste trabalho mostrarem que esta alteração da geometria da plataforma apresenta resultados promissores principalmente para a redução do movimento vertical, outras análises mais detalhadas devem ser feitas para verificar a viabilidade construtiva desta geometria. 


\section{ANÁLISES DE RESULTADOS E COMPARAÇÕES}

Este capítulo apresentará comparações dos principais resultados obtidos numericamente com os resultados obtidos experimentalmente. Verificações dos critérios de aceleração vertical, elevação da coluna d'água interior ao moonpool e o comportamento em ondas da plataforma serão avaliados. Adicionalmente, serão apresentadas comparações com os modelos ULFPSO e a plataforma P55. O modelo ULFPSO é utilizado nesta comparação devido à semelhança geométrica com o modelo proposto. Embora a plataforma P55 não apresente semelhanças de capacidade de armazenamento ou de geometria, esta unidade foi desenvolvida para utilização de risers rígidos, portanto, é interessante comparar os valores de aceleração vertical e movimentos em heave principalmente.

Primeiramente serão apresentadas as características de cada modelo estudado. A Tabela 9-1 a seguir apresenta os parâmetros da plataforma proposta e suas as principais características:

\begin{tabular}{|c|c|c|}
\hline Parâmetro & Valor & Dimensão \\
\hline $\mathrm{L}$ & 340 & $\mathrm{~m}$ \\
\hline $\mathrm{B}$ & 100 & $\mathrm{~m}$ \\
\hline $\mathrm{D}$ & 40 & $\mathrm{~m}$ \\
\hline Deslocamento & 586.000 & ton \\
\hline Saia hidrodinâmica interna & $75 \times 5 \times 5$ & $\mathrm{~m}$ \\
\hline Saia hidrodinâmica externa & $120 \times 5 \times 5$ & $\mathrm{~m}$ \\
\hline $\mathrm{\alpha}$ & 0.2 & \\
\hline $\mathrm{I}$ & 35 & $\mathrm{~m}$ \\
\hline $\mathrm{b}$ & 35 & $\mathrm{~m}$ \\
\hline$\beta$ & 0.3 & \\
\hline$l_{\text {moonpool }}$ & 270 & $\mathrm{~m}$ \\
\hline$b_{\text {moonpool }}$ & 30 & $\mathrm{~m}$ \\
\hline $\mathrm{KG}$ & 18.3 & $\mathrm{~m}$ \\
\hline
\end{tabular}

Tabela 9-1 Parâmetros FPSO condição de operação

FONTE: Elaborada pelo autor 

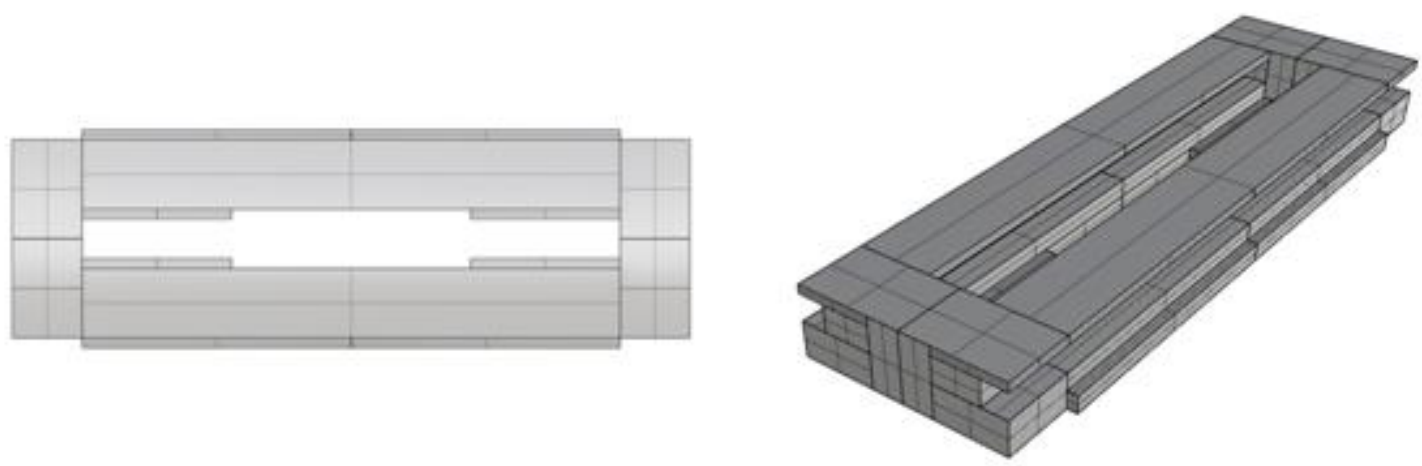

Figura 9-1 Modelo do casco final

FONTE: Elaborada pelo autor

É importante notar que análise para a definição das dimensões priorizou o desempenho do comportamento em ondas da plataforma sob a restrição de atender os critérios estruturais determinados pelas classificadoras. Desta forma, esta geometria inovadora pode ter uma alteração dos parâmetros $\alpha$ e $\beta$ devido a uma avaliação estrutural mais refinada principalmente em relação ao custo de construção. Consequentemente, o arranjo geral também deverá ser reavaliado e o comportamento em ondas final será alterado para atender os critérios de viabilidade da plataforma. A Figura 9-2 mostra o comportamento da plataforma utilizando um lid para amortecimento do moonpool.

É possível observar que a inclusão de saia hidrodinâmicas e da redução da área de linha d'água permitiu alterar os períodos dos movimentos verticais da plataforma para a faixa superior a $25 \mathrm{~s}$ além de reduzir amplitudes de roll como discutido no capítulo anterior.

Do ponto de vista exclusivo do comportamento de ondas, a plataforma deve reduzir o máximo seus movimentos oscilatórios para que a operação da plataforma não seja interrompida. Observa-se que a inclusão de saia hidrodinâmicas e reduções na área de linha d'água com maiores dimensões auxilia a redução do downtime operacional. 


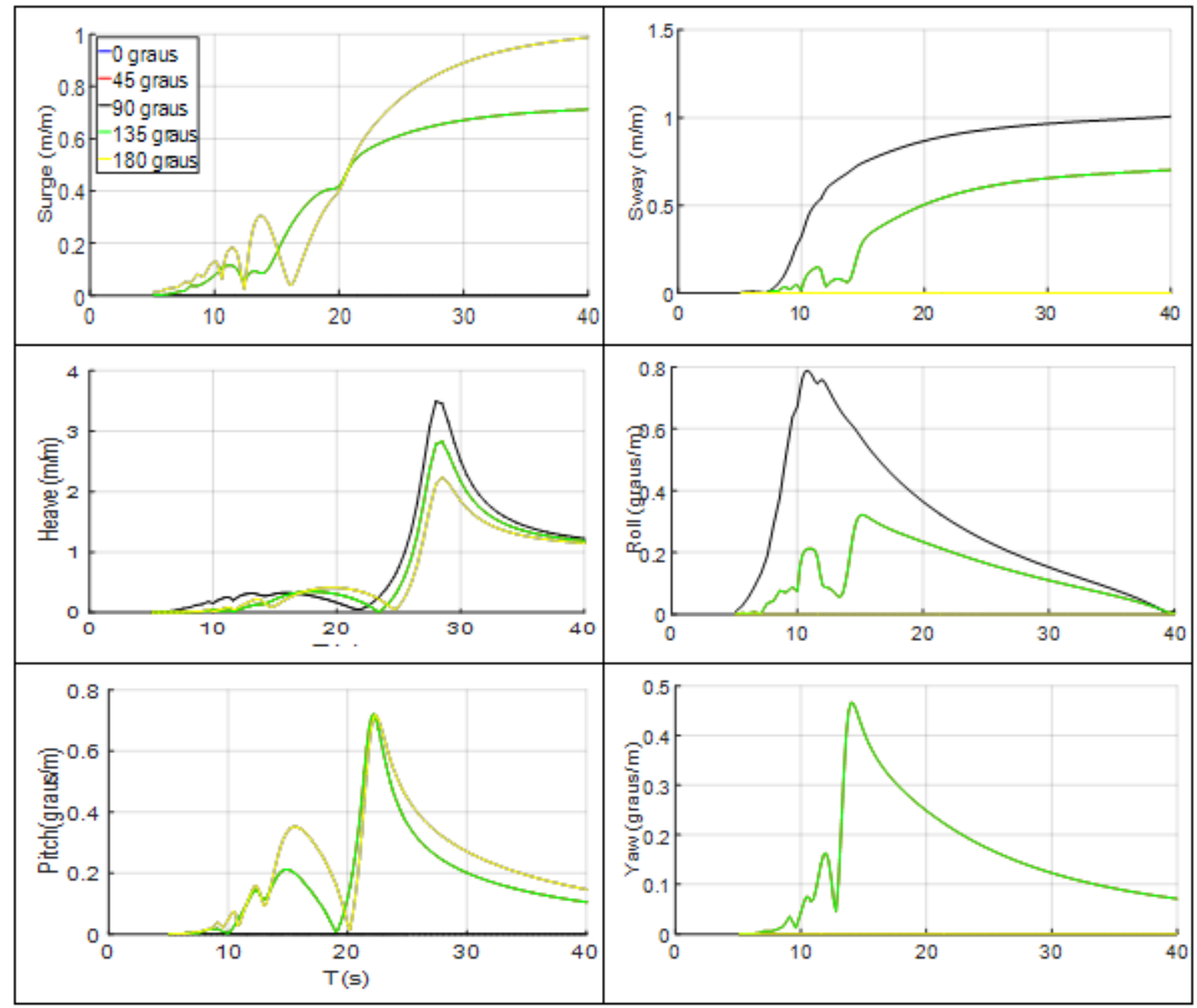

Figura 9-2 RAOs do modelo com Lid

FONTE: Elaborada pelo autor

\subsection{Comparação de geometrias}

Os modelos propostos para o ULFPSO (Vilamea, E. M., 2017) e a plataforma P55 (Blog MARANAUTA, 2015) serão utilizados para a comparação do desempenho em ondas da plataforma proposta.

A plataforma ULFPSO possui dimensões principais semelhantes ao modelo proposto e desta forma espera-se diferenças no comportamento hidrodinâmico apenas devido à forma do casco e do moonpool, para a qual a região da proa e da popa são arredondadas.

Um breve levantamento das características de cada plataforma é apresentado na Tabela 9-2 e Figura 9-3 para a P-55 e na Tabela 9-3 e Figura 9-4 para o ULFPSO. 


\begin{tabular}{|c|c|c|}
\hline Dimensão & Valor & Unidade \\
\hline Colunas & $19.8 \times 19.8$ & $\mathrm{~m}$ \\
\hline Pontoon & $54.7 \times 19.8 \times 11.4$ & $\mathrm{~m}$ \\
\hline Calado & 34 & $\mathrm{~m}$ \\
\hline Comprimento Total & 95 & $\mathrm{~m}$ \\
\hline Largura Total & 95 & $\mathrm{~m}$ \\
\hline Area Deck & 9025 & $\mathrm{~m}$ \\
\hline VCG & 24.07 & $\mathrm{~m}$ \\
\hline Deslocamento & 105800 & ton \\
\hline
\end{tabular}

Tabela 9-2 Dimensões da plataforma P55

FONTE: Elaborada pelo autor

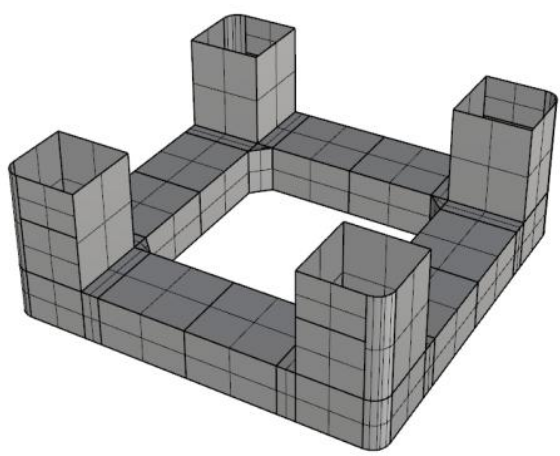

Figura 9-3 Geometria do casco submerso da plataforma P55

FONTE: Elaborada pelo autor 


\begin{tabular}{|c|c|c|c|}
\hline Parâmetro & Modelo Proposto & ULFPSO & Unidade \\
\hline $\mathrm{L}$ & 340 & 340 & $\mathrm{~m}$ \\
\hline $\mathrm{B}$ & 100 & 100 & $\mathrm{~m}$ \\
\hline $\mathrm{D}$ & 40 & 40 & $\mathrm{~m}$ \\
\hline$l_{\text {moonpool }}$ & 270 & 25 & $\mathrm{~m}$ \\
\hline$b_{\text {moonpool }}$ & 30 & 295 & $\mathrm{~m}$ \\
\hline $\mathrm{KG}$ & 18.3 & 55 & $\mathrm{~m}$ \\
\hline Deslocamento & 586.000 & 570.00 & ton \\
\hline
\end{tabular}

Tabela 9-3 Dimensões da plataforma ULFPSO e do modelo proposto

FONTE: Elaborada pelo autor

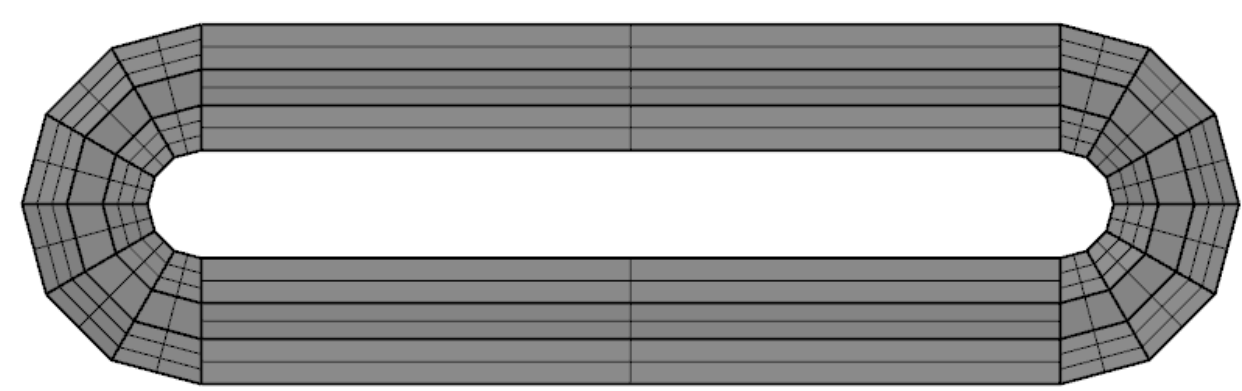

Figura 9-4 Vista superior da geometria do casco submerso da plataforma ULFPSO

FONTE: Elaborada pelo autor

A seguir são apresentados três estudos avaliando a influência da modificação da geometria por meio dos parâmetros definidos do ponto de vista estrutural, estabilidade e de comportamento em ondas.

\subsection{Avaliação Estrutural}

O comportamento estrutural foi estudado variando-se os parâmetros $L, B$ e b como apresentado na Tabela 14-3 no Anexo D. Neste estudo foi comparado a influência destes parâmetros no módulo da seção $Z$, momentos de alquebramento e tosamento e na variação do KG.

A Figura 9-5 e a Figura 9-6 mostra os resultados do módulo da seção $Z$ e os resultados do momento de alquebramento e tosamento para todos os casos descritos na Figura 4-4, acrescidos dos resultados obtidos para o modelo da plataforma ULFPSO. Na comparação apresentada é possível observar uma grande semelhança entre os valores obtidos, independente da configuração analisada. Os 
valores obtidos ficaram entre 1,0 E+02 e 1,5E+03 para o módulo de seção Z, entre 1,4 E+07 e 2,1E+07 para os módulos de alquebramento e entre 2,3E+07 e 3,0E+07 para os módulos de tosamento. A semelhança da ordem de grandeza com os valores da ULFPSO eram esperados devido à semelhança entre as geometrias das unidades de produção.

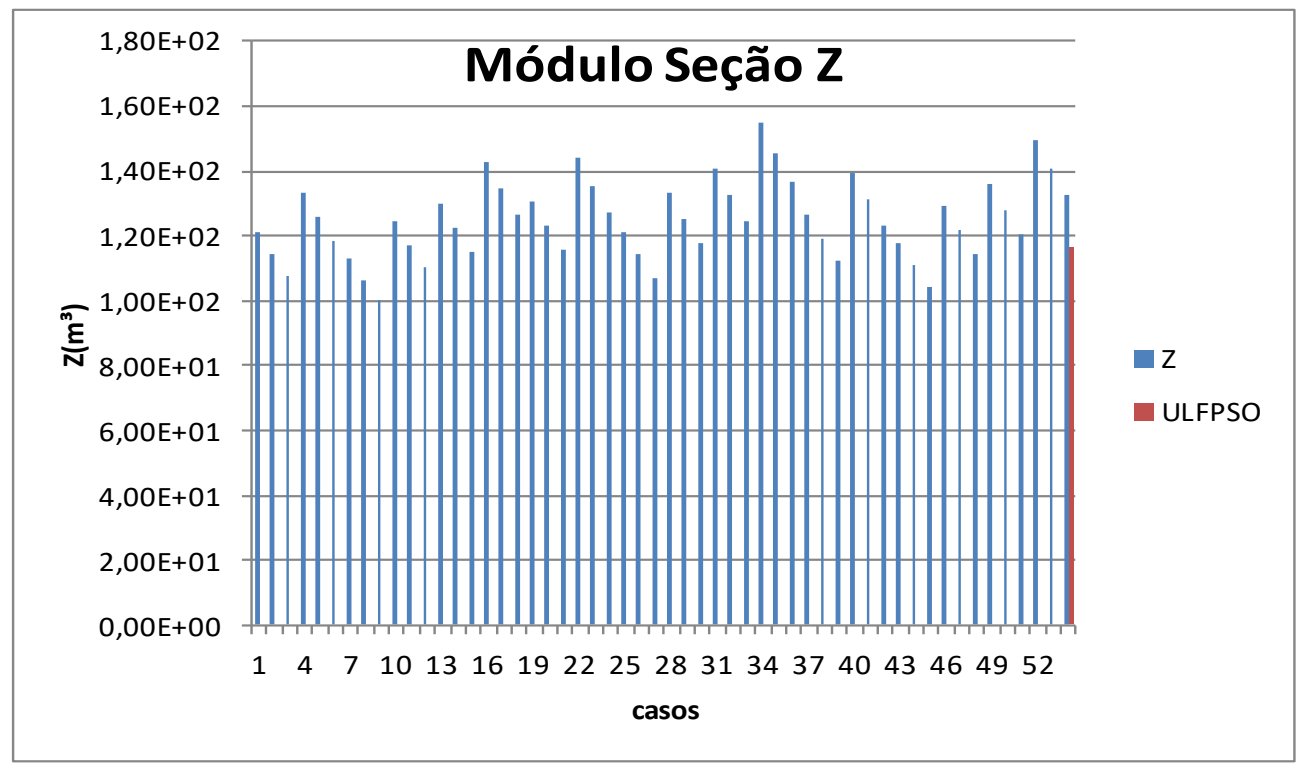

Figura 9-5 Comparação dos módulos de seção Z para cada configuração analisada.

FONTE: Elaborada pelo autor

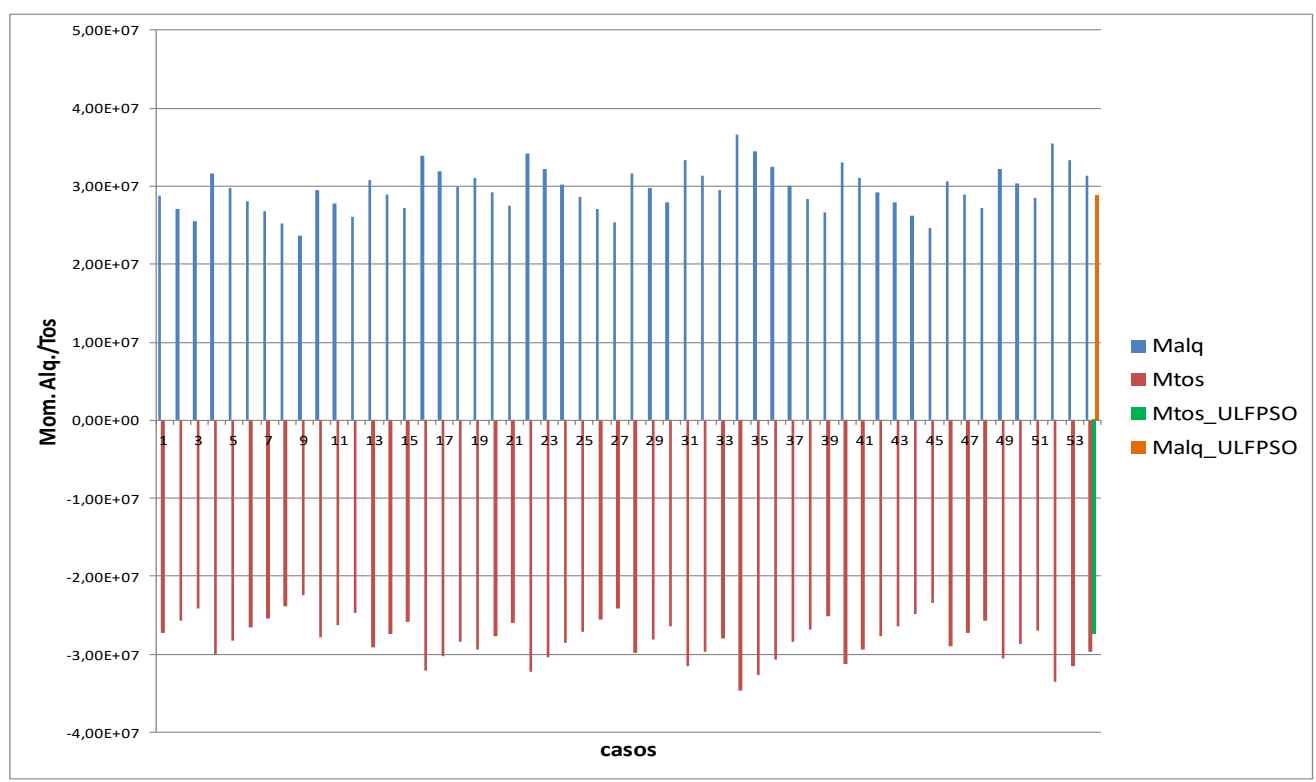

Figura 9-6 Comparação entre os momentos de tosamento e alquebramento para as diversas configurações analisadas.

FONTE: Elaborada pelo autor 
A Figura 9-7 a seguir mostra uma comparação feita entre a capacidade de armazenamento de óleo e os valores de KG obtidos para cada uma das geometrias apresentadas no Anexo D. Os gráficos da esquerda e da direita apresentam os resultados obtidos para os carregamentos de óleo de $50 \%$ e $100 \%$, respectivamente. Para efeitos de comparação, as geometrias foram agrupadas com um mesmo marcador em função do parâmetro $\beta$ que representa a redução na linha d'água.
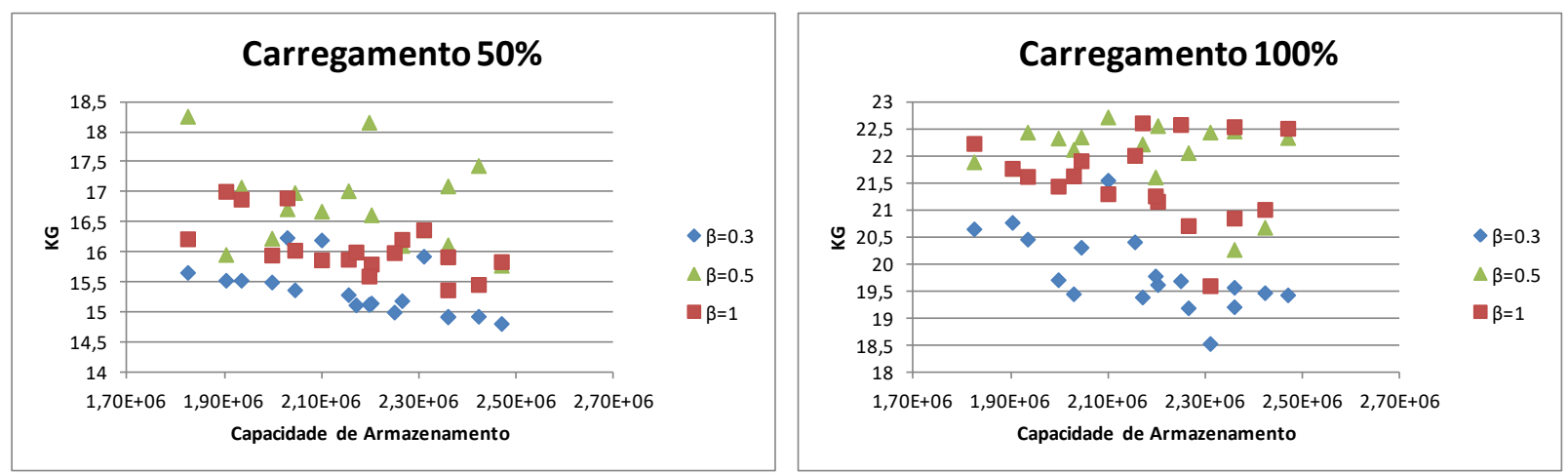

Figura 9-7 Comparação entre os valores de capacidade de armazenamento de óleo e de KG obtidos para cada configuração e para os dois carregamentos estudados: 50\% (esq.) e 100\% (dir.).

FONTE: Elaborado pelo autor

Esta comparação entre os parâmetros sugere que a variação do $K G$ depende do parâmetro $\beta$, pois, devido à redução na altura de linha d'água, plataformas com paredes de moonpool lisa ( $\beta$ próximo de 1) possuem o VCG da carga de óleo mais elevado do que plataformas $\operatorname{com} \beta$ pequeno.

\subsection{Avaliação de estabilidade}

De maneira semelhante ao estudo estrutural, a influência dos parâmetros $B$ e $b$ foram verificadas por meio de uma comparação das curvas de estabilidade GZ associadas a cada geometria. Dentre as 54 geometrias apresentadas no Anexo D, foram selecionadas apenas cinco geometrias representativas e a geometria ULFPSO devido a grande semelhança da curva GZ entre todas as 54 geometrias.

A Figura 9-8 mostra o cálculo da curva GZ entre as quatro geometrias com diferentes parâmetros de B e b conforme apresentado na Tabela 9-4. Devido a 
grande influência desse parâmetro no comportamento em ondas de roll da unidade, juntamente com o GZ são apresentadas as respectivas curvas de RAO de roll.

É observado que a redução dos parâmetros de dimensões transversais $\mathrm{B}$ e b aumenta a estabilidade e reduz o período natural de roll da plataforma como sublinhado na Figura 9-8. Ao mesmo tempo, como as unidades separadas na Tabela 9-4 possuem moonpool com as mesmas dimensões, nota-se que o período de ressonância da coluna d'água permaneceu o mesmo. A variação na amplitude do movimento é devida apenas à diferença de amortecimento potencial causado pelas modificações nos outros apêndices hidrodinâmicos.

\begin{tabular}{|c|c|c|c|c|c|}
\hline caso & L & B & b & GM & Tn \\
\hline 1 & 340 & 100 & 35 & 7.4 & 45 \\
\hline 4 & 340 & 110 & 35 & 9.2 & 40 \\
\hline 11 & 340 & 110 & 30 & 13.4 & 31.5 \\
\hline 13 & 340 & 100 & 40 & 3.5 & 51.3 \\
\hline 16 & 340 & 110 & 40 & 7.4 & 44 \\
\hline ULFPSO & 340 & 100 & 35 & 2.5 & 65 \\
\hline
\end{tabular}

Tabela 9-4 Geometrias para avaliação de estabilidade

FONTE: Elaborada pelo autor
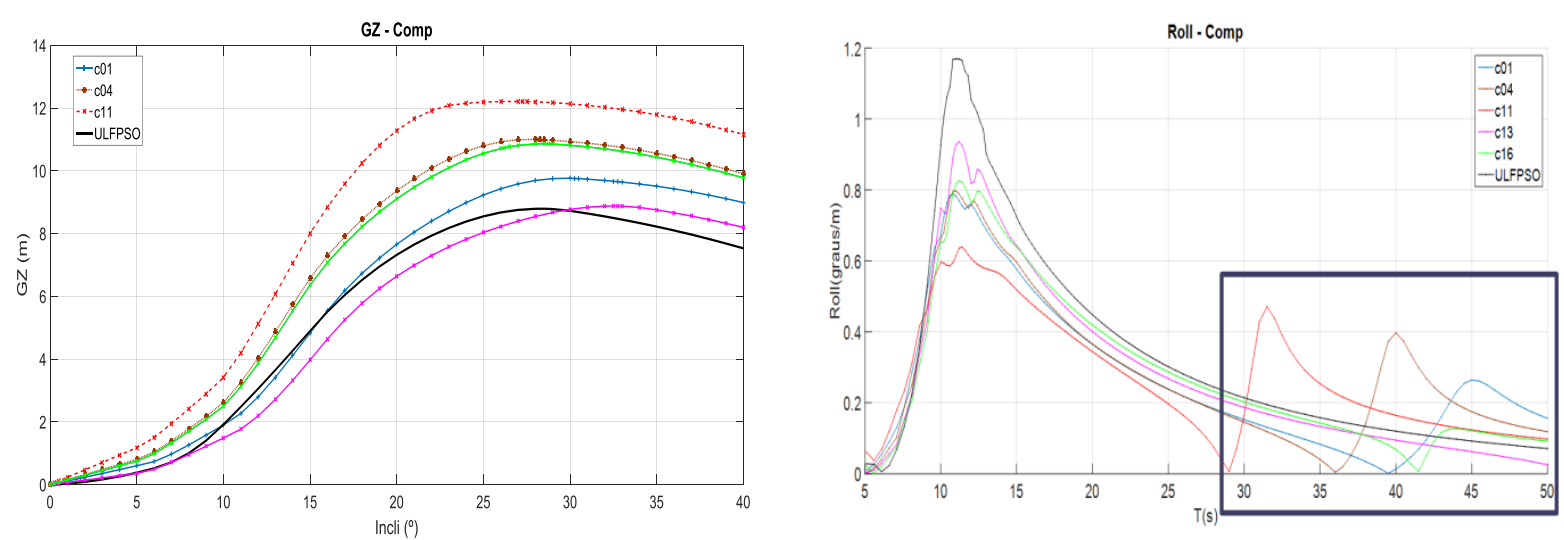

Figura 9-8 Avaliação do parâmetro B e b para a curva GZ e movimento de roll FONTE: Elaborada pelo autor 


\subsection{Avaliação comportamento em ondas}

A Figura 9-9 ilustra a comparação de RAO dos modelos ULFPSO, P55 e o modelo proposto, todos os modelos utilizaram um amortecimento externo de $2 \%$. Devido à semelhança de inércias, deslocamento e dimensões principais entre o modelo proposto e o modelo ULFPSO era esperado que ambos apresentassem comportamentos dinâmicos semelhantes. Entretanto, as diferenças de área de linha d'água alteram principalmente os períodos de heave da plataforma deixando-os mais próximas dos períodos da P55. Isto sugere que o parâmetro $\beta$ possui grande importância no caso de viabilidade de SCR's. Deste modo, maiores períodos são considerados desejáveis para o modelo proposto.

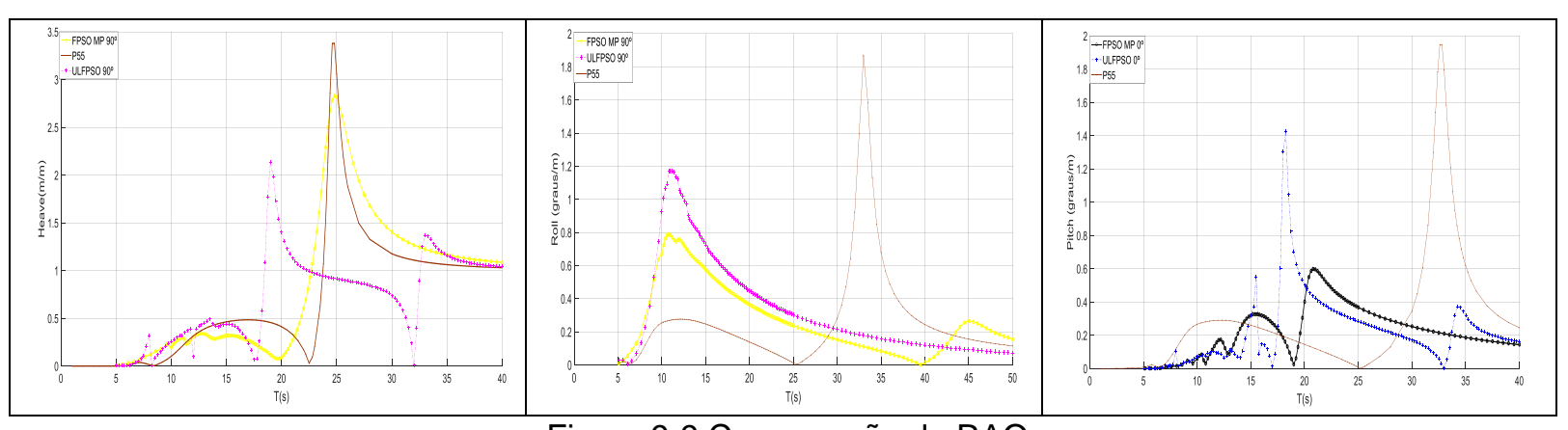

Figura 9-9 Comparação do RAO

FONTE: Elaborada pelo autor

No caso das plataformas ULFPSO e do modelo proposto, é notada uma faixa de energia com pico próximo de $12 \mathrm{~s}$ referente à elevação da coluna d'água. Este resultado era esperado devido às dimensões semelhantes do moonpool de cada plataforma.

Verifica-se que as faixas de energia de movimento do FPSO proposto estão distantes das faixas de energia típica da costa brasileira, atendendo assim um dos requisitos deste trabalho.

\subsection{Acelerações e movimentos}

Uma segunda abordagem foi feita para comparação dos movimentos angulares de pitch e roll devido as grandes diferenças das características geométricas e inerciais entre o conceito FPSO e semissubmersível.

As acelerações e movimentos nos pontos de conexão da plataforma com o sistema de risers foram definidos como critério de limite operacional como 
apresentado no Capítulo 3. A dinâmica do movimento do corpo nos pontos de conexão de riser foi avaliada tomando o n-ésimo momento espectral de resposta como é apresentado a seguir:

- Momento de ordem 0 - movimentos

- Momento de ordem 2 - velocidades

- Momento de ordem 4 - acelerações

O n-ésimo momento espectral é calculado pela equação (9-1), onde $R A O_{j}$ é o operador de amplitude de resposta no grau de liberdade j, e $S_{\zeta}(\omega)$ é o espectro de energia de ondas aqui considerado adotando-se a formulação do espectro Jonswap.

A resposta relativa aos pontos de interesse é calculada para o movimento nas direções $x, y$ e $z$, de modo que os operadores de amplitude de resposta na equação (9-1) são substituídos pelas equações (9-2), (9-3) e (9-4) de acordo com a direção analisada, onde $\left(X_{G}, Y_{G}, Z_{G}, \alpha, \beta, \gamma\right)$ correspondem aos movimentos de surge, sway, heave, roll, pitch e yaw, e $\left(x_{p}, y_{p}, z_{p}\right)$ a posição do centro de gravidade respectivamente.

$$
\begin{gathered}
m_{n, j}=\int_{0}^{\infty} \omega^{n} S_{\zeta}(\omega)\left|R A O_{j}(\omega)\right|^{2} d \omega \\
R A O_{p, x}(\omega)=X_{G}+\beta(\omega)\left(z_{p}-z_{G}\right)-\gamma(\omega)\left(y_{p}-y_{G}\right) \\
R A O_{p, y}(\omega)=Y_{G}+\gamma(\omega)\left(x_{p}-x_{G}\right)-\alpha(\omega)\left(z_{p}-z_{G}\right) \\
R A O_{p, z}(\omega)=Z_{G}+\alpha(\omega)\left(y_{p}-y_{G}\right)-\alpha(\omega)\left(x_{p}-x_{G}\right)
\end{gathered}
$$

O espectro de Jonswap $\left(S_{\zeta}\right)$ é definido pelas equações ( 9-5), (9-6), (9-7) e (9-8) em função da frequência de pico $\omega_{p}$ e da altura significativa de onda $H_{s}$. Neste trabalho foram utilizados espectros de Jonswap com diferentes períodos de pico Tp correspondente às condições ambientais da costa brasileira como apresentado na Figura 9-10. 


$$
\begin{array}{r}
S_{\zeta}(\omega)=\alpha H_{s}{ }^{2} \frac{\omega^{4}}{\omega^{5}} \exp \left(-\beta \frac{\omega_{p}{ }^{4}}{\omega^{4}}\right) \gamma^{a} \\
a=\exp \left(-\frac{\left(\omega_{p}-\omega\right)^{2}}{2 \omega_{p}^{2} \sigma^{2}}\right) \\
\sigma\left\{\begin{array}{l}
0.07, \text { se } \omega \leq \omega_{p} \\
0.09, \text { se } \omega>\omega_{p}
\end{array}\right. \\
\gamma=6.4 T_{p}^{-0.491}
\end{array}
$$

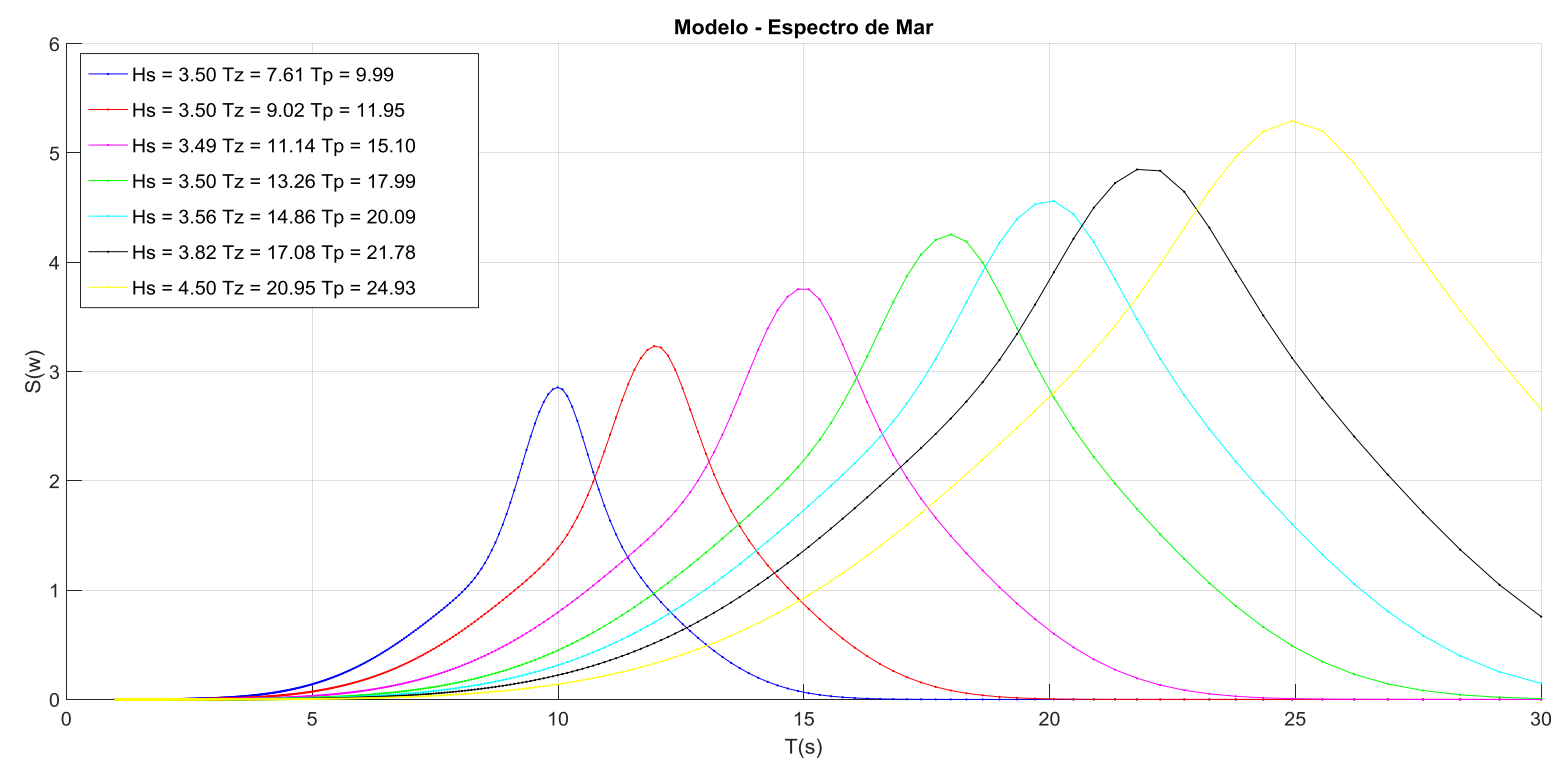

Figura 9-10 Espectro de mar

FONTE: Elaborada pelo autor

Escolheu-se a direção norte como referência para o aproamento da plataforma e a direção anti-horária para a direção de incidência de ondas por meio da equação (9-9), em que $\theta_{R A O}$ é o ângulo tomado dos RAOs calculados para as predições de comportamento em ondas, $\theta_{\text {plat }}$ é o aproamento da plataforma e $\theta_{\text {onda }}$ é a direção de onda, como mostra a Figura 9-11. 


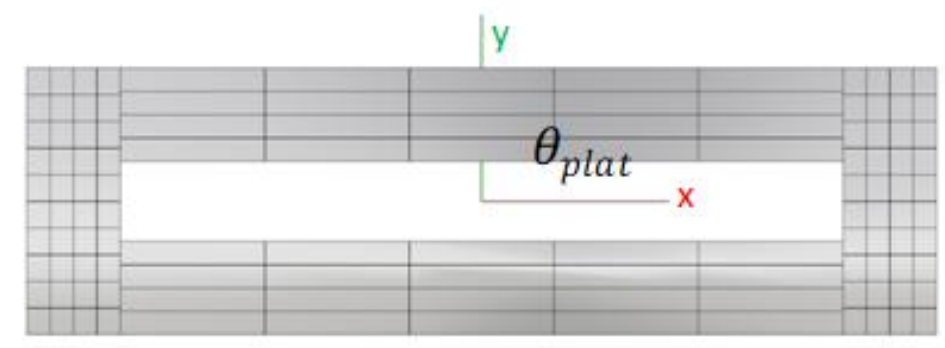

Figura 9-11 Aproamento e direção de ondas

FONTE: Elaborada pelo autor

$$
\theta_{R A O}=180^{\circ}+\theta_{\text {plat }}-\theta_{\text {wave }}
$$

\subsection{Movimento da coluna d'água}

A teoria matemática apresentada a seguir é obra de Aalbers, A.B., (1984). É possível derivar um modelo matemático que descreva os movimentos relativos em um moonpool localizado em um corpo flutuante a partir da teoria potencial e do equivalente dinâmico de fluido da lei de Newton. Neste modelo, os termos não lineares, por exemplo, aqueles devidos à expressão de Bernoulli para a pressão do fluido são desconsiderados na primeira abordagem. No entanto, no decorrer do estudo, alguns efeitos relacionados a essas não linearidades serão discutidas.

O modelo matemático, mais bem formalizado no Anexo A, é apresentado abaixo para servir de base para a discussão dos resultados da análise atual. Por simplicidade, assume-se que a origem do sistema de coordenadas (coincidindo com o centro de gravidade do corpo flutuante) está na linha central do moonpool, pois neste caso a interação com os movimentos de roll e pitch da embarcação pode ser desconsiderada como descrito em Aalbers, 1984.

O movimento relativo h no moonpool segue de:

$$
\begin{gathered}
\left\{\rho A\left(T+h+a_{h}\right\} \ddot{h}+b_{h} \dot{h}+b_{2} \dot{h}|\dot{h}|+\rho g A h+\right. \\
\left\{d_{h z}+\rho A(T+h)+a_{h}\right\} \ddot{z}+\left(e_{h z}+b_{h}\right) \dot{z}+\rho g A z+\text { termos high order }=F_{w h}
\end{gathered}
$$


Em que:

- $\mathrm{A}=$ área transversal do moonpool $\left(\mathrm{m}^{2}\right)$

- $\mathrm{T}$ = calado do moonpool(m)

- $\mathrm{h}=$ movimento relativo do moonpool $(\mathrm{m})$

- $\rho=$ massa específica da água $\left(\mathrm{kg} / \mathrm{m}^{3}\right)$

- $a_{h}=$ coeficiente de massa adicional da teoria potencial $(\mathrm{kg})$

- $b_{h}=$ coeficiente de amortecimento da teoria potencial (kgs)

- $b_{2}=$ coeficiente de amortecimento quadrático $\left(\mathrm{kgm}^{2}\right)$

- $g$ = aceleração da gravidade $\left(\mathrm{m} / \mathrm{s}^{2}\right)$

- $d_{h z}=$ coeficiente de massa adicional do heave (da teoria potencial)

- $e_{h z}=$ coeficiente de iteração do amortecimento (kgs)

- $\quad \mathrm{z}=$ movimento de heave da plataforma

- $\quad F_{w h}=$ força de excitação em ondas do movimento relativo a $\mathrm{h}(\mathrm{N})$

Na Equação 9-10, a primeira linha descreve os aspectos hidrodinâmicos da coluna d'água do moonpool, relacionado com o movimento relativo $h$. A segunda linha descreve a interação com o movimento de movimentação do FPSO relacionado ao movimento $z$.

$\mathrm{Na}$ teoria potencial, as equações são derivadas em um sistema de coordenadas fixas em terra, no qual o movimento absoluto da coluna de água do moonpool é levado em consideração. Para este caso, o movimento absoluto é a soma do movimento da plataforma e o movimento relativo d'água do moonpool, o que explica a presença dos coeficientes característicos do moonpool $\rho(\mathrm{T}+\mathrm{h}), a_{h} \mathrm{e}$ $b_{h}$ na a segunda linha da Equação 9-10. Assim, os coeficientes $a_{h}, b_{h}$ e $d_{h z}$ e $e_{h z}$ aplicam-se à descrição da teoria potencial em um sistema de coordenadas fixas em terra.

Ou seja, quando a plataforma se está sob uma determinada incidência de ondas, a distribuição da pressão ao redor do casco varia devido à ação das ondas, à reflexão das ondas e à reação hidrodinâmica aos movimentos do casco. A coluna de água dentro do moonpool é excitada por estas variações de pressão e, à medida que ela oscila, experimenta a reação hidrodinâmica nos seus movimentos. As flutuações de pressão devido aos movimentos da plataforma também causam uma 
força excitante na coluna de água do moonpool, denotada como uma força de interação.

Além dos mecanismos de excitação mencionados anteriormente, que são de caráter linear. Estas excitações em segunda ordem podem ser observadas em ensaios experimentais apenas sugerindo que a sua origem é não linear. A Figura 9-12 apresenta uma série temporal do movimento relativo referente à coluna d'água interior ao moonpool e de uma onda irregular na qual as frequências de ondas eram inferiores à frequência de ressonância do moonpool, mas incluíam uma componente de onda com metade da frequência de ressonância. Estes efeitos de segunda ordem relacionados a componentes de onda com altas frequências estão descritos em PINKSTER (1980) com estudos de segunda ordem em oscilações com moonpool. Este fenômeno não será investigado a fundo neste trabalho, porém, este tema é interessante para um possível trabalho futuro.
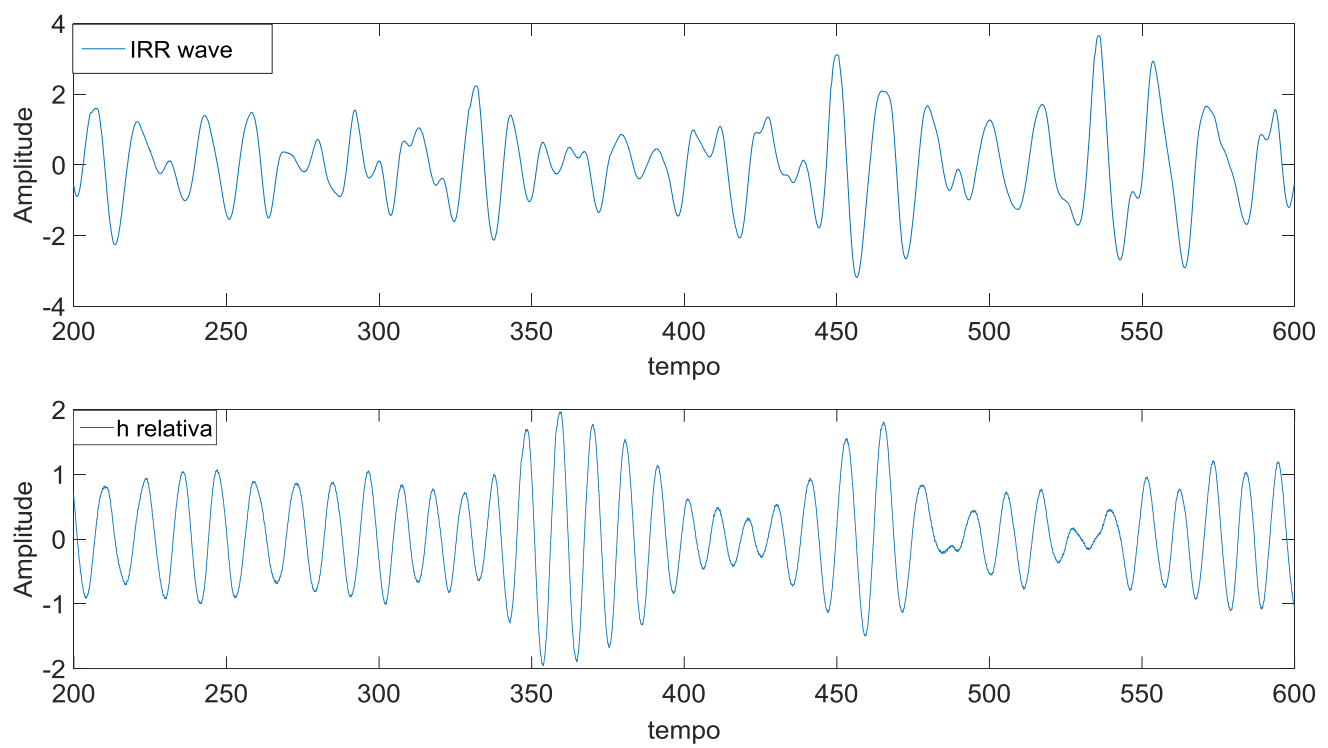

Figura 9-12 Série temporal de onda IRR, $T p=10$ s e elevação relativa da coluna d'água FONTE: Elaborada pelo autor

A avaliação numérica da elevação da coluna d'água foi feita a partir do cálculo do campo de pressão de pontos da superfície livre do moonpool novamente utilizando o software WAMIT. Foi construída uma malha de pontos na superfície livre tanto na região interna do FPSO quanto na região externa em águas próximas à plataforma. Para avaliar cada ponto, são definidas as cotas $x$ e y de cada ponto como apresentado na Figura 9-13. 

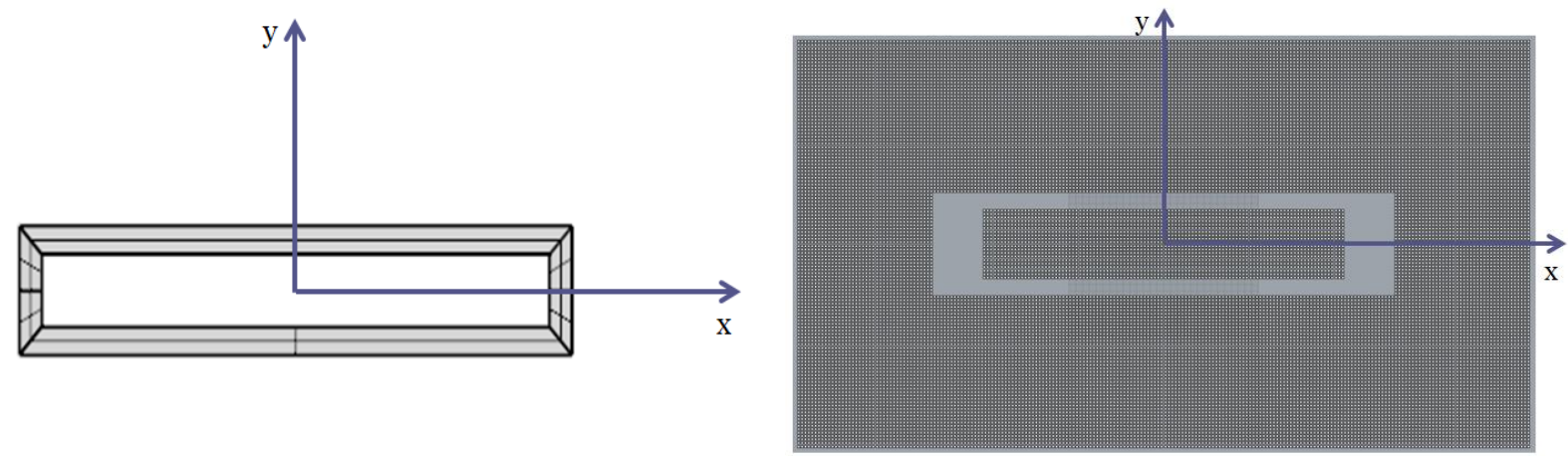

Figura 9-13 Vista superior da malha de pontos para o cálculo da elevação da superfície FONTE: Elaborada pelo autor

Os resultados para incidência de $180^{\circ}, 135^{\circ}$ e $270^{\circ}$ para a cota y de $35 \mathrm{~m}$ são apresentados a seguir na Figura 9-14, Figura 9-15 e Figura 9-16, respectivamente.
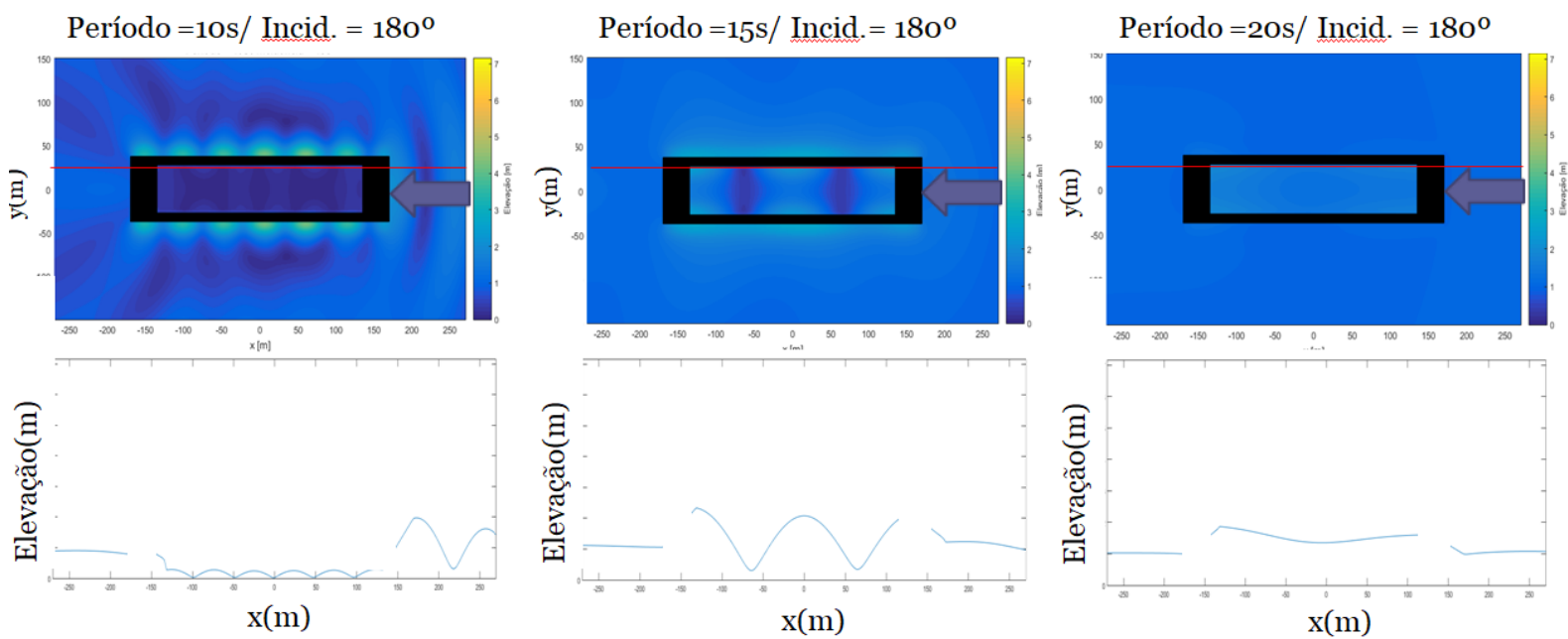

Figura 9-14 Elevação da coluna d'água $T=12 \mathrm{~s}$

FONTE: Elaborada pelo autor 

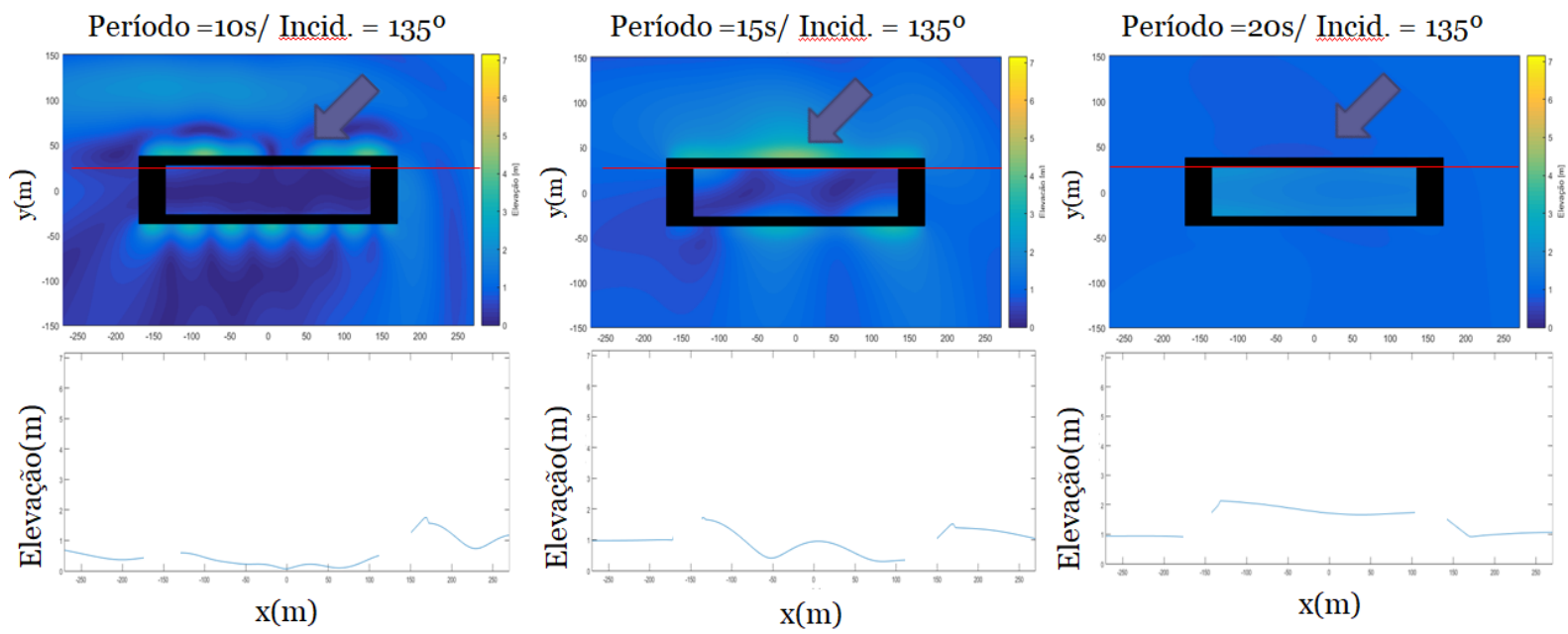

Figura 9-15 Elevação da coluna d'água $T=15 \mathrm{~s}$

FONTE: Elaborada pelo autor
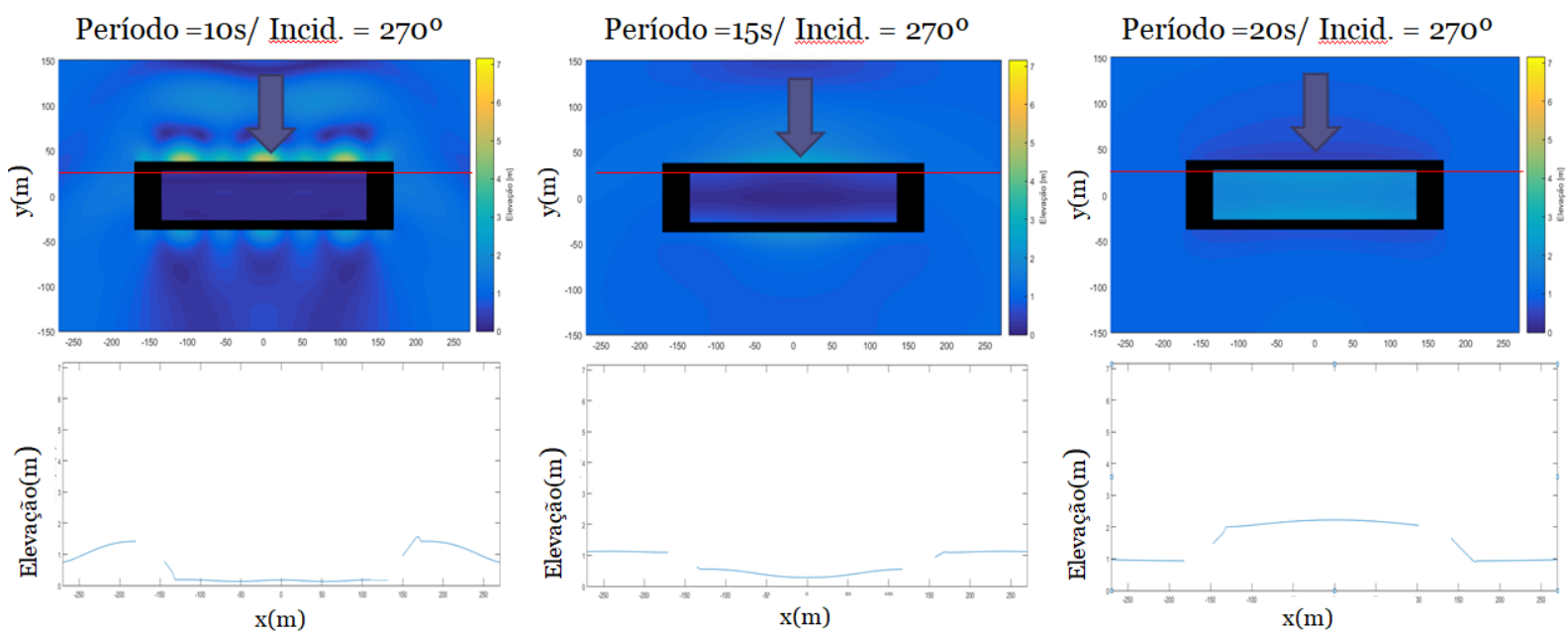

Figura 9-16 Elevação da coluna d'água $\mathrm{T}=20 \mathrm{~s}$

FONTE: Elaborada pelo autor

Os resultados apresentados mostram que podem ocorrer amplificações de até duas vezes a altura da onda incidente dependendo do período de ressonância do moonpool e do ângulo de incidência. Considerando que a borda livre da plataforma proposta é de 15 metros, não é esperado transbordo da água (green water) interna para o convés.

Nas condições de incidência de onda de $180^{\circ}$ é notado uma oscilação da elevação de onda em períodos próximos de $15 \mathrm{~s}$ devido ao período de ressonância da coluna d'água interna da plataforma. 
Do ponto de vista de projeto é interessante minimizar o efeito causado por estas amplificações de onda para evitar danos à bancada de risers e outros equipamentos posicionados dentro ou próximos do moonpool. Assim, estes resultados podem auxiliar na definição do sistema de amarração da plataforma e no posicionamento de equipamentos no convés do FPSO.

\subsection{Movimento da plataforma}

Para verificar se os movimentos da geometria proposta foram feitas comparações entre as curvas de STR (Short Term Response), ou seja, em termos da resposta de movimento por uma altura unitária em mar irregular. Os movimentos de heave, roll e pitch são apresentados a seguir nas figuras a seguir:

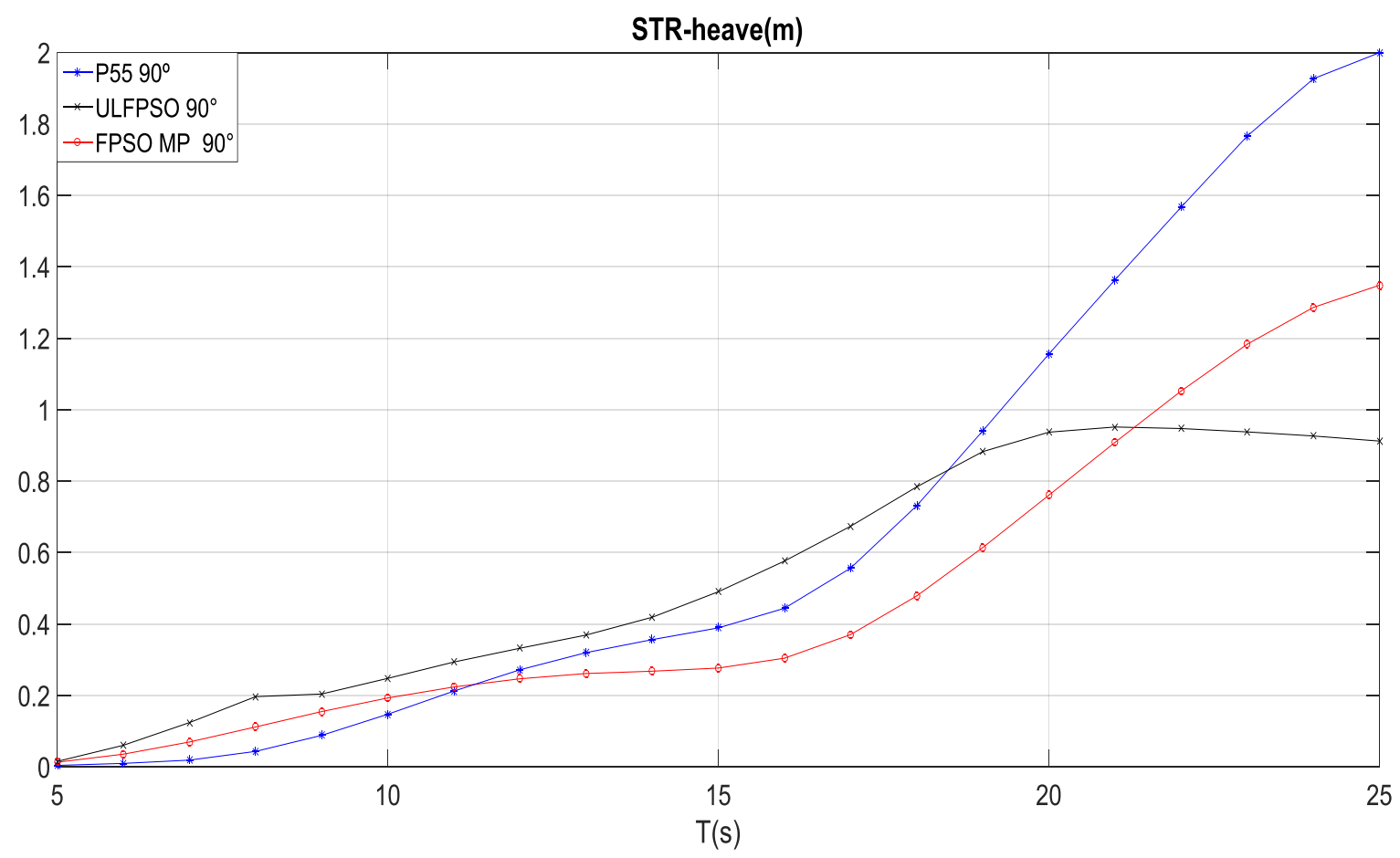

Figura 9-17 Comparação STR heave

FONTE: Elaborada pelo autor 


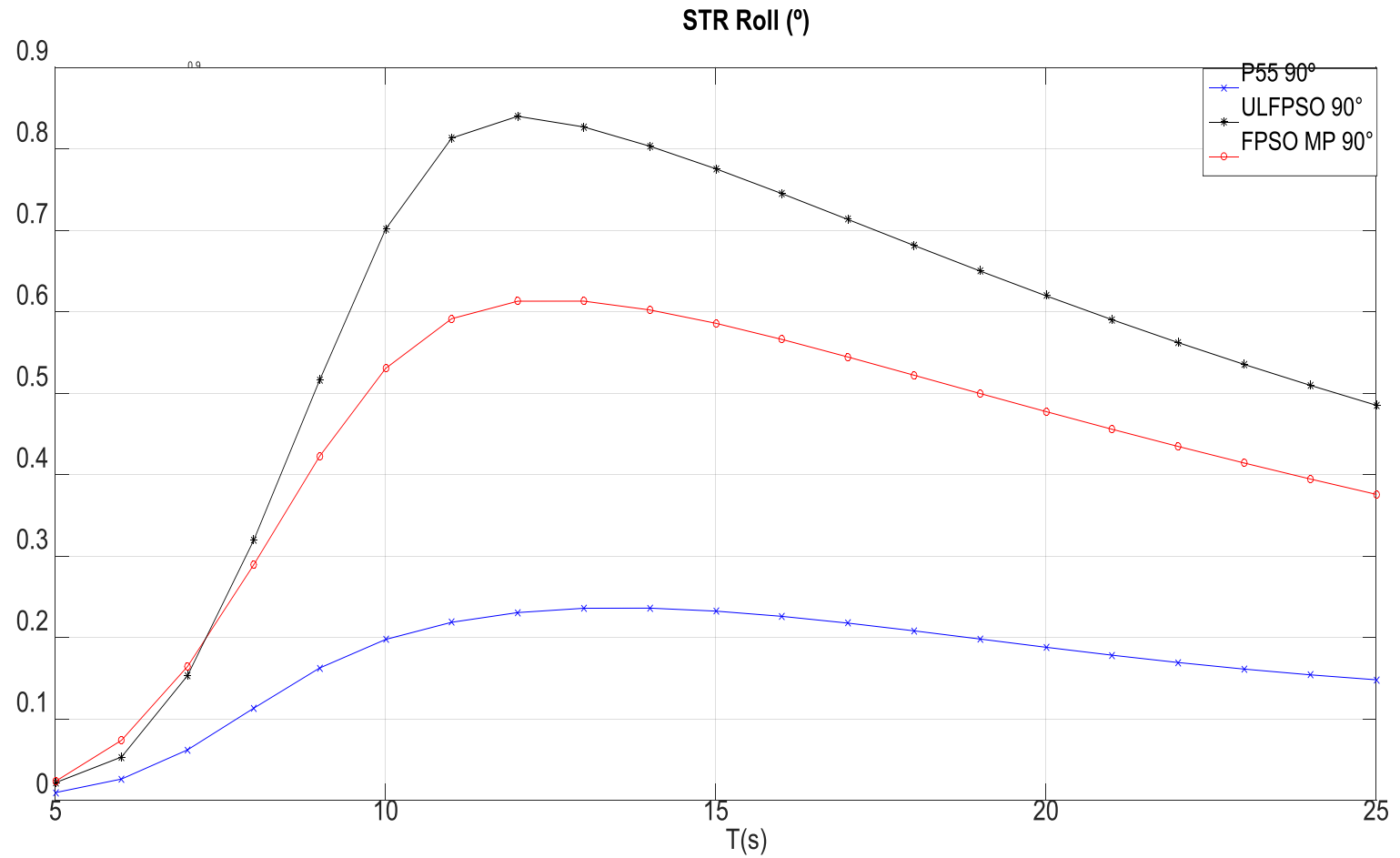

Figura 9-18 Comparação STR roll

FONTE: Elaborada pelo autor

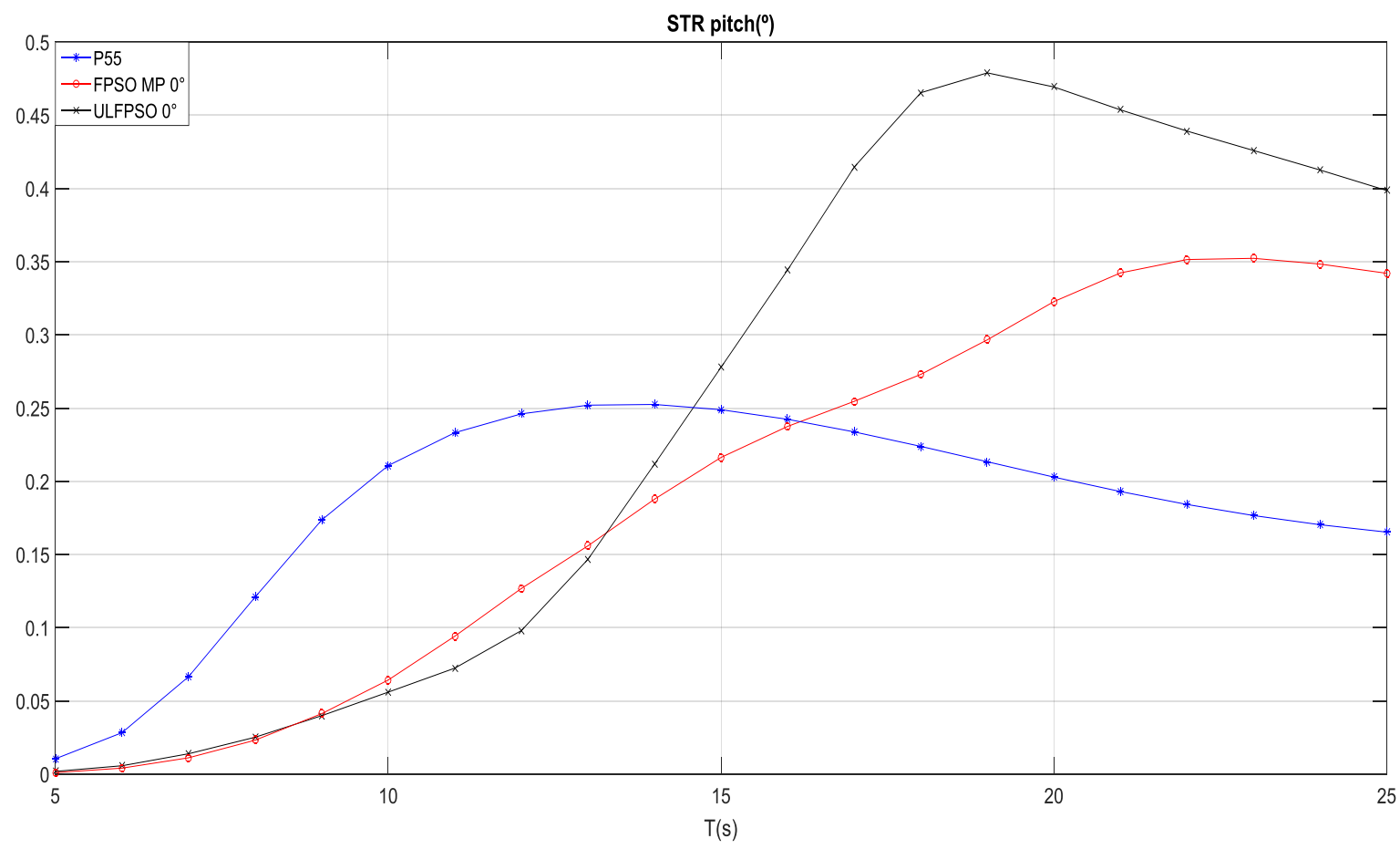

Figura 9-19 Comparação STR pitch

FONTE: Elaborada pelo autor 
Nota-se que os movimentos apresentam valores similares, o que indica que os conceitos propostos apresentam comportamentos similares ao da semissubmersível em relação ao uso de SCRs.

É importante notar que do ponto de vista de projeto ainda existem verificações do método de operação com risers rígidos, em especial ao sistema de pull in, pois uma vez que o sistema de risers encontra-se dentro do moonpool é necessário proteger os pontos de conexão de possíveis colisões, reduzir a distância ao centro da plataforma, reduzindo também os movimentos verticais na posição das conexões. Estas alterações devem causar alterações na planta de processo, uma vez que a posição dos risers também será alterada. A escolha de utilizar risers em ambos os lados internos do moonpool ou apenas um lado também resulta em diferentes arranjos submarinos com oportunidades de redução de custos da tubulação.

\subsection{Avaliação da aceleração vertical e disponibilidade de operação}

As acelerações nos pontos de conexão de riser foram feitas utilizando 0 equacionamento apresentado anteriormente. Foram definidos seis pontos distribuídos simetricamente na plataforma como descrito na Figura 9-20 e na Tabela 9-5.

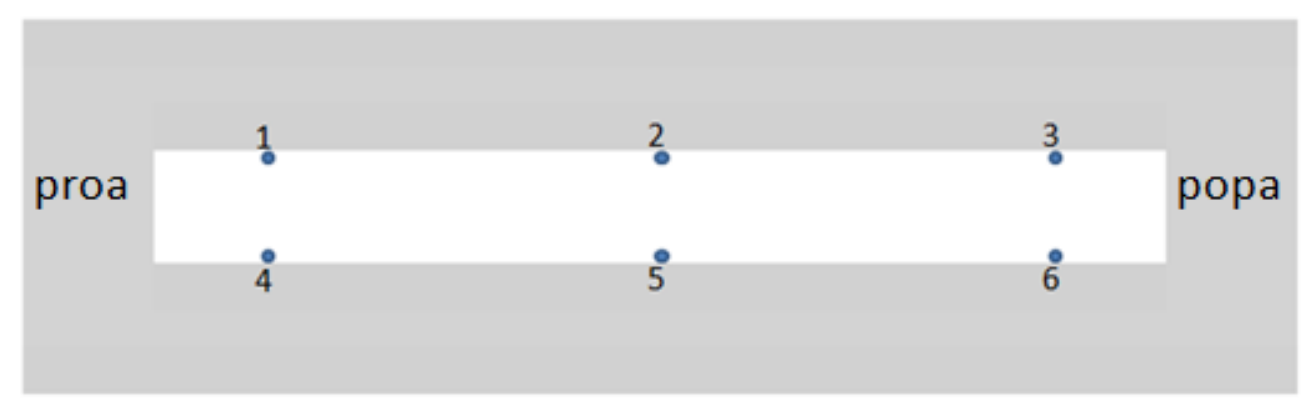

Figura 9-20 Posição dos pontos de medição - Vista de topo

FONTE: Elaborada pelo autor 


\begin{tabular}{|c|c|c|c|}
\hline & $\mathrm{X}$ & $\mathrm{Y}$ & $\mathrm{Z}$ \\
\hline $\mathrm{P} 1$ & -80 & $-\mathrm{B} / 2+\mathrm{b}$ & $-\mathrm{VCG}$ \\
\hline $\mathrm{P} 2$ & 0 & $-\mathrm{B} / 2+\mathrm{b}$ & $-\mathrm{VCG}$ \\
\hline $\mathrm{P} 3$ & 80 & $-\mathrm{B} / 2+\mathrm{b}$ & $-\mathrm{VCG}$ \\
\hline P4 & -80 & $-\mathrm{B} / 2-\mathrm{b}$ & - VCG \\
\hline P5 & 0 & $-\mathrm{B} / 2-\mathrm{b}$ & - VCG \\
\hline P6 & 80 & $-\mathrm{B} / 2-\mathrm{b}$ & -VCG \\
\hline
\end{tabular}

Tabela 9-5 Posição dos pontos de medição

FONTE: Elaborada pelo autor

Fixando o ângulo da plataforma $\theta_{\text {plat }}=0$ para a direção norte e variando o ângulo de incindência de ondas $\theta_{\text {wave }}$, foram calculadas as acelerações verticais máximas considerando os tanques de carga 100\% carregados nas incidências de onda de $0^{\circ}, 135^{\circ}$ e $90^{\circ}$ respectivamente como mostra na Figura 9-21, Figura 9-22 e Figura 9-23 respectivamente. Os demais ângulos de incidência podem ser observados no Anexo C.

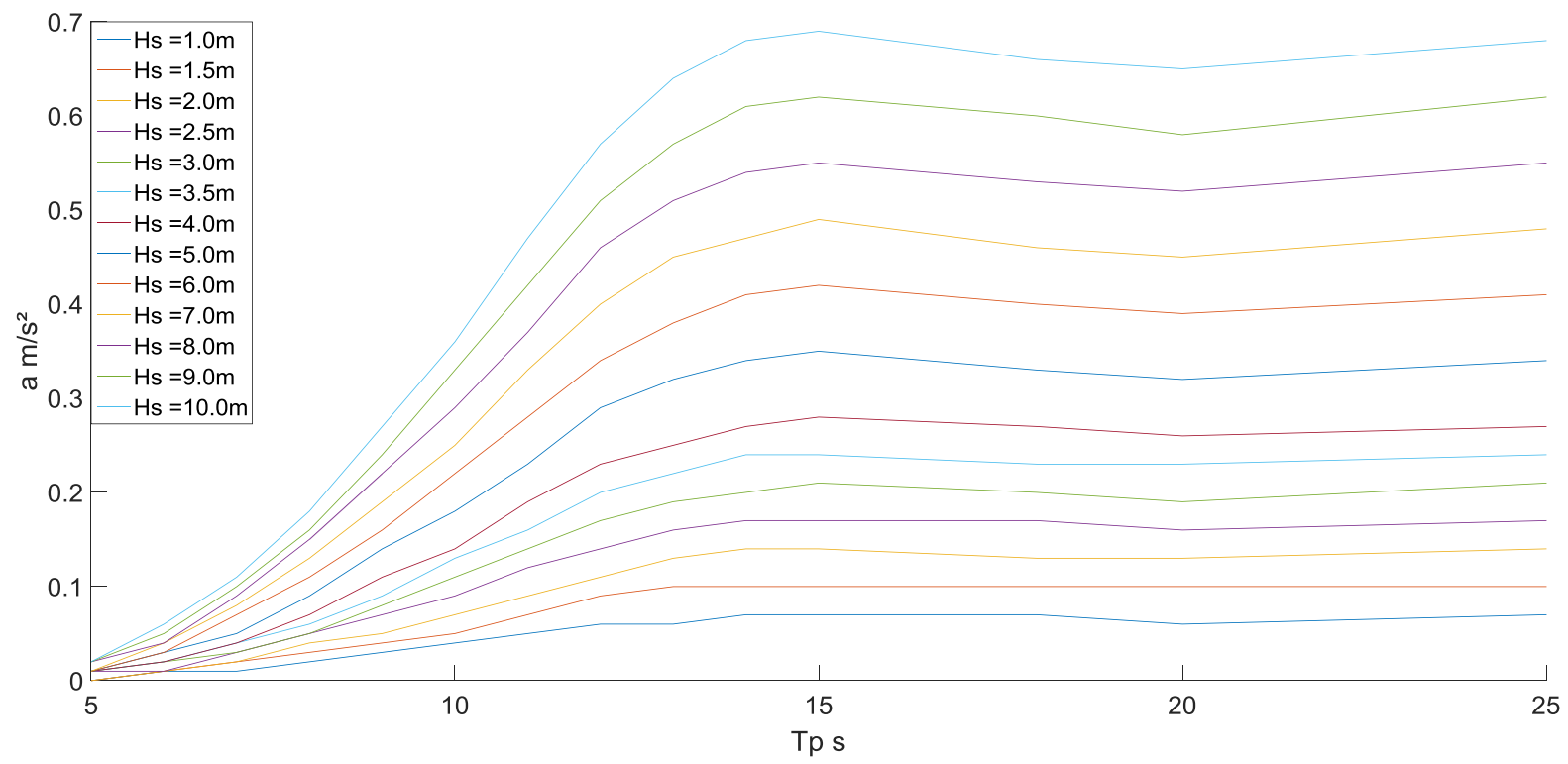

Figura 9-21 Acelerações verticais máximas - Incidência $0^{\circ}$

FONTE: Elaborada pelo autor 


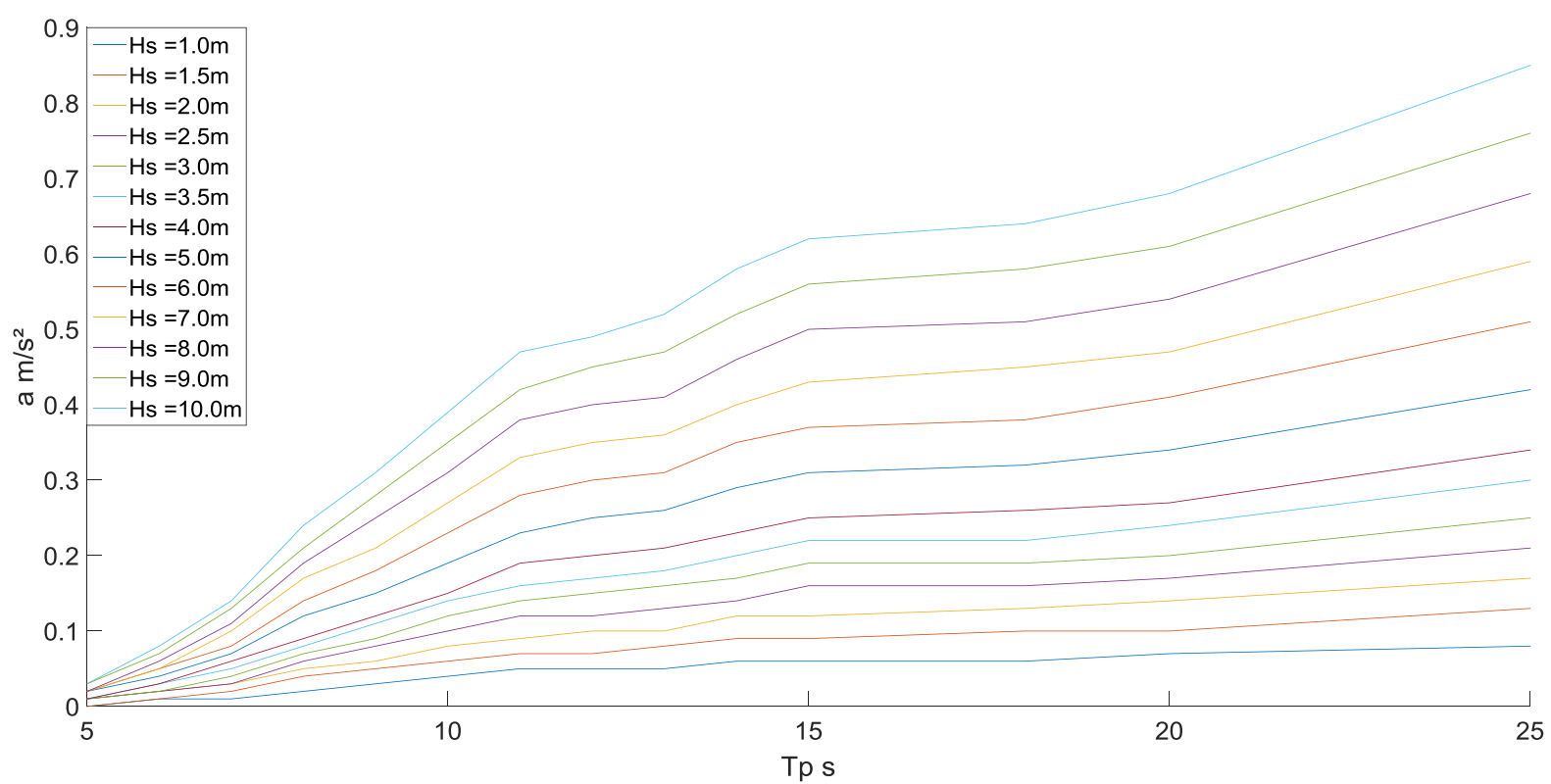

Figura 9-22 Acelerações verticais máximas - Incidência $135^{\circ}$

FONTE: Elaborada pelo autor

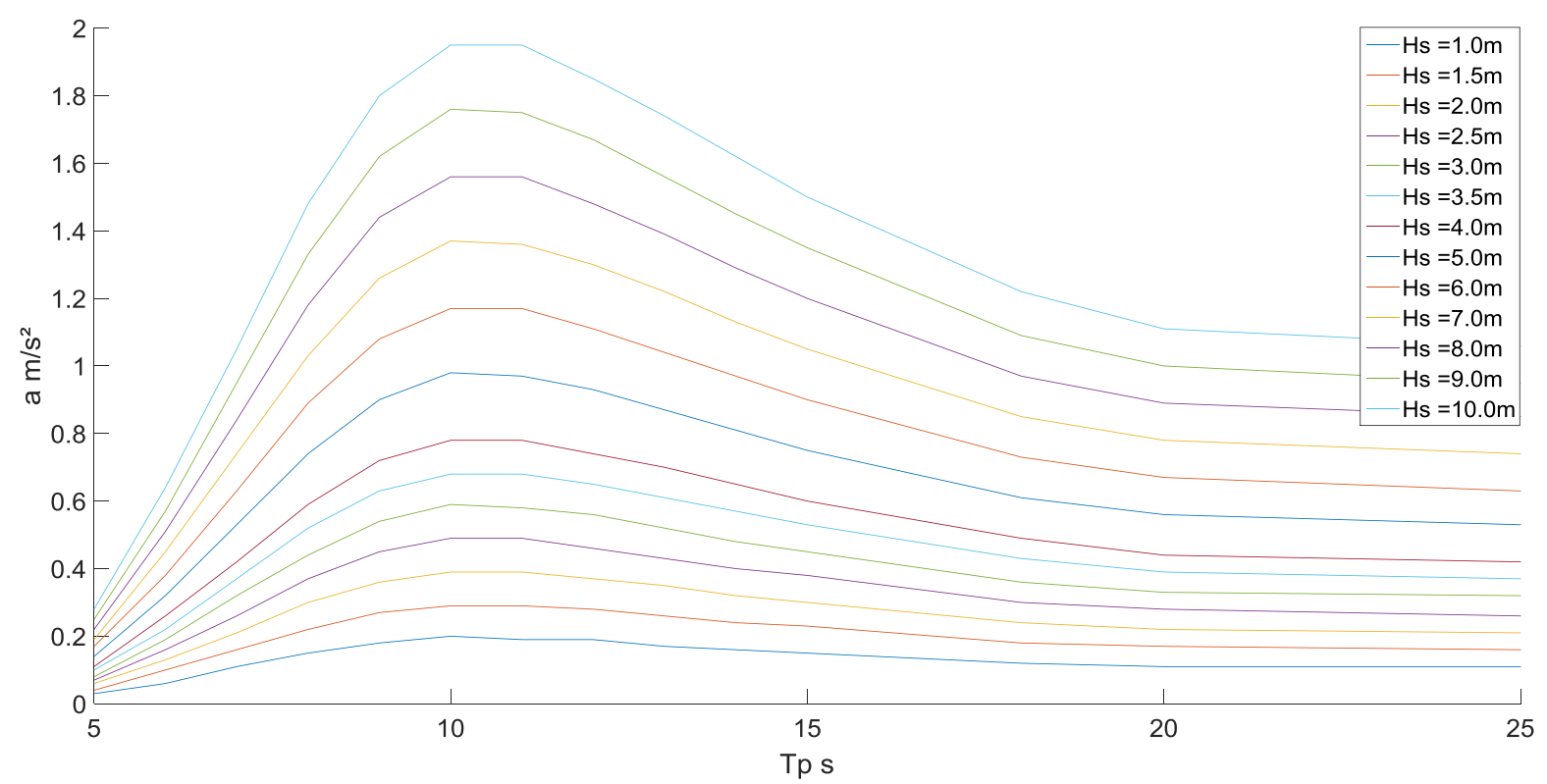

Figura 9-23 Acelerações verticais máximas - Incidência $270^{\circ}$

FONTE: Elaborada pelo autor

A análise dos gráficos sugere que ondas de través são as mais perigosas para a operação da plataforma. Como era esperado, o movimento de roll possui grande influência nos movimentos da plataforma principalmente na faixa de períodos de $10 \mathrm{~s}$ a $15 \mathrm{~s}$. Em ondas com incidência de $90^{\circ}$, as acelerações verticais podem danificar os equipamentos instalados na plataforma. 
Os resultados sugerem que acelerações superiores a $0.8 \mathrm{~m} / \mathrm{s}^{2}$ ocorrem apenas na condição de través na faixa de períodos de 10 s à $15 \mathrm{~s}$ com alturas significativas superior a seis metros.

Desta forma, uma avaliação de downtime, isto é, uma avaliação do tempo em que a plataforma não é capaz de operar pode ser interessante para o estudo de viabilidade do projeto. Para esta avaliação utilizou-se as condições ambientais (Hs e Tp) para a Bacia de Santos medidas durante um ano descritas em VOGEL et al (2010). A tabela a seguir denota as condições ambientais (Hs e Tp) encontradas.

\begin{tabular}{|c|c|c|c|c|c|c|c|c|c|c|c|c|c|}
\hline \multirow[b]{2}{*}{$\mathrm{Hs}(\mathrm{m})$} & & \multicolumn{12}{|c|}{$\mathrm{Tp}(\mathrm{s})$} \\
\hline & & 5 & 6 & 7 & 8 & 9 & 10 & 11 & 12 & 13 & 14 & 15 & $>15$ \\
\hline 1 & I & $0,10 \%$ & $0,40 \%$ & $0,30 \%$ & $0,40 \%$ & $0,70 \%$ & $0,10 \%$ & $0,10 \%$ & $0,10 \%$ & $0,10 \%$ & $0,10 \%$ & $0,10 \%$ & $0,05 \%$ \\
\hline 1,5 & I & $0,20 \%$ & $0,70 \%$ & $0,40 \%$ & $1,50 \%$ & $1,10 \%$ & $0,30 \%$ & $0,30 \%$ & $0,30 \%$ & $0,60 \%$ & $0,60 \%$ & $0,20 \%$ & $0,05 \%$ \\
\hline 2 & I & $0,30 \%$ & $1,20 \%$ & $2,80 \%$ & $3,20 \%$ & $1,40 \%$ & $1,10 \%$ & $1,10 \%$ & $1,20 \%$ & $1,30 \%$ & $0,70 \%$ & $0,30 \%$ & $0,05 \%$ \\
\hline 2,5 & I & $0,40 \%$ & $1,70 \%$ & $6,60 \%$ & $3,20 \%$ & $3,60 \%$ & $2,70 \%$ & $2,50 \%$ & $2,40 \%$ & $1,30 \%$ & $0,70 \%$ & $0,40 \%$ & $0,05 \%$ \\
\hline 3 & 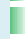 & $0,50 \%$ & $4,70 \%$ & $4,50 \%$ & $6,00 \%$ & $7,90 \%$ & $3,90 \%$ & $2,10 \%$ & $1,30 \%$ & $0,70 \%$ & $0,70 \%$ & $0,70 \%$ & $0,05 \%$ \\
\hline 3,5 & 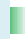 & $0,50 \%$ & $1,50 \%$ & $2,40 \%$ & $4,80 \%$ & $3,20 \%$ & $0,80 \%$ & $0,50 \%$ & $0,30 \%$ & $0,30 \%$ & $0,30 \%$ & $0,30 \%$ & $0,05 \%$ \\
\hline 4 & I & $0,01 \%$ & $0,01 \% \|$ & $0,01 \%$ & $0,01 \%$ & $0,01 \%$ & $0,30 \%$ & $0,10 \%$ & $0,20 \%$ & $0,10 \%$ & $0,10 \%$ & $0,15 \%$ & $0,05 \%$ \\
\hline 5 & I & $0,01 \%$ & $0,01 \% \|$ & $0,01 \%$ & $0,01 \%$ & $0,01 \%$ & $0,01 \%$ & $0,01 \%$ & $0,30 \%$ & $0,10 \%$ & $0,10 \%$ & $0,10 \%$ & $0,05 \%$ \\
\hline$>5$ & I & $0,01 \% \|$ & $0,01 \% \|$ & $0,01 \%$ & $0,01 \%$ & $0,01 \%$ & $0,01 \%$ & $0,01 \%$ & $0,20 \%$ & $0,10 \%$ & $0,10 \%$ & $0,10 \%$ & $0,05 \%$ \\
\hline
\end{tabular}

Tabela 9-6 Probabilidade de ocorrência de mar

FONTE: VOGEL et al (2010)

Nota-se que o período de onda típico da região varia entre $5 \mathrm{~s}$ a $13 \mathrm{~s}$ com ondas de períodos superiores a $15 \mathrm{~s}$ sendo eventos raros. De maneira similar, a altura significativa típica da região encontra-se na faixa de $1 \mathrm{~m}$ até $4 \mathrm{~m}$. Comparando os gráficos obtidos pelas Figura 9-21, Figura 9-22 e Figura 9-23 com as condições descritas na Tabela 9-6 verifica-se que as restrições de acelerações verticais inferiores a $0.8 \mathrm{~m} / \mathrm{s}^{2}$ são atendidas em toda faixa de ondas típica. Acelerações verticais superiores a $0.8 \mathrm{~m} / \mathrm{s}^{2}$ são encontradas apenas no caso de través $\left(90^{\circ}\right)$ em ondas com Hs superior a $5 \mathrm{~m}$. Considera-se assim que o downtime da plataforma devido às acelerações verticais nas conexões de riser é inferior a 1\% considerando incidências de ondas equiprováveis.

É importante ressaltar que estas probabilidades de ondas foram calculadas levando-se em conta a média de medições feitas durante o período de um ano. Desta forma, existe uma variação das condições de mar devido às alterações de ventos e correnteza pelas estações do ano. Como o objetivo desta análise é verificar a tendência central da distribuição probabilística de condições ambientais para a 
plataforma em todo o seu período de operação, foi utilizado o uso da média das distribuições de cada estação do ano.

Com o objetivo de comparar os resultados obtidos com o de outras soluções, a mesma metodologia foi então aplicada para as geometrias ULFPSO e da P55 para efeitos de comparação. A Figura 9-24, Figura 9-25 e Figura 9-26 Figura 9-27 apresentam os resultados obtidos:

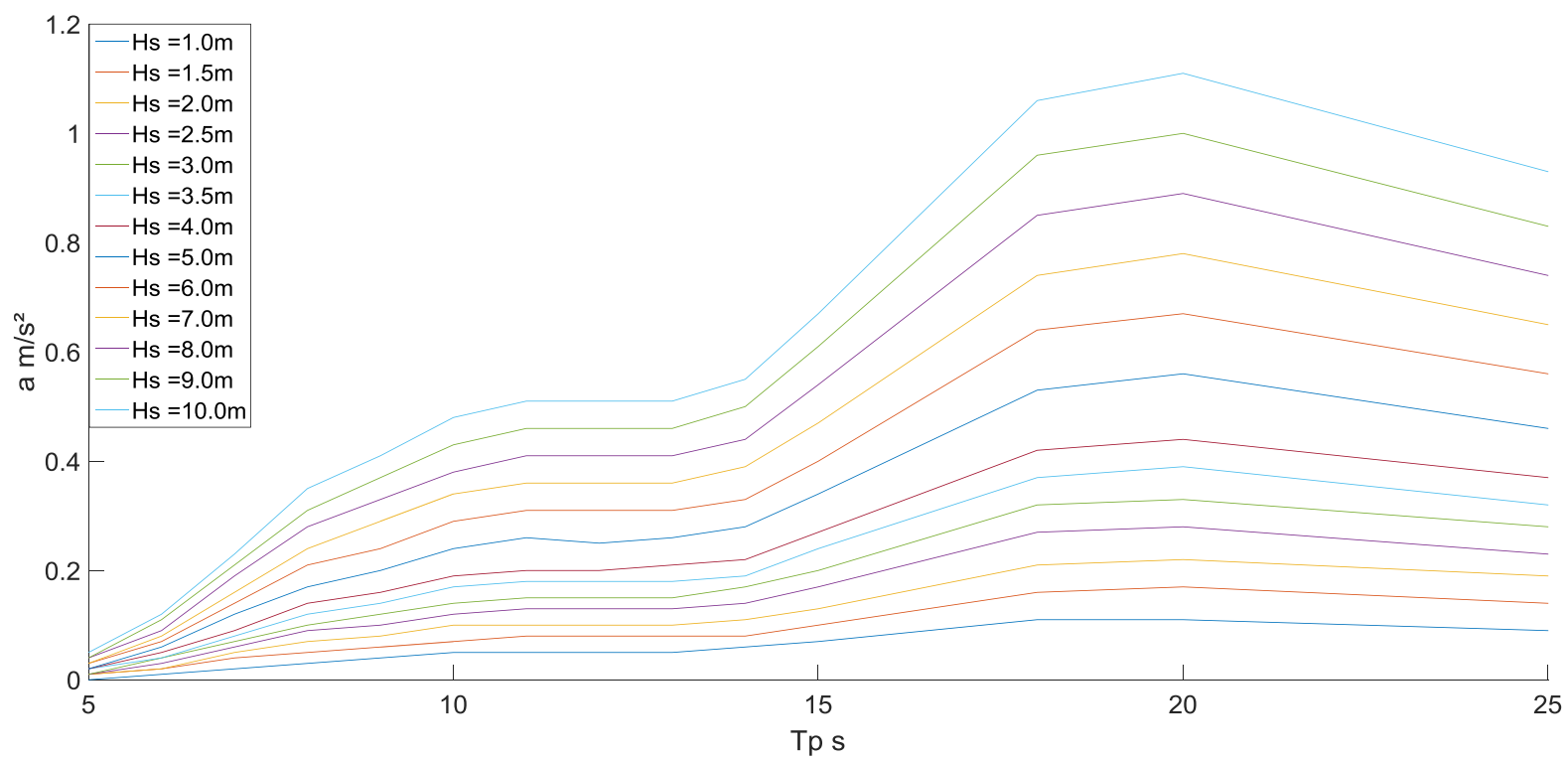

Figura 9-24 Acelerações verticais máximas ULFPSO incidência $0^{\circ}$

FONTE: Elaborada pelo autor

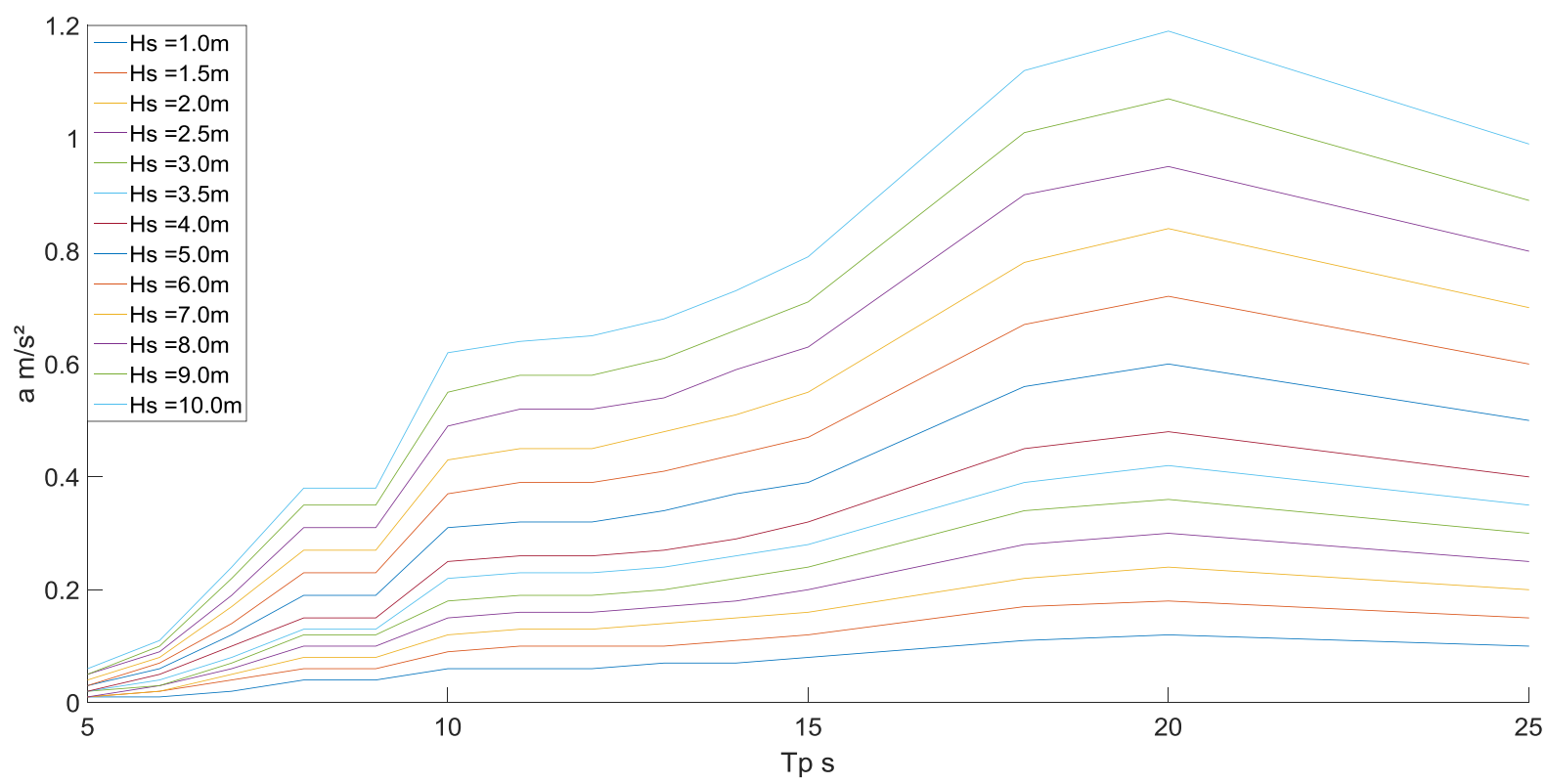

Figura 9-25 Acelerações verticais máximas ULFPSO incidência $135^{\circ}$

FONTE: Elaborada pelo autor 


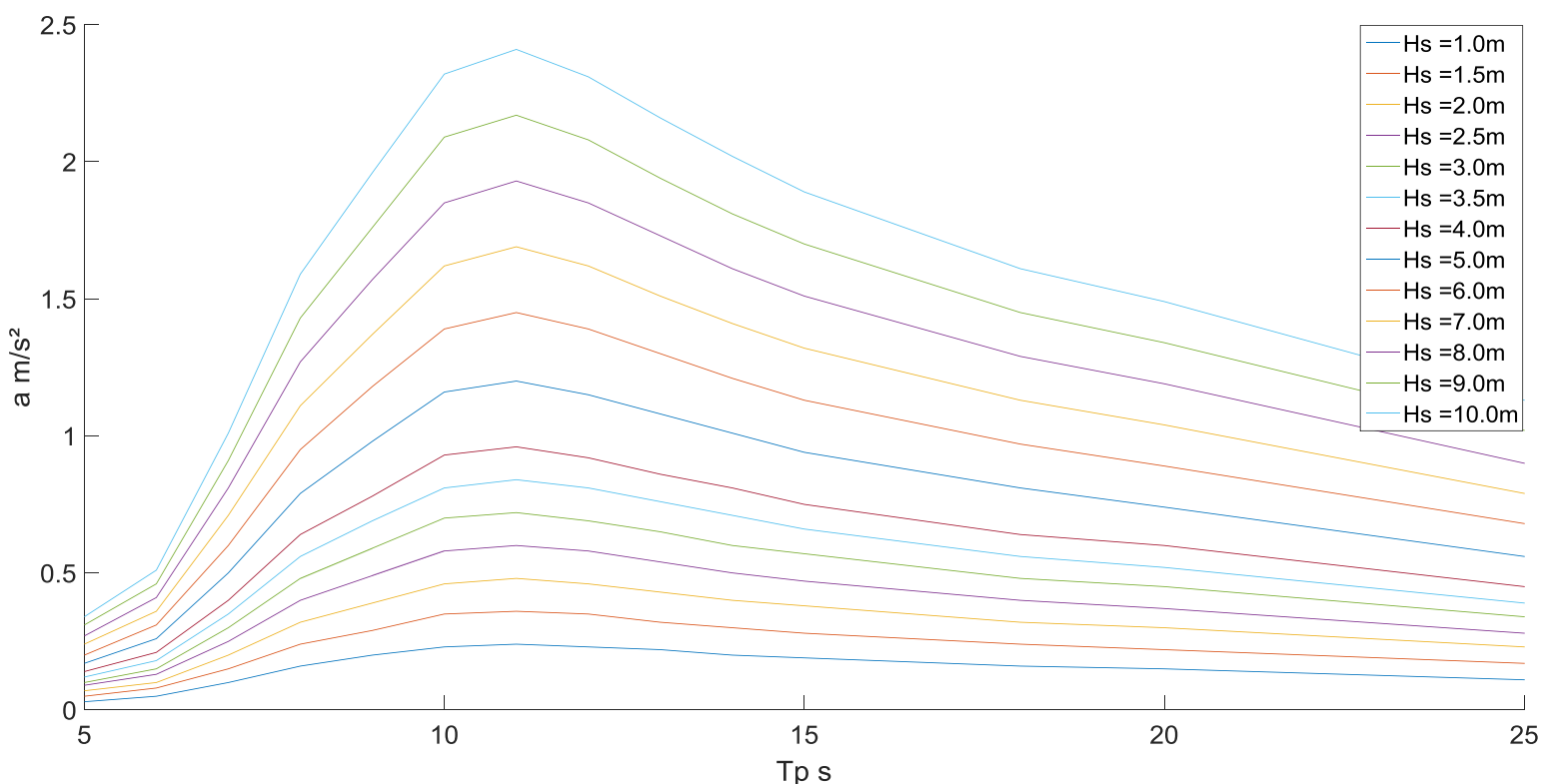

Figura 9-26 Acelerações verticais máximas ULFPSO incidência $270^{\circ}$

FONTE: Elaborada pelo autor

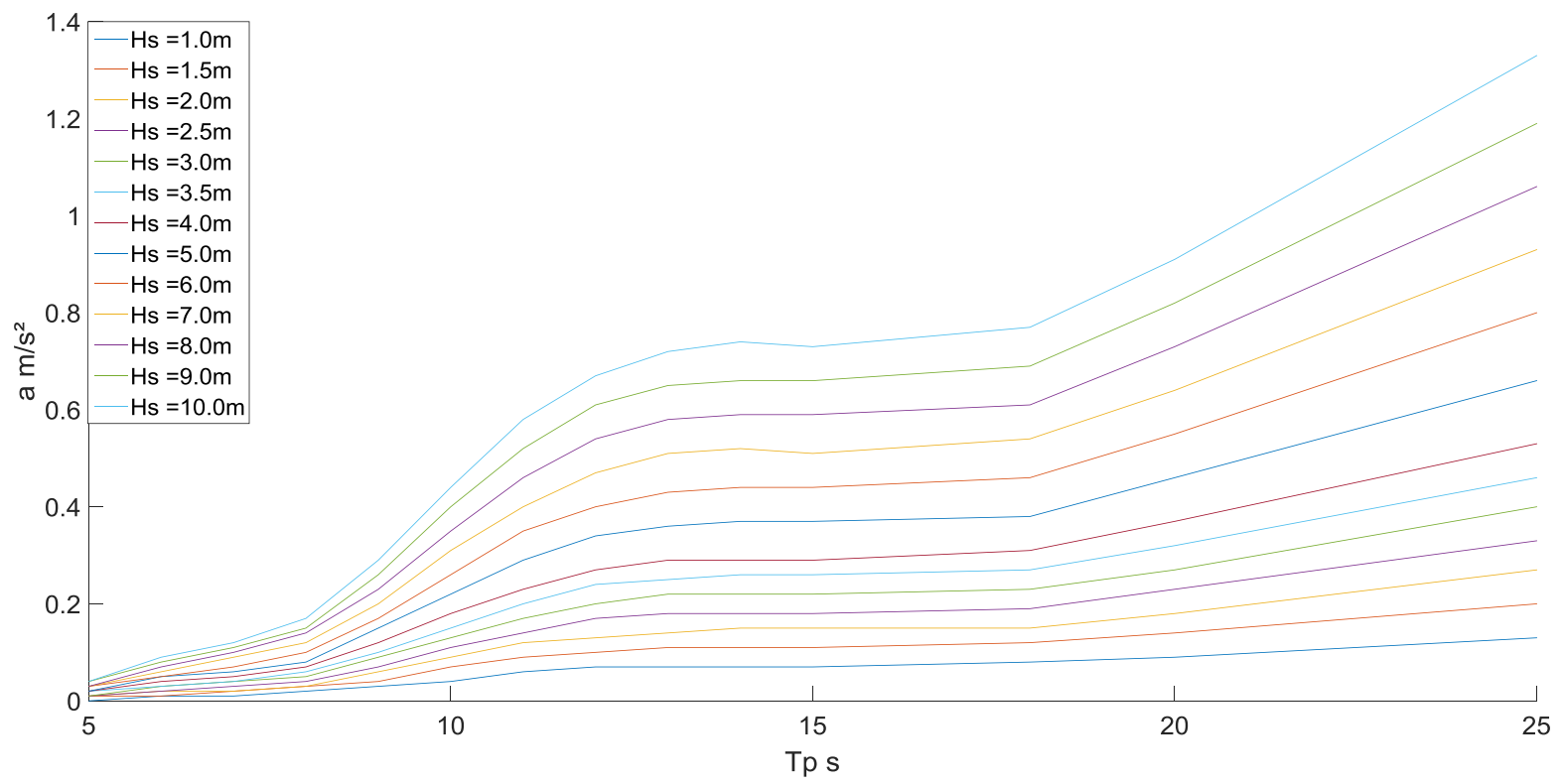

Figura 9-27 Acelerações verticais máximas P55 incidência $270^{\circ}$

FONTE: Elaborada pelo autor

Como esperado, os resultados mostram que as soluções FPSO possuem maiores acelerações na condição de través e em períodos tipicamente da faixa de 10 s a 15 s enquanto a plataforma semissubmersível apresenta maiores acelerações para períodos superiores a 20s. Entretanto, a utilização do moonpool na plataforma FPSO permite uma redução acentuada destas acelerações e com valores próximos da plataforma P55 em ambas as soluções. 
Como explicado anteriormente, o desenvolvimento desta solução prioriza o desempenho do comportamento em ondas da plataforma enquanto atende às regras e convenções estabelecidas pelas classificadoras. Desta forma, existem outras soluções viáveis que consideram alocações dos módulos da planta de processo, custo de construção e capacidade de armazenamento. Estas alterações podem alterar a posição dos pontos de conexão de risers para pontos mais próximos do centro de gravidade da plataforma, o que reduziria as acelerações nos risers.

Além disso, este trabalho não incluiu uma análise aprofundada no sistema de amarração da plataforma. As respostas da linha de amarração são fortemente dependentes dos movimentos do corpo flutuante que são induzidos pelas ações ambientais devido a ondas, vento e correnteza. Essas ações ambientais em longo prazo são processos não estacionários com características estatísticas específicas para cada local. Um possível método de avaliar o corpo flutuante em uma análise dinâmica é um longo ensaio numérico no domínio do tempo considerando todos os eventos em curto prazo. Isto seria um método muito custoso do ponto de vista computacional, principalmente quando efeitos não lineares de segunda ordem são necessários para avaliar a resposta da amarração. Este tópico, assim como os efeitos de segunda ordem da coluna d'água do moonpool, é interessante para um futuro trabalho. 


\section{CONCLUSÕES E TRABALHOS FUTUROS}

As definições utilizadas neste trabalho aplicam os conceitos básicos do processo de criação de um novo sistema flutuante com a definição das características principais do casco, gerando uma solução viável para uma unidade que possua capacidade de armazenamento e movimentos adequados para utilização de SCR.

Os estudos anteriores sugerem que a coluna d'água interna influencia no comportamento em ondas da plataforma. Desta forma, foi feito um estudo variando as dimensões e a geometria do moonpool por meio de apêndices hidrodinâmicos. Verificou-se que a interação entre coluna d'água e a plataforma influencia principalmente os movimentos verticais do sistema.

Após um estudo dos fenômenos físicos envolvidos na utilização de apêndices hidrodinâmicos, realizou-se uma avaliação do atendimento dos critérios de construção da plataforma e a disponibilidade de construção em diques e estaleiros brasileiros, além de uma avaliação estrutural e de estabilidade. Como este trabalho priorizou o desenvolvimento de uma plataforma com comportamento em ondas adequado para o Pré-sal brasileiro, limitou-se em avaliar o atendimento aos critérios e normas exigidos pelas principais sociedades classificadoras. Trabalhos futuros em maior detalhe podem ser interessantes.

Destaca-se o emprego de um método que inclui ensaios experimentais em escala reduzida e estudos numéricos para avaliar a influência dos parâmetros escolhidos para o comportamento da plataforma. Estes resultados podem ser futuramente aplicados para validação de um algoritmo para a otimização da geometria da plataforma. Além disso, os ensaios em escala reduzida sugerem a necessidade de estudar os efeitos de superfície livre do moonpool e outros efeitos secundários de forma mais aprofundada.

Utilizando como cenário típico uma plataforma FPSO para operação na costa brasileira, este estudo aponta para maior dependência dos parâmetros principais ( $L, B$ e $D$ ) utilizados na plataforma, tanto para os critérios construtivos quanto para os critérios hidrodinâmicos.

O modelo ULFPSO apresentou pequenas diferenças entre os modelos numéricos e experimentais principalmente no período de ressonância do moonpool 
que podem ser atribuídas aos efeitos não lineares viscosos. Tais amplificações tiveram a mesma escala de magnitude prevista na literatura. Do ponto de vista de projeto, é conveniente que o moonpool também possua período ressonância distante dos períodos típicos da costa brasileira.

Foi observado que o movimento vertical da coluna d'água do moonpool altera significativamente o comportamento da plataforma principalmente no movimento de heave e, desta forma, para obter um FPSO com movimento reduzido na faixa de 5 a 25 segundos o período natural do moonpool deve ser calibrado de forma que este reduza o movimento da plataforma o máximo possível.

Como a geometria do FPSO proposto possui características e dimensões similares ao conceito ULFPSO, era esperado a existência de efeitos de amplificação causados por sloshing e vorticidades em um ensaio em escala reduzida tal como o ULFPSO. No entanto, as diferenças geométricas devem alterar os coeficientes viscosos.

Finalmente, ressalta-se o potencial de expansão deste estudo com adoção de métodos de otimização em projetos de sistemas de produção, estudos relacionados a sistemas de ancoragem e operações da plataforma utilizando um moonpool, estudos de elementos finitos com a finalidade de analisar a estrutura desta plataforma de forma mais aprofundada ou por meio de estudos direcionados aos efeitos não lineares de segunda ordem relacionados à amarração da plataforma e da ressonância do moonpool. 


\section{REFERÊNCIAS}

AALBERS, A.B. The water motions in a moonpool. Ocean Engineering, v.11 , n. 6, p. 557-579, 1984.

BIRK, L.; Clauss, G.F. Automated hull optimization of offshore structures based rational Seakeeping Criteria. In: INTERNATIONAL OFFSHORE AND POLAR ENGINEERING CONFERENCE, 11. Stavanger, Norway, 2001. Proceedings. Cupertino : International Society of Offshore and Polar Engineers, 2001.

Blog MARANAUTA, 2015, http://maranauta.blogspot.com.br/2012/09/petrobras-plataformap-55- feito-inedito.html

CEPOWSKI, T. The modeling of seakeeping qualities of floating production, storage and offloading (FPSO)sea-going ships in preliminary design stage. Polish Maritime Research, v.17, n.4 p. 3-12, 2001.

CHAKRABARTI, S.K. Hydrodynamics of Offshore Structure. 5 ed. Southampton: WIT Press, 1987.

COELHO, L.C.G., NASCIMENTO, A. A. SSTAB User's Manual. Campinas : PUC/Tecgraf, 2003.

CRUZ F. R. Análise dos Critérios de Estabilidade para Projetos do tipo Monocoluna . São Paulo. 2008. Dissertação (Mestrado) - Escola Politécnica da Universidade de São Paulo.

DAY, A.H. The Design of moonpools for subsea operations. Marine Technology , v.27, n.3 p. 167-179, May 1990.

DAY, A.H. An Integrated Approach to the design of moonpools for subsea operations. 1987. Thesis (Doctor) - University of Strathclydè, Marine Technology Department of Mechanical and Offshore Engineering, Glasgow, 1987.

DNV-GL. (DNV-OSS-103) Rules for Classification of Floating LNG/LPG Production, Storage and Loading Units (2012).

DRL engineering -DeepwaterProjects DRL Capabilities Offshore Rev N6 Feb 2017

ENGLISH. J. W. A means of reducing the oscillations in drill wells caused by vessel's forward speed. The Naval Architect, 3.88 , p. 88-90, 1976.

FALTINSEN , M.; ROGNEBAKKE , O. F.; TIMOKHA , A. N. Two-dimensional resonant piston-like sloshing in a moonpool. Journal of Fluids Mechanics, v. 575, p. 359-397, March 2007.

FRANK, M WHITE. Fluid Mechanics. 4.ed. New York : McGraw-Hill, 2001.

FUKUDA, K. Behavior of water in vertical well with bottom opening of ship, and its effects on ship-

Motion. Journal of the Society of Naval Architects of Japan, v.1977, n 141, p.107- 122, 1977.

FUNG, D.P.K. Added mass and damping of circular moonpools. In: INTERNATIONAL OFFSHORE AND POLAR ENGINEERING CONFERENCE,6., Los Angeles, 1996. Proceedings. Golden, Colo. : ISOPE, 1996. v. 3, p. 1-8.

GAILLARDE, G.; COTTELEER, A. Water motions in moonpools empirical and theorical approach. Netherlands : Maritime Research Institute Netherlands (MARIN), 2004. (Technical Report, n. 2435) 
Gonçalves, Rodolfo \& Matsumoto, Fabio \& Malta, Edgard \& Rosetti, Guilherme \& Fujarra, André \& Nishimoto, Kazuo. (2010). Evolution of the MPSO (monocolumn production, storage and offloading system). Marine Systems \& Ocean Technology. 5. 45-53. 10.1007/bf03449242.

Hoffman, J., Yun, H., Modi, A. and Pearce, R. (2010). Parques das Conchas (BC-10) Pipeline, Flowline and Riser System Design, Installation and Challenges. In: Offshore Technology Conference, Houston, USA, 3-6 May 2010. Shell International E\&P Inc. and Nomad Consulting.

Kima, M.H.; Kooa B.J.; Mercierb, R.M. , et al. Vessel/mooring/riser coupled dynamic analysis of a turret-moored FPSO compared with OTRC experiment. Ocean Engineering v. 32, n. 14, p. 1780-1802, 2005.

KNot, G. F. and FLOWER, J. D. Measurement of energy losses in oscillatory flow through a pipe exit. Appied Ocean Reseach, v.2, n. 4, p. 155-164, 1980.

LAPIDAIRE, P.J.M and LEEUW,P.J. The Effect of Ship Motions on FPSO Topsides Design OTC. In: OFFSHORE TECHNOLOGY CONFERENCE, 28, Houston, Texas, 1996. Proceedings. Richardson, Tex.. : OTC, 1996.

LEWIS, E.V. Principles of Naval Architecture: motions in waves and controllability. Jersey City, NJ : SNAME, 1989 . v.3, p. 41-83

MALTA, E.B. et al. Numerical moonpool modeling. In: INTERNATIONAL CONFERENCE ON OFFSHORE MECHANICS AND ARTIC ENGINEERING, 25., Hamburg, Germany, 2006. OMAE 2006: Proceedings. New York: ASME 2006.

MATSUURA,M;ISOZAKI,Y.;ISHIBASHI,Y. Development of mono-column type hull form with passive type motion damping devices for floating production system. In: INTERNATIONAL CONFERENCE ON OFFSHORE MECHANICS AND ARTIC ENGINEERING, 14, Copenhagen, 1995. Proceedings. New York: ASME, 1995. v.1, p. 403-410

MEI, C.C. The Applied dynamics of ocean surface waves. New York: John Wiley \& Sons, 1983.

MEIROVITCH, L. Methods of Analytical Dynamics. New York: Mcgraw-Hill, 1970.

MELLEM, T. Measuring of hydrodynamic forces acting on a diving bell. S.I : s.n. 1978. DNV Report, 78-059.

MEYER. R.E. Introduction to mathematical fluid dynamics: pure and applied mathematics a series of monographs. In : COURANT. R.; BEXS. L. ; STOKER. J. J. Ney York: Wiley-Interscience, 1971. v.24

MOLIN, B. On the piston and sloshing modes in moonpools. Journal of Fluid Mechanis, v.430, p. $27-$ 50, March 2001.

MOREU , M. et al. Ultra deepwater steel risers systems hosted on FPSOs Offshore Brazil. In: ANNUAL CONFERENCE TECHNOLOGY, Houston, Texas, 2015. Proceedings. S.I. : OTC, 2015. v. 4, p. 3178-3195

MONTGOMERY, D. C.; RUNGER, G. C.; HUBELE, N. F. Estatística Aplicada à Engenharia. 2.ed. Rio de Janeiro : Livros Técnicos e Científicos, 2004.

NEWMAN, J.N. Low-frequency resonance of moonpools. In: INTERNATIONAL WORKSHOP ON WATER WAVES AND FLOATING BODIES, 19. , Cortona, 2004. Proceedings. S.I. : CNR-INSEAN, 2004.

NEWMAN, J.N. Progress in wave load computations on offshore structures. In: Invited lecture. Proceedings. 23th OMAE Conference, Vancouver , Canada, 2004. 
NEWMAN, J.N. Marine hydrodynamics. Cambridge: The MIT Press, 1977.

NEWMAN, J.N. Radiation and diffraction analysis of Mcliver toroid. Journal

Engineering Mathematics, v. 35, n. 1, p. 135-147, 1999.

NISHIMOTO K., et al. A Study of Motion Minimization Devices of FPDSOS. In: INTERNATIONAL CONFERENCE ON OFFSHORE MECHANICS AND ARTIC ENGINEERING, 20., Rio de Janeiro, 2001. OMAI 2001. New York: ASME, 2001.

OLIVEIRA, A.C. Novas abordagens para análise do amortecimento não linear do balanço transversal de FPSOs. Rio de Janeiro. 2011. Tese ( Doutorado) - Universidade Federal do Rio de Janeiro, Rio de Janeiro, 2011.

OLIVEIRA, A.C. ; FERNANDES, A. C. An Empirical nonlinear model to estimate FPSO with extended bilge keel roll linear equivalent damping in extreme seas. In: INTERNATIONAL CONFERENCE ON OCEAN, OFFSHORE AND ARTIC ENGINEERING, 31., Rio de Janeiro, 20012. OMAE 2012: proceedings. New York : Asme, 2012. paper, 2012-83360.

OLIVEIRA, A.C. ; FERNANDES, A.C. The Non-linear roll Damping of a FPSO hull. Journal Offshore Mechanics and Arctic Engineering, v. 136, n. 1, p. 011106-1,2013.

OLIVEIRA, A.C; FERNANDES, A.C. Roll Damping of Flat-Bottom Hulls: critique of the Quadratic Reason. In: Soares, Soares, C., et al. Eds. Marine Technology and Engineering: marine environment and Dynamics \& hydrodynamics. Boca Raton, Fla. : CRC Press, c2011. v. 1

- Oliveira, A. C; \& Vilameá, E. The Development of the ULFPSO Concept Design. Offshore Technology Conference Brasil 10.4043/26153-MS, 2015.

PESCE, C.P. The Application of Lagrange Equations to Mechanical Sustems With Mass Explicitly Dependent on Position. Journal of Applied Mechanics, v. 70, n. 5, p. 751-756, sept. 2003.

PESCE, C.P. TANNURI, E.A.; CASETTA, L. The Lagrange equations for systems with mass varying explicitly with position: some applications to offshore engineering. Journal of the Brazilian Society of Mechanical Sciences \& Engineering, v.28, n.4, Oct./Dec. 2006. on-line.

PINKSTER, J.A. Low frequency second order wave exciting forces on floating

structures. 1980. These (Doutorado) - Delft University of Technology, Delft, 1980.

SEUNG, H. Y. Experimental study on piston- and sloshing- mode moonpool resonances. Journal of Marine Science and Technology, v.21, n.4, p. 715-728, 2016.

TERPSTRA, T . FPSO Design and Conversion: a designer's approach . In: OFFSHORE TECHNOLOGY CONFERENCE , 33., Houston, 2001. Proceedings. Richardson, Tex. : OTC, 2001. p. 319-340.

TORRES, F., CUEVA, M., MALTA, E. B., NISHIMOTO, K., FERREIRA, M. Study of Numerical Modeling of Moonpool as Minimization Device of Monocolumn Hull. Doi:10.1115/OMAE2004-51540.

TORRES, Fernando Gomes da Silva. Estudo do moonpool como sistema de minimização de movimento em uma plataforma do tipo monocoluna. 2007. Dissertação (Mestrado em Engenharia Naval e Oceânica) - Escola Politécnica, Universidade de São Paulo, São Paulo, 2007. doi:10.11606/D.3.2007.tde-04072007-144331.

VILAMEA E.M. Estudo de Viabilidade Técnica aplicado ao Desenvolvimento do Conceito de Plataforma ULFPSO com Utilização de Riser Rígido em Catenária Livre. 2017. 141 p. Dissertação (Mestrado) - Escola Politécnica, Universidade de São Paulo, São Paulo, 2017. 
VOGEL, M. da Silveira, et al. I . Metocean measurements at Northern Santos basin - Brazil. In: OFFSHORE TECHNOLOGY CONFERENCE, Houston, 2010. OTC 2010. Richardson, Tex. : OTC, c2010. doi:10.4043/20947-MS

YOO, S. O. et al. New monnpool design of drillship for operability improvement. Journal of Offshore Mechanics and Arctic Engineering, v.141 n. 5 , p. 051301, 2019. 


\section{ANEXO A MODELAGEM DE SISTEMA MASSA-MOLA-AMORTECEDOR}

Este anexo apresenta a modelagem apresentada em TORRES, Fernando Gomes da Silva (2007) apresentando as características do acoplamento entre FPSO e a coluna d'água interna ao moonpool como um sistema dinâmico massa-molaamortecedor de dois corpos.

Primeiramente, para o moonpool acoplado a um FPSO funcionar como um sistema de dois corpos, ele pode ser representado pela equação na forma matricial:

$$
\left[m_{i j}\right] \ddot{x}_{i j}+\left[c_{i j}\right] \dot{x}_{i j}+\left[k_{i j}\right] x_{i j}
$$

O equacionamento apresentado a seguir é mais bem apresentado em Hartog, J. P., (1985) e Meirovitch, L. (1970). Um absorvedor dinâmico de vibração consiste por um relativamente simples composto por dois corpos $\mathrm{m} 1$ e $\mathrm{m} 2$ e duas restaurações $\mathrm{k} 1$ e k12. Este acoplamento é definido de forma que a frequência natural $\mathrm{k} 12 \mathrm{~m} 2$ do absorvedor é equivalente à frequência $w$ da força P0sen( $\omega t)$ que atua no corpo principal. Isto resulta no corpo principal que não vibra e o sistema vibratório oscila de modo que a força da mola é igual e oposta à força que atua no corpo principal e, portanto, cancelando a mesma. Este sistema proposto por Frahn (1909) é um caso específico do sistema vibratório geral de dois corpos. Utilizando duas massas que possuem a mesma frequência $w$ e as amplitudes a1 e a2 respectivamente, as equações deste sistema são:

$$
\begin{gathered}
{\left[a_{1 .}\left(-m_{1} \omega^{2}+k_{1}+k_{2}\right)-a_{2} k_{12}\right] \operatorname{sen}(\omega t)=P_{0} \operatorname{sen}(\omega t)} \\
{\left[-a_{1} k_{12}+a_{2} \cdot\left(-m_{2} \omega^{2}+k_{12}\right)\right] \operatorname{sen}(\omega t)=0} \\
\frac{x_{1}}{x_{e s t}}=\frac{\left(\frac{\omega^{2}}{\omega_{n}{ }^{2}}+1\right)}{\left(\frac{\omega^{2}}{\omega_{n}{ }^{2}}+1\right) \cdot\left(\frac{\omega^{2}}{\Omega_{n}{ }^{2}}+1\right)-\frac{k_{12}}{k_{1}}} \cdot \operatorname{sen}(\omega t)
\end{gathered}
$$




$$
\frac{x_{2}}{x_{e s t}}=\frac{1}{\left(\frac{\omega^{2}}{\omega_{n}{ }^{2}}+1\right) \cdot\left(\frac{\omega^{2}}{\Omega_{n}{ }^{2}}+1\right)-\frac{k_{12}}{k_{1}}} \cdot \operatorname{sen}(\omega t)
$$

Em que, quando $\omega_{n}^{2}$ (frequência natural do absorvedor) é igual à $\omega$ (frequência de excitação da força $P_{0}$ ) o numerador desta equação torna-se nulo.

Como o denominador é o mesmo em ambas as equações e a multiplicação de seus termos recai-se na equação da frequência com um termo proporcional a $\left(\omega^{2} / \omega_{n}{ }^{2}\right)^{2}$, um termo proporcional à $\left(\omega^{2} / \omega_{n}{ }^{2}\right)$ e um independente, existe temos uma equação quadrática em termos de $\left(\omega^{2} / \omega_{n}^{2}\right)$. Sendo assim, existem dois valores de $\omega$ que tornam o denominador igual a zero e resultam nos movimentos dos dois corpos tendendo ao infinito, sugerindo que este sistema possui duas frequências de ressonância.

No caso de um sistema amortecido, ainda existe a necessidade de adicionar um coeficiente de amortecimento entre as massas $m_{1}$ e $m_{2}$ apresentadas anteriormente. Desta forma, obtém-se:

$$
\frac{x_{1}{ }^{2}}{P_{o}^{2}}=\frac{\left(k_{12}-m_{2} \omega^{2}\right)^{2}-\omega^{2} c^{2}}{\left\{\left(-m_{1} \omega^{2}+k_{1}\right)\left(k_{12}-m_{2} \omega^{2}\right)-m_{2} \omega^{2} k_{12}\right\}^{2}+\omega^{2} c^{2}\left(-m_{1} \omega^{2}+k_{1}-m_{12} \omega^{2}\right)^{2}}
$$

Conclui-se que:

1- Independentemente do valor do coeficiente de amortecimento utilizado para um amortecedor que conecta o corpo principal e o absorvedor em um sistema dinâmico de vibração amortecida, haverá dois pontos distintos nos quais todas as respectivas curvas irão se interceptar.

2- Quando o valor do coeficiente de amortecimento é zero, observam-se dois picos de ressonância, como explicado anteriormente. Quando o amortecimento tende ao infinito, os dois corpos tornam-se conectados, ou seja, como um sistema rígido de apenas um grau de liberdade, apresentando um único pico de ressonância. 
Além disso, nota-se que com esta modelagem não existe mais a simetria das matrizes de massa e rigidez que representam as equações das funções de movimento, velocidade e aceleração relativa do moonpool. Este resultado será utilizado para a modelagem do amortecimento viscoso utilizando o WAMIT com dois corpos.

Para obter um modelo mecânico massa mola amortecedor para o sistema acoplado plataforma-moonpool, Torres, F. (2007), representou o moonpool acoplado ressaltando três pontos:

1. A estrutura moonpool a ser considerada na modelagem é representada pela água interna à plataforma e trabalha em conjunto com o próprio FPSO. Logo, ao se considerar que o segundo corpo é formado por uma massa de valor constante, obtém-se uma aproximação para o modelo inicial.

2. Ao representar a interação entre a água interna ao moonpool e a estrutura principal por um sistema massa mola amortecedor é necessário separar o amortecimento devido ao movimento puro do corpo; o amortecimento devido ao movimento relativo entre a água interna ao moonpool e a plataforma e o amortecimento do próprio FPSO.

3. Quando a plataforma recebe excitação de uma onda, tanto a plataforma quanto a água interna do moonpool recebem a energia da onda.

De acordo com suas observações dos resultados obtidos e características apontadas, Torres, F. (2007) sugeriu que a dinâmica entre o movimento da água interna e da plataforma pode ser representado pelo sistema a seguir:

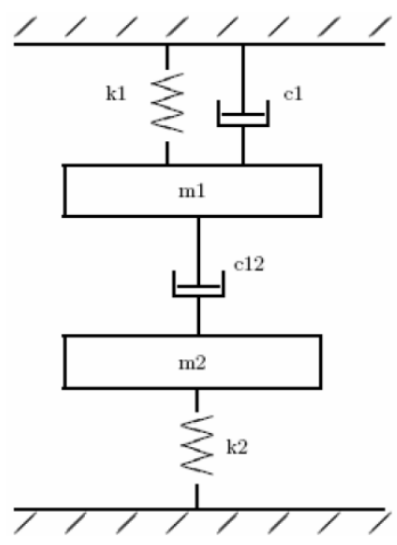

Figura 11-1 Absorvedor Dinâmico de Vibração

FONTE: TORRES, FERNANDO (2007) 
As equações que representam o sistema acima são:

$$
m_{z} \cdot \ddot{z}=-k_{z} \cdot z-c_{z} \cdot \dot{z}-c_{z \zeta} \cdot(\dot{z}-\dot{\zeta})
$$

$$
m_{\zeta} \cdot \ddot{\varsigma}=-k_{\zeta} \cdot \varsigma-c_{\zeta Z} \cdot(\dot{\zeta}-\dot{z})
$$

Onde:

$$
\begin{gathered}
m_{z}=m_{1}, c_{z}=c_{1}, k_{z}=k_{1}, \\
m_{\zeta}=m_{2}, c_{\varsigma}=c_{2}, k_{\varsigma}=k_{2} \\
c_{z \zeta}=c_{\zeta z}=c_{12}
\end{gathered}
$$

Expressando o resultado em relação aos movimentos do corpo obtêm-se:

$$
m_{z} \cdot \ddot{z}+\left(c_{z}+c_{z \zeta}\right) \cdot \dot{z}+k_{z} \cdot z-c_{z \zeta} \cdot \dot{\zeta}=0
$$

$$
m_{\zeta} \cdot \ddot{\zeta}+c_{\zeta z} \cdot \dot{\zeta}+k_{\varsigma} \cdot \varsigma-c_{\zeta z} \cdot \dot{z}=0
$$

E, escrevendo na forma matricial:

$$
\left[\begin{array}{cc}
m_{z} & 0 \\
0 & m_{\zeta}
\end{array}\right] \cdot\left[\begin{array}{l}
\ddot{z} \\
\ddot{\zeta}
\end{array}\right]+\left[\begin{array}{cc}
\left(c_{z}+c_{z \zeta}\right) & -c_{z \zeta} \\
-c_{\zeta z} & c_{z \zeta}
\end{array}\right] \cdot\left[\begin{array}{l}
\dot{z} \\
\dot{\zeta}
\end{array}\right]+\left[\begin{array}{cc}
k_{z} & 0 \\
0 & k_{\zeta}
\end{array}\right] \cdot\left[\begin{array}{l}
Z \\
\varsigma
\end{array}\right]=0
$$

Pode-se escrever também o movimento vertical da água interna ao moonpool em relação ao movimento vertical do corpo principal. Define-se o movimento, velocidade e aceleração relativas da água interna ao moonpool como:

$$
\varsigma_{r}=\varsigma-z
$$




$$
\begin{aligned}
& \dot{\zeta_{r}}=\dot{\zeta}-\dot{z} \\
& \ddot{\zeta_{r}}=\ddot{\zeta}-\ddot{z}
\end{aligned}
$$

Substituindo nas equações 11 e 12 obtêm-se:

$$
\begin{gathered}
m_{z} \cdot \ddot{z}+c_{z} \cdot \dot{z}+k_{z} \cdot z-c_{z \zeta} \cdot \dot{\zeta_{r}}=0 \\
m_{\varsigma} \cdot \ddot{\zeta}+\left(c_{\zeta z}\right) \cdot \dot{\zeta_{r}}+k_{\zeta} \cdot \varsigma_{r}+m_{\varsigma} \cdot \ddot{z}+k_{\zeta} \cdot z=0
\end{gathered}
$$

Por fim, na forma matricial:

$$
\left[\begin{array}{cc}
m_{z} & 0 \\
m_{\varsigma} & m_{\zeta}
\end{array}\right] \cdot\left[\begin{array}{c}
\ddot{Z} \\
\ddot{\zeta_{r}}
\end{array}\right]+\left[\begin{array}{cc}
c_{z} & -c_{z \varsigma} \\
0 & c_{z \varsigma}
\end{array}\right] \cdot\left[\begin{array}{c}
\dot{Z} \\
\dot{\zeta}_{r}
\end{array}\right]+\left[\begin{array}{cc}
k_{z} & 0 \\
k_{\varsigma} & k_{\varsigma}
\end{array}\right] \cdot\left[\begin{array}{c}
z \\
\varsigma_{r}
\end{array}\right]=0
$$

Um ponto importante é a ser notado no novo sistema de equações é a assimetria das matrizes de massa e rigidez quando escritas em termos de movimento, velocidade e aceleração relativa do moonpool. 


\section{ANEXO B ENSAIO EM ESCALA REDUZIDA}

Este capítulo anexo tem como objetivo descrever o procedimento experimental em escala reduzida feito neste trabalho. Como explicado no Capítulo 8, foi utilizado um modelo mais simples e com dimensões menores para facilitar o estudo da coluna d'água interior a plataforma FPSO. O segundo modelo a ser apresentado é o modelo ULFPSO que também teve resultados apresentados no Capítulo 8.

O modelo a ser apresentado consiste em um casco de FPSO com moonpool e pequena área de linha de água. O modelo foi construído em madeira do tipo compensado naval mostra a geometria do modelo em escala.

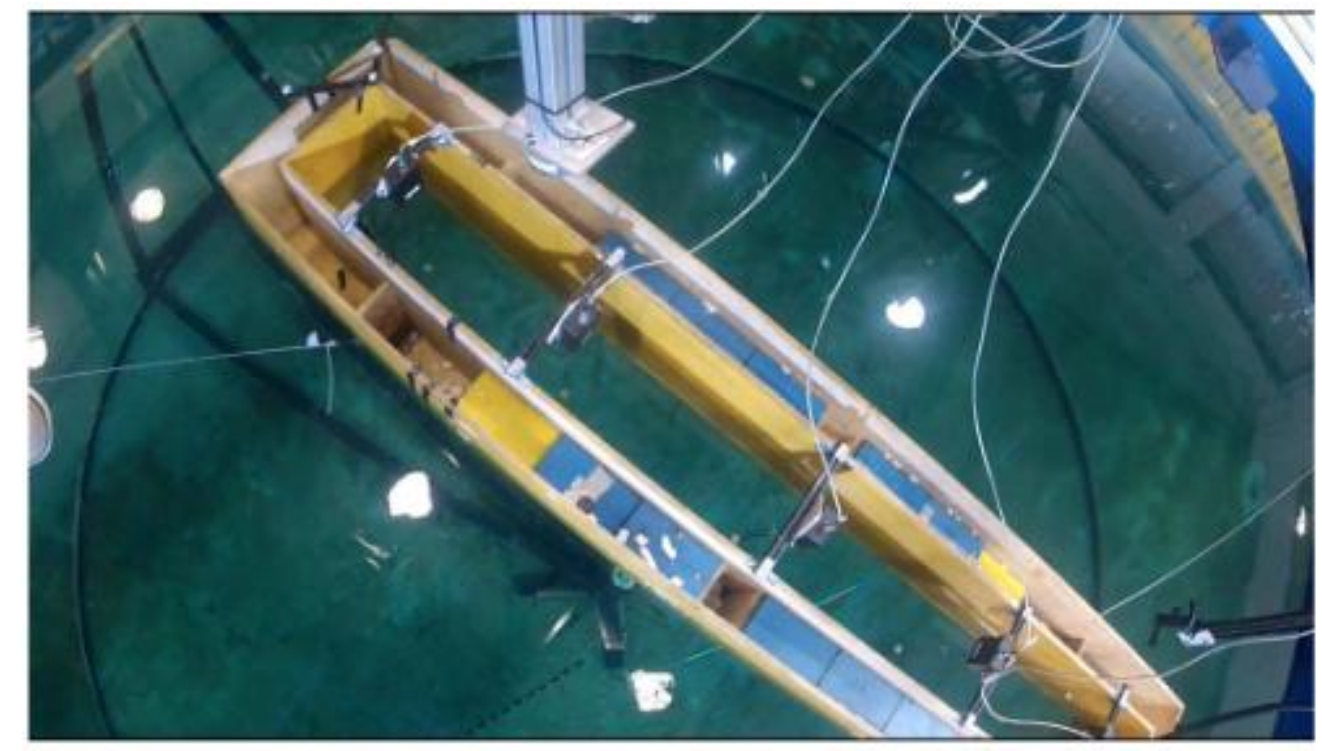

Figura 12-1 Modelo FPSO "caixa" com moonpool FONTE: Elaborada pelo autor

As características principais do casco em escala reduzida são mostradas na Tabela 12-1: 


\begin{tabular}{|c|c|c|}
\hline \multicolumn{3}{|c|}{ Dimensões principais do casco } \\
\hline Dimensão & Valor & Unidade \\
\hline Comprimento & 2955 & $\mathrm{~mm}$ \\
\hline Boca & 555 & $\mathrm{~mm}$ \\
\hline Pontal & 415 & $\mathrm{~mm}$ \\
\hline \multicolumn{3}{|c|}{ Dimensões principais do moonpool } \\
\hline Comprimento & 2682 & $\mathrm{~mm}$ \\
\hline Boca & 275 & $\mathrm{~mm}$ \\
\hline \multicolumn{3}{|c|}{ Condições de carregamento } \\
\hline Calado & 210 & $\mathrm{~mm}$ \\
\hline $\mathrm{LCG}^{*}$ & 0 & $\mathrm{~mm}$ \\
\hline $\mathrm{TCG}^{\star *}$ & 0 & $\mathrm{~mm}$ \\
\hline $\mathrm{VCG}^{* * *}$ & 235 & $\mathrm{~mm}$ \\
\hline \multicolumn{3}{|c|}{ *(+) A vante da seção mestra } \\
\hline \multicolumn{3}{|l|}{${ }^{\star *}(+)$ Bombordo } \\
\hline \multicolumn{3}{|l|}{${ }^{* * *}(+)$ a cima da quilha } \\
\hline
\end{tabular}

Tabela 12-1 Modelo"caixa" em Escala

FONTE: Elaborada pelo autor

O modelo ULFPSO apresentado na também consiste em um casco de FPSO com moonpool e com uma área de linha de água reduzida devido ao contorno da praia do casco. As características principais do ULFPSO são apresenta tabela

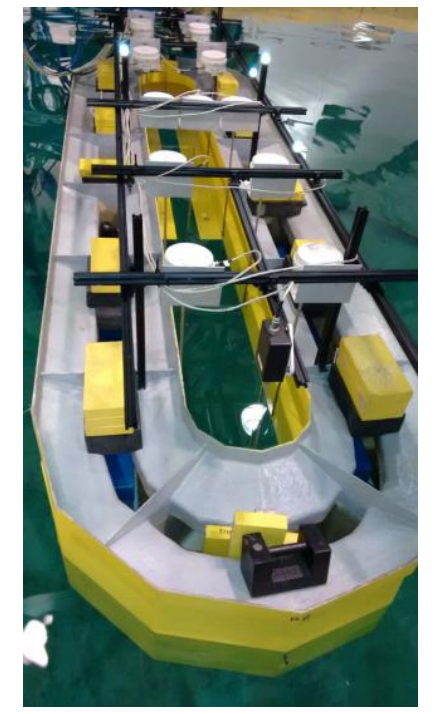

Figura 12-2 Modelo escala reduzida ULFPSO

FONTE Relatório ULFPSO Ensaio em ondas de modelo 


\begin{tabular}{|c|c|c|}
\hline \multicolumn{3}{|c|}{ Dimensões principais do casco } \\
\hline Dimensão & Valor & Unidade \\
\hline Comprimento & 3400 & $\mathrm{~mm}$ \\
\hline Boca & 1000 & $\mathrm{~mm}$ \\
\hline Pontal & 400 & $\mathrm{~mm}$ \\
\hline \multicolumn{3}{|c|}{ Dimensões principais do moonpool } \\
\hline Comprimento & 2950 & $\mathrm{~mm}$ \\
\hline Boca & 550 & $\mathrm{~mm}$ \\
\hline \multicolumn{3}{|c|}{ Condições de carregamento } \\
\hline Calado & 250 & $\mathrm{~mm}$ \\
\hline $\mathrm{LCG}^{*}$ & 0 & $\mathrm{~mm}$ \\
\hline $\mathrm{TCG}^{\star \star}$ & 0 & $\mathrm{~mm}$ \\
\hline $\mathrm{VCG}^{* * *}$ & 203 & $\mathrm{~mm}$ \\
\hline \multicolumn{3}{|c|}{ *(+) A vante da seção mestra } \\
\hline \multicolumn{3}{|l|}{ **(+) Bombordo } \\
\hline \multicolumn{3}{|l|}{${ }^{* *}(+)$ a cima da quilha } \\
\hline
\end{tabular}

Tabela 12-2 Modelo ULFPSO em Escala

FONTE: Elaborada pelo autor

\subsection{Instrumentação}

O sistema de aquisição de dados analógico usado foi o HBM MX-840, o sistema óptico de detecção de movimentos do modelo usado foi o Qualisys. O gerador de ondas e os sistemas de aquisição citados acima estavam sincronizados entre si através de uma linha de controle para que todos fossem disparados simultaneamente ao início da geração de ondas.

\subsection{Monitoração dos movimentos da plataforma}

A monitoração dos movimentos foi realizada com 0 uso de 4 câmeras Qualysis, ver Figura 12-3, que monitoram, através de um sistema óptico, a posição real do modelo em teste. 


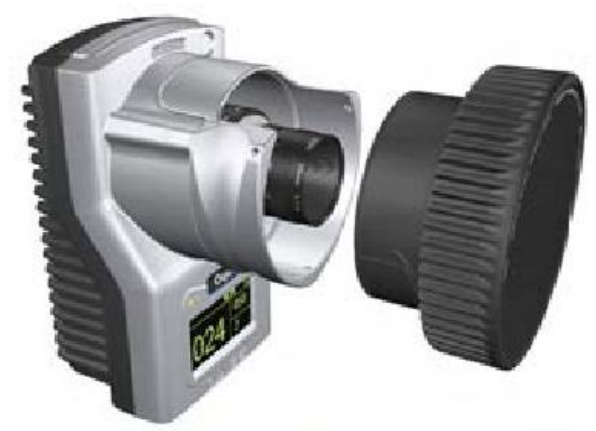

Figura 12-3 - Câmera com dispositivo infravermelho

FONTE: Qualisys

As principais características do sistema de monitoramento por imagens podem ser observadas na Tabela 12-3.

\begin{tabular}{|c|c|}
\hline Especificações & Descrição \\
\hline Dimensões & $(185 \times 110 \times 124)$ \\
\hline Ângulo de visão da lente & $40^{\circ}$ (padrão) \\
\hline Faixa do espectro de luz & Infravermelho \\
\hline Sensor CMOS (pixels) & $640 \times 320$ \\
\hline${\text { Taxa de aquisição máxima (fps }{ }^{10} \text { ) }}^{2}$ & 250 na resolução máxima \\
\hline Capacidade do buffer de vídeo & 3800 frames na resolução máxima \\
\hline
\end{tabular}

Tabela 12-3 - Principais características das câmeras de monitoração de movimentos

FONTE: Qualisys

Foram utilizados cinco alvos passivos montados em prolongadores de altura acima do convés em duas linhas longitudinais; uma com dois alvos e outra com três alvos. O convés foi pintado de preto para evitar reflexão de luz entre câmeras e os alvos.

O sistema de coordenadas local do sistema óptico foi transladado para o CG do modelo para que os 6 graus de liberdade do modelo fossem medidos diretamente pelo sistema. Assim, os arquivos de saída do ensaio têm referencial no CG do modelo. A calibração do sistema de referência das câmeras foi refeita sempre que 0 resíduo de medição do $C G$ do modelo excedia $0.5 \mathrm{~mm}$. O resíduo de medição é o indicador da incerteza da medição do sistema; indicado no software de operação da Qualisys. A taxa de amostragem utilizada é a mesma do sistema analógico HBM (aquisição de sensores de ondas e célula de carga), ou seja, $100 \mathrm{~Hz}$. 


\subsection{Wave probes}

Os waves probes utilizados para a avaliação das ondas progressivas no interior do tanque durante a calibração das ondas e também durante os ensaios com modelo são do tipo capacitivo. Um fio encapado de pequena espessura serve para converter a altura do nível da água em sinal elétrico de capacitância variável. Um circuito eletrônico condicionador de sinais converte a capacitância do fio em tensão elétrica que é então adquirida no sistema de aquisição analógico HBM.

A calibração da escala dos sensores foi obtida usando-se regressão linear utilizando um mecanismo de calibração. O mecanismo posiciona simultaneamente todos os wave probes nas posições definidas para a calibração. Nove pontos foram utilizados na regressão $(0, \pm 50, \pm 100, \pm 150)$, sendo a mesma considerada satisfatória quando o resíduo médio quadrático fosse maior do 0.9999 em um ajuste à uma reta (linear). A calibração da onda foi feita sem o modelo na água, através de três wave probes dispostos em posições relevantes como mostram a Tabela 12-4 e Figura 12-4.

\begin{tabular}{ccl} 
ID & Localização & Coordenada \\
\hline WP-01 & Em frente ao modelo & $\mathrm{X}=3,5 \mathrm{~m} ; \mathrm{Y}=3,5 \mathrm{~m}$ \\
WP-02 & Do lado do modelo & $\mathrm{X}=7,0 \mathrm{~m} ; \mathrm{Y}=-3,5 \mathrm{~m}$ \\
WP-03 & Na posição do modelo & $\mathrm{X}=7,0 \mathrm{~m} ; \mathrm{Y}=3,5 \mathrm{~m}$ \\
& & \\
\hline
\end{tabular}

Tabela 12-4 - Posição dos wave probes no tanque

FONTE: Elaborada pelo autor 


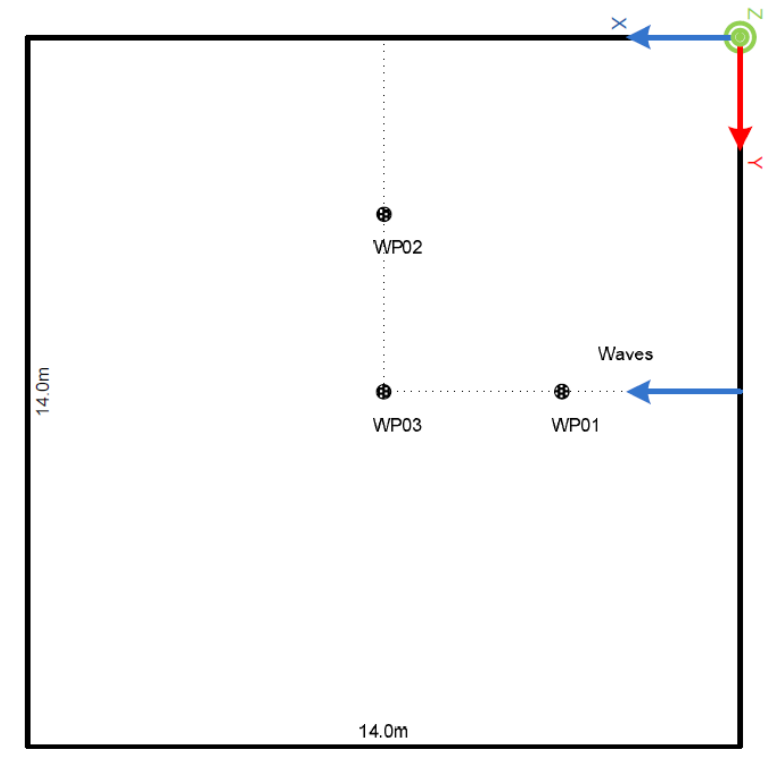

Figura 12-4 Wave probes para calibração da onda no tanque.

FONTE: Mello, Pedro Cardozo de et al. "USP Active Absorption Wave Basin: From Conception to Commissioning." (2009).

A posição dos wave probes no modelo foi mantida através de um suporte construído em perfis de alumínio fixado as anteparas de reforço verticais do modelo. A Figura 12-8 mostra o arranjo dos wave probes no moonpool do modelo. A Tabela 12-5 determina as cotas longitudinais das posições dos wave probes no modelo.
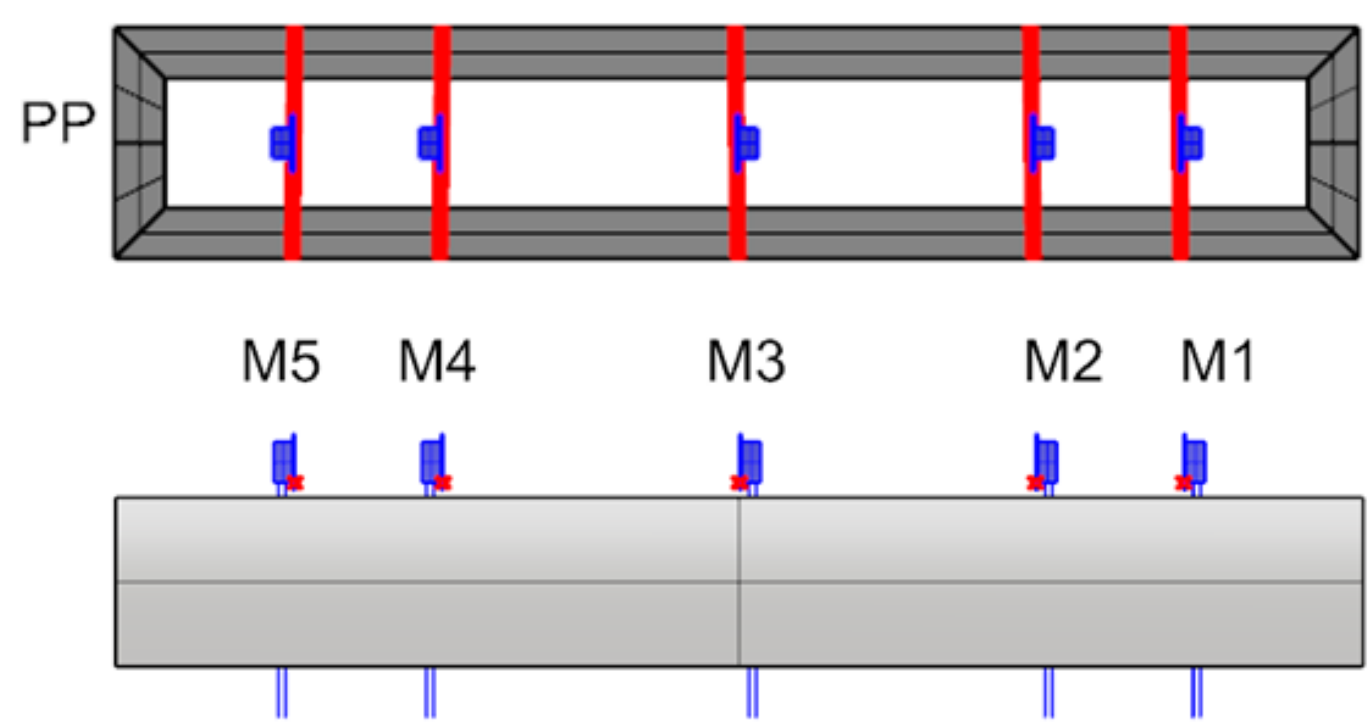

Figura 12-8 Disposição dos wave probes no modelo "caixa"

FONTE: Elaborada pelo autor 


\begin{tabular}{|c|c|}
\hline Wave Probe ID & Posição longitudinal X (mm) \\
\hline M1 & 1050 \\
\hline M2 & 700 \\
\hline M3 & 0 \\
\hline M4 & -700 \\
\hline M5 & -1050 \\
\hline
\end{tabular}

Tabela 12-5 Posição dos wave probes no modelo "caixa"

FONTE: Elaborada pelo autor

No caso ULFPSO, cada wave probe foi posicionado próximo às paredes internas do moonpool como apresentado no Capítulo 9 devido às maiores dimensões deste em comparação à plataforma "caixa".

\subsection{Ensaio em Ondas}

Nesta seção é apresentado o resultado experimental dos ensaios com o modelo de FPSO recebendo ondas com incidência de $90^{\circ}$. Os resultados apresentados são comparados com a simulação feita no WAMIT para as mesmas condições de calado e aproamento experimental.

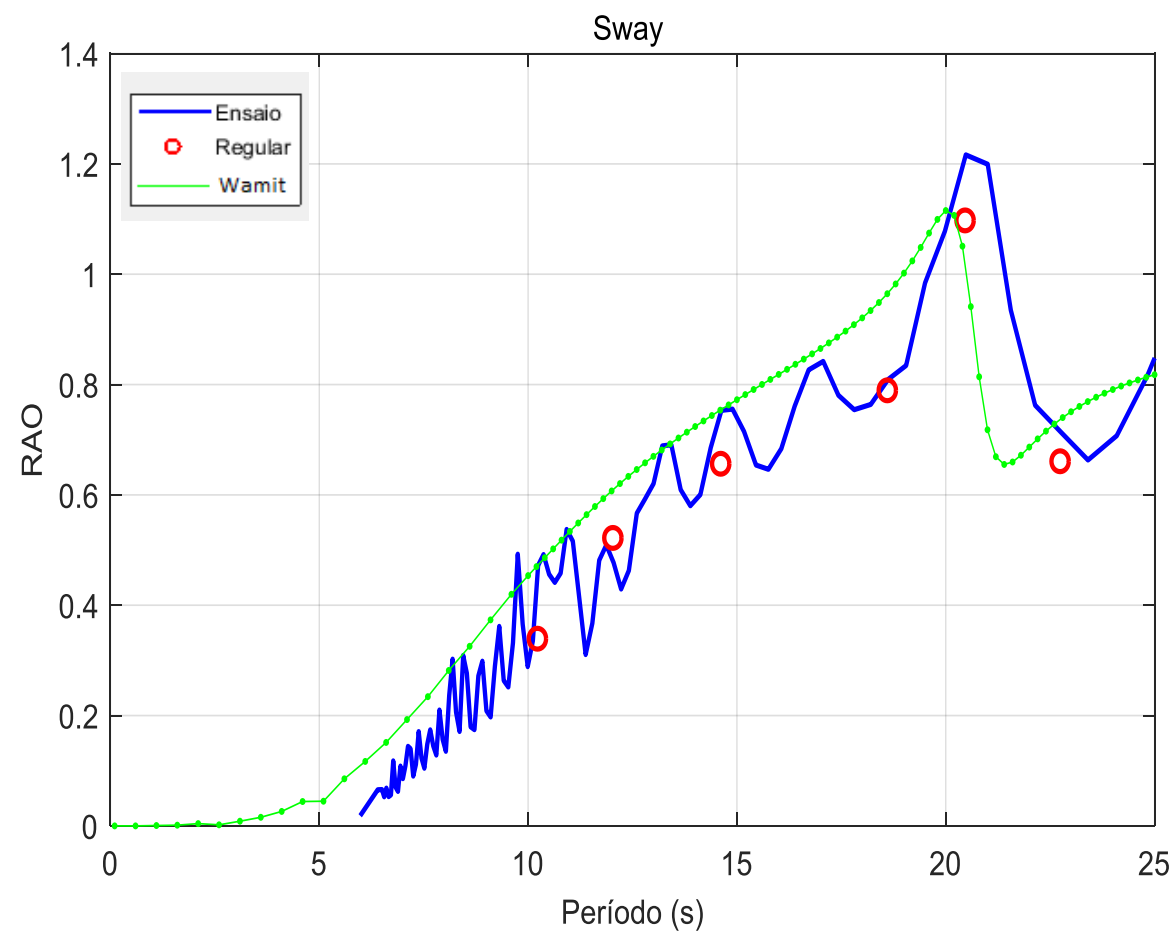

Figura 12-5 Comparação modelo "caixa" Sway - incidência 90

FONTE: Elaborada pelo autor 


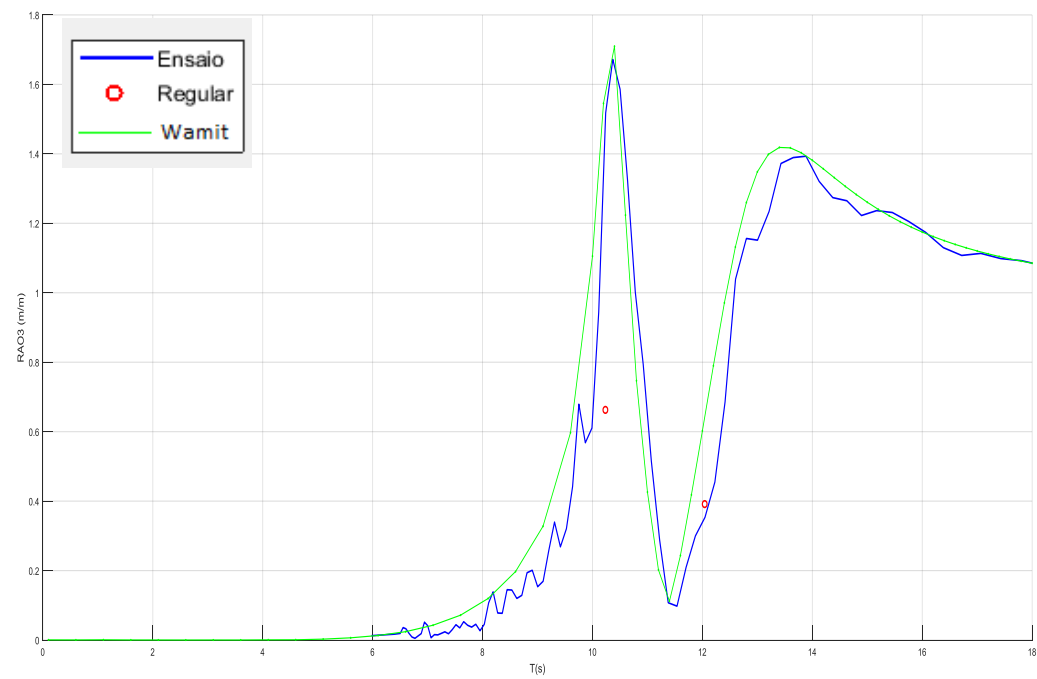

Figura 12-6 Comparação modelo "caixa" Heave - incidência 90 FONTE: Elaborada pelo autor

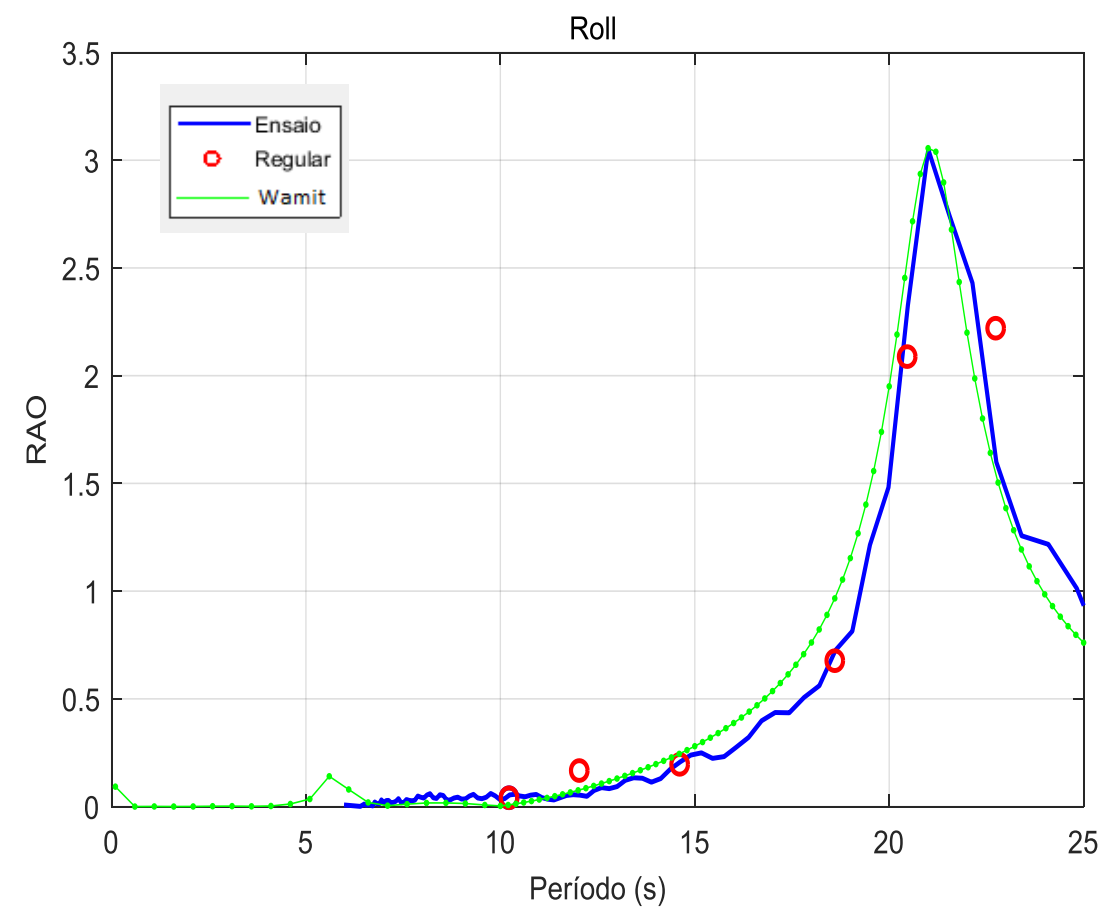

Figura 12-7 Comparação modelo "caixa" Roll - incidência 90 FONTE: Elaborada pelo autor 


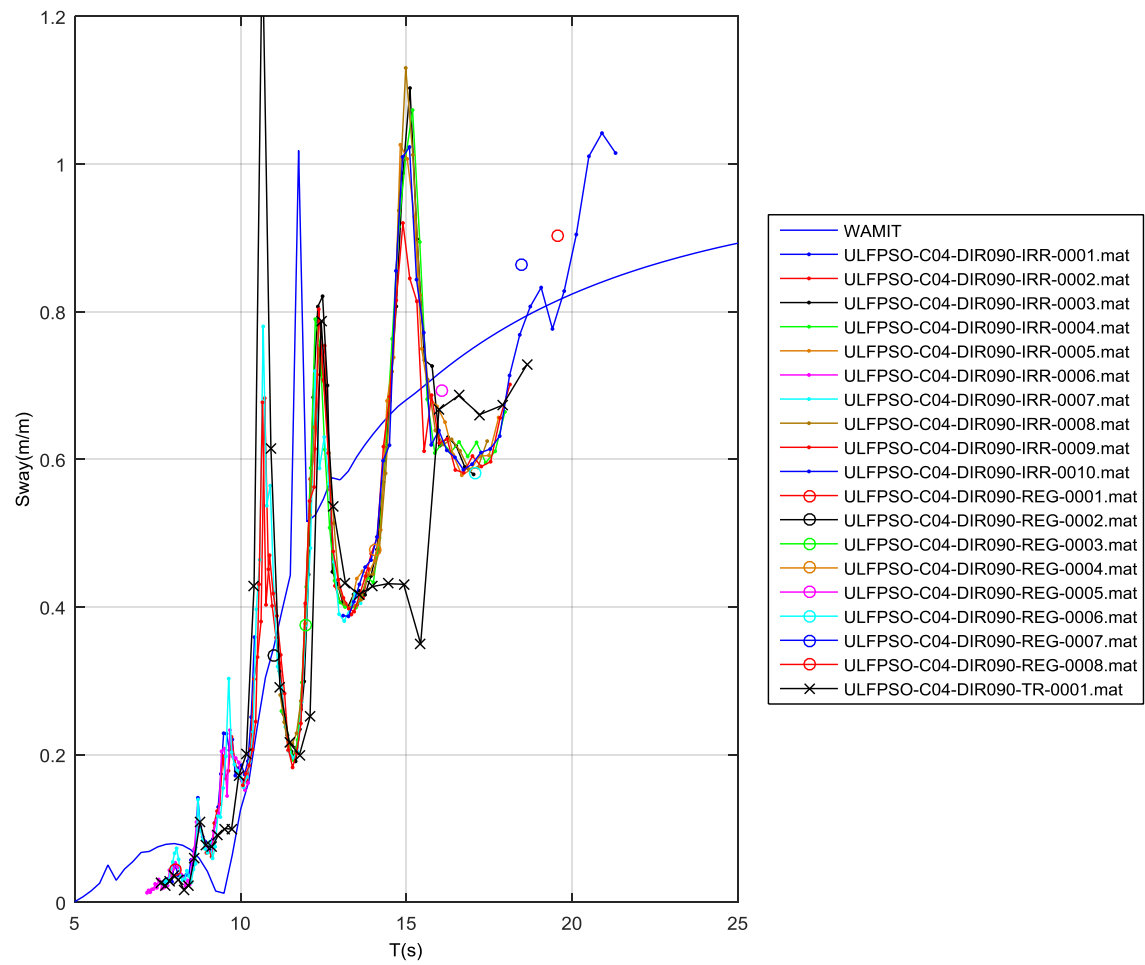

Figura 12-8 Comparação modelo ULFPSO Sway - incidência 90

FONTE Relatório ULFPSO Ensaio em ondas de modelo em escala reduzida

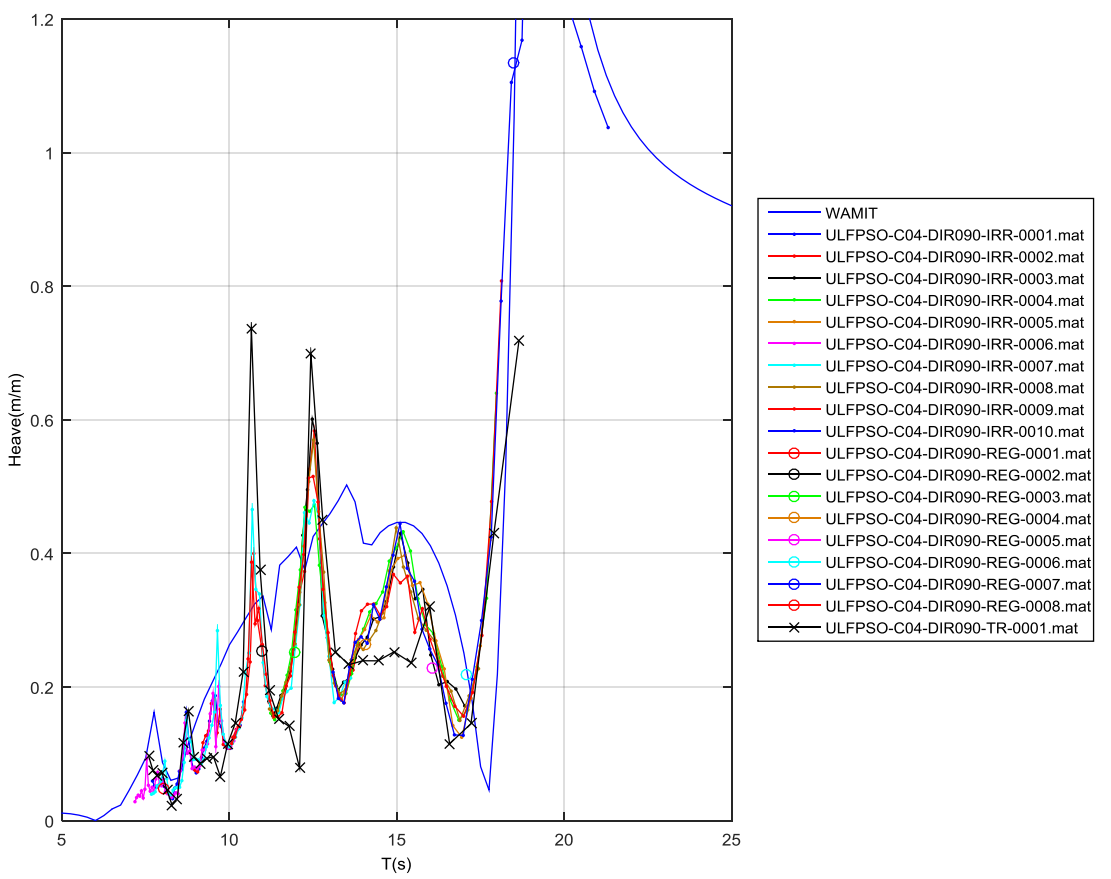

Figura 12-9 Comparação modelo ULFPSO Heave - incidência 90 


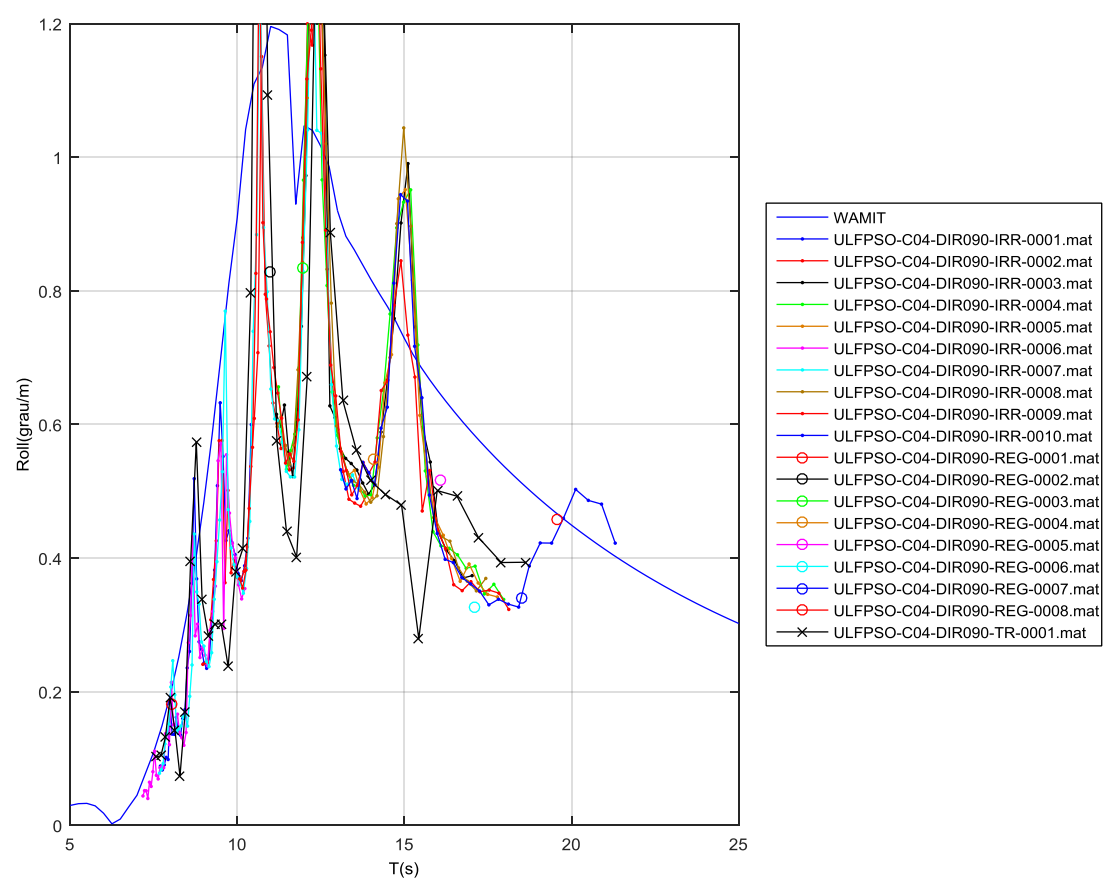

Figura 12-10 Comparação modelo ULFPSO Pitch - incidência 90

FONTE Relatório ULFPSO Ensaio em ondas de modelo em escala reduzida

\subsection{Avaliação do volume de água dentro do moonpool}

A obtenção da elevação da coluna d'água é obtida a partir do cruzamento do movimento de onda obtido pelos wave probes dentro do moonpool e do movimento da plataforma obtido pelo sistema Qualisys. Desta forma, foi utilizada uma rotina que avalia o movimento total da plataforma e da elevação relativa de água dentro do moonpool para separar os movimentos da plataforma dos movimentos causados exclusivamente pela amplificação do moonpool. A Figura 12-11 e ilustra um exemplo das elevações da coluna d'água em cada wave probe para uma condição de mar irregular com a amplitude do movimento no eixo y e o tempo de ensaio no eixo $x$ : 
IRR1 $-T p=10 s$
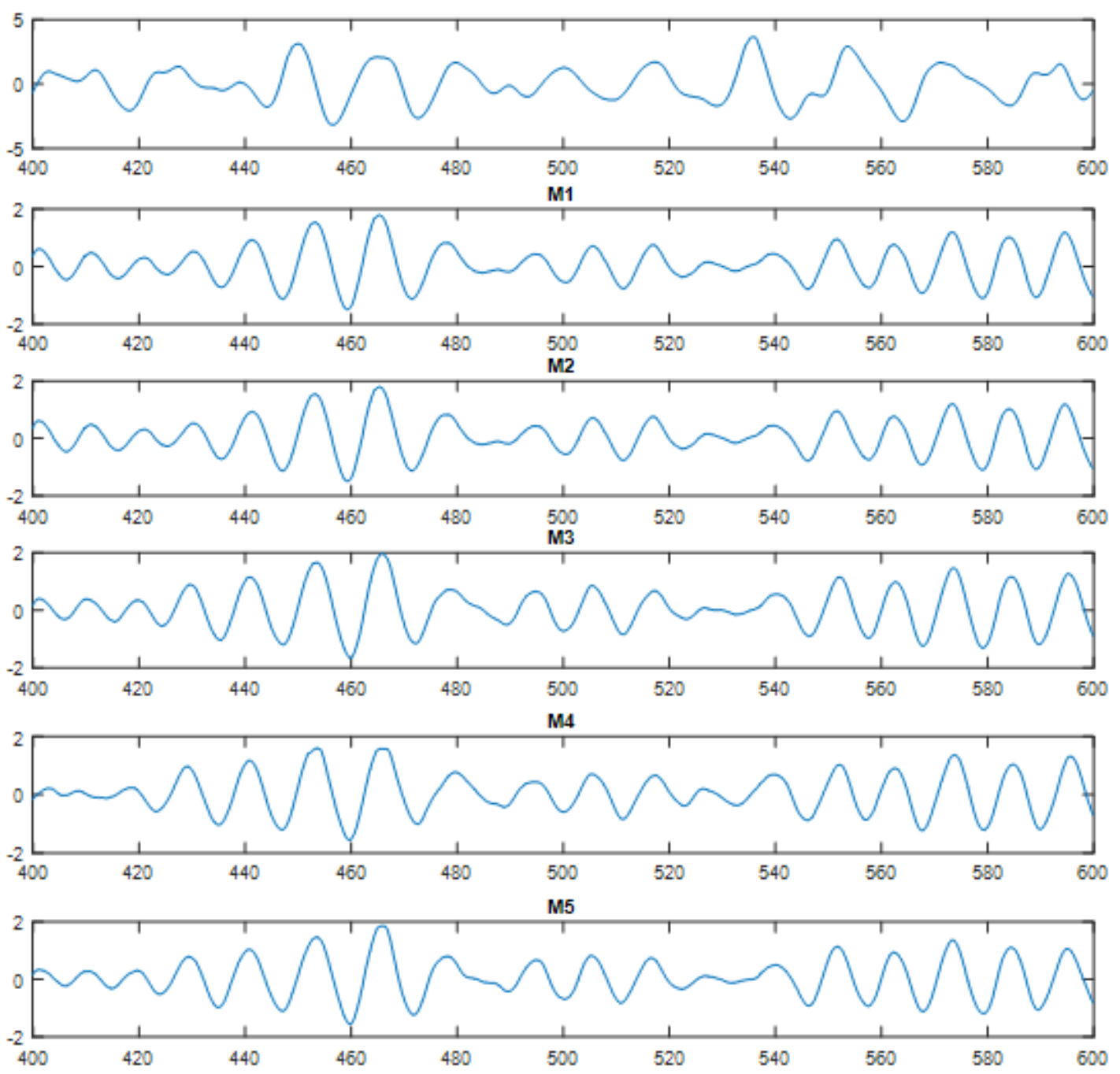

Figura 12-11 Série temporal onda, modelo "caixa" IRR1, $T p=10$ s

FONTE: Elaborada pelo autor

Cada série temporal é então tratada para a obtenção dos dados estatísticos apresentados no Capítulo 9. 
13. ANEXO C ACELERAÇÕES VERTICAIS

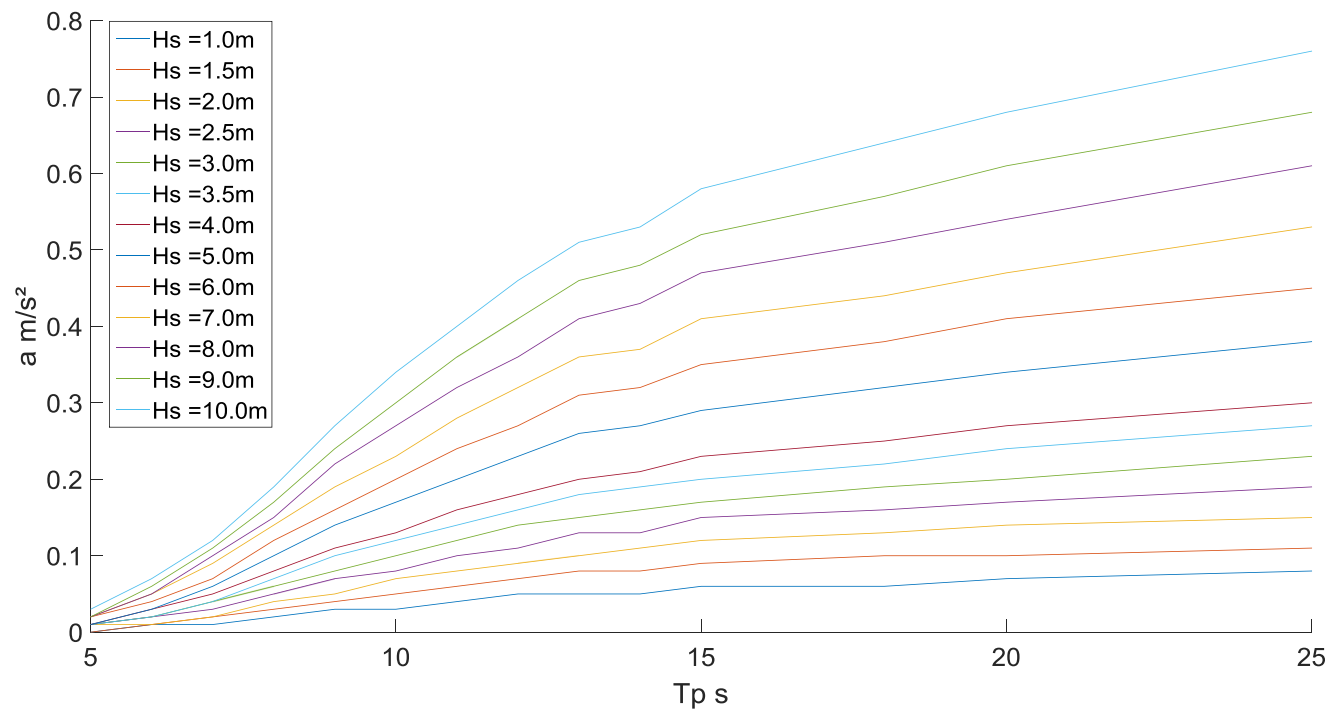

Figura 13-1 Aceleração vertical incidência 210

FONTE: Elaborada pelo autor

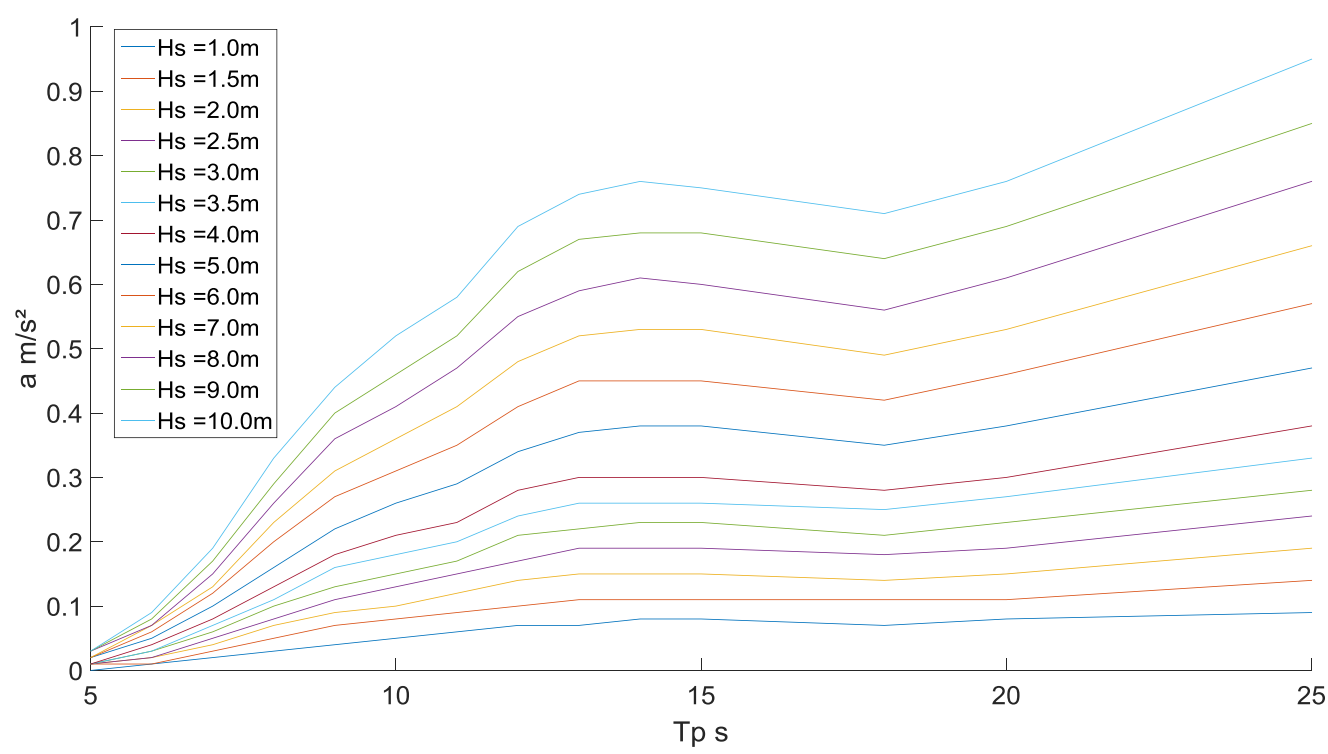

Figura 13-2 Aceleração vertical incidência $240^{\circ}$

FONTE: Elaborada pelo autor 


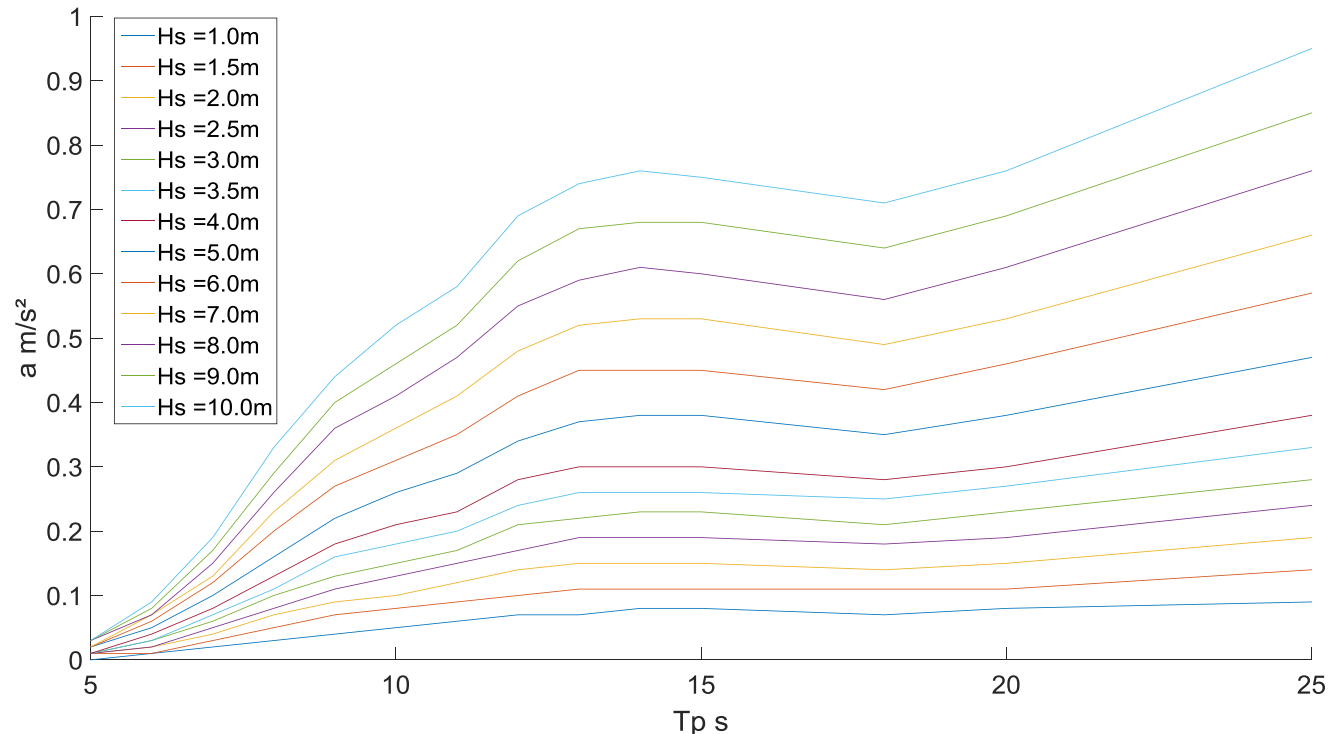

Figura 13-3 Aceleração vertical incidência $300^{\circ}$

FONTE: Elaborada pelo autor

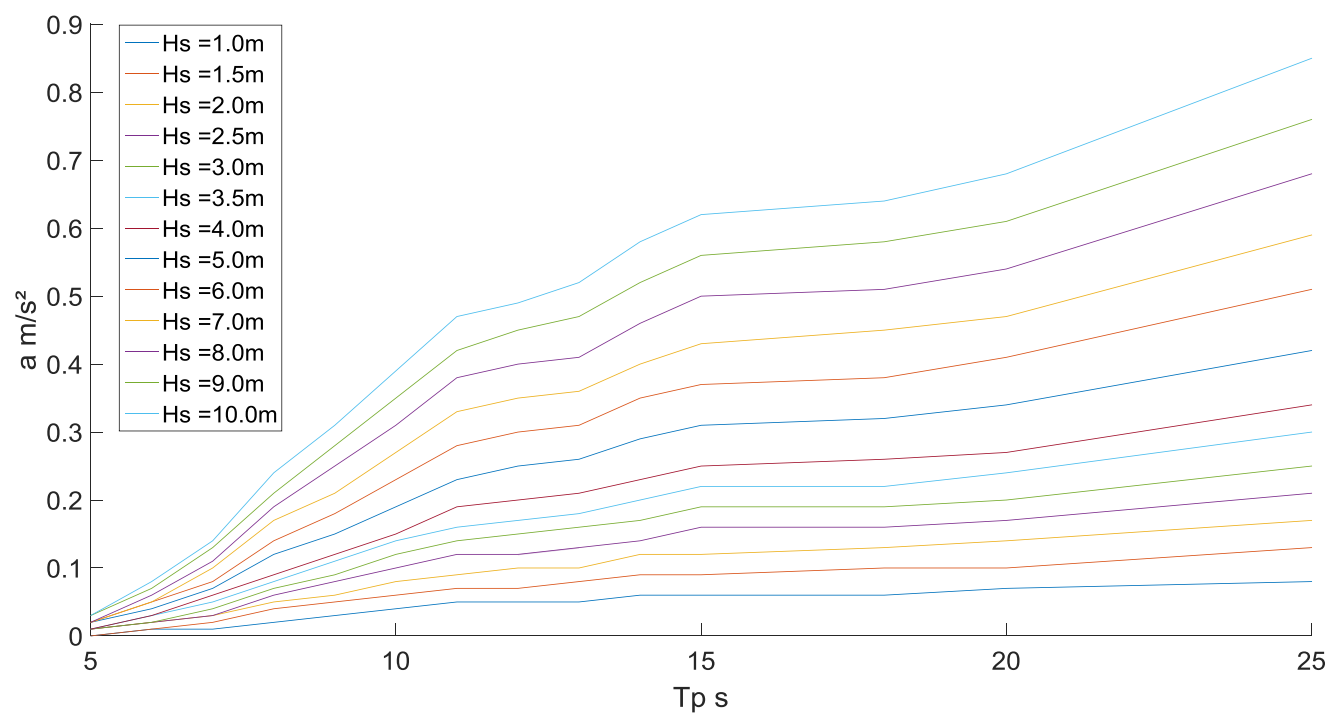

Figura 13-4 Aceleração vertical incidência 315

FONTE: Elaborada pelo autor 


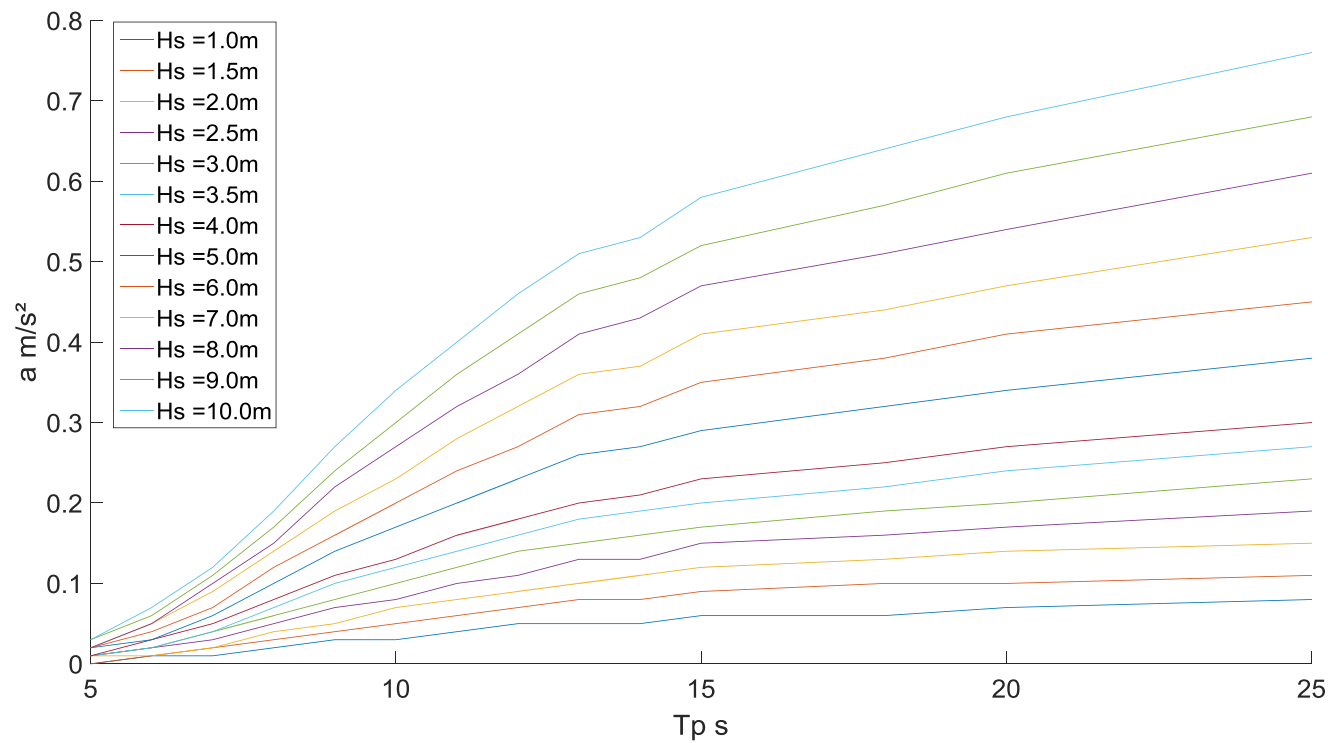

Figura 13-5 Aceleração vertical incidência 330

FONTE: Elaborada pelo autor 
14. ANEXO D CARACTERÍSTICAS DOS CASOS ESTUDADOS

\begin{tabular}{|c|c|c|c|c|c|c|c|c|}
\hline caso & $\mathrm{L}(\mathrm{m})$ & $B(m)$ & $\mathrm{b}(\mathrm{m})$ & $\beta$ & desloc. (ton) & $\mathrm{Ixx}\left(\right.$ ton. $\left.\mathrm{m}^{2}\right)$ & Iyy (ton. $\mathrm{m}^{2}$ ) & Izz (ton. $\mathrm{m}^{2}$ ) \\
\hline 1 & 340 & 100 & 35 & 0.3 & $5,59 \mathrm{E}+05$ & $5,83 E+08$ & $5,66 \mathrm{E}+09$ & $5,93 E+09$ \\
\hline 2 & 330 & 100 & 35 & 0.3 & $5,42 E+05$ & $5,66 \mathrm{E}+08$ & $5,50 E+09$ & $5,76 E+09$ \\
\hline 3 & 320 & 100 & 35 & 0.3 & $5,26 \mathrm{E}+05$ & $5,49 \mathrm{E}+08$ & $5,33 E+09$ & $5,58 \mathrm{E}+09$ \\
\hline 4 & 340 & 110 & 38,5 & 0.3 & $6,14 \mathrm{E}+05$ & $6,41 E+08$ & $6,23 E+09$ & $6,53 E+09$ \\
\hline 5 & 330 & 110 & 38,5 & 0.3 & $5,96 \mathrm{E}+05$ & $6,23 E+08$ & $6,05 E+09$ & $6,34 \mathrm{E}+09$ \\
\hline 6 & 320 & 110 & 38,5 & 0.3 & $5,78 \mathrm{E}+05$ & $6,04 \mathrm{E}+08$ & $5,86 \mathrm{E}+09$ & $6,14 \mathrm{E}+09$ \\
\hline 7 & 340 & 100 & 30 & 0.3 & $4,79 E+05$ & $5,00 E+08$ & $4,86 \mathrm{E}+09$ & $5,09 E+09$ \\
\hline 8 & 330 & 100 & 30 & 0.3 & $4,65 E+05$ & $4,85 \mathrm{E}+08$ & $4,71 E+09$ & $4,94 \mathrm{E}+09$ \\
\hline 9 & 320 & 100 & 30 & 0.3 & $4,51 \mathrm{E}+05$ & $4,70 \mathrm{E}+08$ & $4,57 E+09$ & $4,79 \mathrm{E}+09$ \\
\hline 10 & 340 & 110 & 30 & 0.3 & $5,27 E+05$ & $5,50 E+08$ & $5,34 E+09$ & $5,59 E+09$ \\
\hline 11 & 330 & 110 & 30 & 0.3 & $5,11 \mathrm{E}+05$ & $5,34 \mathrm{E}+08$ & $5,18 \mathrm{E}+09$ & $5,43 E+09$ \\
\hline 12 & 320 & 110 & 30 & 0.3 & $4,96 \mathrm{E}+05$ & $5,17 \mathrm{E}+08$ & $5,03 E+09$ & $5,27 \mathrm{E}+09$ \\
\hline 13 & 340 & 100 & 40 & 0.3 & $6,38 \mathrm{E}+05$ & $6,66 \mathrm{E}+08$ & $6,47 \mathrm{E}+09$ & $6,78 \mathrm{E}+09$ \\
\hline 14 & 330 & 100 & 40 & 0.3 & $6,20 \mathrm{E}+05$ & $6,47 E+08$ & $6,28 \mathrm{E}+09$ & $6,58 \mathrm{E}+09$ \\
\hline 15 & 320 & 100 & 40 & 0.3 & $6,01 E+05$ & $6,27 \mathrm{E}+08$ & $6,09 E+09$ & $6,38 \mathrm{E}+09$ \\
\hline 16 & 340 & 110 & 40 & 0.3 & $7,02 E+05$ & $7,33 E+08$ & $7,12 \mathrm{E}+09$ & $7,46 \mathrm{E}+09$ \\
\hline 17 & 330 & 110 & 40 & 0.3 & $6,82 \mathrm{E}+05$ & $7,11 E+08$ & $6,91 E+09$ & $7,24 \mathrm{E}+09$ \\
\hline 18 & 320 & 110 & 40 & 0.3 & $6,61 E+05$ & $6,90 \mathrm{E}+08$ & $6,70 E+09$ & $7,02 E+09$ \\
\hline 19 & 340 & 100 & 35 & 1 & $6,48 \mathrm{E}+05$ & $6,76 \mathrm{E}+08$ & $6,57 E+09$ & $6,88 \mathrm{E}+09$ \\
\hline 20 & 330 & 100 & 35 & 1 & $6,29 \mathrm{E}+05$ & $6,56 \mathrm{E}+08$ & $6,38 \mathrm{E}+09$ & $6,68 \mathrm{E}+09$ \\
\hline 21 & 320 & 100 & 35 & 1 & $6,10 \mathrm{E}+05$ & $6,37 \mathrm{E}+08$ & $6,18 \mathrm{E}+09$ & $6,48 \mathrm{E}+09$ \\
\hline 22 & 340 & 110 & 38,5 & 1 & $7,13 E+05$ & $7,44 \mathrm{E}+08$ & $7,23 \mathrm{E}+09$ & 7,57E+09 \\
\hline 23 & 330 & 110 & 38,5 & 1 & $6,92 \mathrm{E}+05$ & $7,22 \mathrm{E}+08$ & $7,02 E+09$ & $7,35 E+09$ \\
\hline 24 & 320 & 110 & 38,5 & 1 & $6,71 \mathrm{E}+05$ & $7,00 \mathrm{E}+08$ & $6,80 \mathrm{E}+09$ & $7,13 E+09$ \\
\hline 25 & 340 & 100 & 30 & 1 & $5,55 \mathrm{E}+05$ & $5,80 \mathrm{E}+08$ & $5,63 \mathrm{E}+09$ & $5,90 \mathrm{E}+09$ \\
\hline 26 & 330 & 100 & 30 & 1 & $5,39 \mathrm{E}+05$ & $5,63 E+08$ & $5,47 E+09$ & $5,73 E+09$ \\
\hline 27 & 320 & 100 & 30 & 1 & $5,23 E+05$ & $5,46 \mathrm{E}+08$ & $5,30 \mathrm{E}+09$ & $5,55 E+09$ \\
\hline 28 & 340 & 110 & 30 & 1 & $6,11 E+05$ & $6,38 \mathrm{E}+08$ & $6,20 \mathrm{E}+09$ & $6,49 \mathrm{E}+09$ \\
\hline 29 & 330 & 110 & 30 & 1 & $5,93 E+05$ & $6,19 E+08$ & $6,01 \mathrm{E}+09$ & $6,30 E+09$ \\
\hline 30 & 320 & 110 & 30 & 1 & $5,75 E+05$ & $6,00 \mathrm{E}+08$ & $5,83 E+09$ & $6,11 \mathrm{E}+09$ \\
\hline 31 & 340 & 100 & 40 & 1 & $7,41 \mathrm{E}+05$ & $7,73 E+08$ & $7,51 E+09$ & $7,87 \mathrm{E}+09$ \\
\hline 32 & 330 & 100 & 40 & 1 & $7,19 \mathrm{E}+05$ & $7,50 \mathrm{E}+08$ & $7,29 \mathrm{E}+09$ & $7,64 \mathrm{E}+09$ \\
\hline 33 & 320 & 100 & 40 & 1 & $6,97 \mathrm{E}+05$ & $7,28 \mathrm{E}+08$ & $7,07 \mathrm{E}+09$ & $7,40 \mathrm{E}+09$ \\
\hline 34 & 340 & 110 & 40 & 1 & $8,15 E+05$ & $8,50 \mathrm{E}+08$ & $8,26 \mathrm{E}+09$ & $8,65 \mathrm{E}+09$ \\
\hline 35 & 330 & 110 & 40 & 1 & $7,91 \mathrm{E}+05$ & $8,25 \mathrm{E}+08$ & $8,02 E+09$ & $8,40 \mathrm{E}+09$ \\
\hline 36 & 320 & 110 & 40 & 1 & $7,67 E+05$ & $8,00 \mathrm{E}+08$ & $7,77 \mathrm{E}+09$ & $8,14 \mathrm{E}+09$ \\
\hline 37 & 340 & 100 & 35 & 0.5 & $6,09 \mathrm{E}+05$ & $6,36 \mathrm{E}+08$ & $6,17 E+09$ & $6,47 E+09$ \\
\hline 38 & 330 & 100 & 35 & 0.5 & $5,91 \mathrm{E}+05$ & $6,17 \mathrm{E}+08$ & $5,99 \mathrm{E}+09$ & $6,28 \mathrm{E}+09$ \\
\hline 39 & 320 & 100 & 35 & 0.5 & $5,73 E+05$ & $5,98 \mathrm{E}+08$ & $5,81 \mathrm{E}+09$ & $6,09 \mathrm{E}+09$ \\
\hline 40 & 340 & 110 & 38,5 & 0.5 & $6,70 \mathrm{E}+05$ & $6,99 \mathrm{E}+08$ & $6,79 E+09$ & $7,11 \mathrm{E}+09$ \\
\hline 41 & 330 & 110 & 38,5 & 0.5 & $6,50 \mathrm{E}+05$ & $6,79 \mathrm{E}+08$ & $6,59 \mathrm{E}+09$ & $6,91 \mathrm{E}+09$ \\
\hline 42 & 320 & 110 & 38,5 & 0.5 & $6,30 \mathrm{E}+05$ & $6,58 \mathrm{E}+08$ & $6,39 \mathrm{E}+09$ & $6,70 \mathrm{E}+09$ \\
\hline 43 & 340 & 100 & 30 & 0.5 & $5,22 \mathrm{E}+05$ & $5,45 E+08$ & $5,29 E+09$ & $5,54 \mathrm{E}+09$ \\
\hline 44 & 330 & 100 & 30 & 0.5 & $5,07 E+05$ & $5,29 \mathrm{E}+08$ & $5,14 \mathrm{E}+09$ & $5,38 \mathrm{E}+09$ \\
\hline 45 & 320 & 100 & 30 & 0.5 & $4,91 E+05$ & $5,13 E+08$ & $4,98 \mathrm{E}+09$ & $5,22 \mathrm{E}+09$ \\
\hline 46 & 340 & 110 & 30 & 0.5 & $5,74 \mathrm{E}+05$ & $5,99 \mathrm{E}+08$ & $5,82 \mathrm{E}+09$ & $6,10 \mathrm{E}+09$ \\
\hline 47 & 330 & 110 & 30 & 0.5 & $5,57 \mathrm{E}+05$ & $5,82 \mathrm{E}+08$ & $5,65 \mathrm{E}+09$ & $5,92 \mathrm{E}+09$ \\
\hline 48 & 320 & 110 & 30 & 0.5 & $5,40 \mathrm{E}+05$ & $5,64 E+08$ & $5,48 \mathrm{E}+09$ & $5,74 \mathrm{E}+09$ \\
\hline 49 & 340 & 100 & 40 & 0.5 & $6,96 \mathrm{E}+05$ & $7,26 \mathrm{E}+08$ & $7,06 \mathrm{E}+09$ & $7,39 \mathrm{E}+09$ \\
\hline 50 & 330 & 100 & 40 & 0.5 & $6,75 E+05$ & $7,05 E+08$ & $6,85 \mathrm{E}+09$ & 7,17E+09 \\
\hline 51 & 320 & 100 & 40 & 0.5 & $6,55 \mathrm{E}+05$ & $6,84 \mathrm{E}+08$ & $6,64 \mathrm{E}+09$ & $6,96 \mathrm{E}+09$ \\
\hline 52 & 340 & 110 & 40 & 0.5 & $7,65 E+05$ & $7,99 \mathrm{E}+08$ & $7,76 \mathrm{E}+09$ & $8,13 E+09$ \\
\hline 53 & 330 & 110 & 40 & 0.5 & $7,43 \mathrm{E}+05$ & $7,75 E+08$ & $7,53 \mathrm{E}+09$ & $7,89 \mathrm{E}+09$ \\
\hline 54 & 320 & 110 & 40 & 0.5 & $7,20 \mathrm{E}+05$ & $7,52 \mathrm{E}+08$ & $7,31 E+09$ & $7,65 \mathrm{E}+09$ \\
\hline
\end{tabular}

Tabela 14-1Dimensões principais, inércia e capacidade de óleo.

FONTE: Elaborada pelo autor 


\begin{tabular}{|c|c|c|c|c|c|c|c|c|}
\hline caso & pesoleve & KG casco nu $(\mathrm{m})$ & KG 30\% & KG 50\% & KG $100 \%$ & t_fundo & t_costado & t_convés \\
\hline 1 & $1,37 \mathrm{E}+05$ & 34,0 & 17,4 & 15,15 & 19,62 & 22,7 & 19,8 & 15,7 \\
\hline 2 & $1,35 E+05$ & 34,3 & 17,88 & 16,2 & 21,55 & 22,5 & 19,7 & 15,6 \\
\hline 3 & $1,33 E+05$ & 34,5 & 17,94 & 15,5 & 19,71 & 22,2 & 19,5 & 15,4 \\
\hline 4 & $1,53 E+05$ & 32,9 & 17,12 & 14,93 & 19,47 & 22,7 & 19,8 & 15,7 \\
\hline 5 & $1,50 \mathrm{E}+05$ & 33,2 & 18,2 & 15,93 & 18,53 & 22,5 & 19,7 & 15,6 \\
\hline 6 & $1,48 \mathrm{E}+05$ & 33,4 & 17,22 & 15,13 & 19,78 & 22,2 & 19,5 & 15,4 \\
\hline 7 & $1,27 \mathrm{E}+05$ & 34,8 & 17,6 & 15,37 & 20,31 & 22,7 & 19,8 & 15,7 \\
\hline 8 & $1,25 \mathrm{E}+05$ & 35,0 & 17,64 & 15,53 & 20,46 & 22,5 & 19,7 & 15,6 \\
\hline 9 & $1,23 E+05$ & 35,3 & 17,71 & 15,66 & 20,65 & 22,2 & 19,5 & 15,4 \\
\hline 10 & $1,33 E+05$ & 34,0 & 17,45 & 15,29 & 20,41 & 22,7 & 19,8 & 15,7 \\
\hline 11 & $1,31 \mathrm{E}+05$ & 34,2 & 18,93 & 16,24 & 19,45 & 22,5 & 19,7 & 15,6 \\
\hline 12 & $1,29 E+05$ & 34,5 & 17,55 & 15,53 & 20,77 & 22,2 & 19,5 & 15,4 \\
\hline 13 & $1,48 \mathrm{E}+05$ & 33,6 & 17,14 & 14,93 & 19,21 & 22,7 & 19,8 & 15,7 \\
\hline 14 & $1,45 E+05$ & 33,8 & 16,41 & 15,19 & 19,19 & 22,5 & 19,7 & 15,6 \\
\hline 15 & $1,43 E+05$ & 34,0 & 17,34 & 15,12 & 19,39 & 22,2 & 19,5 & 15,4 \\
\hline 16 & $1,57 \mathrm{E}+05$ & 32,8 & 16,91 & 14,81 & 19,43 & 22,7 & 19,8 & 15,7 \\
\hline 17 & $1,54 \mathrm{E}+05$ & 33,1 & 16,97 & 14,92 & 19,57 & 22,5 & 19,7 & 15,6 \\
\hline 18 & $1,51 \mathrm{E}+05$ & 33,3 & 17,01 & 15 & 19,69 & 22,2 & 19,5 & 15,4 \\
\hline 19 & $1,37 \mathrm{E}+05$ & 34,5 & 17,34 & 15,8 & 21,16 & 22,7 & 19,8 & 15,7 \\
\hline 20 & $1,35 \mathrm{E}+05$ & 34,7 & 17,4 & 15,87 & 21,3 & 22,5 & 19,7 & 15,6 \\
\hline 21 & $1,33 \mathrm{E}+05$ & 34,9 & 17,45 & 15,95 & 21,44 & 22,2 & 19,5 & 15,4 \\
\hline 22 & $1,53 \mathrm{E}+05$ & 33,0 & 16,95 & 15,46 & 21,01 & 22,7 & 19,8 & 15,7 \\
\hline 23 & $1,50 E+05$ & 33,2 & 17,89 & 16,37 & 19,6 & 22,5 & 19,7 & 15,6 \\
\hline 24 & $1,48 \mathrm{E}+05$ & 33,4 & 17,05 & 15,6 & 21,26 & 22,2 & 19,5 & 15,4 \\
\hline 25 & $1,27 \mathrm{E}+05$ & 35,7 & 17,52 & 16,03 & 21,91 & 22,7 & 19,8 & 15,7 \\
\hline 26 & $1,25 E+05$ & 35,9 & 17,69 & 16,88 & 21,62 & 22,5 & 19,7 & 15,6 \\
\hline 27 & $1,23 E+05$ & 36,2 & 17,66 & 16,22 & 22,23 & 22,2 & 19,5 & 15,4 \\
\hline 28 & $1,33 E+05$ & 34,9 & 17,37 & 15,88 & 22,01 & 22,7 & 19,8 & 15,7 \\
\hline 29 & $1,31 \mathrm{E}+05$ & 35,2 & 17,6 & 16,9 & 21,63 & 22,5 & 19,7 & 15,6 \\
\hline 30 & $1,29 E+05$ & 35,4 & 17,68 & 17,01 & 21,77 & 22,2 & 19,5 & 15,4 \\
\hline 31 & $1,48 \mathrm{E}+05$ & 33,4 & 16,83 & 15,37 & 20,85 & 22,7 & 19,8 & 15,7 \\
\hline 32 & $1,45 \mathrm{E}+05$ & 33,6 & 18,08 & 16,21 & 20,71 & 22,5 & 19,7 & 15,6 \\
\hline 33 & $1,43 E+05$ & 33,9 & 17,01 & 16 & 22,61 & 22,2 & 19,5 & 15,4 \\
\hline 34 & $1,57 E+05$ & 32,7 & 16,79 & 15,84 & 22,51 & 22,7 & 19,8 & 15,7 \\
\hline 35 & $1,54 \mathrm{E}+05$ & 32,9 & 16,84 & 15,92 & 22,54 & 22,5 & 19,7 & 15,6 \\
\hline 36 & $1,51 \mathrm{E}+05$ & 33,1 & 16,9 & 15,99 & 22,58 & 22,2 & 19,5 & 15,4 \\
\hline 37 & $1,37 E+05$ & 34,2 & 19,01 & 16,53 & 22,38 & 22,7 & 19,8 & 15,7 \\
\hline 38 & $1,35 E+05$ & 34,5 & 19,06 & 16,62 & 22,56 & 22,5 & 19,7 & 15,6 \\
\hline 39 & $1,33 \mathrm{E}+05$ & 34,7 & 19,09 & 16,68 & 22,72 & 22,2 & 19,5 & 15,4 \\
\hline 40 & $1,53 \mathrm{E}+05$ & 33,1 & 18,64 & 16,23 & 22,33 & 22,7 & 19,8 & 15,7 \\
\hline 41 & $1,50 \mathrm{E}+05$ & 33,3 & 19,76 & 17,44 & 20,68 & 22,5 & 19,7 & 15,6 \\
\hline 42 & $1,48 \mathrm{E}+05$ & 33,6 & 18,73 & 16,37 & 22,44 & 22,2 & 19,5 & 15,4 \\
\hline 43 & $1,27 \mathrm{E}+05$ & 35,0 & 20,22 & 18,16 & 21,61 & 22,7 & 19,8 & 15,7 \\
\hline 44 & $1,25 \mathrm{E}+05$ & 35,2 & 19,54 & 16,99 & 22,35 & 22,5 & 19,7 & 15,6 \\
\hline 45 & $1,23 E+05$ & 35,5 & 19,6 & 17,08 & 22,44 & 22,2 & 19,5 & 15,4 \\
\hline 46 & $1,33 E+05$ & 34,2 & 19,86 & 18,26 & 21,89 & 22,7 & 19,8 & 15,7 \\
\hline 47 & $1,31 \mathrm{E}+05$ & 34,4 & 19,68 & 17,02 & 22,01 & 22,5 & 19,7 & 15,6 \\
\hline 48 & $1,29 \mathrm{E}+05$ & 34,7 & 17,4 & 16,72 & 22,12 & 22,2 & 19,5 & 15,4 \\
\hline 49 & $1,48 \mathrm{E}+05$ & 33,7 & 18,21 & 15,96 & 21,77 & 22,7 & 19,8 & 15,7 \\
\hline 50 & $1,45 E+05$ & 33,9 & 19,29 & 17,1 & 20,27 & 22,5 & 19,7 & 15,6 \\
\hline 51 & $1,43 \mathrm{E}+05$ & 34,2 & 18,31 & 16,11 & 22,06 & 22,2 & 19,5 & 15,4 \\
\hline 52 & $1,57 \mathrm{E}+05$ & 33,0 & 18,31 & 16 & 22,22 & 22,7 & 19,8 & 15,7 \\
\hline 53 & $1,54 \mathrm{E}+05$ & 33,2 & 18,34 & 15,78 & 22,34 & 22,5 & 19,7 & 15,6 \\
\hline 54 & $1,51 E+05$ & 33,4 & 18,39 & 16,12 & 22,46 & 22,2 & 19,5 & 15,4 \\
\hline
\end{tabular}

Tabela 14-2 Pesos, centros e espessuras de chapa.

FONTE: Elaborada pelo autor 


\begin{tabular}{|c|c|c|c|c|c|c|c|c|}
\hline caso & Mswalq & Mvwtos & Mswtos & Mvwalq & Malq & Mtos & $I \mathrm{~min}$ & $Z \mathrm{~min}$ \\
\hline 1 & 13261235 & $-1,9 \mathrm{E}+07$ & $-8,69 E+06$ & $1,55 \mathrm{E}+07$ & $2,88 \mathrm{E}+07$ & $-2,7 \mathrm{E}+07$ & 1548,299 & 121,4177 \\
\hline 2 & 12492634 & $-1,7 \mathrm{E}+07$ & $-8,19 E+06$ & $1,46 \mathrm{E}+07$ & $2,71 E+07$ & $-2,6 \mathrm{E}+07$ & 2317,28 & 114,3805 \\
\hline 3 & 11746977 & $-1,6 \mathrm{E}+07$ & $-7,70 \mathrm{E}+06$ & $1,37 \mathrm{E}+07$ & $2,55 E+07$ & $-2,4 \mathrm{E}+07$ & 2112,938 & 107,5534 \\
\hline 4 & 14587359 & $-2 \mathrm{E}+07$ & $-9,56 E+06$ & $1,71 E+07$ & $3,17 E+07$ & $-3 E+07$ & 2787,829 & 133,5595 \\
\hline 5 & 13741898 & $-1,9 \mathrm{E}+07$ & $-9,00 E+06$ & $1,61 E+07$ & $2,98 \mathrm{E}+07$ & $-2,8 \mathrm{E}+07$ & 2549,008 & 125,8186 \\
\hline 6 & 12921674 & $-1,8 \mathrm{E}+07$ & $-8,47 E+06$ & $1,51 \mathrm{E}+07$ & $2,80 \mathrm{E}+07$ & $-2,7 \mathrm{E}+07$ & 2324,232 & 118,3088 \\
\hline 7 & 13482914 & $-1,7 \mathrm{E}+07$ & $-8,09 \mathrm{E}+06$ & $1,33 \mathrm{E}+07$ & $2,68 \mathrm{E}+07$ & $-2,5 E+07$ & 2823,696 & 113,0185 \\
\hline 8 & 12701465 & $-1,6 \mathrm{E}+07$ & $-7,62 E+06$ & $1,25 \mathrm{E}+07$ & $2,52 \mathrm{E}+07$ & $-2,4 \mathrm{E}+07$ & 2581,802 & 106,4681 \\
\hline 9 & 11943342 & $-1,5 E+07$ & $-7,16 E+06$ & $1,18 \mathrm{E}+07$ & $2,37 E+07$ & $-2,2 E+07$ & 2354,133 & 100,1133 \\
\hline 10 & 14831205 & $-1,9 \mathrm{E}+07$ & $-8,90 \mathrm{E}+06$ & $1,46 \mathrm{E}+07$ & $2,95 \mathrm{E}+07$ & $-2,8 \mathrm{E}+07$ & 3106,065 & 124,3203 \\
\hline 11 & 13971611 & $-1,8 \mathrm{E}+07$ & $-8,38 \mathrm{E}+06$ & $1,38 \mathrm{E}+07$ & $2,78 \mathrm{E}+07$ & $-2,6 \mathrm{E}+07$ & 2839,982 & 117,1149 \\
\hline 12 & 13137677 & $-1,7 \mathrm{E}+07$ & $-7,88 \mathrm{E}+06$ & $1,30 E+07$ & $2,61 E+07$ & $-2,5 E+07$ & 2589,547 & 110,1246 \\
\hline 13 & 1303 & $-2 \mathrm{E}+07$ & $-9,29 E+06$ & $1,77 \mathrm{E}+07$ & $3,08 \mathrm{E}+07$ & $-2,9 \mathrm{E}+07$ & 2317,411 & 817 \\
\hline 14 & 12283804 & $-1,9 \mathrm{E}+07$ & $-8,75 \mathrm{E}+06$ & $1,67 \mathrm{E}+07$ & $2,90 E+07$ & $-2,7 \mathrm{E}+07$ & 2118,889 & 122,293 \\
\hline 15 & 611 & $-1,8 \mathrm{E}+07$ & $-8,23 \mathrm{E}+06$ & $1,57 \mathrm{E}+07$ & $2,73 E+07$ & $-2,6 \mathrm{E}+07$ & 193 & 936 \\
\hline 16 & 14343513 & $-2,2 \mathrm{E}+07$ & $-1,02 E+07$ & $1,95 \mathrm{E}+07$ & $3,39 E+07$ & $-3,2 \mathrm{E}+07$ & 2549,153 & 142,7987 \\
\hline 17 & 135 & $-2,1 \mathrm{E}+07$ & $-9,63 E+06$ & $1,84 \mathrm{E}+07$ & $3,19 E+07$ & +07 & 2330,778 & 223 \\
\hline 18 & 12705672 & $-1,9 \mathrm{E}+07$ & $-9,05 E+06$ & $1,73 \mathrm{E}+07$ & $3,00 E+07$ & $-2,8 \mathrm{E}+07$ & 2125,245 & 126,4929 \\
\hline 19 & 130 & & $-9,36 E+06$ & $1,80 \mathrm{E}+07$ & +07 & +07 & 965 & 249 \\
\hline 20 & 12258745 & $-1,9 \mathrm{E}+07$ & $-8,82 E+06$ & $1,70 \mathrm{E}+07$ & $2,92 \mathrm{E}+07$ & $-2,8 \mathrm{E}+07$ & 2098,366 & 123,2425 \\
\hline 21 & 47 & $-1,8 \mathrm{E}+07$ & $-8,29 \mathrm{E}+06$ & $1,59 E+07$ & +07 & +07 & 328 & 864 \\
\hline 22 & 14314251 & $-2,2 \mathrm{E}+07$ & $-1,03 E+07$ & $1,98 \mathrm{E}+07$ & $3,41 E+07$ & $-3,2 \mathrm{E}+07$ & 2524,462 & 143,9074 \\
\hline 23 & 13484619 & $-2,1 \mathrm{E}+07$ & $-9,70 \mathrm{E}+06$ & $1,87 \mathrm{E}+07$ & $3,21 \mathrm{E}+07$ & $-3 E+07$ & 2308,202 & 5667 \\
\hline 24 & 12679752 & $-1,9 \mathrm{E}+07$ & $-9,12 E+06$ & $1,75 \mathrm{E}+07$ & $3,02 E+07$ & $-2,9 \mathrm{E}+07$ & 2104,66 & 127,475 \\
\hline 25 & 13270103 & $-1,9 \mathrm{E}+07$ & $-8,67 E+06$ & $1,54 \mathrm{E}+07$ & $2,87 \mathrm{E}+07$ & $-2,7 \mathrm{E}+07$ & 2544,366 & 818 \\
\hline 26 & 12500988 & $-1,7 \mathrm{E}+07$ & $-8,16 \mathrm{E}+06$ & $1,45 \mathrm{E}+07$ & $2,70 E+07$ & $-2,6 \mathrm{E}+07$ & 2326,402 & 114,064 \\
\hline 27 & 11754831 & $-1,6 \mathrm{E}+07$ & $-7,68 E+06$ & $1,37 \mathrm{E}+07$ & $2,54 \mathrm{E}+07$ & $-2,4 \mathrm{E}+07$ & 2121,255 & 558 \\
\hline 28 & 14597113 & $-2 \mathrm{E}+07$ & $-9,53 E+06$ & $1,70 E+07$ & $3,16 E+07$ & $-3 E+07$ & 2798,803 & 133,1899 \\
\hline 29 & 13751086 & $-1,9 \mathrm{E}+07$ & $-8,98 \mathrm{E}+06$ & $1,60 \mathrm{E}+07$ & $2,97 \mathrm{E}+07$ & $-2,8 \mathrm{E}+07$ & 2559,042 & 1704 \\
\hline 30 & 12930315 & $-1,8 \mathrm{E}+07$ & $-8,44 \mathrm{E}+06$ & $1,50 \mathrm{E}+07$ & $2,80 E+07$ & $-2,6 \mathrm{E}+07$ & 2333,38 & 117,9814 \\
\hline 31 & 12755809 & $-2,1 \mathrm{E}+07$ & $-1,01 E+07$ & $2,06 \mathrm{E}+07$ & $3,33 \mathrm{E}+07$ & $-3,2 \mathrm{E}+07$ & 2107,915 & 568 \\
\hline 32 & 12016502 & $-2 \mathrm{E}+07$ & $-9,48 E+06$ & $1,94 \mathrm{E}+07$ & $3,14 \mathrm{E}+07$ & $-3 E+07$ & 1927,339 & 132,4209 \\
\hline 33 & 11299263 & $-1,9 \mathrm{E}+07$ & $-8,91 E+06$ & $1,82 \mathrm{E}+07$ & $2,95 E+07$ & $-2,8 \mathrm{E}+07$ & 1757,382 & 517 \\
\hline 34 & 14031390 & $-2,4 \mathrm{E}+07$ & $-1,11 E+07$ & $2,26 \mathrm{E}+07$ & $3,67 E+07$ & $-3,5 \mathrm{E}+07$ & 2318,706 & 154,6248 \\
\hline 35 & 1321 & $-2,2 E+07$ & $-1,04 \mathrm{E}+07$ & $2,13 E+07$ & +07 & +07 & 212 & 663 \\
\hline 36 & 12429189 & $-2,1 E+07$ & $-9,80 E+06$ & $2,00 \mathrm{E}+07$ & $3,25 \mathrm{E}+07$ & $-3,1 E+07$ & 1933,12 & 136,9687 \\
\hline 37 & 13121578 & $-1,9 \mathrm{E}+07$ & $-9,07 E+06$ & $1,69 \mathrm{E}+07$ & $3,00 \mathrm{E}+07$ & $-2,8 \mathrm{E}+07$ & 2391,065 & 126,7092 \\
\hline 38 & 12361071 & $-1,8 \mathrm{E}+07$ & $-8,54 \mathrm{E}+06$ & $1,59 E+07$ & $2,83 \mathrm{E}+07$ & $-2,7 \mathrm{E}+07$ & 2186,233 & 119,3654 \\
\hline 39 & 11623266 & $-1,7 \mathrm{E}+07$ & $-8,03 E+06$ & $1,50 \mathrm{E}+07$ & $2,66 \mathrm{E}+07$ & $-2,5 E+07$ & 1993,446 & 112,2407 \\
\hline 40 & 14433736 & $-2,1 \mathrm{E}+07$ & $-9,97 E+06$ & $1,86 \mathrm{E}+07$ & $3,30 E+07$ & $-3,1 E+07$ & 2630,171 & 139,3802 \\
\hline 41 & 13597179 & $-2 E+07$ & $-9,40 E+06$ & $1,75 E+07$ & $3,11 E+07$ & $-2,9 \mathrm{E}+07$ & 2404,856 & 131,3019 \\
\hline 42 & 12785593 & $-1,9 \mathrm{E}+07$ & $-8,84 \mathrm{E}+06$ & $1,65 \mathrm{E}+07$ & $2,93 E+07$ & $-2,8 \mathrm{E}+07$ & 2192,791 & 123,4648 \\
\hline 43 & 13363208 & $-1,8 \mathrm{E}+07$ & $-8,41 E+06$ & $1,45 E+07$ & $2,79 E+07$ & $-2,6 \mathrm{E}+07$ & 2656,483 & 117,5541 \\
\hline 44 & 12588696 & $-1,7 \mathrm{E}+07$ & $-7,93 \mathrm{E}+06$ & $1,37 \mathrm{E}+07$ & $2,62 E+07$ & $-2,5 \mathrm{E}+07$ & 2428,913 & 110,7408 \\
\hline 45 & 11837305 & $-1,6 \mathrm{E}+07$ & $-7,45 E+06$ & $1,28 \mathrm{E}+07$ & $2,47 E+07$ & $-2,3 \mathrm{E}+07$ & 2214,727 & 104,1309 \\
\hline 46 & 14699528 & $-2 \mathrm{E}+07$ & $-9,25 E+06$ & $1,59 E+07$ & $3,06 \mathrm{E}+07$ & $-2,9 \mathrm{E}+07$ & 2922,131 & 129,3095 \\
\hline 47 & 13847566 & $-1,9 \mathrm{E}+07$ & $-8,72 E+06$ & $1,50 \mathrm{E}+07$ & $2,89 E+07$ & $-2,7 \mathrm{E}+07$ & 2671,805 & 121,8149 \\
\hline 48 & 13021035 & $-1,8 \mathrm{E}+07$ & $-8,20 E+06$ & $1,41 \mathrm{E}+07$ & $2,71 E+07$ & $-2,6 E+07$ & 2436,199 & 114,544 \\
\hline 49 & 12879949 & $-2,1 E+07$ & $-9,72 E+06$ & $1,93 \mathrm{E}+07$ & $3,22 E+07$ & $-3 E+07$ & 2192,002 & 135,8644 \\
\hline 50 & 12133446 & $-2 \mathrm{E}+07$ & $-9,16 E+06$ & $1,82 \mathrm{E}+07$ & $3,03 E+07$ & $-2,9 \mathrm{E}+07$ & 2004,223 & 127,9899 \\
\hline 51 & 11409228 & $-1,8 \mathrm{E}+07$ & $-8,61 E+06$ & $1,71 \mathrm{E}+07$ & $2,85 \mathrm{E}+07$ & $-2,7 \mathrm{E}+07$ & 1827,486 & 120,3505 \\
\hline 52 & 14167944 & $-2,3 E+07$ & $-1,07 E+07$ & $2,13 E+07$ & $3,54 \mathrm{E}+07$ & $-3,4 \mathrm{E}+07$ & 2411,202 & 149,4509 \\
\hline 53 & 13346791 & $-2,2 \mathrm{E}+07$ & $-1,01 E+07$ & $2,00 E+07$ & $3,34 \mathrm{E}+07$ & $-3,2 \mathrm{E}+07$ & 2204,645 & 140,7889 \\
\hline 54 & 12550151 & $-2 \mathrm{E}+07$ & $-9,47 E+06$ & $1,88 \mathrm{E}+07$ & $3,14 \mathrm{E}+07$ & $-3 E+07$ & 2010,235 & 132,3855 \\
\hline
\end{tabular}

Tabela 14-3 Momentos e modulo da seção

FONTE: Elaborada pelo autor 